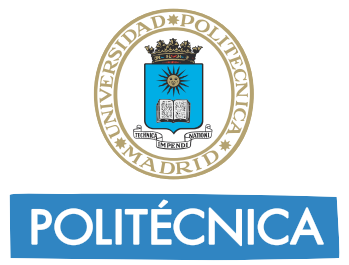

Departamento de Ingeniería de la Organización Administración de Empresas y Estadísticas

UNIVERSIDAD POLITÉCNICA DE MADRID Escuela Técnica Superior de Ingenieros Industriales

\title{
Performance Measurement and Management in Networks: \\ Studies from the Airport Industry
}

\author{
Tesis Doctoral
}

\section{Simon Okwir}

\author{
Directores \\ Felipe Ruiz \\ Universidad Politécnica de Madrid, Spain \\ Pernilla Ulfvengren \\ KTH Royal Institute of Technology, Sweden
}



Tribunal nombrado por el Magfco. y Excmo. Sr. Rector de la Universidad

Politécnica de Madrid, el dia

de

de 2017.

\section{PRESIDENTE:}

D JOAQUIN BIENVENIDO ORDIERES MERE

CATEDRATICO DE UNIVERSIDAD. ETSI INDUSTRIALES - UNIVERSIDAD POLITECNICA DE MADRID (UPM)

\section{SECRETARIO:}

D GUSTAVO MORALES ALONSO

PROFESOR AYUDANTE DOCTOR. ETSI INDUSTRIALES - UNIVERSIDAD POLITECNICA DE MADRID (UPM)

\section{VOCAL:}

D NIKLAS ARVIDSSON

ASSOCIATE PROFESSOR. SCHOOL OF INDUSTRIAL ENGINEERING AND MANAGEMENT - KTH ROYAL INSTITUTE OF TECHNOLOGY. SUECIA

\section{VOCAL:}

D ALFONSO DURAN HERAS

CATEDRATICO DE UNIVERSIDAD. ESCUELA POLITECNICA SUPERIOR - UNIVERSIDAD CARLOS III DE MADRID (UC3M)

\section{VOCAL:}

D JAVIER CONDE COLLADO

CATEDRATICO DE UNIVERSIDAD. ETSI INDUSTRIALES - UNIVERSIDAD NACIONAL DE EDUCACION A DISTANCIA (UNED)

\section{SUPLENTE:}

D MIGUEL PALACIOS FERNANDEZ

DIRECTOR ACADEMICO DE FORMACION EJECUTIVA/DIRECTOR DE CATEDRA DE EMPRENDIMIENTO. - ESCP EUROPE BUSINESS SCHOOL. CAMPUS DE MADRID

\section{SUPLENTE:}

D CARLOS CASANUEVA NARDIZ

PROFESOR. - ESCP EUROPE

Realizado el acto de lectura y defensa de la Tesis el día .... de ........ de 2017 en la Escuela Técnica Superior de Ingenieros Industriales.

El Presidente

El Secretario

Los Vocales

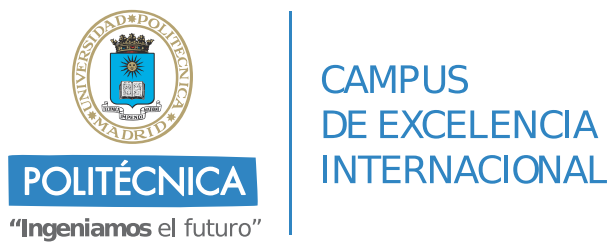





\section{Acknowledgments}

My Ph.D. JOURney has OFFERED ME MANY PATHS WHich I HAVE CLIMBED AND SOMETIMES OTHERS, WHICH WERE DEAD-ENDS. I would like to thank important organisations and persons who contributed to this thesis academically and finically and, last but not least, who contributed to my personal development during my time at $U P M$ and $K T H$.

I am grateful for and to my supervisors. I would like to thank Pernilla Ulfvengren whom I started this journey with in my first year at KTH. I want to thank her for always challenging my assumptions and broadening my ideas, constantly supervising me \& encouraging me to aim ever higher and for all the industrial collaborations which have greatly enriched my thesis; also for introducing me to airport operations through EU projects, which enabled me to see everything much more clearly and vividly. I value Matti Kaulio and his engagement with my work during my second year. He unselfishly taught me several important skills, upheld my confidence and helped me shape my ideas.

My mobility path at UPM was quite instrumental. I would like to thank Prof. Felipe Ruiz for providing me with excellent advice during my stay in Madrid and for expanding my empirical works through IBERIA operations.

Finally, I would like to thank Jannis Angelis, working with whom has enriched my thesis and given me new perspectives. To him, I am grateful for allowing me to teach ME2065 master course and for all the discussions we had at Konditori Ritorno.

My co-authors have been very cooperative and extremely important to my work. Firstly, I would like to thank Lena K. Mårtensson for inviting me to participate as one of the co-authors. I gained many insights during our discussions and she motivated me to learn more about the Single European Sky. I am also grateful to have worked with her during the SESAR innovation days at KTH in 2013. Secondly, I would like to thank Sai Nurudupati for encouraging my ideas and accepting me as a co-author. My gratitude also goes to Siobhan Corrigan, Alison M. Kay, Maria Nunez and Matias Ginieis for their commitment and all the skype calls we made to produce parts of this work.

I would like to thank my sponsors at EU and the EDIM scientific committee: my profound thanks goes to Felipe Ruiz, Mats Engwall, Cali Nuur, Kristin Lohse, Martina Sani, Isabel Herran, Paolo Trucco \& Raffaella Cagliano. I would like to express my special thanks to IBERIA handling, AENA and SWEDAVIA, where the empirical works for this thesis were conducted. I am indebted to many of my colleagues at IBERIA handling: Cristina Carretero Herrera, Durán-Cantero Martín, Daniel, Moreno Gómez, Rosa Patricia, Basso Martínez, Alejandro \& Rodriguez Corona for being generous and patient with me, answering my questions daily, in such a multiplex environment. Working with them on CDM database advanced my professional skills in the airport turnaround.

My special thanks to Knut och Alice Wallenbergs stiftelse "Jubileumsanslaget" for funding my conference travels.

I appreciate my former opponents, with whom I discussed my thesis at different stages: Svante Schriber, Guido Micheli and Lena K. Mårtensson, thank you.

For the constructive engagement with the senior faculty at INDEK, with whom I interacted quite often, and who unselfishly offered their time and knowledge, I would like to thank Anna 
Jabrant, Lars Uppvall, Bosse Karlsson, Jan Forslin, Niklas Arvidsson, Feldmann Andreas, Westin Thomas, Pär Blomkvist, Steffan Laestadius \& Charlotte Holgersson. Thank you all for your encouragement and your manifold support. My thanks to Sebby and Vardan for always helping me out of technical difficulties. My cordial thanks goes to Caroline Ahlstedt, Elisabeth Stolt Wahlman and Elisabeth Lampen for guiding me through the administrative procedures, even when I was away.

My sincere thanks goes to the staff at UPM: Prof Carlos Monroy, Prof Mercedes Grijalvo, Gustavo Morales, Susana - thank you for the conducive environment during my stay at UPM.

Thanks to my fellow $\mathrm{PhD}$ students at my home department, I sometimes believe I learned more in our corridors and coffee time during WIPS seminars than I ever did in the lecture halls. I have had a great time with Max $\mathcal{E}$ Sudipa, whom I thank for all of their contributions. Matthew Stogsdill, Caroline, Charlotte, Vikash \& Marin, thank you for many an advice and for all the comments - both during the WIPS and for those in the above mentioned corridors. Working with you on HULT in London was a great honor. Hat tip to Emrah, who introduced me to Mendeley software, which saved much of my time during the development of this thesis. I would like to thank Sarah Behnam, Frano, Raul, Shoaib, and Mitra for all that we shared during our time in Madrid. I would like to thank my office mate Anna Svarts for all the quick chit-chats that gave us the thrust into the day. Anna, thank you also for the wonderful review and feedback during WIPS. I would like to thank Yasmine Sabri \& Yasmin for all the important tips they provided. I would like to thank Isaac Lemus for his Spanish skills, which contributed to this thesis. Enes, thank you for the book on PMM, that you gave me as a present. I would like to thank Yury for his important advice during the final steps of meeting the UPM and KTH requirements. Gisela, thank you for teaching me Nvivo. My special thanks goes to Vikash: thank you for always questioning everything in my thesis and sharing your views on management control systems. Your critical eyes have contributed a lot to my work. Stefan Tongur, thank you for your valuable tips on system thinking theory concept Thanks to Claudia, Rami, Milan, Andra, Monia, Petter, Aziza $\mathscr{E}$ Richard: all of you have supported me by sharing valuable insights on many matters. I also need to mention my seniors here: Jonatan, Nidal, Anna D., Seyoum, A. Ramirez, because I learnt a lot reading your work. To my collogues at my host university: Sayem, Sina, Hakan, Artha, Hussein, Ed, \& Ebru - our time at UPM gave use much more than we ever thought it would. I would like to thank Marta Valero for her consistent support during my stay in Madrid. It was tremendous.

Lastly, to my family: I cannot imagine the frustrations you have accepted to cope with while we were apart during all these years, and, more importantly, not hearing from me as much we all wished. To my brother Sam: I cannot ask for anything more than for a big brother that you are. Sam, thank you for your support and for always believing in me. I would like to thank my lovely sisters Damali \& Dorren for their love and support. My thanks to Conrad, Diane K., Eudie, Babrah and Simon M., for constantly checking on me-Rukundo egumeho. I also need to mention Ivo Kafemann, Frank Mireri, Terry and Suzan: thank you for all the inspirations and friendship. To my dad: although you have not lived long enough to see me grow, the inspiration you gave me during my formative years helped me persevere through the pressures of a Ph.D. Lastly, to my mother: it is your unconditional love and your strong desire for knowledge, combined with the way you raised me that have given me the patience to write this thesis. I dedicate this work to you. Mukama Asimwe.

Simon Okwir

Madrid, May 2017 


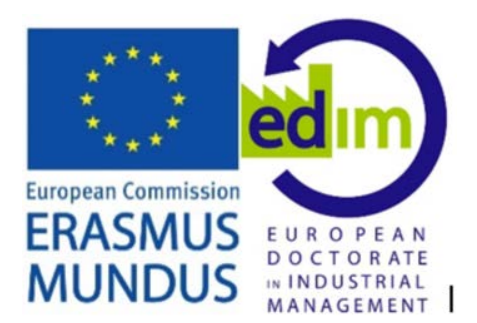

This research was conducted within the framework of the "European Doctorate in Industrial Management" - EDIM - which was funded by The Education, Audiovisual and Culture Executive Agency (EACEA) of European Commission under Erasmus Mundus Action 1. 



\section{Resumen}

La Medición del Desempeño (MD) ha avanzado desde su uso en las operaciones como un Sistema interno de Gestión del Desempeño (SGD) hasta entornos más complejos donde los actores a menudo enfrentan el reto de gestionar las operaciones a través de Medidas de Colaboración. La gestión a través de medidas de colaboración plantea una rareza de doble cara para la funcionalidad del sistema y la interoperabilidad en un sistema de sistemas. Por un lado, las medidas de colaboración facilitan el mantenimiento de la funcionalidad del sistema y establecen programas para mejoras continuas, pero por otro lado, las medidas de colaboración son difíciles de manejar debido a la composición diversa e independiente de los actores. Como consecuencia de que un SGD colaborativo no es suficientemente dinámico y receptivo, siempre hay una retirada significativa de los mecanismos de retroalimentación para el control y la falta de autoridad central de toma de decisiones tanto horizontal como verticalmente. Esto plantea una cuestión importante. ¿Los conocimientos actuales en el campo de la medición y gestión del desempeño (MGD) de SGD son adecuados para abordar los desafíos de gestión para las MD interorganizacionales? El propósito de esta tesis es explorar el MDG colaborativo extendiéndolo a contextos operacionales donde se implementan y gestionan medidas de colaboración. La tesis se basa en cinco documentos adjuntos para estudiar la optimización de la capacidad para las operaciones aeroportuarias. Como Sistema de Sistemas (SdS), las operaciones aeroportuarias proporcionan un ajuste empírico adecuado para el estudio de MP que trasciende las fronteras de las organizaciones debido a su complejidad operativa. MDG como resultado de medidas de colaboración es operacionalizado con los siguientes aspectos inter-organizacionales: Complejidad organizacional, Mejora Continua y MD como sistema social. El reto de la retroalimentación está asociado con cuatro funciones cibernéticas: sensor, comandante, actuador y proceso para proponer un mecanismo tentativo de retroalimentación para los actores que gestionan con medidas de colaboración. Este estudio se aparta de la investigación previa en la literatura de MGD, tales como, empresas ampliadas, empresas virtuales, MGD integrado, cadenas de suministro colaborativo cuestionando la gestión de medidas de colaboración. Lo hace informando a MGD sobre la desalineación entre insumos y productos en dichos sistemas. Por otra parte, el estudio establece una base para repensar cómo el futuro de la MGD colaborativa debe ser visto especialmente para las plataformas interorganizacionales, tales como empresas conjuntas, coaliciones, consorcios de empresas ampliadas, asociaciones y alianzas. El principal resultado y conclusión es que MGD todavía un tema limitado para hablar de ello

Palabras Clave: Medidas de Colaboración, Medida del Desempeño, Complejidad, Mejora Continua, Sistema Social, Operaciones Aeroportuarias. Mecanismos de retroalimentación del sistema. 


\begin{abstract}
Performance Measurement (PM) has advanced from its use in operations as an intra Performance Management System (PMS) to more complex environments where actors often deal with a challenge of managing operations through Collaborative Measures. Managing through collaborative measures pose a double-sided oddity for system functionality and interoperability in system of systems. On one hand collaborative measures facilitate to maintain system functionality and sets out programs for continuous improvements, but on the other, collaborative measures are challenging to manage due to diverse and independent composition of actors. As a consequence of a collaborative PMS not being sufficiently dynamic and responsive, there is always a significant withdraw of feedback mechanisms for control and lack of central decision making authority both horizontally and vertically. This raises an important question. Is the current knowledge in the field of Performance Measurement \& Management (PMM) of PMM suitable to address managerial challenges for inter-organizational PM? The purpose of this thesis is to explore collaborative PMM by extending it to operational contexts where collaborative measures are implemented and managed. The thesis builds upon cases to study capacity optimization for airport operations. As System of System (SoS), airport operations provide a fitting empirical setting for studying PM that transcends organizations boundaries due their operational complexity. PMM as a resultant of collaborative measures is operationalized with the following inter-organizational aspects: Organizational complexity, Continuous Improvement and $P M$ as a social system. The challenge of feedback is associated with four cybernetic functions: sensor, commander, actuator and process to propose a tentative feedback mechanism for actors managing with collaborative measures. This study departs from previous research in PMM literature such as, Extended Enterprises, virtual enterprises, integrated PMS, collaborative supply chains by questioning the management of collaborative measures. It does so by informing PMM on the misalignment between inputs and outputs in such systems. Moreover, the study lays a foundation to rethink how the future of collaborative PMM should be viewed especially for inter-organizational platforms, such as joint ventures, coalitions, Extended Enterprises consortia, partnerships and alliances. The main result and conclusion is that PMM is still limited to address.
\end{abstract}

Keywords: Collaborative Measures, Performance Measurement, Complexity, Continuous Improvement, Social system, Airport Operations. System feedback Mechanisms. 


\section{DISCLAIMER}

Some parts of this $\mathrm{PhD}$ Thesis have already been published as:

\section{Paper 1}

Corrigan, S., Mårtensson, L., Kay, A., Okwir, S., Ulfvengren, P., \& McDonald, N. (2015). Preparing for Airport Collaborative Decision Making (A-CDM) implementation: an evaluation and recommendations. Cognition, Technology \& Work, $17(2), 207-218$.

\section{Paper 2}

Okwir, S., Ulfvengren, P., Kaulio, M., (2016), Sources of Complexity Within a System of Systems: Implications for Performance Measurement and Management. An earlier version of this paper was presented at EurOMA Conference, Palermo, Italy, 20- 25 June 2014 To be submitted to Production Planning \& Control Journal

\section{Paper 3}

Okwir, S., Angelis, J., Ginieis, M., Nudurupati, S. (2017). Performance Measurement System - Art and Science: A perspective from Complexity theory.

International Journal of Management Reviews

An earlier version was presented at the Performance Management Association (PMA) conference, Edinburgh, Scotland, 26-29 June 2016 and invited for inclusion in a special issue on PMM - Towards a Theoretical Foundation for Performance Measurement and Management.

\section{Paper 4}

Okwir, S., Ulfvengren, P., Angelis, J., Ruiz, F., \& Guerrero, Y. M. N. (2017). Managing turnaround performance through Collaborative Decision Making. Journal of Air Transport Management, 58, 183-196.

\section{Paper 5}

Okwir, S., Prediction of Airport Infrastructure performance with collaborative measures: Studies from Barajas Airport.

Status: To be submitted to Journal of Air Transport Management

\section{Paper 6}

Okwir, S. and Antonio, C., Collaborative Decision Making (CDM) in Airport Surface: Europe vs USA implementations, challenges and best practices. 2014 Integrated Communications, Navigation and Surveillance Conference (ICNS) Conference Proceedings. IEEE, Washington. 2014.

\section{Paper 7}

Okwir, S. and Ulfvengren, P., (2013) System change in airport networks: A case study for studying the concept of coopetition, $22^{\text {nd }}$ Nordic Academy of Management, Reykjavik, August 21-23, 2013, conference proceedings ISSN 2298-3112 



\section{Contents}

FOREWORD 1

1. Introduction 3

1.1. Aim and background . . . . . . . . . . . . . . . 3

1.2. The research problem . . . . . . . . . . . . . . . 6

1.3. Approach and focus of the thesis . . . . . . . . . . . 7

1.4. Purpose and research questions ... . . . . . . . . . . . 9

1.5. Disposition ....................... 9

2. Airport Operations 11

2.1. The Air Transportation System in Europe . . . . . . . . . . . . . . 12

2.2. Actors in the system of aviation . . . . . . . . . . . . . 12

2.3. At the Airport Level . . . . . . . . . . . . . . . . . . . . . . 13

2.4. Performance management at airports . . . . . . . . . . . . . . . 14

2.5. Collaborative Decision Making $(\mathrm{CDM})$. . . . . . . . . . . . . 14

2.6. CDM operational concept . . . . . . . . . . . . . . 16

2.7. Collaborative Measures emerging from CDM . . . . . . . . . . . 17

2.8. Main operational concepts-TOBT and TSAT . . . . . . . . . 18

2.9. Research context . . . . . . . . . . . . . . . . . . . . . 19

3. Theoretical Frame of Reference 21

3.1. System theory and interoperability . . . . . . . . . . . . 21

3.1.1. Challenges with interoperability . . . . . . . . . . . 22 
3.2. Literature Review Study . . . . . . . . . . . . . . . . . . . 24

3.2.1. Background on complexity in PMM . . . . . . . . . . 25

3.2.2. Findings and Discussion . . . . . . . . . . . . 35

3.2.3. Conclusion . . . . . . . . . . . . . . . . . 47

3.3. Performance Management Systems and System of System . . . . . . 49

3.4. Performance management dimensions for collaborative measures . . 50

3.5. The role of Cybernetic Control Theory . . . . . . . . . . . . 53

3.6. Inter-organizational Performance Management in System of System 56

4. Methods 59

4.1. Selection of Methods . . . . . . . . . . . . . . . . . . 59

4.1.1. Case study . . . . . . . . . . . . . . . . . 60

4.1.2. Systematic Literature Review . . . . . . . . . . . . 63

4.1.3. Longitudinal action based research . . . . . . . . . . 69

4.1.4. CART_Classification and regression Tree Method . . . . . 75

4.1.5. Artificial Neural Network . . . . . . . . . . . . . . . 80

4.2. Research quality . . . . . . . . . . . . . . . 86

4.3. Research limitations . . . . . . . . . . . . . . . . 90

5. Results 91

5.1. Study one -Exploring the airport turnaround process . . . . . . . . 91

5.1.1. Findings . . . . . . . . . . . . . . . . . . . 92

5.1.2. Implications for Performance Measurement and Management 100

5.2. Study two-Implementation of collaborative measures . . . . . . . 100

5.2 .1 . Introduction to study three . . . . . . . . . . . 100

5.2.2. Overall Conclusion . . . . . . . . . . . . . . . 113

5.3. Study three - Exploring the Management of Collaborative Measures 114

5.3.1. Introduction to study four . . . . . . . . . . . . . 114

5.3.2. Analysis of Results . . . . . . . . . . . . . . . 116

5.3.3. Discussion of Results . . . . . . . . . . . . . . . 120

5.3.4. Conclusions and Implications for Future Research . . . . . . 123

xiv 
5.4. Study four-A Neural Network Method to Predict Performance of Collaborative Measures . . . . . . . . . . . . . . . . . . . . . 130

5.4.1. Introduction to study four . . . . . . . . . . . . . . . . 130

5.4.2. Results . . . . . . . . . . . . . . . . . . 131

5.4.3. Conclusions . . . . . . . . . . . . . . . . . . 134

$\begin{array}{ll}\text { 6. Discussion } & 137\end{array}$

6.1. Research questions answered . . . . . . . . . . . . . . . . 137

6.2. Reconnecting to the Main Research Question . . . . . . . . . . . . . 140

7. Conclusions 143

7.1. The implication for the theory . . . . . . . . . . . . . . 143

7.1.1. Organizational complexity . . . . . . . . . . . . . 143

7.1.2. Continuous improvement . . . . . . . . . . . . . . . . . 144

7.1.3. Social system . . . . . . . . . . . . . . . . . . . 147

7.2. Implication for practice . . . . . . . . . . . . . . . . . . 148

7.3. Avenues for further research . . . . . . . . . . . . . . . . . . . . . . 151

7.4. Reflections and final remarks . . . . . . . . . . . . . . . . . 152

$\begin{array}{ll}\text { A. Literature REVIEW } & 157\end{array}$

$\begin{array}{lr}\text { B. Study One } & 169\end{array}$

$\begin{array}{ll}\text { C. Interview SChedule For Airline } & 171\end{array}$

$\begin{array}{ll}\text { D. INTERVIEW SCHEDULE FOR AIRPORT } & 175\end{array}$

$\begin{array}{lr}\text { E. INTERVIEW SCHEDULE FOR ATC } & 179\end{array}$

F. Interview SCHEDUle FOR Ground HANDLING 183

$\begin{array}{ll}\text { REFERENCES } & 200\end{array}$ 



\section{List of Tables}

3.2.1. Complexity dimensions associated with Performance Measurement Systems . . . . . . . . . . . . . . . . . . . . 29

3.2.2. Combinations of control factors at each process stage . . . . . . . . 44

4.1.1. Interview participants and positions with airport actors. . . . . . . . 61

4.1.2. Keyword analysis and papers until 2015 . . . . . . . . . . . . 67

4.1.3. Evolution of the number of publications PMM in journals WOK/ABS/Scopus . . . . . . . . . . . . . . . . 68

4.1.4. Sample data selected . . . . . . . . . . . . . . . . . . 78

4.1.5. Dependent variables (star values) . . . . . . . . . . . . . 80

4.1.6. Independent variables . . . . . . . . . . . . . . . . . 81

4.1.7. Case processing summary . . . . . . . . . . . . . 85

4.1.8. Summary table of processing cases . . . . . . . . . . . . . . 86

4.2.1. Strategies used for research quality . . . . . . . . . . . . . . . 89

5.2.1. Summary Recommendations as per the Structured Enquiry Elements 107

5.3.1. Set of components extracted from independent variables . . . . . . . 117

5.3.2. Predicted CDM indicators from turnaround . . . . . . . . . . . . 120

5.3.3. Risk Tables . . . . . . . . . . . . . . . . . . 120

5.3.4. Classification Table . . . . . . . . . . . . . . . . . . 121

5.4.1. Error computations based on testing sample . . . . . . . . . . . . 131

5.4.2. Classification of neural network training . . . . . . . . . . . . 132

5.4.3. Classification of neural network training for second test . . . . . . . 133

7.1.1. Contributions made in this thesis from appended papers . . . . . . 148 
A.1.1. The interaction between control factors at different process stages . . 158

A.1.2. Mutual exchanges between actors (interview participants working for each actor in the top row they responded about each actors in the left column) . . . . . . . . . . . . . . . . . . 168

B.1.1. Profiles of companies participating as turn-round actors. . . . . . . . 170 


\section{List of Figures}

1.3.1. Focus of this thesis: The misalignment between inputs and outputs . 8

2.7.1. CDM benefits, work foundations and airport actors involved . . . . . 17

2.8.1. Factors that affect the quality of TOBT . . . . . . . . . . . . . . 18

2.9.1. System of Interest: The turnaround process and its actors . . . . . . 20

3.2.1. Integrative model for external and internal environments Adapted from Pettigrew's (1985) framework . . . . . . . . . . . . . 31

3.2.2. Complexity system view of PMS . . . . . . . . . . . . . 33

3.2.3. Categorisation of sources of complexity under Social and technical control . . . . . . . . . . . . . . . . . 36

3.5.1. Basic cybernetic control cycle (Leveson \& Heimdahl, 1994) . . . . . . 54

3.6.1. Conceptual operationalization of PMM for collaborative measures . . 58

4.1.1. Step by step process for sample selection. . . . . . . . . . . . . . 65

4.1.2. Number of articles on PMM . . . . . . . . . . . . . . . . 66

4.1.3. Action research Lewin model as revisited by Kolb (1984) . . . . . . . 70

4.1.4. Model to Evaluate CDM Indicators . . . . . . . . . . . . . . . . . 77

4.1.5. A screenshot from a CDM management tool . . . . . . . . . . . . . . 78

5.1.1. A schematic representation showing actors with contractual and workrelated dependencies. . . . . . . . . . . . . . . . . . . . 95

5.1.2. Number of critical incidents reported for each actor . . . . . . . . . . 99

5.3.1. Classification tree plot for Database 1 . . . . . . . . . . . . . 126

5.3.2. Classification tree plot Database 2 . . . . . . . . . . . . . . . . . . 127 


\section{List OF Figures}

5.3.3. Classification tree plot for Database 3 . . . . . . . . . . . . . . . 128

5.3.4. CDM airport vs non-CDM Feedback Mechanism . . . . . . . . . . . 129

5.4.1. The critically of importance of exogenous on time performance . . . . 134

6.2.1. A cybernetic framework for collaborative measures . . . . . . . . . . . 141

7.1.1. The evolution of inter-organizational PM as a result of interactive complexity (expanded from Folan and Browne, 2005) . . . . . . . 145

7.1.2. Reflective performance measurement system for continuous improvement adapted for the Operational Strategic Management System by Pinheiro De Lima et al. (2013) . . . . . . . . . . . . . . . . . 146 


\section{Foreword}

Madrid-Barajas airport

$6^{\text {th }}$ July 2012

Today, 6th July 2012, Madrid-Barajas Airport is expected to handle at least 800 arriving aircraft and more than 600 departing aircraft. $50 \%$ of these arrivals have a short Turnaround Process (TAP). Normally, a typical TAP ranges between 45 minutes and 2 hours. There are several actors involved in the airside operations of the TAP. These include Air Traffic Control (ATC), which controls the supply and demand of the runway, and the airport hub operations team, which has over 50 staff members with giant screens and networked telecoms to dispatch airport resources such as staircases, pushback tugs and runway airport shuttles. The main ground-handling company offers airside services to more than $70 \%$ of airlines including cleaning, catering, and fueling, supplied by various companies. The ground-handling company alone has up to 200 turnaround co-coordinators who conduct all turnaround processes, ensuring smooth and on time operation. In addition, the baggage handling companies are expected to handle at least 3,200 bags on departure flights and 52,000 bags on arrival. Normally, of all bags handled each day, over 1,200 should be delivered to connecting flights during the turnaround process. It is an operational hitch that nearly 100 bags miss targeted flights, and are declared lost, stolen, or damaged. Finally, there are over 100 airline companies that have contracts with the airport management for slot allocation.

Given that the airport operates with scarce resources and with only four functional runways, two of which are closed in the evenings for noise abatement purposes, the airport lies at the lower end of its operational limits. It is being realized that important metrics such as on-time performance, lost baggage complaints, taxi time, fuel, $\mathrm{CO}_{2}$ emissions and runway congestion vary on daily. With the recent initiatives from regulators, the airport management agrees to implement a collaborative Performance Management System (PMS) called Collaborative Decision-Making (CDM). Regulators state that CDM integrates all processes in real-time, improves levels of situation awareness and optimizes operations to reduce taxi times, which translates to lower fuel costs, lower $\mathrm{CO}_{2}$ emissions, optimal use of airport resources and stable runway throughput. Given the interdependency and complexity of the airport operations management and a diversity of actors who have different interests and views, it is therefore worthwhile to investigate how actors manage the demand and supply of runways through a collaborative PMS. 



\section{1 \\ Introduction}

Chapter one provides a background to the research problem, focus of the thesis, research questions and the overall thesis structure.

\subsection{Aim AND BACKGROUND}

The aim of this research is to develop a framework for actors managing through a collaborative performance measurement \& management system. Within the context of this thesis, collaborative measures are observed to be a result of interdependent roles that are simultaneously integrated and interwoven into partners and/or ingrained in operating processes along the system value stream. As a result, Collaborative Measures become essential for system interoperability and functionality. However, creating a framework for managing through collaborative measures, i.e. to be able to discern collectively what is measurable, observable and controllable for functional collaborative PMS. Actors are faced with challenges as they adopt functional Performance Management (PM) practices for inter-organizational performance since they are not aligned with respective internal measures. In this research, it is argued that its fundamental to understand the underlying processes 


\section{INTRODUCTION}

that sustain PMS so as to understand factors that delimit their operational capabilities However, in Performance Measurement \& Management (PMM) literature this is seldom discussed.

Based on the theory of feedback and feedforward as a dual-control mechanism, the thesis investigates challenges related with inter-organizational performance that hinder the efficiency and effectiveness within complex multi-stakeholder settings. PMM, which is examined in this thesis as a domain theory, has evolved over time. The seminal publication Relevance Lost: the rise and fall of management accounting ( $\mathrm{H}$. Thomas Johnson and Kaplan, 1987) raised doubts about the significance of PM both in academia as well as among practitioners. The paper ensured that academics put new innovative perspectives on PM practices. As a result, PM has not only become a common mechanism for managing business performance (Hoque, 2014; Micheli et al., 2011; Micheli and Mari, 2014), it has also garnered interest from a variety of fields such as accounting (Otley, 1999), management (Atkinson and Hammersley, 1994; Pinheiro De Lima et al., 2013), public and nonprofit organizations (Micheli and Kennerley, 2005; Moxham and Boaden, 2007) and operations/process management (Bititci et al., 1997; Bourne et al., 2000; Neely et al., 1995). This multi-disciplinary perspective led to an enormous amount of academic and practitioner-based work in the area of performance measurement (Bititci et al., 2005a; MacBryde and Mendibil, 2003; Melnyk et al., 2014).

A major development came with the introduction of Balanced Score Cards (BSC) by Kaplan and Norton (1992), which streamlined complex organizational structures into four main parts. BCS and several other PM frameworks played a significant role in determining the reasons why certain organizations succeeded and others failed (Hoque, 2014). However, the weaknesses associated with these frameworks were tested by Bititci (1997) which led to more collaborative frameworks that focused more on stakeholder needs (Mendibil and Macbryde, 2005). For example, the Integrated Performance Measurement Reference Model and the Performance Prism were developed with a recognition that many businesses serve a range of stakeholders and need to separate financial and non-financial measures. As a result, organizations that focused on assessing departments independently, started to examine holistic measurement. This aroused curiosity among research- 
ers about how a collaborative PMS should be designed and managed (Bititci et al., 1997; Pekkola and Ukko, 2016; Pun and White, 2005).

However, as the business landscape continued to change, trans-organizational communities of practice and collaborations seemed to occupy a significant part of existing PM practices. With the new pace of environmental change, traditional hierarchical organizational forms, in which decision-making was centralized, were gradually being replaced with new collaborative-based organizations where decision-making is more distributed. For example, the emergence of global multicultural networks within expanding organizations, the rise of service-based transformations (servitization) such as Rolls Royce which no longer sells jet engines but power-by-the-hour, the shift from manual work to knowledge-based work (Bititci, 2015), and the changing nature of work from autocracy to netocracy. With such transformations, trans-organizational collaborations have been examined for example through Extended Enterprise (Braziotis and Tannock, 2011; Ferreira and Otley, 2009; Lehtinen and Ahola, 2010). However, recent research (Ashmos et al., 2002; Melnyk et al., 2014) has recognized that some organizations in operations management operate in complex environments with multiple stakeholders who are operating with specific interests and with differing views, which adds another dimension of what it means to collaborate within such settings. In addition, operations have been seen to exist in a sequential manner but with high complexity and uncertainty and where actors in collaboration are interdependent to create value. It is also being observed that they are involved in coopetitive ${ }^{1}$ relationships. Such settings, such as airports, are often affected by top-down change processes, regulatory aspects, government and to some extent the wider system which makes most existing collaborative PMS frameworks somehow limited.

This logically creates tension between collaborative strategic intent and current collaborative approaches, implying that an imbalance exists between interests and viewpoints. This leads to a debate on what to measure how to measure. It is then fundamental that, in inter-organizational contexts, PM needs to address strategic common levels as well as balanced operational levels where processes

\footnotetext{
${ }^{1}$ Coopetition means the simultaneous existence of cooperation and competition. The term emerged in strategic management literature in the 1990s as a shift from win-loss to win-win strategies (Dyer and Singh, 1998; Mina, 2011), with its official introduction into research by Brandenburger and Nalebuff (1996).
} 


\section{INTRODUCTION}

are collaboratively produced to discern best practices for managing through collaborative measures. For these reasons, PMM is potentially falling out of touch with the evolving trends of such organizations breaking the alignment between collaborative strategic intent and collaborative operational measurement and being criticized for not being sufficiently dynamic and responsive (Melnyk et al., 2014). This on-going challenge has always prompted scholars in PMM to question how collaborative performance measures can exist in an inter-organizational context and how management should administer them (Agostini and Nosella, 2015; Busi and Bititci, 2006).

\subsection{The RESEARCH PROBLEM}

The research problem being explored is the systematic administration of collaborative measures due to the misalignment between collaborative inputs and collaborative outputs. To examine the research problem, this thesis views transorganizational communities of practice and collaborations using system of systems (SoS) characteristics. A SoS is defined as a "whole compounded of several parts or members" which are independent with various functions. As an implication, a known challenge for managing a SoS is that of interoperability (Alfaro et al., 2009; Nudurupati et al., 2015; Toor and Ogunlana, 2010).

To explain the research problem, there are three important challenges that affect the administration of collaborative measures within complex multi-stakeholder setting.

First, there is the challenge of how to attain a common strategic alignment within a diversity of actors. While measures link operations to new business strategies, such an alignment becomes rather complex for collaborative measures as the process for continuous improvement is hindered (Bond, 1990; L.Brown and Eisenhardt, 1997). Consequently, such systems are often seen as "performing under ignorance." The question then is: Who will be the focal business? Who will own the data to set the new measures? Do collaborative measures play any role in terms of inter-organizational performance?

Second, there is the challenge of many elements and components that depend on each other for the system to function. With the range of interacting elements, 
complexity would be expected with new behaviors which can be unpredictable and ambiguous. Hence it becomes particularly problematic with system of systems environments to manage through collaborative measures for the system's interoperability and functionality (Berman and Jones, 2016; Castro and Almeida, 2017).

Third, there is the challenge of social logic. SoS environments are unique since they are socially constructed (Schein, 1996). This creates different institutional logics and various social maps within management in terms of how collaborative measures should be managed (McDonald, 2015; Carlsson-Wall et al., 2016). Additionally, because collaborative measures are dynamic, multifaceted, and multileveled, but also multilateral, various contradictory factors and incongruences exist. As a result, the plurality of ideas is always expected in terms of what to measure and how; it is within this context that when intra-PM features are applied as a dual control for feedback, they are in conflict.

In sum, the research problem is that while managing through collaborative measures, feedback mechanisms are hindered due to limited collaborative decisionmaking. This creates incongruences in determining how to keep the system both strategically and operationally efficient. Therefore, PMM literature must identify key performance guidelines for inter-organizational PM

\subsection{APPROACH AND FOCUS OF THE THESIS}

Figure 1.3.1 on the following page illustrates the focus of the thesis, which is to investigate the challenge of feedback mechanisms within a SoS. The research focus is addressed in the following ways. First, in order to explore the feedback mechanism, the study proposes to combine two different theories: PMM theory as a domain theory and system theory - Cybernetic Control Theory (CCT) as a method theory (Lukka and Vinnari, 2014, 2016). This approach enhances the current debate on the value and usefulness of employing method theories in research.

Second, the challenge of feedback mechanisms is explored empirically through airport operations as a System of Systems, specifically investigating the operations management of the Turnaround Process (TAP) as the System of Interest (SoI). The empirical focus is then delimited to the TAP by looking at the apparent nature 


\section{INTRODUCTION}

of feedback as a needed practice for inter-organizational performance.

Third and most importantly, the thesis burrows through the main intra-PM features to examine them as inter-organizational PM features. As a result, the management of collaborative measures in this research is then operationalized with three dimensions, namely: organizational complexity, continuous improvement and PM as a social system. These dimensions have been carefully selected from both literature and empirical observations. As this thesis will demonstrate later, the exploration of CCT theory in this thesis advances our knowledge and tentatively sets a discussion on how the future of inter-organizational PM may incorporate a closed signaling loop which opens up a window for the application of cybernetics controls in organizations (Beer, 2002; Kandjani and Bernus, 2012; Rosenblueth et al., 1943). This is a concept that has been asked for in PMM literature (Kandjani and Bernus, 2012; Malmi and Brown, 2008).

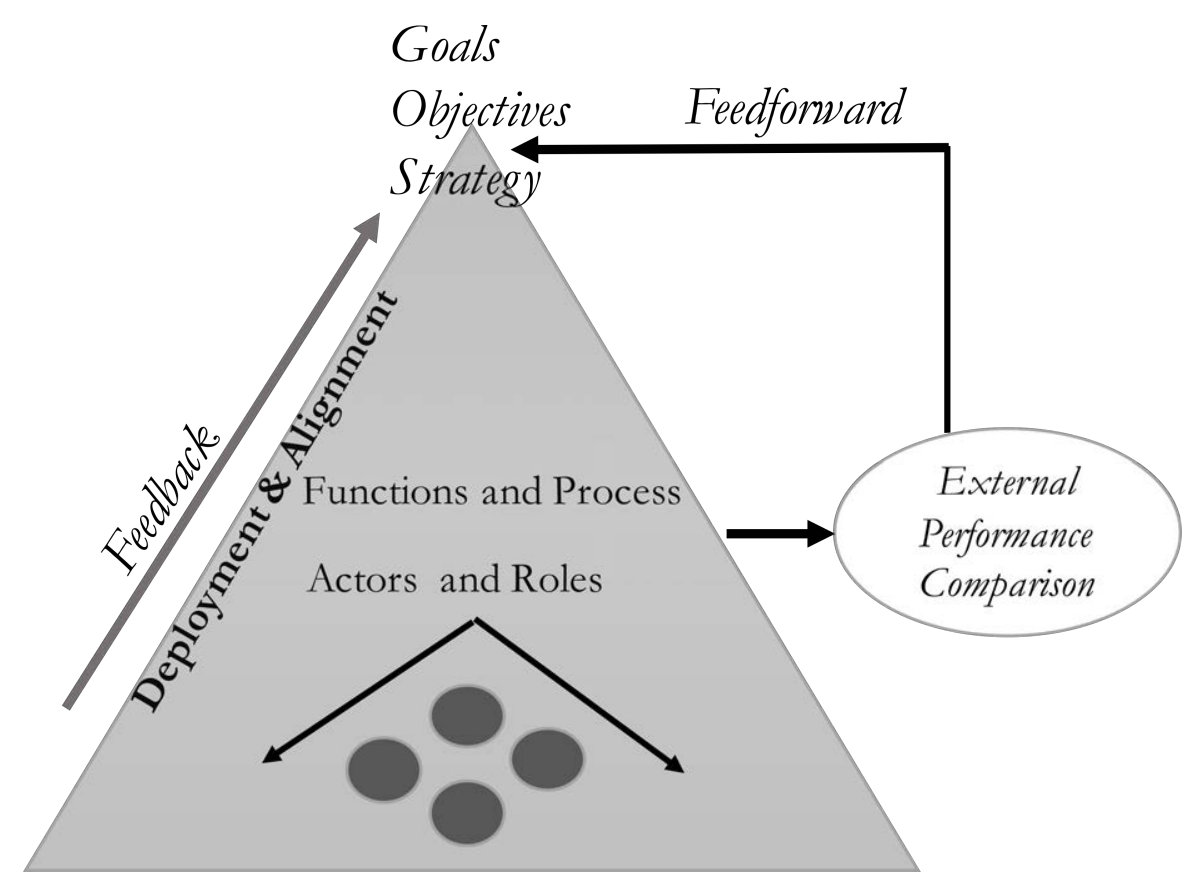

Figure 1.3.1.: Focus of this thesis: The misalignment between inputs and outputs 


\subsection{Purpose And Research Questions}

\subsection{Purpose AND Research Questions}

The purpose of this thesis is to investigate PM dimensions how they affect the management of collaborative measures in a quest to attain better operational performance for inter- organizational PM. To achieve this, the thesis addresses the following Main Research Question (MRQ):

MRQ: How do actors manage operations through inter- organizational performance measures?

To answer this question, the thesis addresses three sub-questions all of which are set in the same airport context. It is important to examine and understand the context in which SoS operate regarding how actors collaborate. Accordingly, the thesis explores this context by investigating sources of complexity that affect inter-organizational PM. Hence, the first sub-question is:

RQ1.1: What are the sources of inter - organizational complexity?

Answering the main research question involves exploring how collaborative measures are being managed during continuous improvement since every actor performs continuous improvement. It is a management concept that, using unique features, keeps a system both operationally efficient and strategic. Hence, the second sub-question is:

RQ1.2: How do actors collaborate while continuously improving?

Since organizations operate under social-technical processes, and people drive processes that deliver performance, the social element is more convoluted than the technical part because the technical element is more easily feasible than the social part, which must adapt. Hence, the third sub- question is

RQ1.3: How do social aspects affect inter-organizational performance?

\subsection{Disposition}

Chapter 1, the introduction, consists of the background of the research problem, focusing on the thesis and research questions. Chapter 2 presents air- 


\section{INTRODUCTION}

port operations and why they implement a collaborative PMS. In Chapter 3, PMM literature is explored as a domain theory and CCT theory as a method theory. Dimensions being explored - complexity, continuous improvement, and social systems - are also presented. Chapter 4 presents the research strategy and methods used in studies, and Chapter 5 presents results. Chapter 6 answers the research questions, and Chapter 7 concludes with influences on theory and practice, with anticipated future research. 


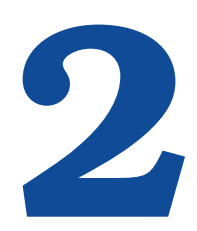

\section{Airport Operations}

This chapter presents a historical account on why airports started implementing a collaborative PMS. It covers reasons for its adoption, Actors involved and main functions for CDM operations.

The overall Air Transportation System (ATS) faces tough challenges ahead which leads to research problems related to increased capacity levels at major airports in Europe. In its very nature, this problem is being described from various system perspectives; the overall ATS, mainly the Air Traffic Management (ATM) capacity issue, need to increase predictability for air traffic movements in the air. Airport operations need to increase capacity on ground. Airport stakeholders need to improve performance in ground operations including the turn-around process. As such, all these adjustments would then lead to overall ATS performance. The research problem exists as a result of a systematic change seen at three different levels. i.e. at the European level, industry level and company level. The first two levels set the research problem while the last level is the unit of analysis which is the focus of this thesis. in doing so, PMM is applied at the industry level where airport actors collaborate. The following sections expands more on the context and the need for airport actors to collaborate. 


\section{Airport Operations}

\subsection{The Air Transportation System in Europe}

Over the years, the air transport in Europe started growing much more quickly than the airport systems' capacity could handle. This created a crisis in the modern commercial aviation in Europe (Wu \& Caves, 2002), as traffic overloads and excessive congestion started to be noticed at major airports. This is also one of the reasons that have been cited as the birth of budget airlines like EasyJet, Ryanair as big traditional carriers could not compete favourably with extra costs caused by delays and fuel costs.

In the beginning of the year 2000, the European Commission launched the Single European Sky (SES) project that seeks to harmonize the European skies and remove national borders. In Feb 2007, the Single European Sky ATM- Joint Undertaking (SESAR-JU) was founded to be responsible for all the research and new technologies needed for a system change in Europe. Up today SESAR has gone through a series of milestones in producing first class technology that will facilitate the use of the single sky. However, system changes to build a single sky still faces a big challenge such as to harmonise the European skies with different national borders, risk in security as many national ATM systems are operated by the national army. The systematic change had implications of the industry level.

\subsection{ACTORS IN THE SYSTEM OF AVIATION}

The industry of aviation is a flexible industry dependent on different factors with different actors; this includes different agencies that operate on a networked scale to provide services from local to global. The industry includes airports, airlines, Air Traffic Management (ATM) agencies and Institutions that manage and regulate their operations.

As a result, in uplift of the globalization in the passing years, there is an equal opportunity for its growth especially with the increasing demand on tourism and trade. This growth of the industry could be attributed to the growth of the complementary industries and the positive developments of the global economy. Today, it is estimated that the European air navigation service providers will be handling almost 11.5 million aircraft movements every year and it is predicted 


\subsection{At the Airport Level}

that by 2020, almost 40,000 flights will be flying per day over the Eurozone alone (Eurocontrol, 2012). The European Commission (EC) as regulators support the implementation of Single European Sky (SES).

This has brought in a lot of pressure on different aviation companies and airports around Europe to provide better products and services to handle large traffic transfers. The need for Single Sky become increasingly important for airport industry as part of larger aviation industry. Airport organizations are now required to implement new standards to optimize operations on the ground for less traffic on runaways but also for route management in the skies. Eurocontrol needs to rely on much higher predictability of flights departure in order to manage air traffic with higher capacity across Europe. Airports as part of the industry, have been selected as empirical setting for this thesis.

\subsection{At the Airport Level}

The major implication for single sky project has been that new needed standards has to take over the traditional methods of work and operations. New methods of work demand novel capabilities such collaborative approaches in management as opposed from traditional forms of management. The need for airport to collaborate is felt now at firm level with new standards as advised by the EU. This puts airport organizations at a challenge; to find means how to collaborate with competitors to implement, and manage inter-organizational on time performance measures. As airports try to meet EU demands for the Single European Sky, airport organizations on the other hand need to meet their strategic objectives. Airport actors have also different interests. As a consequence, new standards are being implemented at airports and airport actors such ground handlers, airlines, Air Traffic Controls and airport management now not only exist as a collaborative network but their performance depends on the actions beyond their organizational borders. 


\section{Airport Operations}

\subsection{PERFORMANCE MANAGEMENT AT AIRPORTS}

The major implication for single sky project has been that new needed standards has to take over the traditional methods of work and operations. New methods of work demand novel capabilities such collaborative approaches in management as opposed from traditional forms of management. The need for airport to collaborate is felt now at firm level with new standards as advised by the EU. This puts airport organizations at a challenge; to find means how to collaborate with competitors to implement, and manage inter- organizational on time performance measures. As airports try to meet EU demands for the Single European Sky, airport organizations on the other hand need to meet their strategic objectives. Airport actors have also different interests. As a consequence, new standards are being implemented at airports and airport actors such ground handlers, airlines, Air Traffic Controls and airport management now not only exist as a collaborative network but their performance depends on the actions beyond their organizational borders. In order to achieve the research objective, the empirical examination was carried out at two major European airports. In the next section, we present the new standard being implemented at major EU airports.

\subsection{Collaborative Decision Making (CDM)}

Collaborative Decision Making (CDM) is an airport operations' standard that has an impact on the Turnaround Process (TAP) at airports. CDM aims to improve air traffic flow and capacity management (ATFCM) by reducing taxi times, turnaround times which translates into for instance, economic benefits and environmental friendly conditions. However, due to its diverse composition of actors, one of the challenges is to measure turnaround performance with collaborative measures. Assessing this performance relies on CDM system that includes diverse actors, such as ground handlers, the airlines, airport management, and air navigation.

The introduction of CDM at airports relies on the accepted fact that air traffic is rapidly increasing globally, and this trend is predicted to continue. In Europe, for example, the monthly monitoring of the European skies, as shown by Euro- 
control (2015b), indicates continuous growth in traffic from month to month. In other areas, studies in airport business show how the commercialization of the airport sector has facilitated air travel with the rise of low cost carriers (Graham, 2013), and how mergers and acquisitions are facilitating growth in aviation markets (Merkert and Morrell, 2012). As a result, flight demand is anticipated to reach 14.4 million movements in the next two decades (Krstić, Simić and Babić, 2015; SESAR, 2014).

This increase in air travel signals positive economic benefits (Profillidis and Botzoris, 2015). However, it also exerts constraints, such as congestion in the skies, delays at airports, and bottlenecks in operations, to the whole network. Moreover, there are negative effects on the environment, notably noise and air pollution (Martini et al., 2013). Increased capacity, safety, efficiency, and the environment are the main goals for the EU. This creates an important supply and demand for runways that is being felt across major airports in Europe.

To address the anticipated needs for future air traffic management and the development of air traffic (Madas \& Zografos 2008; Forsyth 2007; Wu \& Caves 2002), new technologies, concepts, and policies are emerging in order to optimize air traffic management (ATM) infrastructure to facilitate the collaborative management of the ATM network via Next Generation (NextGen) in the USA, and Single European Sky Air Traffic Research (SESAR) in Europe. For example, at the network level, the long-term strategic development of the entire air traffic infrastructure in the EU (SESAR, 2015) involves many programs such as moving from airspace to $4 \mathrm{D}^{1}$ trajectory management and traffic synchronization. At the airport level, Airport Collaborative Decision Making (ACDM) is one of the optimization standards for airport services under the Single European Sky (SES) initiative, and was introduced in Europe almost a decade ago (Eurocontrol, 2006). Aside from its unique implementation requirements (Corrigan et al., 2015), an implication for CDM post implementation at airports, has been that turnaround performance from all actors can be measured to explicitly show both operational and financial benefits to a diversity of actors, such as ground handlers, airlines, airport management, and air navigation.

\footnotetext{
${ }^{1} 4 \mathrm{D}$ is a new concept being investigated by SESAR and Eurocontrol as a way to connect aircraft and ground systems to optimize aircraft trajectory in three dimensions over time.
} 


\section{Airport Operations}

In Europe, CDM is a standard for interoperability and a requirement for all airports (ETSI, 2010). At the airport level, CDM is required of all airport actors. However, the completion of CDM implementation does not necessarily mean that the expected outcomes are realized (Eurocontrol, 2006). After CDM implementation at an airport, continuous improvement becomes a daily activity in order to maintain optimal on-time performance. This Study argues that there is a lack of strategic alignment on how actors manage their operations in the TAP by using collaborative measures that are part of CDM. When CDM is viewed as a singleloop performance system, turnaround operations are difficult to manage, not only because of the diversity of airport actors, but also because there is poor alignment of both horizontal and vertical collaborative measures. The CDM performance indicators are not connected to airport actors to support operational improvements. This misalignment highlights the need of appropriate key performance indicators (KPIs) within CDM as a feedback mechanism to push for continuous improvement.

One driving force for CDM implementation has been the anticipation of its benefits to all actors involved at the airport level (Eurocontrol, 2006). However, there is still no recognized cross-organizational approach to how collaborative measures can be used by airport actors as a reference for cost benefit analysis. Because the CDM system is adjustable and there are variations in measures, the relationship between output from CDM operations and actions taken by diverse actors, such as ground handlers, airlines, air traffic controllers, and airport management, need to be examined. This may create a driving element that transforms the CDM system for airports, seen earlier as an ATM system, to a Performance Management System (PMS) (Bititci et al., 2015), defined as "the cultural and behavior routines that determine how measures are used to manage the performance of an organization" (Bititci, 2015a).

\subsection{CDM OPERATIONAL CONCEPT}

As part of the Single European Sky (SES), Airport CDM (Airport Collaborative Decision Making) is a concept for optimizing airside operations. ACDM relies heavily on collaboration, trust and information sharing among different airport actors such ATC, airlines, ground handling and airport operators. For ACDM 


\subsection{Collaborative Measures emerging from CDM}

to achieve its role in the TAP at airports and in the single sky network, it must coordinate the inbound, turnaround and outbound operations, reducing delays as much as possible. The following section highlights basic foundations of CDM.

\subsection{Collaborative Measures emerging from CDM}

Figure 2.7.1 shows an example of a collaborative measure called TOBT. Here the measure is collaboratively generated between different parties. In doing so, such measures become problematic how to fine tune for effective use of resources and efficient system functionality.

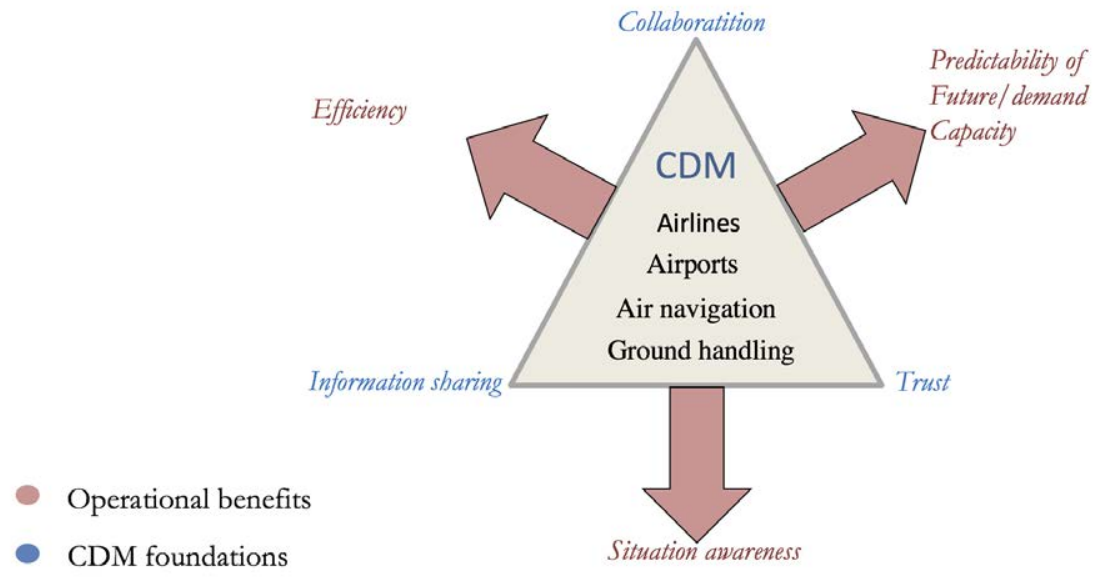

Figure 2.7.1.: CDM benefits, work foundations and airport actors involved

\section{Information sharing, Trust, Collaboration}

Information sharing, trust and collaboration are three general foundations for CDM at airports. For ATC, CDM information sharing replaces the "first come, first served" principle with the "best planned, best served" principle, which is supported by the pre-departure procedures. Ground handlers are to predict off-block times, receive accurate Estimated In-Block Times (EIBT) and pre-departure sequencing (EUROCONTROL, 2012). Information sharing also makes it possible for the 16-milestone approach to be achieved through confirmations in the flight plan. 


\section{Airport Operations}

Information exchange is also vital for the Central Flow Management Unit (CFMU) to allow space usage. For the TAP, real-time information is also important, since not every actor has full situation awareness.

Because of the strict times and the nature of the operations, trust is critical between airport actors in collaboration. In order to meet target times, all actors are expected to not only share the right information, but also accurate information even when it is not in favor of their own operations, but rather for the good of the entire network. In cases where less information is shared, this may lead to bottlenecks and stall operations. As a dependency network, CDM actors depend on each other not only for information, but also for airport space, resources and target times. Since CDM is all about information sharing, the quality of the information matters to the other actors, hence collaboration is vital. A problem may occur when actors have less information on which to base operational decisions, such as insufficient information or late information.

\subsection{MAIN OPERATIONAL CONCEPTS-TOBT AND TSAT}

In this section, we present two indicators that are affected by the quality of collaboration, information sharing and trust, which are critical to the TAP operations (i.e., TOBT and TSAT).

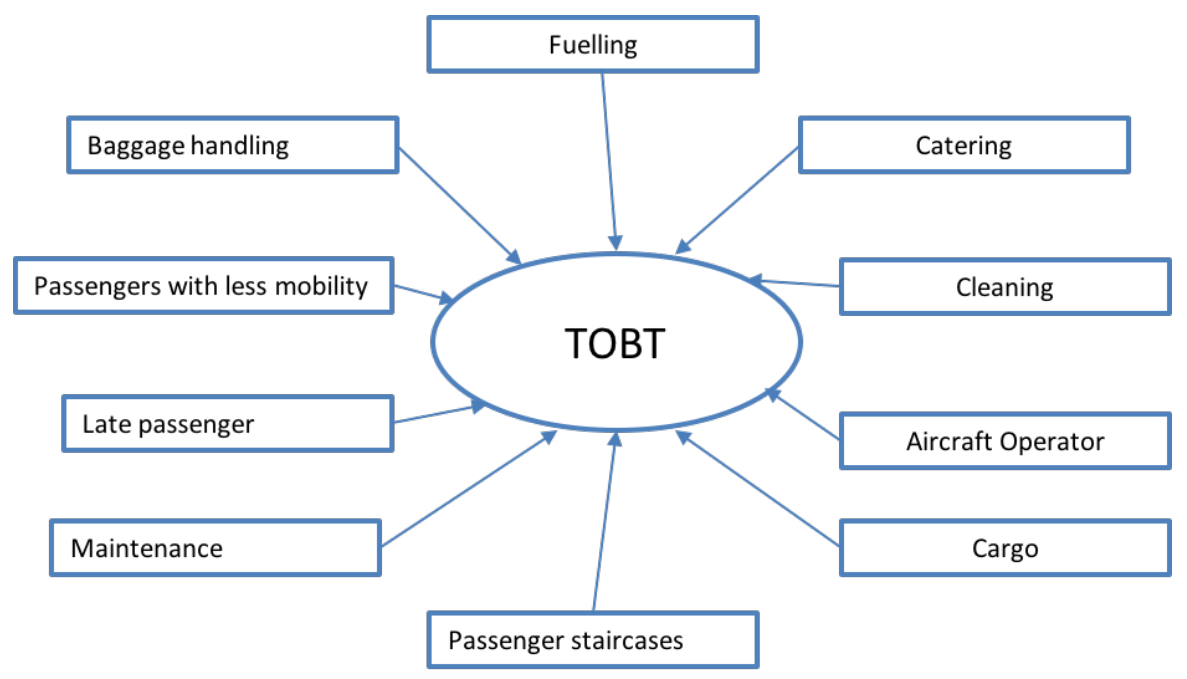

Figure 2.8.1.: Factors that affect the quality of TOBT 
Target Off-Blocks Time (TOBT) represents the time when the turnaround coordinator estimates that an aircraft will be ready for off-block. TOBT time is communicated to all actors via CDM platform; this time means that all doors are closed, the boarding bridge removed, a pushback vehicle is available, and the plane is ready for start-up immediately with pushback within 5 minutes after reception of start-up clearance from ATC. This means that within a window of -5 to +5 minutes, the aircraft is ready to leave the stand. According to CDM operations, in case the aircraft is not ready, TOBT is lost and a new time is scheduled, and any other aircraft that is ready takes the space for taxiing. A new TOBT is then updated for the first aircraft to be ready. This kind of collaboration between actors forms the "best planned, best served" principle. Target Start-Up Approval Time (TSAT) is the time issued by ATC for the aircraft to start-up while considering local constraints. TSAT is vital in reducing queuing time and creates better runway utilization. TSAT for pilots can be revised if there is a change in runway, or if there is an update in TOBT, and this can be communicated to pilots via a different channel. The accuracy of TOBT and TSAT at a CDM airport is an operational partnership procedure between all involved actors in the process of turnaround of an aircraft, which is to say between the Airport Operations, ATC, Aircraft Operators, and Ground Handling, including service companies such as, refuelling, catering firms, cleaning companies, and then the main actor's airline and air traffic control, who are responsible for coordinating all the processes to be able to produce and maintain TOBT and TSAT quality as always scheduled.

\subsection{Research context}

A-CDM has a broad covering sphere and considers many actors in the vast European aviation for its functionality. Within the context of this thesis, the following section sets borders for a unit of analysis which is local CDM in the turnaround operations. Figure 2.9.1 shows the overall unit of analysis for the thesis. For the purpose of the thesis, airports were preferred as they covered all three conditions that were set for a suitable research context for the thesis. First, the operations management of airports is assumed to be complex as it involves many actors and different systems that are interconnected for the overall functionality. Second, air- 


\section{Airport Operations}

ports are more likely to implement collaborative approaches within all segments of their operations, in business, operations, security and safety (Nucciarelli and Gastaldi, 2009). Third, the turnaround process (TAP) would be picked as the System of Interest (SoI) as a sub unit of the larger airport. By adopting the TAP system as the system of interest, the thesis was able to study the management of a collaborative PMS as it is shared between several actors as shown below.

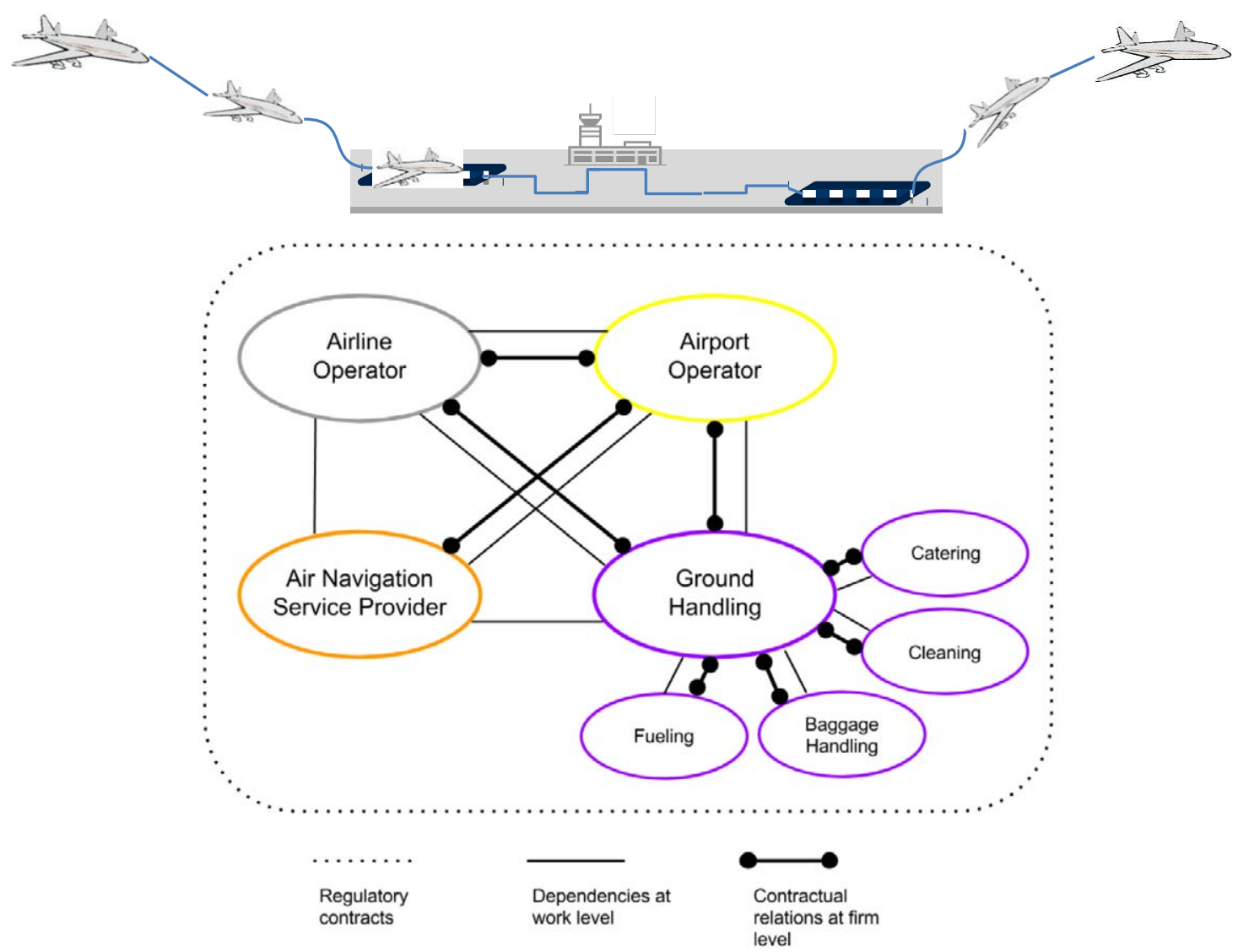

Figure 2.9.1.: System of Interest: The turnaround process and its actors 


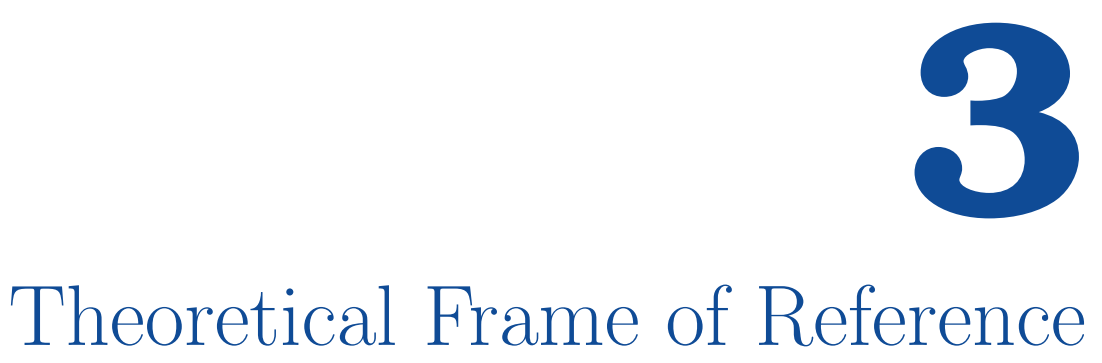

This research is positioned within PMM literature as a domain theory and Cybernetic Control Theory (CCT) as a method theory. The chapter defines and describes $P M$ practices in airport as a System of Systems. The chapter also makes an inquiry into CCT, it covers PM dimensions that are being examined. The chapter ends by discussing the operationalization of collaborative measures within a system of systems.

\subsection{SySTEM THEORY AND INTEROPERABILITY}

To understand the operations management of the airport. This thesis views it as a System of System (SoS). A SoS is defined as a "whole compounded of several parts or members" which is also a complex system according to the ISO/IEEE 15288 standard. The operations management consists of also several parts as independent sub systems to facilitate the functioning of the whole airport. One way to understand a SoS systems is to apply the reductionist approach where parts of the system are broken down to manageable or understandable parts. However, with the reductionist approach, a lot of complexity is absorbed which is ultimately 


\section{Theoretical Frame of Reference}

important to understand for system functionality. As such, SoS require a holistic approach for sorting out such complexity. The tension between the reductionist approach and keeping the holistic approach must be dynamically managed through linear and interactive processes.

\subsubsection{Challenges with interoperability}

According to Dahmann (2014), there are 6 challenges that influence SoS: Authorities, Leadership, constituent systems perspective, capabilities and requirements and autonomy testing and validation

To reach the purpose of this thesis, SoS challenges are discussed in regard to their implication while managing collaborative measures. It is then that the role of PMM will be analysed for SoS in the light of the challenges below.

\section{SoS authorities}

In most of SoS, the organisation structure is not under one leadership. Each part of the system as users, business process or stakeholders tend to be managed by local owner. However, for entire system to be functional all parts need to be integrated with collective a aim even when they conflict which those of individual parts in the system. The airport exhibits a similar situation. The airport as SoS has many parts that sustains the system to stay functional. When it comes to manage on time performance several processes are needed to be integrated and yet tend not to coincide with those of airport actors.

\section{Leadership}

The lack of central leadership authority is another challenge for SoS. As many parts of the system are managed differently, there is a challenge for influence and incentives for whole system. For example, actors involved in the airport turnaround, there are is lack of collaborative leadership that is important for PMM if this part of the system is to continually improve while managing with measures as part of the whole airport. 


\subsection{System THEORY AND INTEROPERABILITY}

Constituent systems perspective

This perspective deals the challenge of incumbent parts of the system that now have to deal with incorporating new processes and new standards. Typically, many parts of the global system were developed for different reasons in the past but because of advancement, these parts must now leverage on old components to meet the requirements for new system objectives or different application. As such, there could be a mismatch which then pose issues for interoperability. For airports, most of the infrastructure was built to handle a minimal number of aircrafts, today because of massive traffic in the skies, much of it is now being felt on the ground.

\section{Capabilities and requirements}

There is always lack of capabilities both at system level for a global system goals which are different capabilities at the local level of the system. For this, SoS must find alternative ways for meeting the gap between what is required and what exists in terms of know how. For airport, the management of PMM for the turnaround also poses several challenges. First there is lack of capabilities to manage system performance of turnaround of which such capabilities are not found within a single actor

\section{Autonomy: interdependencies, and emergence}

Since SoS constitutes many parts which are independent, this could be a source of technical issues for global system. Since the system is open and new parts continue to change with interdependence's of other parts affects the system with emergent new behaviours as such the system is not autonomous for control. In the airport, the system is open and allows new parts of the system to integrate. As such lack of autonomy for a global system is one challenge for functionality.

\section{Testing, validation and learning}

In order to conduct validation for new standards in SoS, there is always an endto-end validation for all parts in the system. Because the system is large and composed several part, each part has to be validated and tested to assess the level 


\section{Theoretical Frame of Reference}

of performance or what is needed. For instance, in an airport, new metrics have to tested for all turnaround actors if they do not give raise to problematic end-to-end validation

System interoperability relates to system integration for functionality. Interoperability presents system integrated and coordination for all components in the system. However, interoperability is always challenged by technology-related aspects which do not allow for the involved system processes and the strategic concerns These may include collaboration, compatibility, performance and cost (Castro, 2015). As such, for a system to function it now must acquire novel principles that will define the new procedures since these dimensions lie beyond the technology layer. One aspect is what this thesis aims for: the challenge of feedback mechanisms for system PMM. Under system theory, a branch of cybernetics theory offers several forms of control the following section examines cybernetics as method theory for this thesis.

\subsection{Literature Review Study}

To understand the current literature on PMM and a specif aspect of its complexity as one of the dimensions for collaborative measures. This section presents a literature review on PMM complexity

Performance Management Systems (PMS) have been posited as a process that helps organisations setting goals and tracking progress. However, growing environmental and organisational complexity has become a barrier in implementing effective PMS (Harkness and Bourne 2015). While environmental complexity has been a focus of several academic studies (Harkness and Bourne 2015; Nudurupati et al. 2015), internal organisational complexity has been ignored by the scholars in the extant Performance Measurement and Management (PMM) literature (Braz et al. 2011; Franco-Santos et al. 2007). PMS incorporates different process stages i.e., design, implementation, and use (Bourne et al. 2000; Nudurupati et al. 2011) and requires management commitment to change (Bourne et al. 2002) thus consuming a lot of organization's time and resources.

As articulated by Bititci (2015a), PMM research can be viewed from two broad perspectives, i.e. art and science. The art aspect focuses more on the subjective 
social controls of the management system. These are posited to be the cultural and behavioural controls achieved through personal traits, structure or bureaucratic elements and interactions. The scientific aspect focuses more on the objective technical controls. These controls focus on the technology, processes and functions of the organisation. It is argued that managing the technical controls without considering the social aspects often leads to a ridged command and control style of management that undermines innovation. However social controls, such as effective leadership can empower people and promote innovation. Ultimately, striking a balance between the social and technical controls always involves dynamic change thus creating competitive advantage (Bititci 2015a).

The study focuses on how control factors give rise to complexity along the three process stages of PMS. To understand how complexity can impact the design, implementation, and use of a PMS, we must first have a working definition of complexity as it applies to process management. This study uses Complex System Theory (CST) (Morel and Ramanujam 1999; Ladyman et al. 2013) to explore how complexity is incorporated as an independent variable in user practices, processes and mechanisms (control factors) that are associated with the design, implementation and use process stages of PMS.

\subsubsection{Background on complexity in PMM}

In this study, a rigorous analysis of the most relevant literature for the field of PMM is carried out. A Systematic Literature Review methodology was applied to identify and synthesize the most relevant academic literature in this field. The study examined the chronological evolution of the research on PMM in order to understand if there is growing interest by academics and demonstrated how its chronological development has been established in publications related to the subject.

The present manuscript focuses on how control factors give rise to complexity along the three process stages of PMS. To understand how complexity can impact the design, implementation, and use of a PMS, we must first have a working definition of complexity as it applies to process management. This study uses Complex System Theory (CST) (Morel and Ramanujam 1999; Ladyman et al. 


\section{Theoretical Frame of Reference}

2013) to explore how complexity is incorporated as an independent variable in user practices, processes and mechanisms (control factors) that are associated with the design, implementation and use process stages of PMS.

A review of the literature found no studies that explicitly studied complexity in PMM. However, a few researchers have studied the impact of complexity on PM (Harkness and Bourne, 2015; McAdam and Bailie, 2002; Neely et al. 2000) and have explored different ways in which managers can make strategic decisions despite high levels of complexity, as well as different approaches to organisational learning (Neely, 2005). Bititci (2006) explored the complex nature of causal links between performance measurement, management styles and organisation culture. In a similar vein, Bititci (2012), claims that practitioners have to deal with complexity by rethinking the future of measurement, but does not explain what exactly amplifies complexity. Braz et al. (2011) and McAdam and Bailie (2002), highlighted complexity in their work but it is mostly dismissed as a minor issue. Nevertheless, there are number of factors that portray complexity as a potential barrier for PMS to attain its efficacy (Bititci, 2015b; Harkness and Bourne, 2015; Paranjape et al., 2006; Sullivan, 2011). The literature also refers to complexity when it talks about the evolution of PMS. For instance, Bititci et al. (2012) demonstrated business trends and how PMM is moving towards challenging operational contexts and thus suggested it to be a social and a self-learning system. It is clear from literature that PMM has not focused on user practices, processes and mechanisms as sources of complexity but instead has focused on operational contexts.

After analysing 76 empirical studies, Franco-Santos et al. (2012) classified contemporary performance measurement into three categories: "people's behaviour, organizational capabilities, and performance consequences". Performance was further divided into external and internal. Franco-Santos et al. also highlighted that it is essential to understand how organisations respond to dynamic situations. Similarly, Braz et al. (2011) studied the process of reviewing and updating a company's existing PMS to reflect the changes. They identified that "the involvement of PMS users, the assessment of performance measures, the establishment of targets, and data availability" create a level of complexity.

Therefore, it is important to explore practices, processes and mechanisms ap- 
plied or used at all process stages of a PMS, with a critical view of complexity theory (Franco-Santos and Bourne 2012). The researchers in this study contend that complexity in PMM arises just from complex environments, and argue that complexity is created from the practices, processes and mechanisms associated with PMS and its stages. These practices, processes and mechanisms can be anything from continuous improvement projects to change management programs used in investigating a problem and fixing it, which in this study are termed control factors.

The argument here is that these control factors are themselves potential sources of complexity, which eventually affect the PMS. A number of factors introduced by Harkness and Bourne (2015) such as ambiguity, lack of control, unpredictability, information issues, which are interacting in the system as a precursor for complexity that need to be operationalised. To date there has been limited research regarding the interplay between what is measured (Micheli and Mari 2014a) and how it is controlled (Mol and Beeres 2005; Canonico et al. 2015) and the process of updating, analysing, and acting on performance data (Bititci 2015a; Bourne et al. 2000; McAdam and Bailie 2002). This becomes relevant because, as will be discussed later, as the system evolves, changes to the control factors and to how they interact can give rise to new and unpredicted behaviours, which signals that the system is a complex one.

On a wider literature in complexity theory, complexity is defined in various ways. Firstly, Simon (1996) conceptualizes complexity with a hierarchic model whereby he argues that to organize complexity with many parts of the system, he proposes a decomposition of the system into subsystems until a low abstraction is reached. Thus in its most basic form, the concept of complexity argues that by understanding the structure, behaviour of each component within a system, the system as a whole could be understood with inter-relations between several components. Secondly, (Anderson, 1999) extends complex adaptive systems by arguing that the "strategic direction of complex organizations consists of establishing and modifying environments within which effective, improvised, self-organized solutions can evolve". Based on these works, most attention has focused on trying to determine all of the interactions within the system, why they interact and how they interact. These interactions among elements continue to hold a big part when studying 


\section{Theoretical Frame of Reference}

complexity.

Early system theory such as Lopreato and von Bertalanffy (1970) describe complexity as a set of interdependent variables that forms an interdependent whole. Studies in organizational science also describe complexity as structural parts that are characterized as activities in their own environment (Anderson 1999; Galbraith 1982). Blau and McKinley (1979) suggest that "complexity can be conceptualized both in terms of how differentiated the structure is and how numerous are the tasks that refer to different kinds of operations and activities." Edmonds (1999) proposes that "Complexity is that property of a model which makes it difficult to formulate its overall behavior in a given language, even when given reasonably complete information about its atomic components and their inter-relations." (Vidal and Marle, 2008).

As stated by (Sahin et al., 2013) complexity is defined as "behaviour that arises from the way the parts of the system are interconnected not because the components of the system are themselves complex, although our components, being people and firms, are indeed complex themselves because they are also complex adaptive systems (Wilkinson 2006)". The system view to characterise complexity is not new (Ladyman et al., 2013). For example, in understanding project complexity a wide range of empirical studies use the systems view to examine complexity (Geraldi et al. 2011; Vidal and Marle 2008).

This definition resonates with PMS in the sense that even though there are several frameworks available to guide PMS through its life cycle telling exactly what organisations need to do, the system behaviour as a whole is not predictable due to the complex nature of the organisational interactions. Just as Miller and Friesen's (1984) organisational life cycle, PMS survives at different process stages: design, implementation and use, where by complexity arises depending on the interaction between various factors in the system. Vidal and Marle (2008) describe complex systems with four system properties, i.e., ontological, teleological, genetic and functional.

As shown in Table 3.2.1, the ontological property represents the internal structures that include leadership styles, organisational culture, behavioural factors, etc. The teleological property represents an object in an environment that aims to reach an objective. The genetic property represents the system's evolution over 
Table 3.2.1.: Complexity dimensions associated with Performance Measurement Systems

System property $\quad$ Performance Management System indicators

Internal structures such as the people component, varied staff, behavior factors, leadership styles variety of information, diversity in practices, number of stakeholders, trust, different views on what to measure and so on (Bititci et al.

OntologicAl 2012; Nudurupati et al. 2015; Toor and Ogunlana 2010; Wijngaard et al. 2006) and organisation culture (Aguinis et al. 2011; Bititci et al. 2006; Elzinga et al. 2009; Ukko et al. 2007).

Measures for specific goals (Jääskeläinen and Laihonen 2013), objectives (Haponava and Al-Jibouri 2009; Mol and

TEleologicAl Beeres 2005;) and managerial practices (Angelis and Jordahl 2015)

Measures need specific methodologies and contingent factors (Lohman et al. 2004; Micheli and Kennerley 2005; Micheli FunCtional and Mari 2014b; Nudurupati et al. 2011b) and PMS frameworks (Ferreira and Otley 2009).

The genetic property considers the time factor, evolution of measures (Ittner and Larcker, 1998; Mol and Beeres 2005),

Genetic Phases of product lifecycles, time factors (Caniato et al. 2014) and maturity of KPI, continuous improvement, (Braz et al. 2011; Elg et al. 2014). 


\section{Theoretical Frame of Reference}

time. The functional property represents the activity in focus to be performed (Boulding 1956; von Bertallanffy 1968). The next section will explore the relationship between the control factors and the system properties.

\section{Controls as responses to the environment}

Integrating strategy formulations in response to the overall industrial environment is a demanding process (Pun and White 2005). The role of monitoring and decision making requires deeper insights into the type of controls organizations use internally. Organizational control can be traced back to Anthony (1965). Several output controls require adjustable performance to meet the changing needs of an organisation as stressed in the works of Mol and Beeres (2005). Garengo (2005) identified three factors (a lack of human resources, managerial capacity for technical excellence in products and operational processes, and misconception of performance measurement), which are influencing PMM in SMEs.

After analysing several longitudinal studies, Mason-Jones and Towill (2000) conclude that "specific processes are required to continuously align the performance measurement system with strategy", which is in agreement with Melnyk et al. (2014). Therefore, in the light of "internal controls", organisations should know what to measure, how to measure, and when to update and adjust their measurements to reflect the changing needs. Hence, the factors that affect these activities are considered to be part of the internal environment and hence can present social or technical challenges (see Figure 3.2.1, based on Pettergrews (1985) framework). As such, companies must employ several internal control factors alongside their PMS to manage their improvement or change programs (see Franco-Santos and Bourne 2005; Halachmi 2005; Michie and West 2004). To understand PMS in full, it is necessary to consider both internal and external contextual factors to avoid an overly narrow analysis (Bititci et al. 2000; Bourne et al. 2000; Neely et al. 1995). The focus should be on the users' responses to the environment, which are the internal factors i.e. the combination of social and technical factors. It should also focus on external factors that also lead to dynamic change. The following sub-sections explore these factors in more depth. 


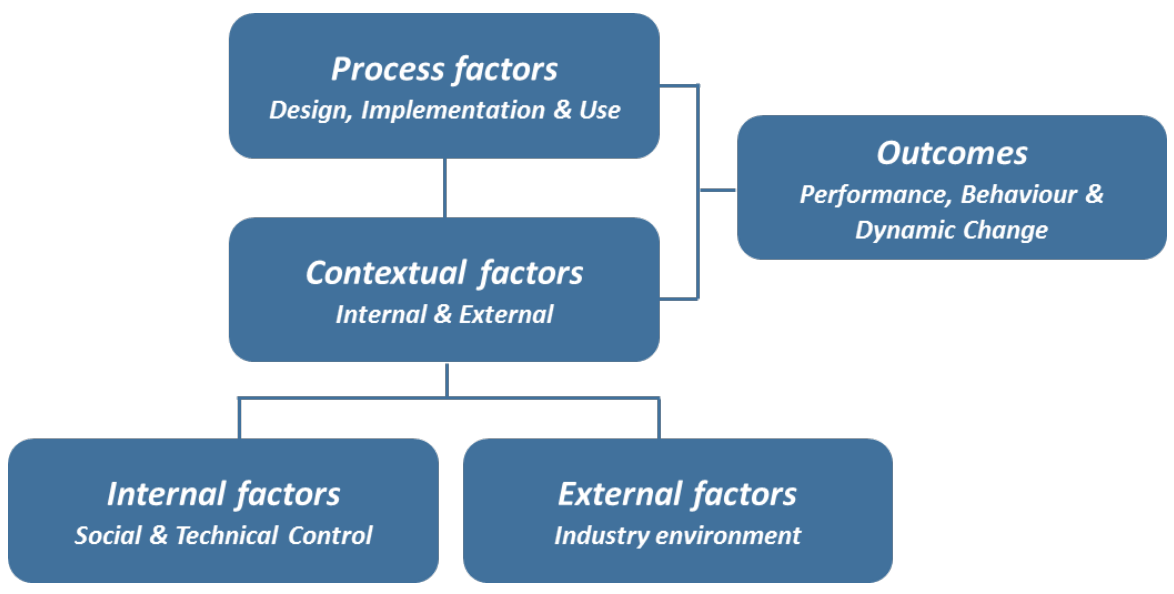

Figure 3.2.1.: Integrative model for external and internal environments Adapted from Pettigrew's (1985) framework and expanded from (Franco-Santos and Bourne 2005).

Technical controls, Social Controls, Dynamic change

Technical controls are scientific and objective in nature that are used to support PMS. Examples include information systems, data collection, analysis and communication, supporting frameworks, etc. (Bititci et al. 2000; Kennerley and Neely 2002). While designing, implementing and using measures is part of PMS, various technical controls that interfere with the system during the process. Often measures are poorly defined which is the source of the ambiguity. If the measures are not reflecting the strategies and objectives of the organisation, complexity can arise in different forms and result in unintended consequences (Courty and Marschke 2003). Similarly, resources such as information systems are used to collect, analyse and communicate performance related information. However, according to Kelman and Friedman (2009) the resources are usually deployed on actions related to improving measures, while neglecting other aspects of the business, which eventually manifests in a complex situation. PMS with its goals, objectives and measures when viewed as a complex system exhibits teleological properties as well as with its implementation methodologies exhibits functional properties

Social controls are mainly concerned with the human aspects that would interact with PMS (Bititci 2015a) leading to complexity. Examples are relationships, commitment, authenticity, behaviours, values, etc. As more and more organisations 


\section{Theoretical Frame of Reference}

become democratic, it is now evident that the focus of control has shifted from technical to social and cultural controls. Johnston (2005) concludes that "performance management systems are largely socially rather than technically constructed and operated" In a similar way, Bititci et al. (2012) argue that a number of social and environmental factors influence different stages of PMSs. The use of top-down, command and control structures causes resistance and complicates the adoption of the PMS (Bourne and Neely 2000). Social factors therefore influence PMS and its stages and are commonly associated with internal factors as responses to the environment. Therefore, in essence "social controls" means that organisations should explore which factors will influence PMSs and how to overcome them. Hence, all the social factors that affect the efficacy of PMSs will fall under this dimension. Achieving a balance between social and technical controls is also a complex task at every process stage, since it involves the unpredictability of what is important and what is not at each process stage. Organisational elements such as staff, their diversity and experience, structure of decision-making will interact with PMS, making it a complex system that exhibits ontological property.

Dynamic change is a form of control that leads to change effecting a PMS, for example a change in strategy, a new business model. Micheli and Mari (2014) conclude that a good PMS supports better decision making rather than showing true representations of performance. It is the basis for informing decisions about how to change to a better or desired position in response to the wider industry. Dynamic change is a cycle in which feedback from technical and social controls drive the organisation to change and implement new measures which in turn will inform future changes. For example, Mason-Jones and Towill (2000) state that "the measurement system can enhance the strategic management process by challenging the assumptions and the strategy itself". Wilson (2009) shows how "capability learning and best practices are positively related to performance improvements in quality, flexibility, and dependability". Therefore, a PMS must be able to adapt and evolve in order to stay responsive. Miller and Friesen (1984) described the organisational life cycle (OLC) stages such as birth, growth, maturity, and revival are explained. In similar manner, PMS have different process stages: design, implementation and use, where by complexity can arise depending on the interaction between control factors as user responses in the system. PMS 
will evolve through its lifecycle in response to the emergent changes exhibiting genetic property of a complex system.

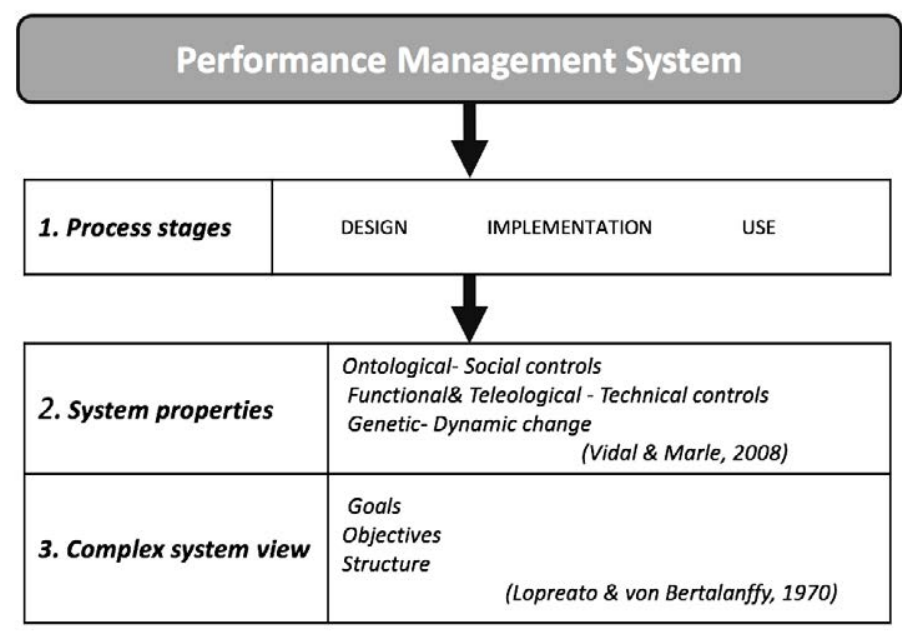

Figure 3.2.2.: Complexity system view of PMS

PMS by its definition and use exhibits similar properties when viewed as a system. i.e. as discussed in general system theory (Lopreato and von Bertalanffy 1970). It is treated as an object operating in an environment (Vidal and Marle 2008) with four system properties. i.e., ontological, teleological, genetic and functional. Figure 3.2.2 summarizes how PMS exhibits system properties that are mapped onto organisational controls when viewed as a complex system with goals, objectives and structure. In addition, it is important to recognise that PMS are complex adaptive social systems (Holland 1975). That is, they are systems in which users both contribute to creating and responding to their environment in order to achieve some goal. In this case the goal is to monitor and measure performance in order to improve and control an overall process. As discussed, both technical and social controls will interact with all three phases of the PMS process in response to emergent change influences over time. It is this interaction between the controls and the activities involved in the various phases that contribute to the emerging complexity. While interactions between social and technical are difficult to manage, their divisions and interactions are quite crucial to facilitate how organizations may achieve responsive and dynamic PMS. 


\section{Theoretical Frame of Reference}

To examine the extent of PMM user practices in literature, this study used a Systematic Literature Review (SLR) approach (Cook et al. 1995; Petticrew and Robert 2006). A SLR provides with useful guidelines that can then be followed by other researchers in different fields. Our work differs from traditional narrative reviews because according to what is indicated in Cook et al. (1997) and Moustaghfir, (2008), a literature review based on SLR adopts a detailed, replicable and transparent scientific process that aims to minimise bias through exhaustive bibliographical searches of published studies. Therefore, a SLR presents an audit trail of the reviews, decisions taken, procedures and conclusions, and allows creating a reliable knowledge base. To sum up, SLR analysis permits focusing on the research purpose rather than on the utility of publications (Ginieis et al. 2012).

The SLR method originated in the 1990s, and it was in the field of medicine that the most significant advances of this method were made (Cook et al. 1997; Davis et al. 1995; Hemsley-Brown and Oplatka, 2006; Wolf et al. 2001). However, this method has also been adopted in other scientific disciplines. A number of SLR related to PMM can be found in the medicine field (Dawson et al. 2015; Fitzsimons et al. 2013; Freeman 2002; Gardner et al. 2016; Knowles et al. 2005). As well, there are reviews of studies in engineering systems (Lee and Sill 2014), marketing (Kamboj and Rahman 2015), human resource management (Patterson et al. 2010), environmental management (Fenerich et al. 2013; Hansen and Schaltegger 2016; Keene and Pullin 2011) and supply chain management (Choong 2014; Ferreira et al. 2013; Kache and Seuring 2014; Keathley et al. 2014), etc.

In this study, SLR provided us a structured way to summarize various findings with minimum bias. The keywords associated with PMM are used as criterion to search literature from the databases. Emphasis was placed on how interactively control factors impact on process stages of PMS design (Lohman et al. 2004; Deng et al. 2012), implementation (Bourne et al. 2003; Jääskeläinen and Sillanpää 2013; Suprapto et al. 2009) and management as adopted by different organisations in different sectors (Bititci et al. 2012; Folan and Browne 2005; Keong Choong 2013; Mason-Jones and Towill 2000; Neely 1999). Figure 4.1.1 illustrates the steps in the selection process, resulting in 58 publications. 


\subsubsection{Findings and Discussion}

\section{Sources of complexity-Technical \& Social controls}

As discussed earlier, two major sources of complexity were identified at each process stage of PMS. While each process stage exhibited considerable diversity in terms of its complexity properties, there were two common themes that emerged, technical \&s social controls. For example, Adler (2011) found that both technical and social controls were necessary to address the implementation of a confrontational strategy. The technical controls include strategies for cost leadership, differentiation, confrontation, etc. and lack of mature technical controls will lead to analytical, methodological, \& technological complexity. Similarly, social controls include training and development, multiskilling, collective responsibility, etc. and lack of mature social controls will lead to roles, procedural and task complexity. The two sets of controls are intrinsically linked and causally interconnected as their association with PMS could be a source of complexity at any particular stage since many components would be interacting at the same time. As such, the findings identified show how complexity emerges at each process stage of PMS as observed under each theme. Table 3.2.2 on page 44 shows the detailed categorization of each type of complexity and control factors.

Figure 3.2.3 shows the categorized sources of complexity at each of the two main themes. Firstly, it was found that many papers that explored social and technical controls constitute complex system properties (Table 3.2.1 on page 29). It was also found that while a considerable number of papers were exploring the use of social and technical controls, there were conflicting interests, different ambitions, and different measures of success. As such, this diversity and plurality on best practices that administer social and technical controls, creates ambiguity and particularly in the inter-relationships and dependency between the mix of social and technical controls at each process stage. In similar way, through roles, tasks and procedural aspects, there is difficulty in providing a concrete set of success results at each process stage which creates unpredictability, ambiguous and poor decision making. These initial findings also confirmed our conceptual associations between the four system properties from complexity theory and the two organisational controls (social and technical). The following sections discusses the two major sources 


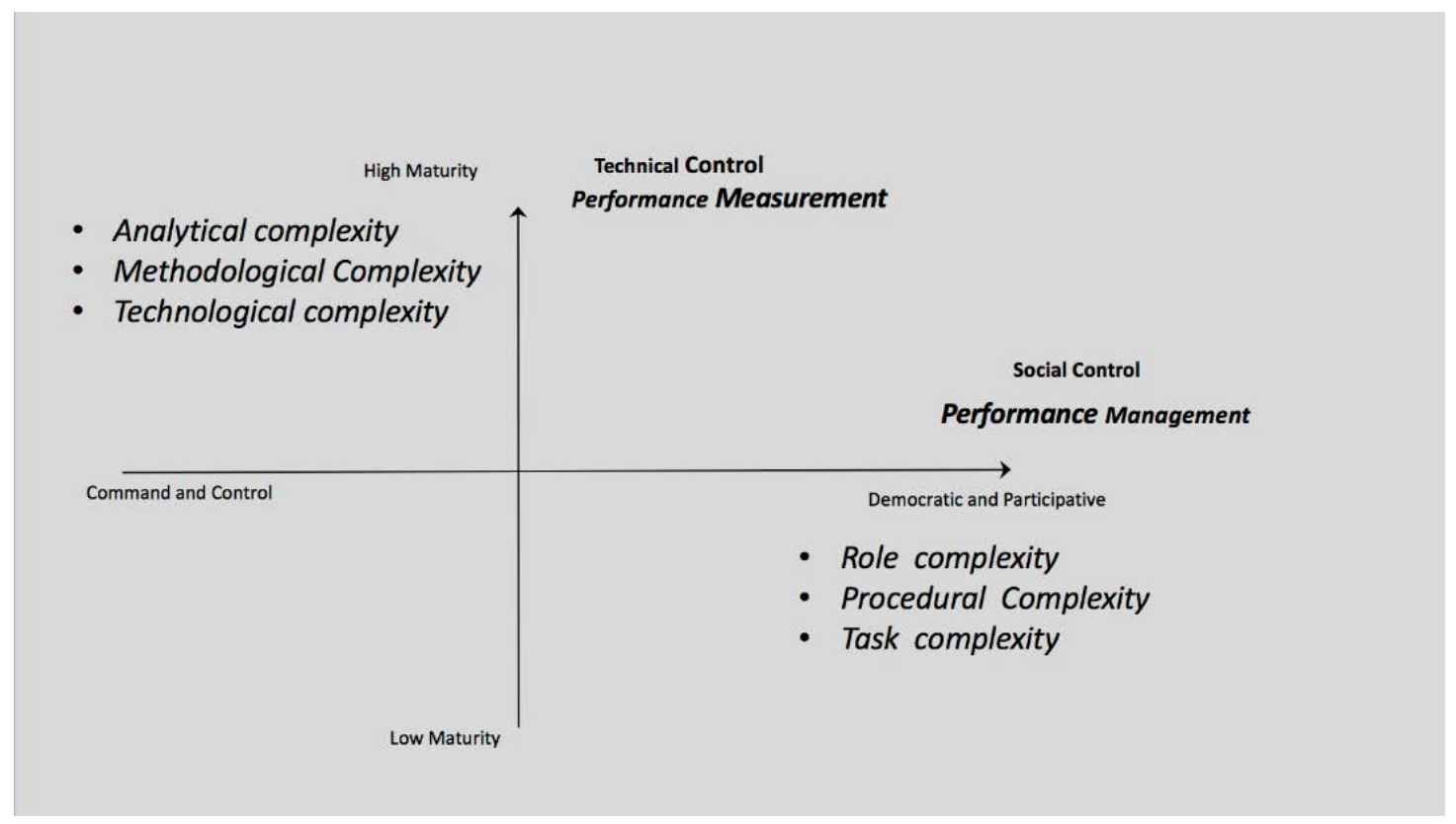

Figure 3.2.3.: Categorisation of sources of complexity under Social and technical control

of complexity.

\section{Social complexity Role complexity, Task Complexity, Procedural com- plexity}

The analysis from SLR abstracted the first theme of social controls such as leadership, hierarchical structures, empowerment, trust, motivation at work, employee behaviour, training, skills, trust and culture, which are closely associated with ontological property of complexity. Social controls are quite implicit and informal but impact process stages of PMS. Most of the studies that explored social controls identified them as a foundation for PMS at every process stage. For example, Elzinga et al. (2009) sets out to identify factors that influence use stage of PMS. They argue that behavioural factors in different roles with in an organisation are most important ones at the use stage of PMS. According to command and control theory, organisations are setup on the basis of hierarchical relationships with a clear flow of authority for its entities in order to achieve economic performance and goals (Rizzo et al. 1970). When a PMS with a democratic culture is adapted in organisations, it can lead to conflict, incompatibility and ambiguity on the exist- 
ing roles, it create role complexity. From theoretical perspective, if organisations do not control these behavioural factors such as empowerment, autonomy, trust, communication and training, it could lead to role complexity. From the analysis, role complexity can be further explained as relationship/conflict between different team's roles and individual's roles and how to allocate them appropriately.

Toor and Ogunlana (2010) highlighted the complexity of social controls in the construction industry. They showed the differing perceptions on a construction project, leading to conflicting requirements about what to measure. According to Wood (1986) organisations set knowledge, skills and resources need for an entity to demonstrate satisfactory performance. Hence, task in these organisations has to be clearly defined without which there is often a lot of ambiguity and conflict leading to task complexity. This is also echoed by Ardler (2011), where he argued that clarity on task and task efficiency are particularly essential to organisations, who are trying to be price minimisers or cost leaders. However, introduction of new measures or new ways of measuring and managing often bring ambiguity and conflict with existing knowledge, skills and resources thus leading to task complexity. Task complexity not only emerge from lack of clarity on tasks but also inter-relationships and conflicts between them, hence it is necessary to explore mature social controls associate with it. Adler (2011) studied the design of PMS for confrontation strategies and found that programs that focus on developing empowerment, multi-skilled teams of self-governing and well-coordinated individuals leading to task efficiency. Here the role of varying tasks are seen to aggregate in efficiecy.

While many authors such as Johnston (2005) \& Bititci et al. (2012) acknowledge the need for social controls at each process stage, there is little consensus regarding how to strike the proper balance between the level of control and the level of freedom or autonomy given to individuals. While organisations have a number of rules to control the way they operate, an introduction of PMS will initiate turbulence and creates a lot of ambiguity and conflict. Procedural complexity emerges when there is lack of information on priorities or the course of action when there is a change in the routine. It occurs when employees were not explained the new processes and the impact of them. With the mature social controls such as autonomy, empowerment, communication and multi-skills, organisations can self- 


\section{Theoretical Frame of Reference}

organize and adapt to this change and create new rules, regulations and policies for operating, without which it leads to procedural complexity.

Overall, this suggest that complexity exists at each of the three process stages, but varies based on how many combination of organisational controls exit to interact at each process stage. On one extreme, an overly controlled process can leave individuals unable to cope with a complex situation due to rigidity. On the other extreme, if the individuals are not given enough guidance (or too much autonomy) to make good decisions and the process may be performed differently by different individuals, which again adversly impacts performance. Hence a striking balance might be a good solution to control complexity. While studying the state-of-theart of performance measurement, Greiling (2005) suggests that "in order to keep the motivation and participation rate high with PMS, it is necessary to concentrate on a few relevant indicators and that measurement for measurement's sake is not a goal in itself". Hence motivation plays as an important social control, particularly during the use stage of PMS. Lack of motivation in employees can lead to role complexity, as they don't effectively do their jobs, which will further lead to task as well as procedural complexities. While the three complexities discussed in this section, i.e. role, task, and procedural in the first instance looks technical, the maturity of social controls such as motivation, leadership, training and skills, empowerment, self-regulation, trust and hierarchy plays a significant role in moderating complexity.

\section{Technical complexity Analytical complexity, Methodological Complexity,}

\section{Technological complexity}

The analysis from SLR abstracted the second theme of technical controls such as supporting frameworks, information systems, data collection methods, analysis and visual communication, which are closely associated with functional and teleological properties of complexity. Table 3.2.1 on page 29 shows how teleological property represents an objective of the system in an environment.

Similarly, functional properties represent the methods of achieving those objectives. This is the main reason why both teleological and functional properties are characterised by technical controls. Technical controls are formal and more explicit than social controls. They use specific methodologies to be more objective and 
rational, and are employed to reach a specific goal. For PMS, technical controls operate on measurement functions, including the introduction of new performance measures, which will impact all process stages (Bititci 2015). This means that any changes made at any process stage can affect the outcome of the goals and strategy. From the SLR and analysis, a diversity of technical controls were identified such as specific methodologies, different visual methods, data driven trends associated with functional properties of complexity.

Often when implementing PMS in organisations, there is often conflict between objectives or measures. In majority of the cases, organisations are less informed on the relationship between these measures, i.e. improving a particular measure will have a knock of effect on other measures. These situations often lead to methodological and analytical complexities. Santos et al. (2002) explored technical controls while investigating how system dynamics and multi-criteria decision analysis can enhance the effectiveness of PMS during design and implementation stages. From their findings, they recommended that the use of such approaches provides a means for tackling methodological and analytical complexity in organisations. Methodological complexity often relates to a conflict between an approach to choose measures (say quantitative vs qualitative), difficulty encountered in KPIs calculations and number of KPIs measures that exist in computation. Analytical complexity on other hand is often related to cause and effect relationships between measures, data presentation, color coding, sophisticated charts and graphs, visual screens and a balance between different perspectives such as financial vs non-financial, internal vs external. Hence, organisations should use more scientific methods such as mathematical and simulation modelling, systems dynamics, cause and effect analysis, correlations and regression, multi criteria decision-making for designing and using measures, while taking input from all stakeholders. This restricts subjectivity, ambiguity and conflict between measures. Spekle and Verbeeten (2014) identified technical controls such as contractibility, clarity of goals, undistorted performance metrics that creates performance effectiveness while studying the use of PMSs in the public sector.

On the other with the advent of technological developments the way we are operating in digital economies is changing (Nudurupati et al. 2015). While, the way customers are engaging with businesses is changing, the way organisations are 


\section{Theoretical Frame of Reference}

gathering data using advanced technologies is also evolving. The implementation of PMS in this context is no excuse and if organisations do not control this situation is often leads into technological complexity. In a previous study, Turner et al. (2005) looked at the implementation of performance measures and recommended that it can enhance business performance, if the implementation is well structured, resourced and focused on improving the capability of technical controls. In another study, technical controls such as metrics, the role of information systems and reporting using balance scorecards took more precedence (Lohman et al. 2004). Technological complexity often emerges, when there is no effective co-ordination between the selection and investment of technology such as IT systems and the business needs and no tighter integration between them.

From complexity theory we also found genetic property, which is not yet discussed. The genetic property of PMS represents how it evolves over time. From the SLR and analysis, genetic property is more associated with exploring the maturity and validity of KPIs over time, continuous improvement, change programmes and external fluctuations that are influencing organisation, etc. For example, Angelis and Jordahl (2015) studied the maturity of various performance management practices at use stage, which keeps the system evolving. As PMS matures, it provides standard management practices, however as Kennerly and Neely (2002) state, "measurements systems should be dynamic, they have to be modified as times change". In this study, the authors studied the factors that affect the evolution of PMSs over time, which include both social and technical controls, which are internal and external to the system. Unlike other properties, genetic property of complexity is associated with both technical and social controls. While the social and technical controls were already discussed in the previous section, the internal context includes elements such as continuous improvement and change programs that are implemented in organisations and interact with PMS. For example, the continuous process framework for PMS was studied along the design stage (Hudson et al. 2001). Similarly, Garengo et al. (2005) presented a model of how PMS evolve over time. This study also explored all three process stages and found that "the models developed in the last 20 years are more horizontal, process-oriented and focus on stakeholder needs". This means that the genetic property, that is, the ability to change over time, exits as part of a PMS and is 
vital to its success. Similarly, the business trends (Melnyk et al. 2014; Bititci et al. 2012) in the external context also influence organisational strategy leading to change in the PMS. The genetic property of PMS was seen to be important in understanding the evolutionary process as highlighted in a study by Jain et al. (2011). The study explored on how scores for future targets are checked against past process modifications to identify performance changes.

Performance Measurement Complexity The overall outcome of this study is that there is an emergent complexity along the three process stages of PMS, which we term it as Performance Measurement Complexity (PMC) that users must contend with. PMC emerges with the interaction of existing social and technical controls with different process stages of PMS. PMC consist of a number of interconnected and interdependent elements that evolve over time. We have discussed two different ways in which complexity emerges at different PMS process stages. Firstly, due to the lack of maturity in technical and social controls at the three process stages of PMS. Secondly, due to the interaction between the technical and social controls at each process stage. In this paper, the findings attempt to explore a specific aspect of performance measurement, which is its complexity.

Within these two ways, there are two key factors that contribute to this complexity. The first is the sheer number of elements (i.e. the number of technical and social controls) that interact at each process stage. The interrelations and embeddedness of process stages and the controls was complex as many elements exist in the system and hence it might affect the process of quantifying and effectiveness of PMS. The second is the unpredictability and lack of proper synchronization of controls by users at each process stage, and the ambiguity on what control factors to consider at each process stage, which causes difficulty in making contextual decisions.

As discussed earlier, a PMS can be considered a complex adaptive social system by virtue of the fact that it consists of a large number of elements whose interactions create new behaviours that cannot be predicted by a complete analysis of the individual elements. We argue that those conditions exist at each of the PMS process stages of design, implementation, and use. As shown in Table 3.2.2 on page 44, these conditions arise from the presence of organisational controls: 


\section{Theoretical Frame of Reference}

technical controls and social controls that are implemented in association with the PMS, and their interaction with the elements and entities within the individual stages, and in many cases with each other. However, Bititci (2015) suggests that increased control and the loss of individual autonomy can have a negative impact on the process of measurement, particularly when PMS is viewed as a complex adaptive system. In a similar manner, it is clear that the exploratory use of PMS also enhances a combination of technical and social controls such as interactive use, communication of goals and learning.

The lack of balance between social and technical controls can be seen from the two common themes of complexity presented in the findings. For example, while studying the advantages and disadvantages for using PMM tools and techniques, de Waal and Kourtit (2013) identified two main reasons for their use, which are focused on controls and strategy. The same study recommended that "management needs to take the explicit advantages of PMM while designing PMS and keep stressing these advantages during and after implementation". De Waal and Kourtit (2013) believe that such practice will increase the level of commitment to the PMS by the organization's members, which emulates more of the role of social controls. However, in another study, Sharma and Bhagwat (2006) also explored PMS implementation at both small and large firms. They presented a framework that shows the role of technical controls in the form of information systems as a foundation for growth and drive strategy. However, the study focused on the technical control factors and neglected to address the influence of the social factors.

The SLR and the analysis suggest that although social and technical controls are crucial at each process stage, there is a lack of standardization and balanced presence in their design and implementation. Ukko et al. (2007) found that it was the role of leadership skills and manager's commitment as social controls that were crucial to aligning manager's and employee's perspectives on the strategy and improving performance. Another study by van Veen-Dirks (2010), focused on controls at the use stage by looking at both non-financial and financial measures without emphasis on any social controls. However, they suggested that it is essential to distinguish between different uses of controls when applying performance measurement choices. Clearly the selection of a particular organisational control (be it technical or social) is determined by the purpose of measurement that is 
made and is contextual as there is no one size that fits all organisations. It is followed that, the use of controls at a process stage, may also be determined by the reasons why a firm invested in PMS. As the sheer number of social and technical controls increases, the interactions between them multiply, leading to a variety of impact outcomes on PMS in organisations depending on the combination of controls. Hence, the moderation of complexity that stems from a PMS is not a linear task and needs to be controlled over time with a number of feedback loops.

In other studies, we found that, lack of standardization also breeds complexity, For example while studying the process of implementation, social factors were narrowed to an individual knowledge, a customer and an organization as a whole (Jääskeläinen and Sillanpää 2013). The challenge here is that at implementation stage managers tend to use holistic approaches rather than individual, customer or organisation knowledge capacity. In other studies where implementation stage was explored, technical controls such as IT systems and management tools, were important to give managers a locus of decision making and continuous improvement (Jääskeläinen and Sillanpää 2013; Nudurupati and Bititci 2005). However, neither study demonstrated which control factors are important at this stage and which one a less important. The lack of predictability on the usefulness of control factors that suits implementation stage causes complexity. It is not a call for the list of social and control factors that are necessary during implementation stage, it is about educating the employees in picking the right organisational controls based on the context. To mirror this in the context of this study, 
Table 3.2.2.: Combinations of control factors at each process stage

\begin{tabular}{|c|c|c|c|c|c|}
\hline No & $\begin{array}{c}\text { Combinations of } \\
\text { organisational } \\
\text { controls }\end{array}$ & Design & Implementation & Use & $\begin{array}{c}\text { Complexity } \\
\text { Type }\end{array}$ \\
\hline 1 & $\begin{array}{l}\text { Technical Control; } \\
\text { Social Control and } \\
\text { Dynamic Change }\end{array}$ & $\begin{array}{l}\text { Bourne et al. (2002); de Waal } \\
\text { and Kourtit (2013); Ferreira } \\
\text { and Otley (2009); Folan and } \\
\text { Browne (2005); Haponava and } \\
\text { Al-Jibouri (2009); Laihonen et } \\
\text { al. (2014); Lohman et al. } \\
\text { (2004); Neely et al. (2000); } \\
\text { Taticchi et al. (2012); Valmo- } \\
\text { hammadi and Servati (2011) }\end{array}$ & $\begin{array}{l}\text { Bourne et al. (2002); } \\
\text { de Waal and Kourtit } \\
(2013) ; \quad \text { Ferreira } \\
\text { and Otley (2009); } \\
\text { Laihonen et al. } \\
(2014) ; \text { Lohman et } \\
\text { al. (2004); Neely et } \\
\text { al. (2000); Valmo- } \\
\text { hammadi and Servati } \\
\text { (2011) }\end{array}$ & $\begin{array}{l}16 \\
\text { Bititci et al. (2005); Bourne et al. } \\
\text { (2002); Carlsson-Wall et al. (2015); } \\
\text { de Waal and Kourtit (2013); Díaz et } \\
\text { al. (2005); Ferreira and Otley (2009); } \\
\text { Folan and Browne (2005); Haponava } \\
\text { and Al-Jibouri (2008); Laihonen et al. } \\
\text { (2014); Lohman et al. (2004); McAdam } \\
\text { and Bailie (2002); Mol and Beeres } \\
\text { (2005); Sharma and Bhagwat (2006); } \\
\text { Spekle and Verbeeten (2014); Taticchi } \\
\text { et al. (2012); Valmohammadi and Ser- } \\
\text { vati (2011) }\end{array}$ & $\begin{array}{l}\text { Technical } \\
\text { Ccomplexity } \\
\text { and Social } \\
\text { Complexity }\end{array}$ \\
\hline
\end{tabular}


Table 3.2.2.: (continued)

\begin{tabular}{|c|c|c|c|c|c|}
\hline No & $\begin{array}{l}\text { Combinations of } \\
\text { organisational } \\
\text { controls }\end{array}$ & Design & Implementation & Use & $\begin{array}{c}\text { Complexity } \\
\text { Type }\end{array}$ \\
\hline \multirow[t]{2}{*}{2} & Technical Control & 4 & 3 & 15 & Technical \\
\hline & and Social Control & $\begin{array}{l}\text { Carpinetti et al. (2008); Nu- } \\
\text { durupati and Bititci (2005); } \\
\text { Santos et al. (2002); van Veen- } \\
\text { Dirks (2010) }\end{array}$ & $\begin{array}{l}\text { Chalmeta et al. } \\
(2012) ; \text { Nudurupati } \\
\text { and Bititci (2005); } \\
\text { Wouters and Sportel } \\
(2005)\end{array}$ & $\begin{array}{l}\text { Ben Hadj Salem-Mhamdia (2013); } \\
\text { Caniato et al. (2014); Carpinetti et } \\
\text { al. (2008); Elzinga et al. (2009); } \\
\text { Garengo and Sharma (2014); Hansen } \\
\text { (2010); Johnston (2005); Nudurupati } \\
\text { and Bititci (2005); Pedersen and Sudz- } \\
\text { ina (2012); Santos et al. (2002); Tung } \\
\text { et al. (2011); Ukko et al. (2007); van } \\
\text { Veen-Dirks (2010); Wouters and Spor- } \\
\text { tel (2005); Yilmaz and Bititci (2006) }\end{array}$ & Complexity \\
\hline \multirow[t]{2}{*}{3} & Technical Control & 5 & 4 & 5 & \\
\hline & $\begin{array}{l}\text { and Dynamic } \\
\text { Change }\end{array}$ & $\begin{array}{l}\text { Braz et al. (2011); Broadbent } \\
\text { and Laughlin (2009); Elg et al. } \\
\text { (2013); Melnyk et al. (2014); } \\
\text { Ngai and Cheng (2001) }\end{array}$ & $\begin{array}{lr}\text { Braz et al. } & (2011) ; \\
\text { Broadbent } & \text { and } \\
\text { Laughlin } & (2009) ; \\
\text { Melnyk et al. } & (2014) ; \\
\text { Ngai and } & \text { Cheng } \\
(2001)\end{array}$ & $\begin{array}{l}\text { Braz et al. (2011); Broadbent and } \\
\text { Laughlin (2009); Elg et al. (2013); } \\
\text { Melnyk et al. (2014); Ngai and Cheng } \\
\text { (2001) }\end{array}$ & \\
\hline \multirow[t]{2}{*}{4} & Dynamic Change & - & - & 1 & \\
\hline & and Social Control & - & - & Garengo et al. (2005) & \\
\hline
\end{tabular}


Table 3.2.2.: (continued)

\begin{tabular}{|c|c|c|c|c|c|}
\hline No & $\begin{array}{l}\text { Combinations of } \\
\text { organisational } \\
\text { controls }\end{array}$ & Design & Implementation & Use & $\begin{array}{c}\text { Complexity } \\
\text { Type }\end{array}$ \\
\hline \multirow[t]{2}{*}{5} & Technical Control & 4 & 3 & 15 & Social \\
\hline & & $\begin{array}{l}\text { Adler (2011); Jääskeläinen and } \\
\text { Sillanpää (2013); } \\
\text { Micheli and Kennerley (2005); } \\
\text { Vernadat et al. (2013) }\end{array}$ & $\begin{array}{lr}\text { Greiling } & (2005) ; \\
\text { Jääskelä̈nen } & \text { and } \\
\text { Sillanpää } & \text { (2013); } \\
\text { Taylor and } & \text { Taylor } \\
(2014) & \end{array}$ & $\begin{array}{l}\text { Adler (2011); Angelis and Jordahl } \\
\text { (2015); Bititci et al. (2015); Canonico } \\
\text { et al. (2015); Franco-Santos et al. } \\
\text { (2007); Greiling (2005); Jääskeläinen } \\
\text { and Laihonen (2013b); Jain et al. } \\
\text { (2011); Micheli and Kennerley (2005); } \\
\text { Pavlov and Bourne (2011); Pongatichat } \\
\text { and Johnston (2008); Sillanpää (2011); } \\
\text { Toor and Ogunlana (2010); Vernadat et } \\
\text { al. (2013); Wijngaard et al. (2006) }\end{array}$ & Complexity \\
\hline \multirow[t]{2}{*}{6} & Social Control & - & 1 & - & \\
\hline & & - & Turner et al. (2005) & - & \\
\hline \multirow[t]{2}{*}{7} & Dynamic Change & - & - & 1 & \\
\hline & & - & - & Hudson et al. (2001) & \\
\hline
\end{tabular}




\subsubsection{Conclusion}

This study started with a purpose to explore how social and technical controls amplify complexity at three core process stages of PMS. A major finding that triggered this study is that performance literature attributed majority of complexity issues to the external environment with little emphasis on internal environment and the users response with it that leads complexity. This study has demonstrated that internal organisational controls, in the form of organisation's response to the wider environment, are also sources of complexity.

The study demonstrated that PMS possesses all system properties (ontological, teleological, genetic and functional) that are described by complexity theory. Specifically, they consist of a large number of interconnected and interdependent elements, which evolve over time, and adapt to changes in both the internal and external environment, making them a complex social adaptive system. These elements that interact with the system are abstracted into two organisational controls, namely, technical and social controls. Changes in the internal environment such as plurality in practices can negatively impact the PMS process and the number of controls that interact at each process stage and the nature of these interactions. This makes it difficult to predict what will be important to measure in the future and how to measure it methodologically. As a result, there is greater unpredictability, ambiguity in the system, and often lack of relevant information for decision making. The results seem to emulate the issues of fit as shown by Melnyk et al. (2014) in which the organization's measures are not synchronized with its strategy and its environment leading to a complex situation. Hence, organizations require more tools and techniques to get through the complex situations.

This study introduced the concept of PMC to describe the problematic nature of the two dimensions along the three process stages. The PMC seems to emerge through lack of mature social controls leading to role, procedural, task as well as through lack of mature technical controls leading to analytical, methodological, technological complexities. A major implication in understanding PMC is that, it recast how users view practices as they respond to the plurality of best practices and by examining how organisations interactively use control factors in design, implementation and use stages. The findings contribute to the current discussion 


\section{Theoretical Frame of Reference}

on why PMSs are lagging behind and not being responsive and resilient to emerging contexts. While it is useful to understand and explore all organisational controls in moderating PMC, it should be noted that the organisational controls will have varying impacts on organisations when they are made up of similar components and operating in the same industry. The organisations should build capabilities to choose the appropriate organisational controls depending on the context and adapt to the changes associated with PMS.

The results open several directions for future research on PMS complexity and $P M M$ in general. Firstly, a major implication is that the definition of PMC, as outlined in this paper, challenges PMM literature by attempting to define foundations of "complexity in performance measurement" which calls also for a definition of complexity as "complexity of performance management". Therefore, future research could attempt to explore research on PMC in these two streams. Secondly, this study only looked at the mix of social and technical controls and how such a mix should be treated. As a continuation, a new study could explore which specific factors and the interaction between them that directly induce complexity. We recommend using the framework by Sahin et al. (2013). Also, more research may unlock critical events from the external environment that are contingent to the practice of measurement and tends to induce complexity in internal environment. For this, we propose the following research questions for future research:

1. What is the difference between complexity in performance measurement and complexity in performance management?

2. More empirical studies need to be done to understand how the mixture of social and technical controls be managed at each process stage?

3. Which process stage is more dependent on social controls and less dependent on technical controls and vice versa?

While interactions between social and technical are difficult to manage, their divisions and interactions are quite crucial to facilitate how organizations may achieve to be responsive and dynamic. Having studied PMC, the study results suggest that complexity theory is an essential element for studying complexity in PMM. It also 


\subsection{Performance Management Systems and System of System}

shows that by understanding how complexity emerges, managers will start to rethink how to organise the use of controls more critical at each process stage. This study has demonstrated how complexity emerges and how it becomes amplified at different process stages. This study made an attempt to understand how organisational controls can be used to moderate complexity and how it evolves in an organizational setting, in a conceptual way through SLR. However, we urge more empirical studies to understand how organisational controls and their interaction can actually moderate complexity over time.

\subsection{Performance Management Systems and System of SYSTEM}

There is limited evidence on how a shared PMS should be administered in relation to the characteristics of SoS as described above. Therefore, it is important to understand several aspects of inter-organizational PMS. According to Bititci (2015), PMS is defined as a "process of setting goals, developing a set of measures, collecting, analyzing, reviewing and acting on performance data." The practical implication of the theoretical definition of PMS as a process becomes vague under SoS with collaborative measures. Intrinsically, PMS of SoS is one that requires feedback ${ }^{1}$ and feedforward control systems to maintain interoperability in such a system. For feedback and feedforward to occur, there must be a performance management process to allow the context in which Performance Measurement will be conducted. This means that management precedes measurement, as such, PMM is an inseparable process as the two processes cannot be separated if objective/effective measurement is to be established.

Other unique characteristics for effective PMS would be that measures should form an integrated entity to support each other, and that measures should provide a platform for continuous improvement (Folan and Browne, 2005; Halachmi, 2005; Neely, 1999; Otley, 1999). However, contrary to the former, for collaborative measures, such realities make SoS imbalanced as collaborative measures lack a

\footnotetext{
${ }^{1}$ In PMM, measures provide timely and accurate feedback (Neely et al., 1996). The concept of feedback is defined by Schwaninger (2015) as a process in a system by which an outcome variable is redirected - normally via a control system as an input, such that the object system's behavior changes.
} 


\section{Theoretical Frame of Reference}

collaborative decision making for design, management and use. In discussing a conceptual model for PMM of a cluster using Balanced Scorecard, Cesar Ribeiro Carpinetti et al. (2008) explains that the need for collective efficiency and types of relationships are among the determinants of quality of measures. Therefore, extending PMS to SoS as a collaborative PMS means extending PMM dimensions which are discussed in the following section.

\subsection{Performance management Dimensions For COLLABORATIVE MEASURES}

A set of three conceptions for exploring collaborative measures as an inter-organizational were selected to position the investigation of this research, namely, organizational complexity, the process of continuous improvement and PM as a social system. This thesis explores these PM dimensions to be examined for inter-organizational PM. The rationale behind these dimensions is derived from the state-of-the-art in PMM literature as they were repeatedly discussed by many authors (Bititci, 2015; Busi and Bititci, 2006; Castro and Almeida, 2017; Harkness and Bourne, 2015; Pinheiro De Lima et al., 2013). The following section discusses these dimensions in detail.

\section{Dimension One-Organizational Complexity}

The first dimension being explored for inter-organizational PM is organizational complexity. PMM literature mostly views complexity as a result of the interaction with the wider environment, such as markets, customers, and changes in technology. PMM considers this environment complex as it dynamic and open. Since users respond to the wider pressures from the external environment, this creates an implication on the practice of measurement along the three process stages of PMS. This argument is partly in agreement with Harkness and Bourne (2015), who suggest that complexity is a barrier to the practice of performance, due to both the environment and a number of practical factors such as ambiguity, lack of control, unpredictability, and a lack of enough information that interacts in the system. After examining the literature, complexity is then explored as the inter- 
play between what is measured (Micheli and Mari, 2014) and how it is controlled in SoS (Mol and Beeres, 2005; Canonico et al., 2015). This involves updating, analyzing, and acting on performance data (Bititci, 2015; Bourne et al., 2000; McAdam and Bailie, 2002).

Another reason for this argument is that complexity lies at the heart of organizations as they are continuously changing (Boulding, 1956; Roehrich and Lewis, 2014; Stacey, 2011). It then follows that the ongoing processes and functions in the internal environment suggest questions for inter-organizational PM. Organizational complexity is investigated by exploring the evolution map developed by Folan and Browne (2005). Specifically, the thesis explores the evolution of interorganizational complexity as a major implication for PM.

\section{Dimension Two-Continuous improvement}

The second dimension being investigated is the process of continuous improvement. According to PMM literature (Neely et al., 1997; Perkins et al., 2014), metrics and indicators give life to organizations. As better management practice, measures provide future trends, help to implement strategies and provide the power of communicating with measures for instance, creating continuous improvement's capability to set new measures and so forth. Continuous improvement is vital practice for businesses as they need to change dynamically (Brown and Eisenhardt, 1997). Continuous improvement considers using measures as a feedback mechanism to effectively improve processes, and whether measures are being used in the balanced manner (Bond, 1990; Olsen et al., 2007; Wu and Chen, 2006).

Continuous improvement also deals with organizational performance management that controls best practices to lead PMS to maturity. For example, while designing a model for profiling organizational PM, Jääskeläinen and Roitto (2015) show existing gaps in maturity model assessments. In other words, even during mature stages, many models concentrate on the design of PMS using performance measurement as a driver for continuous improvement. For this, even maturity models require measures for continuous improvement, which is a versatile practice and special action is needed to offer grounds for improvements (Elg et al., 2014).

Questions about this dimension include how the lifecycle of a PMS that tran- 


\section{Theoretical Frame of Reference}

scends an organization exists with continuous improvement programs, i.e from birth to maturity, and more specifically, how it will become a mature performance system using an inter-organizational approach. In this thesis, continuous improvement is therefore investigated and discussed by exploring a theoretical model developed by Pinheiro De Lima et al. (2013) which is influenced by the work of (Folan and Browne, 2005). The model is applicable to managing operational strategy, of which continuous improvement is one of the core elements. Specifically, this thesis explores whether and how double and single loops can be applied with this model in the light of collaborative measures. Papers 4 and 5 examined this dimension.

\section{Dimension Three-Social System}

The third and last dimension explores social system. PMS are social-technical systems. Conventionally, previous research shows that organizations are social systems (Johannessen, 1998). In PMM literature, managing performance, the universal structure underpins people, processes and performance. For this reason, there is a need to understand the social component, which is currently being investigated as social system. Within the context of this thesis, there are two reasons for investigating social system. One is that, for inter-organizational PM, measurement occurs within several social organizations with the managerial support of both technical and social controls (Bititci, 2015). Technical controls deal with effectiveness and are considered to be the most objective. Social controls deal with people. Most managerial challenges for collaborative measures seem to germinate from managing social controls, especially when different departments and organizations have different social logics on what to measure and how. Secondly, previous research also confirms that PM as a social system is one of the centric points for a holistic research framework for performance measurement (Bititci, 2012). In addition to this, McDonald (2015, p. 197) demonstrates that "People operate as part of a social system, managing the dependencies within the process system." Thus, the social system is as much a part of overall system functionality as any other part. In sum, social system creates important implications for inter-organizational PM. This dimension is explored in two ways. Paper 1 explores dimensions us- 
ing the operational framework for system analysis proposed by McDonald (2014), while Paper 3 explores dimensions using a theoretical framework that typifies both social and technical controls.

\subsection{The role of Cybernetic Control Theory}

Cybernetics is a discipline that has been studied to explore governing systems, and their constraints, structures, and capabilities. Since its establishment in the 1940s, cybernetics has been explored in many fields, such as biological systems, technical systems and social systems (Schwaninger, 2015). Wiener (1948) defines cybernetics as the science of 'control and communication' in animal and machine. In management, a foundational work in applying cybernetics to organizations by Beer (2002) introduced the viable system model, a model that enhanced the effectiveness of collaboration. In his work, Beer discusses the intrinsic control in real-time by bringing cybernetics to industrial management, defining management as the "science of effective organization." Ultimately, management cybernetics applies the theory of cybernetics control to organizational structures and management in any institution. Cybernetics form the basis for the cycle of a cybernetic control and management, to observe, capture and monitor governing and control systems for performance. The cycle is composed of four elements that ensure feedback and control, i.e. sensor, commander, actuator and process. These elements influence each other through a chain and cause effect.

As a domain theory, CCT is then adapted to influence inter-organizational management to have a central decision authority. Christopher (2011) argues that a principle of cybernetic science is that systems have the capability for self-control in a system. In doing so, he explains that the controller is just as effective as the decision-maker. To elaborate more on this, cybernetic functions are discussed according to Leveson and Heimdahl (1994) as follows. The sensor element, which is concerned with error detection in the system behavior, gives feedback to control system. According to the circular property of cybernetics, this allows for an explanation of a system from within. The actuator manipulates the process there by executing commands. The process is the interpreter to the sensor, which provides immediate and constant feedback and the desired output, which is repeated in a 


\section{Theoretical Frame of Reference}

continuous manner with inputs and outputs. The controller performs the corrective action where feedback is provided via controlled variables.

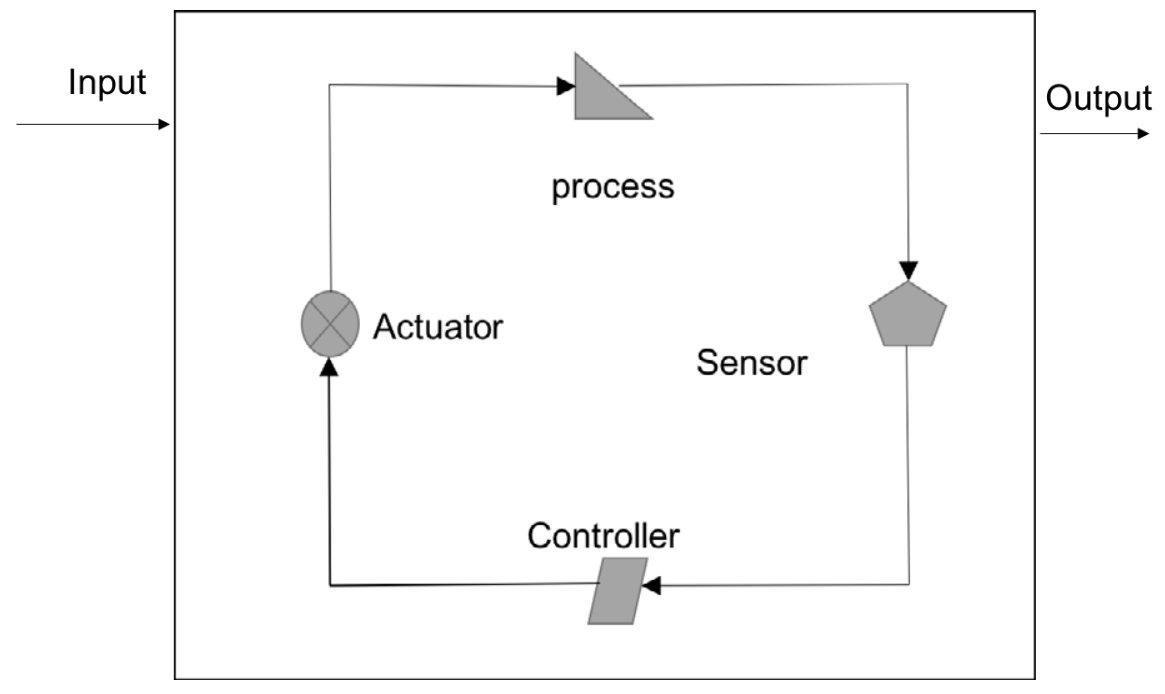

Figure 3.5.1.: Basic cybernetic control cycle (Leveson \& Heimdahl, 1994)

Figure 3.5.1 shows the basic cybernetic cycle between inputs and outputs. Malmi and Brown (2008) proposes the idea that cybernetics is all about processes and change that involves uncertainty. Such processes evolve into adaptation and then growth. This clearly depicts a system under change. The system tends to manifest what is explained in cybernetics. For instance, the feedback loops account for the regulation and the efforts of the system to maintain a state of equilibrium to reach a target. Based on this understanding, this thesis argues that feedback is a function of specific cybernetics roles which assist managers with explicit information for inter-organizational PM. This thinking is also supported by previous research in PMM. For example, while developing a cross-organizational methodology, it was found that PM should be specific to business units (Kaplan and Norton, 2000; Neely et al., 1996; Bititci et al., 1997).

In other areas of PMM literature, cybernetic structures have been adapted such as Bititci and Carrie (1998) who adopted the viable systems model and identified cybernetic thinking for a business approach between parties (Bititci and Turner, 1999). In other areas of operations, previous research has applied cybernetic controls to link shop floor process to strategic outcomes (Chenhall and LangfieldSmith, 2007), which allows managers and shop floor workers to engage in critical 
decision-making along the value chain (Bititci et al., 2005). While exploring the use of PMS in the public sector, Spekle and Verbeeten (2014) critically discuss the role of cybernetic incentives in contracting and their role in aligning goals with objectives. Cybernetic controls have also been mentioned in connection with hybrid PMS, where measures enable the quantification of phenomena, generate standards and enable a feedback mechanism which allows modifications in a system (Malmi and Brown, 2008).

\section{The chain and cause effect in System of System}

In cybernetics, feedback occurs when the outputs of a system are re-routed back into the system as inputs. This is called the chain and cause effect. The challenge of feedback is either negative or positive depending on the type of error that cybernetics is tasked to patrol and control (Steer, 1952). Feedback in cybernetics is always assumed to be negative, hence correction is desired (Folan, 2002). Controlling performance using cybernetics always falls back to a central factor which is error correction. As articulated by Lehtinen (2010), cybernetics is all about what one system does to another in order to control. This means that the first system in the series influences the second system to form a chain and cause effect (Dormer and Gill, 2010; McAdam and Bailie, 2002).

In a similar manner, for inter-organizational PM, collaborative measures are treated as inputs and collaborative decisions as outputs. Most importantly, if a feedback loop is to be governed in a balanced manner, including all actors, feedback mechanisms in cybernetics must be patrolled by all actors' efforts as one system to determine the measurement and performance of collaborative measures, meaning that the chain and cause effect should be emulated and reproduced in such systems. If this is accepted to be the case, this thesis proposes that a circular feedback loop is applied in a similar manner in line with organizational cybernetics, and inter-organizational PM could be corrected and maintain a central decisionmaking authority to allow inter-organizational to PM be configured. Customarily, such an analysis of the system should be done regularly since reasoning is based on cause and effect.

Measuring performance and managing the system must come from a mutual 


\section{Theoretical Frame of Reference}

understanding of the root functions of the system and the relationships between each actor as a loop in the system and the next system that is affected (Lehtinen, 2010). The notion of controlling performance informed by cybernetic control theory comes into the limelight with collaborating actors who have specific roles and are aligned within the network.

Overall, the ideology of cybernetic theory on performance control, measurements, and management applies to almost every walk of life, from the body system which is homeostatically organized into feedback loops that restore balance in body systems to mechanical and medical inputs, such as cranes, cars and life support machines. Consequently, this makes cybernetic theory a better theory with which to explain the inter-organizational feedback challenge. In conclusion, inter-organizational PMM in cybernetics is a function of error correction. Hence, monitoring and measuring is a function of the single systems that are interconnected into a series of stringed systems to create a feedback loop mechanism that works on error detection and correction. As an implication, such a system corrects the challenge of feedback and a central decision-making authority could be ratified.

\subsection{Inter-organizational Performance Management in System OF System}

For inter-organizational performance, Figure 3.6.1 on page 58 shows the misalignment between inputs and outputs caused by the SoS challenges within a system of system. As such the three PM dimensions are tested in the conducted four studies. Cybernetic Control Theory is introduced as a method theory to govern and correct such misalignment. Below the framework is explained in detail.

For inter-organizational PM, researchers such as Yadav and Sagar (2013) and Folan and Browne (2005) have addressed the challenge of inter-organization PM through frameworks such as extended enterprises (Bititci et al., 2005b; Lehtinen and Ahola, 2010), integrated PMS, and collaborative supply chains (Busi and Bititci, 2006). However, these frameworks fail to capture all stakeholder demands which makes them limited, and some researchers question whether PMM is fit for managing collaborative measures (Lehtinen and Ahola, 2010). To this end, PM continues to be noted both in academia and in industry for being insufficiently 
dynamic and unresponsive (Melnyk et al., 2014). After examining the literature on system theory and PMM, this thesis is anchored on several studies. Firstly, Harkness and Bourne (2015) who suggest that there is a need to explore complexity so as to understand principal limitations in the use of PM in different operational contexts. Secondly, Nudurupati et al. (2015) who report on the use of measures to unlock collaboration in innovation, and Busi and Bititci (2006) who identify gaps in collaborative performance management. Thirdly, Bititci (2015) who distinguishes between managing technical controls and social controls in PMM. Lastly, Pinheiro De Lima et al (2013) and Folan and Browne (2005) who examine the theoretical framework for operations management of a system between inputs and outputs.

To construct a framework for inter-organizational Performance Management, collaborative performance in SoS is described in terms of interoperability and functionality of the system. Interoperability is the extent to which a system within a system can exchange data, interpret shared data and use it as information to support operations/management. Also, functionality of a system is typically expressed in terms of the interactions of the system with its operating environment. With regard to six challenges shown in figure 3, interoperability is to what extent the system of systems manages these challenges. In addition, after examining the domain literature, among numerous PM practices, three PM dimensions were selected to be investigated for their functionality in inter-organizational PM. Finally, by inquiring the principles of CCT theory as a method theory (Lukka and Vinnari, 2014), it follows that with the four cybernetic roles found in the framework, it enables identification of role distribution among actors in the network for output loop to be completed. 
3. Theoretical Frame of Reference

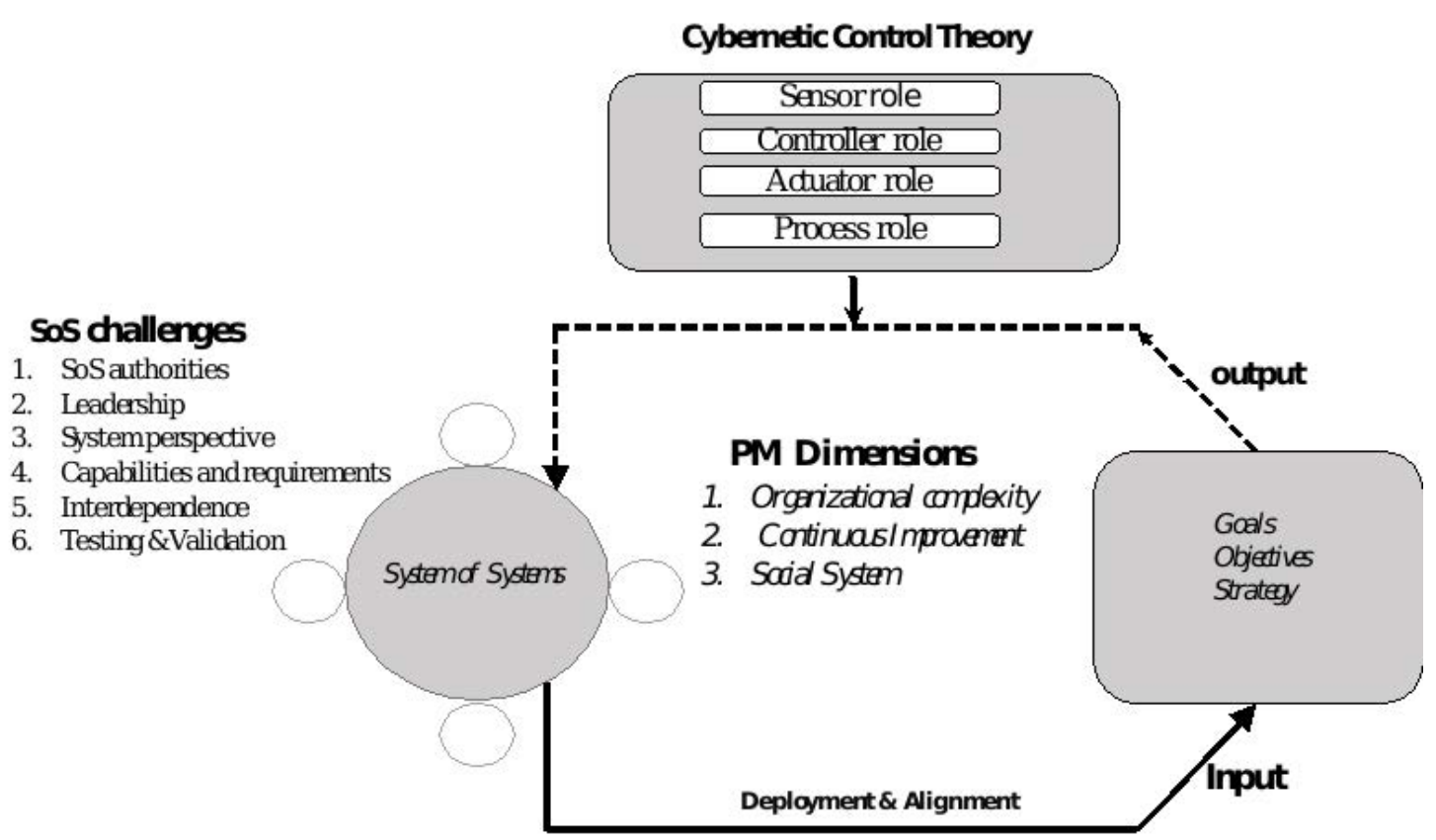

Figure 3.6.1.: Conceptual operationalization of PMM for collaborative measures 


\section{4 Methods}

This chapter presents and discusses the research methods used in the investigation of collaborative measures in the airport turnaround operations management. The chapter explains the rationale behind the research methods adopted in the research. The chapter then ends by presenting the four studies and literature review how methods are applied. Finally, the quality of results is presented.

\subsection{Selection of Methods}

The methods applied in this thesis are those that have been applied in different studies. These methods are, longitudinal action based research, Case study, Systematic Literature Review, Classification and Regression Tree method (CART) and Neural Network Method. These methods are introduced below in connection how they have been applied within the context of this thesis. These methods were selected according to the purpose and aim for each of the studies. The next sections explain reasons for why they were selected, use and application. 


\section{Methods}

\subsubsection{Case study}

For study one, the thesis adapted a case study methodology to uncover the organisational complexity and dependencies between airport actors. 24 interviews (approx..30-90 minutes) were conducted from seven different airport organisation. The case study choice relies on the need to explore factors that induce complexity, as such a case study was conducted. In order to capture unique behaviours between different actors in collaborators. The Critical Incident Technique (CIT) was used where subjects were asked to recall any event that was salient in any way to uncover latent dependencies.

Case study research is a unit of analysis research. In operations management case study methodology is applied with several methods for different purposes such as exploration, theory building, theory testing or theory extension (Voss et al., 2002; Wacker, 2008). According to Voss (2002), views case research in operations for theory building and testing and shows that case studies as a methodology, examines the historical or current phenomenon with several sources of evidence. These may include, interviews, which can also be of different types, direct observations. Using archives but within a particular context or unit of analysis.

\section{Research setting and research approach}

Twenty-three interviews were conducted with turn-around managers and turnaround coordinators at a major Swedish airport. Each interview focused on how work is coordinated between different service organizations and how contracts are designed beyond organizational borders. A multiple case study (Yin, 2003) of turn-round was used to cross-examine how each actor perceived each other. For this study, the interviews were held in two phases over a period of eight months. Phase one consisted of 15 one-on-one interviews, which were used to gain a better understanding of nature of the multi-actor collaborations that occur in the turnround process. Phase two consisted of nine interviews that built on the information gained in Phase one. Participants were recruited by email, using partner contacts and suggestions from previous participants. They were not compensated for their participation. Each participant was interviewed once for an average of 50-60 minutes. 


\subsection{Selection of Methods}

The research setting was at a major Swedish airport as a marketplace for airport service organizations that we call actors in this study. At the airport, service organizations act as clients as well as service providers, in many-to-many context. The service organizations included the four major actor types known to the air transport industry, namely: Airport Operators, Airline Operators, Air Navigation Service Providers (ANSP) and Ground Handling firms. Table B.1.1 on page 170 in Appendix A gives a profile of each firm.

\section{Data collection}

Data was collected from seven different firms participating in the turn-round process with a total of 23 semi-structured interviews. The firms were grouped into four types: Airport Operators, Airline Operators, Air Navigation Service Providers (ANSP) and Ground Handling. See Table 4.1.1.

Table 4.1.1.: Interview participants and positions with airport actors.

\begin{tabular}{lcl}
\hline $\begin{array}{l}\text { Airport Actors } \\
\text { Companies interviewed (7) }\end{array}$ & $\begin{array}{c}\text { Interview } \\
\text { Participants } \\
n=23\end{array}$ & Participant Positions \\
\hline $\begin{array}{l}\text { Airport Operators } \\
\text { Swedavia } \\
\begin{array}{l}\text { Airline Operators } \\
\text { SAS, Norwegian }\end{array}\end{array}$ & 6 & Middle Managers \\
$\begin{array}{l}\text { Air Navigation Service } \\
\text { Providers (ANSP) }\end{array}$ & 5 & Pilots \\
$\begin{array}{l}\text { LFV } \\
\text { Ground Handlers } \\
\text { SAS Ground, Menzie Avi- } \\
\text { ation, AFCO AB Fueling }\end{array}$ & 7 & Air Traffic Officers \\
\hline
\end{tabular}

The goal of the interviews was to capture the participants' perspective of their organization's role in using and sharing information during the turn-round process and how those roles may have changed over time within the service network. The interviews consisted of 12 questions (see Table $\mathrm{x}$ ) which focused on four main areas. First, it covered the responsibilities stemming from contracts, and specifically if 


\section{Methods}

any (formal?) roles violate perceived expectations from actors due to the nature of the working environment. Formal roles in this study refer to behaviors expected by actors, which stem directly from contracts and formalized agreements.

Participants were also asked about any informal roles they may perform. These are roles that are not explicitly written in any formal contracts. They are borne from psychological contracts with implicit expectations (Cullinane and Dundon, 2006). In some cases, such roles can cause service breakdowns, which would not occur if actors were strictly limited to their contract, in other cases they may improve work and make collaboration more fruitful.

Participants were asked about the extent to which they depended on the operations of others. Ongoing interactions between partners may also result in redefinition and re-negotiation of previous contracts to change role expectations (Herriot and Pemberton, 1996).

Finally, subjects were asked questions regarding their roles and how they depend on other parties. This was mainly to get an understanding if there was a connection between contracts renewal and the demands of actors in collaborations. The Critical Incident Technique (Chell \& Simon (2003) was used to guide the participants in recalling any salient events occurring with other actors that contributed to breach or violation of expectations between them.

\section{Validity, reliability, and generalizability}

After the results of this study were analyzed, a workshop was organized with actors from the same airport to get more insights and validate our findings. The findings were presented to a panel of airport service providers. They found the findings clear, vivid and they related to them in many ways. To our knowledge and their understanding, actors expressed the role of such factors and how collaborative performance is vital, the need to manage critical target times and being efficient in the turnaround through different levels of contracts. During the workshop, ways to remedy mentioned factors and non-linear dependencies were then suggested; a change management design that would transform the whole network to a new level of sharing information, roles and collaborative decision-making was discussed.

Based on their input we validated our findings on the existence of a unique 


\subsection{Selection of Methods}

form of complexity and the factors that contribute to it. From the meetings with actors we found that by studying interactions between actors through contracts and dependencies gives us knowledge on what induces complexity and not only mutually exclusive but also mutually reinforcing to induce complexity in such contexts.

\subsubsection{Systematic Literature Review}

Systematic Literature Review (SLR) approach (Cook et al., 1995; Petticrew and Robert, 2006) offers to focus on the research purpose rather than on the utility of publications as explained in studies made by (Ginieis et al., 2012). Traditionally, SLR provides a structured way to summarize various findings with minimum bias. In this thesis, SLR was applied in study 2 in order to identify how organisational controls amplify complexity along three process stages of PMS. We used keywords associated with PMM for a criterion search of literature output from Thomson Reuters Web of Science (WOS) and SCOPUS. We particularly concentrated how interactively organisational controls impact process stages of PMS such as design (Deng et al., 2012; Lohman et al., 2004), implementation (Bourne et al., 2003; Jääskeläinen and Sillanpää, 2013; Suprapto et al., 2009) and management as adopted by different organizations in different sectors (Bititci et al., 2012; Folan and Browne, 2005; Keong Choong, 2013; Mason-Jones, R. and Towill, 2000; Neely, 1999).

\section{Search terms and sources}

The keywords are defined for each research axis and combinations of words to search in the selected databases. It was established that these keywords should appear in the title of the paper or in the abstract of the paper or in the keywords of the paper. The following keywords were selected.

1. performance management AND system AND design AND implementation

2. performance measurement AND system AND design AND implementation

3. performance management system AND system AND design AND implementation 


\section{Methods}

4. performance indicators AND system AND design AND implementation

5. organisational performance AND system AND design AND implementation

6. performance assessment AND system AND design AND implementation

7. supply chain management AND system AND design AND implementation

8. performance measurement system AND system AND design AND implementation

9. performance measurement and management AND system AND design AND implementation

10. performance strategy AND system AND design AND implementation

For the SLR we have used two databases, Thomson Reuters Web of Science (WOS) and Scopus from Elsevier (Scopus) and we have also based on the guide of the Chartered Association of Business Schools (ABS Guide). Regarding the search in these databases, we have used AND because the secondary keywords (design, implementation, system) are very generic so we needed to limit the search. In this way, we made sure that we could identify the maximum quantity of relevant papers to continue with the subsequent analysis. During this process we also eliminated any duplicates papers. This broad search resulted in 3,287 relevant publications. Eliminating duplicates reduced the total to 1,981, and applying a publication cutoff date of 2015 further reduced the total to 1,952 papers (see Figure 4.1.1).

As can be seen in Figure 4.1.2, it is noted that until the late 1990s, only 107 papers of PMM (5\%) had been published. The remarkable evolution in the publications is observed at the beginning of the year 2000, because only in the decade 2000-2010 only in the first ten years of the present century have been published 799 papers have been published (41\%). Finally, it is important to remark that in the last five years 1,046 studies on PMM (54\%) were published. This demonstrates the growing importance that this topic has had for academic literature.

For the selection of journals and papers within them, two factors were taken into account. Firstly, only academic articles were considered to ensure in line with researchers who conducted SLR (Cook et al. 1995; Petticrew and Robert 


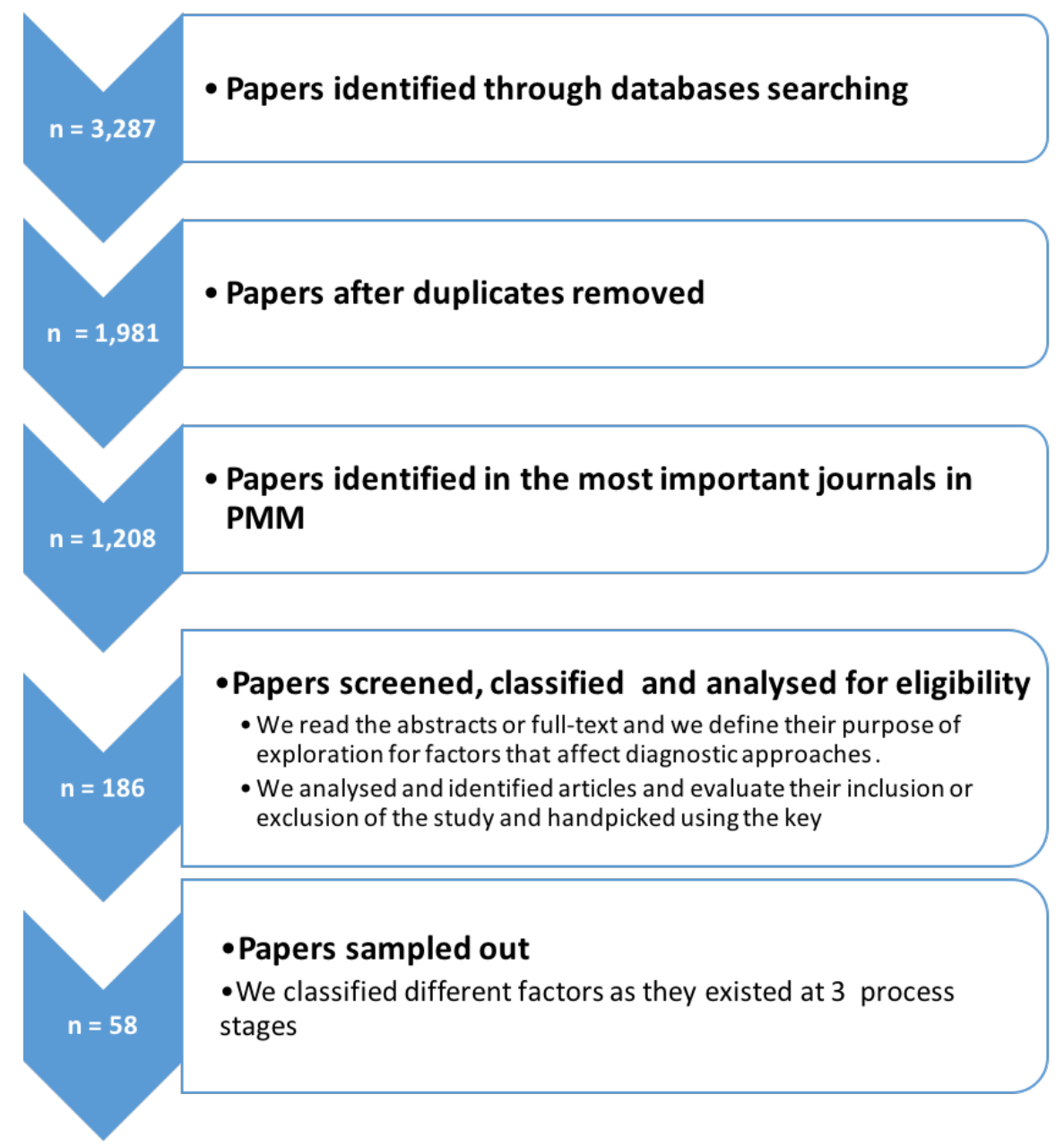

Figure 4.1.1.: Step by step process for sample selection.

2006). A number of publications such as reports, conference papers, editorials and books were removed in this phase. Secondly the most important journals that publish PMM topics were selected. These journals are in the categories Management/Business (WOS), Operations and Technology Management/General Management, Ethics and Social Responsibility (ABS), Business, Management and Accounting (Scopus) (see Table 3). Applying these two factors yielded 1,208 papers as demonstrated in Table 3 with the journals that published work on PMM arranged by year of publication. Following the above filtration approach, analysing abstracts, yielded 186 articles. From this sample, each paper is quickly reviewed 


\section{Methods}

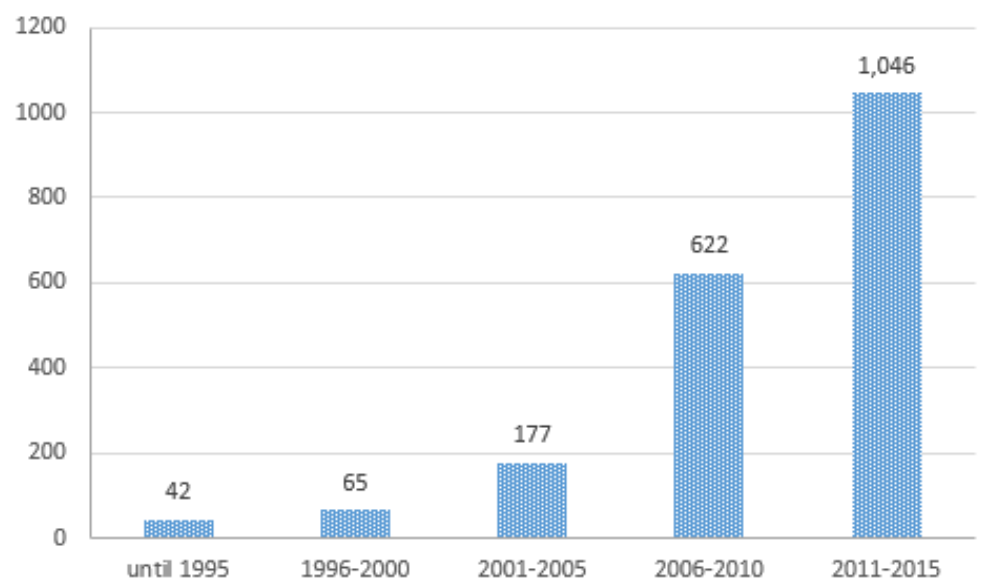

Figure 4.1.2.: Number of articles on PMM

to see if it discussed different and PMS process stages. Following this process, 58 papers were hand-picked that were empirical and more related to the research purpose. As the study is interested in abstracting complexity associated with PMS stages, the study emphasised on user practices as being applied in different operational contexts.

In Table 4.1.3 it is possible to can be observed how the number the distribution of published publications in the field of PMM of the in top journals published can be observed in the field of PMM. It is observed that until the year 2000 only $11 \%$ (134) of the total studies have been were published. Also, it is important to note that $40 \%$ (487) of the papers have been published in the last five years (2011-2015).

\section{Data Analysis}

The focus of this study is to explore how complexity emerges along the three process stages of PMS. From the outset, we made an assumption that complexity is a result of the conflicts in practices and mechanisms of how social and technical control is used at different stages. The selected papers covered a wide range of aspects such as human resources, manufacturing, measurement systems in SMEs, financial and non-financial operations, leaderships styles, and motivation at work, etc. As such, the papers were grouped by their purpose, control factors and what 
Table 4.1.2.: Keyword analysis and papers until 2015

\begin{tabular}{|c|c|c|c|c|c|c|c|c|c|}
\hline Keyword & 1999 & 2000 & 2001 & 2002 & 2003 & 2004 & 2005 & 2006 & 2007 \\
\hline Performance management & 62 & 11 & 10 & 13 & 13 & 16 & 23 & 43 & 42 \\
\hline Performance measurement & 15 & 4 & 9 & 3 & 12 & 14 & 28 & 25 & 38 \\
\hline Performance management system & 6 & 1 & 1 & 3 & 4 & 5 & 3 & 6 & 10 \\
\hline Performance indicators & 1 & - & - & - & - & 1 & 2 & 2 & 2 \\
\hline Organisational performance & 1 & - & - & 1 & - & 1 & 2 & 2 & 5 \\
\hline Performance assessment & - & 1 & - & 2 & 2 & - & - & 3 & 3 \\
\hline Supply chain management & - & - & - & - & - & - & 1 & 1 & 1 \\
\hline Performance measurement system & 1 & 2 & - & 1 & - & 1 & 5 & - & 2 \\
\hline Performance measurement and management & 1 & - & - & - & - & - & - & - & 2 \\
\hline Performance strategy & 1 & - & - & - & - & 1 & - & - & - \\
\hline Total & 88 & 19 & 20 & 23 & 31 & 39 & 64 & 82 & 105 \\
\hline \multirow[t]{2}{*}{$\%$} & 0.05 & 0.01 & 0.01 & 0.01 & 0.02 & 0.02 & 0.03 & 0.04 & 0.05 \\
\hline & 2008 & 2009 & 2010 & 2011 & 2012 & 2013 & 2014 & 2015 & Total \\
\hline Performance management & 45 & 66 & 80 & 80 & 90 & 89 & 88 & 68 & 849 \\
\hline Performance measurement & 45 & 33 & 68 & 69 & 81 & 91 & 109 & 81 & 737 \\
\hline Performance management system & 10 & 12 & 5 & 11 & 10 & 10 & 9 & 4 & 111 \\
\hline Performance indicators & 10 & 10 & 11 & 3 & 10 & 8 & 12 & 5 & 79 \\
\hline Organisational performance & 4 & 4 & 5 & 6 & 5 & 12 & 8 & 15 & 73 \\
\hline Performance assessment & 2 & 1 & 2 & 4 & 3 & 2 & 12 & 12 & 49 \\
\hline Supply chain management & 2 & 2 & 6 & 2 & 5 & 4 & 4 & 5 & 34 \\
\hline Performance measurement system & - & 5 & 2 & 2 & 4 & 1 & 2 & 2 & 30 \\
\hline Performance measurement and management & 1 & 2 & 2 & 2 & - & 2 & - & 1 & 13 \\
\hline Performance strategy & - & - & - & - & - & - & 2 & 1 & 5 \\
\hline Total & 119 & 135 & 181 & 179 & 208 & 219 & 246 & 194 & 1,952 \\
\hline$\%$ & 0.06 & 0.07 & 0.09 & 0.09 & 0.11 & 0.11 & 0.13 & 0.10 & 1.00 \\
\hline
\end{tabular}




\section{Methods}

Table 4.1.3.: Evolution of the number of publications PMM in journals WOK/ABS/Scopus

\begin{tabular}{|c|c|c|c|c|c|c|}
\hline Journal & 2005 & 2006 & 2007 & 2008 & 2009 & 2010 \\
\hline International Journal of Productivity and Performance Management & 22 & 14 & 21 & 18 & 18 & 20 \\
\hline International Journal of Operations and Production Management & 84 & 6 & 10 & 6 & 5 & \\
\hline International Journal of Project Management & 12 & 4 & 6 & 7 & 12 & \\
\hline Measuring Business Excellence & 10 & 14 & 13 & 9 & 11 & 10 \\
\hline International Journal of Business Performance Management & 45 & 4 & 8 & 2 & 6 & . \\
\hline International Journal of Production Economics & 41 & 2 & 4 & 3 & 8 & 3 \\
\hline International Journal of Production Research & 21 & 6 & 5 & 2 & 4 & 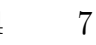 \\
\hline Management Accounting Research & 37 & 2 & 4 & 6 & 6 & \\
\hline Production Planning and Control & 26 & 3 & 6 & 4 & 7 & \\
\hline Business Process Management Journal & 2 & - & 1 & 4 & 1 & \\
\hline Team Perform & 1 & 1 & 1 & 8 & 2 & \\
\hline European Management Journal & 8 & - & - & - & 2 & \\
\hline International Journal of Services and Operations Management & - & 2 & - & 2 & 2 & \\
\hline Journal of Ope & 6 & - & - & 1 & 1 & \\
\hline International Journal of Mana & 6 & - & - & - & 1 & \\
\hline Other journals & 12 & 3 & 2 & 5 & 7 & 12 \\
\hline \multirow[t]{2}{*}{ Total } & 333 & 61 & 81 & 77 & 93 & 76 \\
\hline & 2011 & 2012 & 2013 & 2014 & 2015 & Total \\
\hline International Journal of Productivity & 20 & 21 & 26 & 16 & 20 & 216 \\
\hline International Journal of Operations and Production Management & 8 & 3 & 7 & 6 & 3 & 142 \\
\hline International Journal of Project Management & 24 & 11 & 12 & 14 & 10 & 120 \\
\hline Measuring Business Excellence & 11 & 7 & 7 & 3 & 8 & 103 \\
\hline International Journal of Business Performance Management & 3 & 6 & 6 & 10 & 6 & 100 \\
\hline International Journal of Production Economics & 5 & 7 & 6 & 4 & 6 & 89 \\
\hline Interna & 2 & 10 & 4 & 5 & 18 & 84 \\
\hline ting Research & 5 & 7 & 3 & 7 & 3 & 82 \\
\hline in Planning and Control & 1 & 3 & 8 & 12 & 5 & 78 \\
\hline Business Process Management Journal & 1 & 6 & 5 & 1 & 5 & 26 \\
\hline Team Performance Management & - & 2 & 3 & 1 & 1 & 22 \\
\hline European Management Journal & - & 1 & - & 1 & 1 & 14 \\
\hline International Journal of Services and Operations Management & 3 & 2 & - & 1 & 2 & 14 \\
\hline Journal of Operations Management & 2 & - & - & 1 & - & 11 \\
\hline International Journal of Management Reviews & - & 1 & - & - & 1 & \\
\hline Other journals & 11 & 13 & 9 & 10 & 14 & 98 \\
\hline Total & 100 & 95 & 97 & 92 & 103 & 1,208 \\
\hline
\end{tabular}




\subsection{Selection of Methods}

process stage was being explored (see Table 4). In order to identify the emerging complexity, the authors independently reviewed each of the manuscripts to identify social and technical aspects by either the process stages or by the user response by the type of control being studied or by the purpose of the paper.

The definition was made according to what was being studied in the papers that represented the impact on practices of PMS. This would be found in the findings section of the paper or from the contribution made in the paper. Based on this definition, each article is analysed and evaluated for its inclusion or exclusion in the study. This step was achieved by reading the abstract at a surface level to check if the article explored factors such as technical controls, social controls and dynamic change controls and if any of these existed in any PMS process stages.

For purposes of reliability, the authors then met and logically described and analysed the factors to determine which category they belonged, i.e. social and technical controls that were described in the papers. Finally, the authors analysed all of the results to identify which system properties they possessed by following the conceptual definitions from Table 3.2.1 and then mapped them accordingly. The results were then analysed in two ways, first we compared the number of controls being explored at each process stage. Second, we analysed the conflicts and mismatch on how controls are being used according to the reports from papers. The two analysis from the sample all pointed out how complexity can emerge. The key findings are presented in Tables 4 and 5 and will be discussed in the next section.

\subsubsection{Longitudinal action based research}

Study two used a longitudinal action reseach. K. Lewin in his contributions to practitioners describes action research as a creation of theory when a researcher actively participates in such platforms (lewin, 1946). Action research with its introduction in the 1940s has been used in many change environments. Lewin further extended the idea to the present classical Lewinian model of research, which stipulates research actions (Lewin, 1947) steps as planning, fact finding and execution. Kolb (1984) later created a framework in four steps emerging from Lewins model that is realized in a learning cycle below. 


\section{Methods}

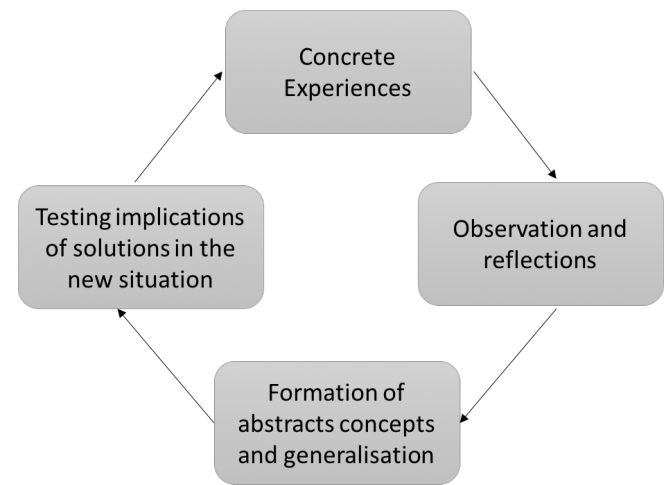

Figure 4.1.3.: Action research Lewin model as revisited by Kolb (1984)

Van de Ven (2007) in his book "Engaged Scholarship" discusses the importance of interactions in theory and research, problem and solving. Such iterations can be made in any order as shown in Figure 4.1.3. This research started with problem formulation from industry. The process of implementing new standards and planning change. This called for multiple data collections with no chronological sequence but rather an abductive learning cycle with multiple iterations. As a consequence, Study 3, adapted a longitudinal action based research that lasted over a period of three years. During this time, a number of other data collection methods were employed such as semi- structured interviews and workshops. Over a period of three years, a total of 27 interviews from various airport actors were conducted focusing on how ready the airport was for new PMS. Five workshops were also held, each workshop lasted for about four hours with various representatives from airport actors.

\section{Case methodology}

The methodological approach adapted in the MASCA project involved a longitudinal study and action-based research over a period of three years that deployed a number of research methodologies including: semi-structured interviews; workshops; Serious Game development; Training and Mentoring. As the objectives of this study is to report on the evaluation of the A-CDM change case-study the methodology section is divided into two parts:

Part 1: The ongoing research methodologies and interventions that were deployed 
throughout the three years and provided a rich dossier on the airport's overall approach to managing change.

Part 2: The application of the Structured Enquiry approach to provide a synthesis and consolidation of the overall evaluation as carried out towards the end of the project.

\section{Part 1: Ongoing Methodological Interventions}

Semi-Structured Interviews Over the three year research period a total of 27 key stakeholders at the airport were interviewed including representatives from the airport, airlines, ground handlers and Air Traffic Control. The objectives of the various interviews changed as the research evolved.

The objectives of the first phase of interviews (March 2011) focused on the airport only. An interview template was designed with the basic concept of change management focusing primarily on the airports overall strategic approach, the process of change, competence and human resources. This initial phase provided clarification of key strategic goals, assessment of the current change initiatives in the airport, lessons learnt from previous change initiatives, readiness for change and key performance indicators. The underlying aim of the interviews was to link the MASCA change and evaluation program to initiatives within the company. As a result of this first exploratory phase of interviews a decision was made to focus on the implementation of A-CDM as one of the key MASCA case-studies and a first critical step was for the researchers to more fully understand the current Turn-Around Process (TAP) at the airport.

Therefore the objectives of the second phase of interviews (December 2011) focused on the preparation for a workshop on the Turn-Around process. Building on the previous interview template, the questions covered: general questions on the work and working conditions, key patterns of communication across actors, the strategy of the company, its visibility and how it is communicated. Other areas covered competence for change within the company, successful and unsuccessful changes, insufficient knowledge about all stakeholders' roles in the turn-around process and their overall knowledge and understanding on what implementing ACDM means for their everyday work. 


\section{Methods}

Similar questions were put to two interviewees of an airline at the third phase (May 2012). Emphasis was put on the operations of the airlines.

The focus of the final phase of interviews (October 2013) was two-fold (i) to prepare for a future training session on enhancing communication and collaboration among key actors and (ii) to provide a final consolidated evaluation of the overall progress of implementing A-CDM at the airport based on the Structured Enquiry.

Workshops MASCA researchers have also facilitated five workshops over the duration of the research involving key stakeholders involved in the implementation of A-CDM. Each of the workshops lasted approximately four hours and included between ten to fifteen representatives from key stakeholders at each workshop. The objectives of the workshops were two-fold (i) to understand the key stakeholder roles and their challenges in implementing A-CDM and (ii) to facilitate the iterative development of a Serious Game to support more effective collaboration and communication among the key actors.

Following from the first phase of interviews, the first workshop took place (March 2011). The overall aim was to present the findings of the interviews and to agree on what change management project within the company that would be suitable for a MASCA intervention. At this stage the A-CDM project was selected. At the second workshop the aim was to map the Turn-Around Process specific to this airport (June 2011). The workshop involved representatives from key actors and an overall map of key roles and tasks was developed. One of the outputs of this workshop was to focus the MASCA research into the development of a training exercise (Serious Game) to facilitate a more collaborative approach among stakeholders. Identifying the challenges of implementing change was part of the workshop.

At the third workshop (December 2011) the first model of a Serious Game was tested by the participants representing different stakeholders. The content of the Serious Game were different scenarios from a normal Turn- Around process. The game was highly appreciated and it was followed by a fourth workshop (May 2012) testing a new version of the serious game.

The fifth workshop (April 2013) was conducted focusing on the 'Challenges of Implementing Change.' This workshop provided key actors with the lessons 
learned from the other change case-studies within the MASCA project and provided a number of suggestions on how to further deploy the Serious Game into a more specific training programme.

SKYBOARD Serious Game As it became apparent that the challenge of establishing more effective collaboration and ongoing learning among the key stakeholders was vital to the overall success, one of the key MASCA interventions involved the development and implementation of a Serious Game (SKYBOARD). The objective of the Serious Game was to initiate a common understanding across the key stakeholder organisations on the shift of the level of collaboration and information sharing required in making the implementation of A-CDM a success. The game involved the four key actors (e.g., airport, airline, ground handler and ATC) where they were faced with a number of obstacles that had to be removed in order to release aircraft. The idea is that if they all work in a more collaborative manner it will result in overall efficiency across all functions. This game was developed iteratively over a two year period and involved the direct participation of the stakeholder representatives in the Serious Game development workshops. The key benefits of introducing the Serious Game to support the implementation of A-CDM in this case included the opportunity for the key stakeholders to spend significant time with each other, getting to know each other in a fairly relaxed and 'fun' environment and getting a better understanding of each other's roles and perspectives on the turn-around processes at the airport and the challenges they were facing with the implementation of A-CDM. A second benefit of the game was that it raised more awareness and initiated a more in-depth discussion of the implementation of A-CDM and what it meant for each of the stakeholders.

Training on Enhancing Communication \& Collaboration During the ongoing analysis and evaluation with key stakeholders it was evident that as the implementation of A-CDM progressed it was becoming more important to ensure the active engagement of a wider stakeholder representation. The initial focus was targeted primarily at four key actors (i) Airports; (ii) ATC; (iii) Airlines; and (iv) Ground handling, however in order for A-CDM to succeed the other stakeholders (e.g., cleaners, fuel companies, catering etc.) had to be brought into the overall pro- 


\section{Methods}

cess in a more active and participatory manner. The interviews also highlighted that basic communication skills would also require enhancement between these key stakeholders in order to ensure the necessary level of collaboration. As a result a three-hour training programme was developed with the objective of enhancing collaboration and communication between the key stakeholders. This training took place in November 2013 and the key learning outcomes centred around raising awareness and the profile of the A-CDM project, creating a shared understanding of the Turn-Around-process and the role of the key actors in delivering this and the criticality of basic communication skills. The Serious Game was also embedded in this training programme.

Where teams are multinational, temporary and short-lived, McHugh et al, (2008) have shown it to be advantageous to create a hybrid "culture" which forges shared mental models for collaborative norms and processes. Doing so fosters more effective collaborative teamwork and decision making earlier in the lifecycle. Serious games have also been shown to improve decision-making for situation awareness, metacognition and resource management (Caird-Daley et al, 2007). This work also highlighted the relative lack of evaluation of serious games being used to improve decision-making in a live operational environment. This research also comments that A-CDM is a vital tool for addressing the needs of dynamic working environments which present complex operating practices and unanticipated events. Conscious of the importance of 1) shared mental models and 2) the need for a compatible common operational picture in A-CDM, the methodology for this MASCA research designed the training workshop with these two themes in mind. They also included process mapping exercises to strengthen the common operational picture that to ensure that it was compatible for all of the different stakeholder groups represented at the training. The Serious Game was also embedded in this training programme which addresses recent research (McHugh et al, 2008 and House et al, 2013) and the importance of Scenario Based Training, enabling interoperability through multi-agency training using simulated learning environments

Mentoring An excellent relationship of research and industry collaboration was established over the project where the leading researchers developed a role of 
mentor and advisor to the project management team (e.g. by taking part in critical meetings and joining the project group in visits to airports which had already implemented A-CDM.

\subsubsection{CART-Classification and regression Tree Method}

Study three applied thet CART methods. In general, CART method has been applied to other areas with various studies (Chang, 2012; Harper and Winslett, 2006; Prakash et al., 2012; Zhang and Bonney, 2000). CART is a nonparametric statistical tool that helps segment, rank, and predict membership of items in the classes of a dependent variable. CART method uses an interpretation of results using a node split to form a classification tree. Each node shows a particular class of indicators and always saturation is reached when terminal node is reached. The CART algorithm begins with all observations in a single data set to form a tree with a particular split fall. For every split there is a particular threshold reached. The observations are then split into two groups. The split is made on the basis of the independent variable to reduce the total variation in the categorical dependent variable. Following the data after split the algorithm then selects the best-fit node for continuous split to reduce the total variation in the categorical dependent variable in order to form a Classification Tree. In order to apply CART method, the thesis as a first step was able to examine the sample data with three algorithms in order to select best suitable for the calculation. The algorithms tested prior to full calculation were QUEST, CRT, and CHAID. From the pilot results, our results show that from all of the three algorithms tested on our sample, QUEST had a higher prediction accuracy compared to the rest results. Secondly, QUEST was able to classify measures with high accuracy and less computational time; in other words, QUEST met all prerequisites for our data. As such, the rest of the analysis was performed using QUEST.

Research Approach

The research approach follows the assessment model presented in Figure 4.1.4 on page 77. We used operational data from Madrid-Barajas Airport, sampled from the CDM database that corresponds to airport actor KPIs. The CART method 


\section{Methods}

was applied for the three databases, and all datasets were analyzed separately. The following is a stepwise description of the method we used.

\section{Model to Evaluate Performance Measurement Management for Airports}

This section proposes a model to evaluate CDM turnaround performance. As part of the large ATM system, theory on CDM implementation has four major network benefits - capacity, efficiency, environment, and safety. For each benefit, a set of major indicators has been recommended for consideration by an airport using CDM. Among these performance indicators, there exist both network and actor benefits (EUROCONTROL, 2006). For CDM network performance, the main objectives for CDM outcomes according to Eurocontrol include: 1) to protect air traffic services, 2) to enable aircraft operations with minimum penalty, and 3) to allow the best use of airport resources.

Following studies on methodology development in ATM, such as by Tobaruela et al. (2014), this study explores the key role of CDM indicators in the airport (i.e., managing turnaround performance). The study fills this gap by considering a nonparametric data-mining technique to validate airport operations from collaborative CDM measures.

Figure 4.1.4 suggests a model derived from CDM theory (Eurocontrol, 2006, 2012), which combines CDM inputs and outputs to obtain performance at airports. For inputs, it considers CDM operational standards, such as trust, information sharing, and collaboration between the actors involved, the resources used at airports, and airport infrastructure (Eurocontrol, 2012).

This model takes into account airport operators, aircraft operators, ground handlers, service providers, and air navigation as airport partners, and their activities as input to the system. As for outputs, this model considers all areas that impact airport activity, such as efficiency, environment, capacity, and safety, as the main, sustainable air-transport system parameters for the future, and they are in line with those of the Advisory Council for Aviation Research. However, this study will be limited to local airport CDM or airport performance, and not network performance, because the former is the main purpose of our study. 


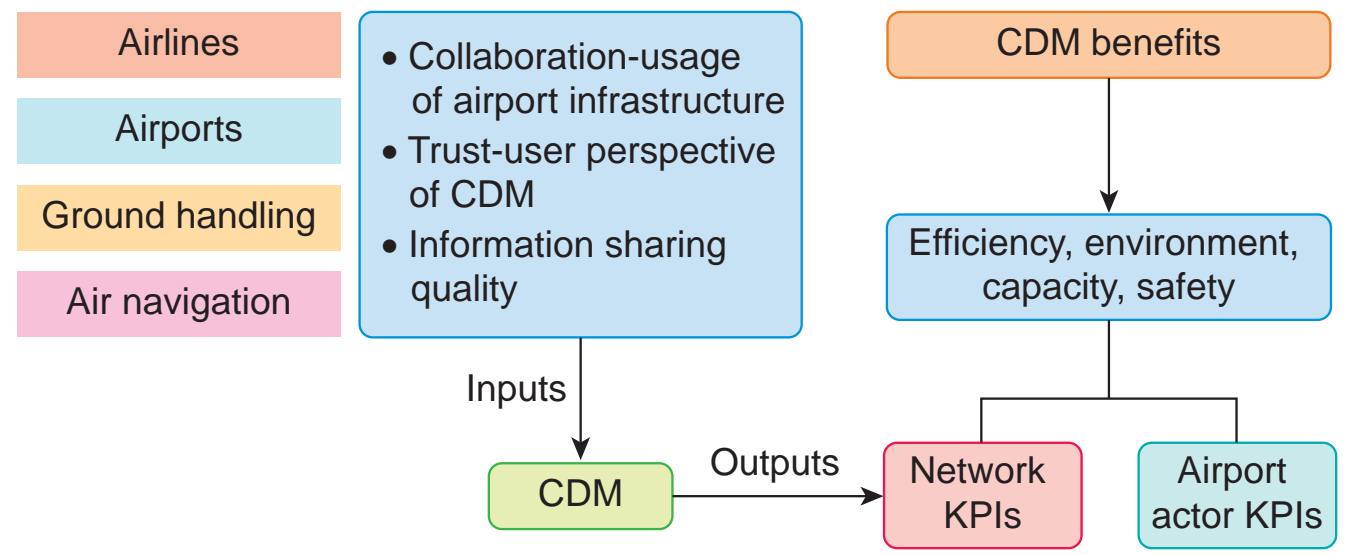

Figure 4.1.4.: Model to Evaluate CDM Indicators

\section{Data and Sample Design}

Table 4.1 .4 on page 78 shows the sample data taken from the Madrid-Barajas Airport database, as previously mentioned; the CDM database is maintained by Aeropuertos Españoles y Navegacion Aérea (AENA) as part of an ongoing CDM project. Moreover, AENA operations use a large integrated database called SCENA. Our sample is drawn from flights operated for the year 2014 along with observations. For every month, we selected a single day to represent the average number of flights for that month. This had the advantage of allowing for the capture of actual flights conducted. Had monthly or aggregated data been employed, specific flight data would not have been available for analysis because then we could not decipher how flights follow each other during turnaround. Therefore, following a daytime selection of the sequence of flights was vital, and allowed for sequential analysis of flight scheduling to be examined by KPIs. The extraction of turnaround-time data included all data from CDM actors. Flight variables included all estimated and actual times for every event, as described by CDM operational indicators. Further, the CDM turnaround data also included variables for every flight, such as type of aircraft, taxi runway, name of airline, stand or gate, and all CDM indicators (independent variables). Three databases were then developed, each of which was analyzed independently with SPSS analytics software. 


\section{Methods}

Table 4.1.4 shows the way in which the data from 12 months was distributed in the three databases.

Table 4.1.4.: Sample data selected

\begin{tabular}{lll}
\hline Databases & Selected months & $\begin{array}{l}\text { Total observations for } \\
\text { each database }\end{array}$ \\
\hline Database one & January, February, March, April & 2100 \\
Database two & May, June, July, August & 2168 \\
Database three & $\begin{array}{l}\text { September, October, November } \\
\text { December }\end{array}$ & 2232 \\
\hline
\end{tabular}

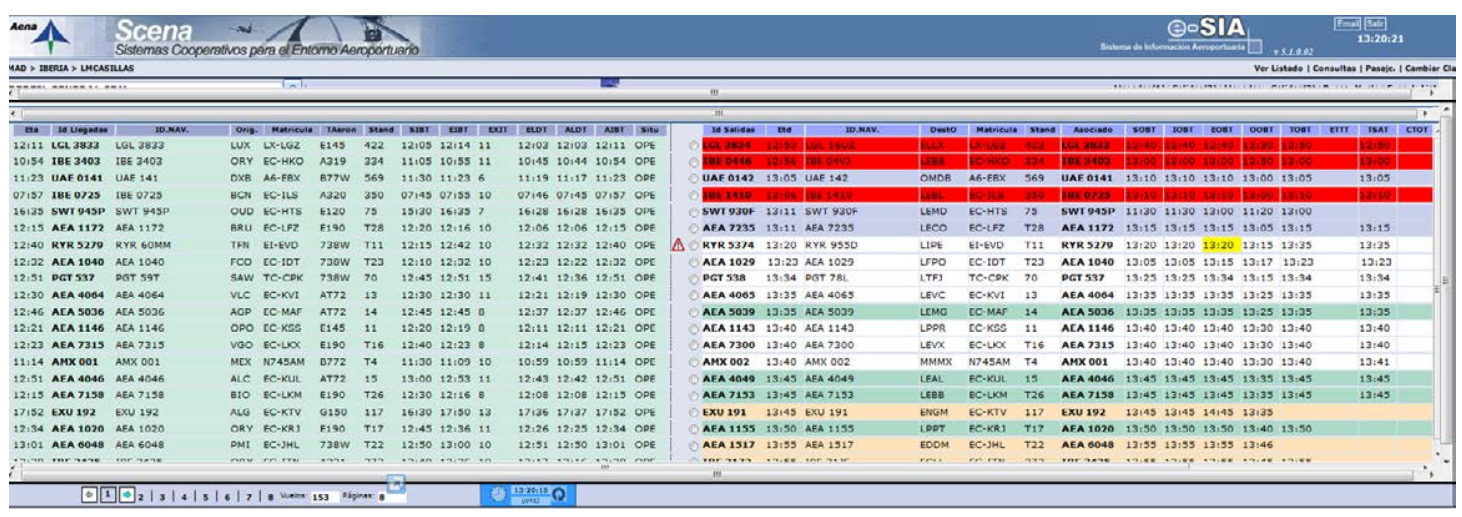

Figure 4.1.5.: A screenshot from a CDM management tool

Figure 4.1.5 shows a record of live performance of CDM operations and how the indicators are recorded. The system database records actual times and estimated time. According to Eurocontrol, delay is the time difference in minutes between Scheduled Times (ST) and Actual Times (AT) of any activity that is being recoded in the milestone. This difference is measured at all phases of flight, inbound, turnaround and outbound. These times are the independent variables presented in Table 4.1.6. To attain on-time performance with perfect conditions, the difference between AT and ST should be delay $=0$ minutes. Hence, for the dependent variables, new variables are proposed and named star values. We call them so because they are the minimal delay conditions that can optimize the system to no delay. 
For example, if the scheduled time for takeoff for flight $X$ was set at 10.30, but because of the nature of operations in the TAP, takeoff occured at 10.37 as actual time. In this instance, the difference between Actual and Scheduled is 7 minutes, which will be the delay time for flight $x$ at takeoff. The other possible event of the delay would be that if flight $x$ takes off at a time 7 minutes earlier than scheduled, so the delay in this case could be -7 minutes. The two possibilities are delay conditions which cause disruptions which may have far-reaching consequences in the whole network. The delay condition is then calculated as:

$$
\text { Delay }=(\mathrm{AT}-\mathrm{ST}) \text { minutes. }
$$

Table 4.1 .5 on page 80 presents dependent variables used. The dependent values are named star values because they define the delay conditions in the turnaround as the most perfect and objective system with no delays. It is important to show the level of delays in the current CDM operations by comparing them to the perfect system of proposed star values. Therefore, for the dependent variables, we composed a set of star values with three delay conditions. The delay condition is the difference between actual and scheduled time, which ultimately gives three alternatives: early arrival, on time arrival and late arrival. In order to have star values cater for all the three alternatives of the delay conditions, the dependent variables were allocated to two classes selecting -0.5 as midpoint. First, all delays recorded in the range from -0.5 minutes and above are marked as On Time (T); second, all the delays in the range from -0.5 minutes and below are marked as Over Time (OT). The two classes then formed a set of dependent variables that was used in the calculation as predictor variables for the independent variables recorded as a difference between scheduled and actual times from major CDM KPIs during operations.

The proposed star values are the key performance target for all actors when the system is considered to be a perfect system with, in other words, no delays. All actors involved should work towards narrowing all CDM Key Performance Indicator times to 0 minutes for better benefits. This is the very reason the dependent variables were set with such precise and minimal delay conditions.

Table 4.1.6 presents 11 independent variables. The independent variables are 


\section{Methods}

Table 4.1.5.: Dependent variables (star values)

\begin{tabular}{cc}
\hline Definition & Star values in minutes (Nominal) \\
\hline ON TIME $(\mathrm{T})$ & For $\mathrm{T}=$ all delays from -0.5 and above \\
OVER TIME $(\mathrm{OT})$ & For OT $=$ ? all delays from -0.5 and below \\
\hline
\end{tabular}

the major CDM Key Performance Indicators extracted from the year 2014 airport database. The independent variables are difference times between the actual and estimated for all the operations recoded, which represents the current CDM performance of all operations. Below are the indicators used as independent variables, which are delays as a result of estimated and actual times in the milestone approach.

\subsubsection{Artificial Neural Network}

Neural networks are also referred to as Artificial Neural Network (ANN). A neural network is a set of units computer that are interconnected (Warner and Misra, 1996). These units are also called nodes and are a representation of neurons that attempt to mimic brain function (Rosenblatt, 1962). Neural networks are used to predict events through a process of training the behaviour of the network. Prediction serves an important role in air transport because of the unforeseen events that impounds the nature of airside services at airports. (Liu et al., 2014; Tobaruela et al., 2014). More to this, as a machine learning practice there is a feed forward artificial neural network model that maps sets of input data onto a set of appropriate outputs. The latter uses a Multilayer Perceptron which consists of multiple layers of nodes in a directed graph, with each layer fully connected to the next one. In this study, we employed the artificial neural networks model which was able to develop a prediction model that automatically incorporates relationships between the variables analysed without explicitly incorporate them into the model (Trujillano et al., 2004). In so doing, the method was able to predict among the exogenous features between organizations if they seem to cause delays and hence effect on time performance during the turnaround. This was also achieved by this method to study and train the collaborative measures. 
Table 4.1.6.: Independent variables ${ }^{a}$

\begin{tabular}{cl}
\hline $\begin{array}{c}\text { Delay codes: } \\
\text { Difference } \\
\text { between Times } \\
\text { (Actual }-\end{array}$ & Description of KPIs according to CDM framework \\
Estimated) & \\
\hline AOBT-SOBT & Actual off-block time - Scheduled off-block time \\
AOBT-TOBT & Actual off-block time - Target off-block time \\
AXOT-EXOT & Actual taxi-out time - Estimated taxi-out time \\
ASAT-TSAT & Actual start-up approval time - Target start-up approval time \\
ASAT-ASRT & Actual start-up approval time - Actual start-up request time \\
TSAT-TOBT & Target start-up approval time - Target off-block time \\
AOBT-ASAT & Actual off-block time - Actual start-up approval time \\
TOBT-SOBT & Target off-block time - Scheduled off-block time \\
ASRT-TSAT & Actual start-up request time - Target start-up approval time \\
AXIT-EXIT & Actual taxi-in time - Estimated taxi-out time \\
ASRT-TOBT & Actual start-up request time - Target off-block time \\
\hline
\end{tabular}

${ }^{a}$ The KPIs described in this table are standard CDM metrics for different operations being employed to track aircraft movements from landing to takeoff. 


\section{Methods}

\section{Methodology \& Research approach}

Prediction serves an important role in air transport because of the unforeseen events that impounds the nature of airside services at airports. (Liu et al., 2014; Tobaruela et al., 2014). The method takes the approach of a predictive analysis (Wilcox and Bourne, 2003) that is based on current and historical data to make predictions about future events, which generally are not absolute statements. Predictive models use statistics with data mining algorithms to analyze and evaluate how likely an event, person or activity will show a specific behavior in the future. This kind of prediction can be used in order to improve the efficiency in operation and can be applied to any type unknown event, regardless of when it occurred. (Monk, 2015).

In predictive modelling several techniques exist, In this study, we employ the artificial neural networks and a mathematical / computer model that attempt to mimic brain function (Rosenblatt, 1962). They are also able to develop a prediction model that automatically incorporates relationships between the variables analyzed without explicitly incorporate them into the model. (Trujillano et al., 2004). More to this, as a machine learning practice there is a feed forward artificial neural network model that maps sets of input data onto a set of appropriate outputs. The latter uses a Multilayer Perceptron which consists of multiple layers of nodes in a directed graph, with each layer fully connected to the next one.

\section{Data}

This research uses a descriptive exploratory method and aims to identify the features or elements that are indicative of cause delays or bottlenecks in airport operations using artificial neuro network method. To achieve this, we used objective data from Adolfo Suarez Barajas Airport Spain, which correspond to the first four months of 2014 turnaround movements. The sample consists of 2100 flight records in aircraft movements in airport operations, the data are analyzed using statistical techniques and data mining are used, with SPSS software 21.

The techniques used specifically correspond to descriptive statistics, multivariate analysis (principal components), data mining techniques such as QUEST decision tree algorithm and neural networks Multilayer Perceptron. The latter have ad- 


\subsection{Selection of Methods}

vantages concerning that require less statistical formalism for development, detect nonlinear relationships, detect interactions between predictor variables and have multiple training algorithms. (Monk, 2015).

The procedure performed corresponds first to the creation of the database, this will then pre-process the data in order to transform it to be used the selected variables that provide the information needed to perform the analysis. The variables used for this study are described below:

\section{Independent variables}

The independent variables used in this method are quantitative variables recoded in the common database from all CDM users (airport actors. These indicators record every minute and activity in the operations and recoded in minutes. The description of indicators was given in Table 4.1.6 on page 81 in Study four.

\section{Dependent variables}

In this case we have used a dependent variable nominal rate which has been called Star-value (Okwir et al., 2016) and the predictor variables used are the categorical factors that are assumed to affect the collaborative turnaround performance.

CDM users involved in airport operations collaboratively share stands, runways, and the impact of size of aircraft may affect the operations. In similar manner, the type of airline is also viewed as a dependent variable since its operations affect other actors and all services are focused to create value when the aircraft closes doors and ready for taxing.

The dependent variable used is created from binary data predictions, it was called Star value, it is a two-level categorical variable (OT, O) and represents the performance of airport operations.

\section{Research approach}

After having prepared the database, it is appropriate to carry out an exploratory analysis of data in order to interpret and understand the interdependencies that occur between the different quantitative variables, then it proceeds through exploratory analysis to study the possibility of collinearity among the variables. Also 


\section{Methods}

an analysis of main components that regroups the variables in new components is performed, in this case the dimensions were reduced from ten indicators of CDM five components, these five components are applied analysis ranking of variables by CART method decision trees and obtained the components that influence the performance of airport operations are the components 2 and 3.

After obtaining this partial result, it proceeds to raise a predictive model through the use of neural networks multilayer perceptron, which are included as dependent variables nominal type which has been called Star-Value and the predictors they are the factors used type for all those who are categorical (Company, Stand, Runway and aircraft) and the scale covariates (component 2 and component 3) type. The scale of the variables used is the standardized.

The analysis was performed by first a random partition of training samples, test and reserve, the architecture of the network is scheduled automatically, at a later analysis variable partition was used to assign cases, values partition Bernoulli variants are generated randomly with probability parameter 0.7. And the architecture of the network was scheduled automatically, the optimal architecture is achieved through an iterative process that validates the predictive ability of different architectures considered. To perform the analysis, we started from the data corresponding to the first quarter of 2014 (January, February, March and April) - a total of 2100 observations as our independent mind.

\section{Selection of components}

Using a sample of the performance of the previous airport processes. This technique was able to train a network of multilayer perceptron, validate the analysis with a reserve sample the performance of the previous airport processes and then use the network to classify the possible future processes according to the possible impact that may arise. This would then be used to properly manage these turnaround processes so as to minimize the negative impact that they can produce.

These include, the type airline, that we call COMPANY, STAND, the type of RUNWAY and the type of AIRCRAFT. All this data was captured by CDM database at the airport.

The covariates type to the scale (component 2 and component 3 ). The scale 


\subsection{Selection of Methods}

of the variables used is the standardized. The analysis was performed by first a random partition of training samples, test and the reserve, in a subsequent analysis a variable partition was used to assign cases, partition values are variants of Bernoulli randomly generated with 0.7 probability parameter. The first analysis was a multilayer perceptron neural network (backpropagation) where the partition used for training samples, test and reserve performed automatically by the (SPSSsoft ware results of this analysis are shown below in table 4.1.7).

Table 4.1.7.: Case processing summary

\begin{tabular}{llrc}
\hline SAMPLE & & $\mathrm{N}$ & PERCENT \\
& TRAINING & 1230 & $61.7 \%$ \\
& TESTING & 585 & $29.4 \%$ \\
& HOLDOUT & 178 & $8.9 \%$ \\
VALID & & 1993 & $100.0 \%$ \\
EXCLUDED & & 107 &. \\
TOTAL & & 2100 &. \\
\hline
\end{tabular}

It shows that 1230 was allocated corresponding to $61.7 \%$ of cases in the training sample and $585(29.4 \%)$ to the test sample and the quiet was assigned 178 cases $(8.9 \%)$. There are 107 cases excluded from the analysis.

Table 4.1.8, the network information table, displays the number of units in the input layer that constitute the variables used as factors and covariates, here also none of the categories are considered "redundant" units. Similarly, a unit separate results for each category of the dependent variable Star-Value is created, for a total of two units in the output layer.

The automatic architecture has chosen five units in the hidden layer. The activation function is the hyperbolic tangent, and the output layer uses softmax activation function, which is why the error entropy, also is the error function that the network tries to minimize during training shown. All these data are summarized in the table presented below. 


\section{Methods}

Table 4.1.8.: Summary table of processing cases

$\begin{array}{lll}\text { Network Information } & \\ \text { Input Layer } & \text { Factors } & 1 \text { Company } \\ & & 2 \text { Stand } \\ & 3 \text { Aircraft } \\ & \text { Covariates } & 4 \text { Runway } \\ & & 1 \text { Component 2 } \\ & \text { Number of Unitsa } & 2 \text { Component 3 } \\ & \text { Rescaling Method for Covariates } & 358 \\ \text { Hidden Layer(s) } & \text { Number of Hidden Layers } & \text { Standardized } \\ & \text { Number of Units in Hidden Layer 1a } & 1 \\ \text { Output Layer } & \text { Dependent Variables } & 4 \\ & \text { Number of Units } & \text { Hyperbolic tangent } \\ & \text { Activation Function } & \text { STAR_VALUE } \\ & \text { Error Function } & \text { Softmax } \\ \text { a. Excluding the bias unit } & \text { Cross-entropy }\end{array}$

\subsection{RESEARCH QUALITY}

Table 4.2.1 on page 89 shows a summary of the research quality and different strategies that were considered. As suggested by several scholars (cf. Eisenhart and Howe, 1992; Golafshani, 2003; Morse et al., 2002; Voss et al., 2002), this research utilized five criteria for establishing the quality of research, viz., construct validity, internal validity, external validity, reliability and generalizability. These criteria in relation to the study are discussed next.

\section{Construct validity}

According to Yin (2009) and Gibbert et al. (2008), construct validity refers to the extent to which a procedure leads to matching theoretical constructs to reality. To achieve construct validity, three approaches were considered. First, multiple sources of evidence, such as multiple interviews, documents, observations in turnaround operations, operational data, and workshops, were used for selected quotes and facts that significantly affected the theoretical constructs as well as the findings in the cases. Second, operationalization of theoretical constructs was based on 


\subsection{RESEARCH QUALITY}

previous similar case studies in the extant literature. Third, as much as possible, transparent and documented approaches were used in defining the theoretical variables and clearly linking them to empirical evidence. These steps were carefully followed during data collection and analysis stages.

\section{Internal validity}

According to Yin (2009), internal validity is referred to as logical validity, which deals with the causal relationships between variables and thus separates appropriate causal relationships from counterfeit relationships. To achieve internal validity, different studies tried to replicate the same findings from different approaches and methodologies. For example, Studies One, Two and Three linked different sources of complexity in PMM from the longitudinal case study, the embedded multiple case study, and the literature review respectively. Similarly, Study Four analyzed the role assignment of actors and its impact on continuous improvement for collaborative PMM. This was achieved from quantitative operational data and the CART method respectively.

\section{External validity}

External validity (generalizability) is the extent to which research findings must explain a phenomenon not only in one setting where it was studied but also within other settings. Since this thesis is mainly based on a case study, statistical generalizations were not possible. Hence, generalizations were achieved by using theories. Thus, for external validity, complexity theory was applied in Studies Two and Three. Furthermore, Cybernetic theory generalized all findings from different studies in the cover essay. Replication in different settings such as the two cases from two different airports also allowed theoretical generalization. Moreover, different methodological approaches such as simulation for prediction and quantitative data analysis within cases were utilized to enhance the generalizability. 


\section{Methods}

\section{Reliability}

According to Yin (2009), a study is said to be reliable when the procedure such as data collection or data analysis can be repeated with the same results. The reliability of case studies is difficult to measure considering the fact that cases are enmeshed with the contexts and it is sometimes difficult to replicate the study. Thus, to ensure the reliability of cases, all followed procedures and protocols were carefully recorded and all the interview questions were properly documented and tagged. Ultimately, all the data used built up a database with transparent and robust analysis methods which were also recorded. With this information, it follows that any other researcher can use the protocols of this thesis to conduct similar studies. 
Table 4.2.1.: Strategies used for research quality

\begin{tabular}{|c|c|c|}
\hline Validity type & Strategies & $\begin{array}{l}\text { Stage in } \\
\text { research }\end{array}$ \\
\hline $\begin{array}{l}\text { Construct } \\
\text { validity }\end{array}$ & $\begin{array}{l}\text { - Multiple sources of evidence, mul- } \\
\text { tiple interviews, documents, liter- } \\
\text { ature search, observations in turn- } \\
\text { around operations, operational data } \\
\text { and workshops. } \\
\text { - Operationalization of theoretical con- } \\
\text { structs using other similar case stud- } \\
\text { ies. } \\
\text { - Clearly and transparently linking the- } \\
\text { oretical constructs to empirical evid- } \\
\text { ence. }\end{array}$ & $\begin{array}{l}\text { Data collection } \\
\text { \& Data analysis }\end{array}$ \\
\hline Internal validity & $\begin{array}{l}\text { - Used robust well known mechanisms } \\
\text { for analysis such as: pattern match- } \\
\text { ing. The results were verified by key } \\
\text { informants (studies one and two). } \\
\text { - Used replication of causal links for } \\
\text { more than one evidence in cases. }\end{array}$ & Data analysis \\
\hline $\begin{array}{l}\text { External validity } \\
\text { (Generaliz- } \\
\text { ability) }\end{array}$ & $\begin{array}{l}\text { - A replication logic with multiple cases } \\
\text { was applied } \\
\text { - Analytical generalization- used the- } \\
\text { ory, used CCT as method theory and } \\
\text { PMM as domain theory. }\end{array}$ & Research design \\
\hline Reliability & $\begin{array}{l}\text { - Protocol preparation for data collec- } \\
\text { tion, data categorization and data } \\
\text { storage. } \\
\text { - Transparent and robust analysis } \\
\text { methods for analysis were employed. }\end{array}$ & Data collection \\
\hline
\end{tabular}




\section{Methods}

\subsection{Research Limitations}

Four research limitations were experienced in this research. First, in the studies documented in Paper 1, a project involved a longitudinal study over a period of three years. This process was complemented with semi-structured interviews, workshops, serious game development, and training and mentoring. Although the results were documented correctly, there was a limitation concerning key informants from year to year who changed roles and new ones appeared which could have an impact on the results. Secondly, in Study Two, there was a smaller sample size to deal with. For more robust results, this study could have been different with more respondents.

Third, in Study Three, the research limitations lie in the way the data was examined. It was not very clear if all the empirical papers discussed social and technical aspects. Although the authors met and agreed on what was technical and what was social, there was still some bias felt in terms of what was actually meant by previous researchers. Fourth, in Study Four, in order to capture system performance, star value was set to minimal delay conditions. However, this could be a limitation due to changes that could arise in the calculation of collaborative measures if star values were to be set with different values, for example \pm 5 -minute delay. Finally, this thesis adopted the use of system theory as a method theory. Although it was applied to explain substantive topics in PMM theory as the domain, not all empirical contingencies were considered which may be a limitation to reflect upon. 


\section{5 Results}

Chapter 5 presents the results made from each study. In summary, Study one and the literature review explore the dimension of organizational complexity. Study four explores the dimension on continuous improvement. Lastly, the dimension social system is explored through Study two and Literature review.

\subsection{Study ONE-EXPloring THE Airport TURNAROUND PROCESS}

The first study of this thesis was exploratory one. In order to understand the dynamics of collaboration and roles among actors, the study adopted an exploratory case study using 23 interviews between managers from different organizations collaborating on a single PMS. In addition, participant observation over eight months was also conducted in the Turn Around Proccess 


\section{Results}

\subsubsection{Findings}

In this section, we present our findings from three sources, first from content, and contexts by analysing the turnaround and also from interviews using a critical incident technique. The data collected presented a broad range of contextual elements within the airport turnaround and results are detailed according to three main core results: The turn-round process, contracts and work dependencies which resulted in significant relationships between airport actors that offered fertile grounds for analytic generalizations (Yin, 2003). The results are presented below starting with the turn-round service identification and process involved.

\section{The Turn-aound Process}

Data analysis from our results generated deeper meanings to the airport turnround services using CDM. It was realized that the services are time and mission critical and a clear case description of such context would be a good result to show a many-to-many perspective. The results show that a service is created in the network when actors integrate resources through their actions and interactions with each other (Maglio et al., 2009). The actors are dependent on a shared service provided by one another using special tools, and must also collaborate to complete the turn-round process on schedule which makes it a dependency network and mainly depending on information that is shared. Furthermore, system size was also identified with resources, which include people, technology, organizations (actors) and shared information (Maglio et al, 2009). Findings are presented below

\section{Processes and activities}

Internal contingencies are categorized (Thompson, 1967) as dependencies in production like pooled, sequential and reciprocal processes in operations.

Pooled interdependence is when each part of an organization acts in a relatively autonomous manner. Sequential interdependence is when the outputs from one part of an organization or process constitute the input for another. Many operators may act autonomously within the time frame that they have access to the aircraft. As soon as they gain access to the aircraft for fueling or cleaning they pursue their 


\subsection{STUDY ONE}

task autonomously. Fuel is delivered more or less in the same way to all aircrafts aiming for minimum delay and maximum fuel sold.

Reciprocal interdependence is where overall effectiveness requires direct interaction between organizational parts or system components.

According to Thompson (1967) the least complex organizations have only pooled interdependences, more complex organizations have both pooled and sequential interdependence, and the most complex organizations have all three types of interdependencies. Clearly the organizations involved in the turnaround process possess all three types of internal

\section{Mass produced \& variability}

Services like fueling, cleaning, and catering are examples of mass production. The way they perform their processes is well defined with standard operations procedures and routine work.

However, the sequencing of their mass produced services may be altered suddenly by a change of ramp, a delayed partner service, unexpected early access to an aircraft, or just due to bad weather.Normal turn-around process operations are highly transparent and constantly scrutinized from an operations performance perspective, for each flight. The challenge is to predict disturbances and manage sudden interruptions.

The debate in marketing and services on the different logics of goods or service is related to these contingencies in services. This gives an indication that the airport service system will be in operating in both goods-logic and service-logics according to the

\section{Organizational size and system complexity}

With regard to the Swedish de-regulation and requirement for two to three airport actors for each service the sheer number of airport actors is contributing to complexity. In other European airports there is often only one ground handling company.

Adding actor's increases complexity. For the individual actor it means fierce competition within a relatively small market place and for the customer it means 


\section{Results}

more involved selection and contracting processes. However, it also contributes to the transparency of operators and performance at a consistent level. In addition, depending on the individual contracts, the composition of the teams can vary.. which in turn can hinder continuous improvement programs.

\section{Factors that induce complexity}

Factors identified to generate to complexity from the case description.

- Number of actors involved and size of whole network

- Number of processes to be conducted to produce a service

- The quality of information needed to be shared among actors

- Mission and time critical considerations

- Different technical tools used to share information, which causes lack of integration

- Outsourcing processes of some services

\section{Contracts}

Contracts may be of business type or service work contracts. In theory, contracts are supposed to set boundaries for managing mutual exchanges. However, from the respondents it was evident that formal contracts are not enough. As complexity of services increases, there is a greater need for flexibility, which results in the creation of informal roles that are not explicitly covered in the formal contracts. Figure 5.1.1 shows the interactions between turn-round actors at the level of contracts and work dependencies plus the regulatory contracts affecting all actors.

From a contextual point of view, work is governed by a Memorandum of Understanding $(\mathrm{MoU})$ between actors. The MoU consists of regulatory agreements to govern the actor's commitment to the turn-round process. This is the contract that unites all actors in a multi- actor perspective to use a shared service concept and technological enablers to share information. 


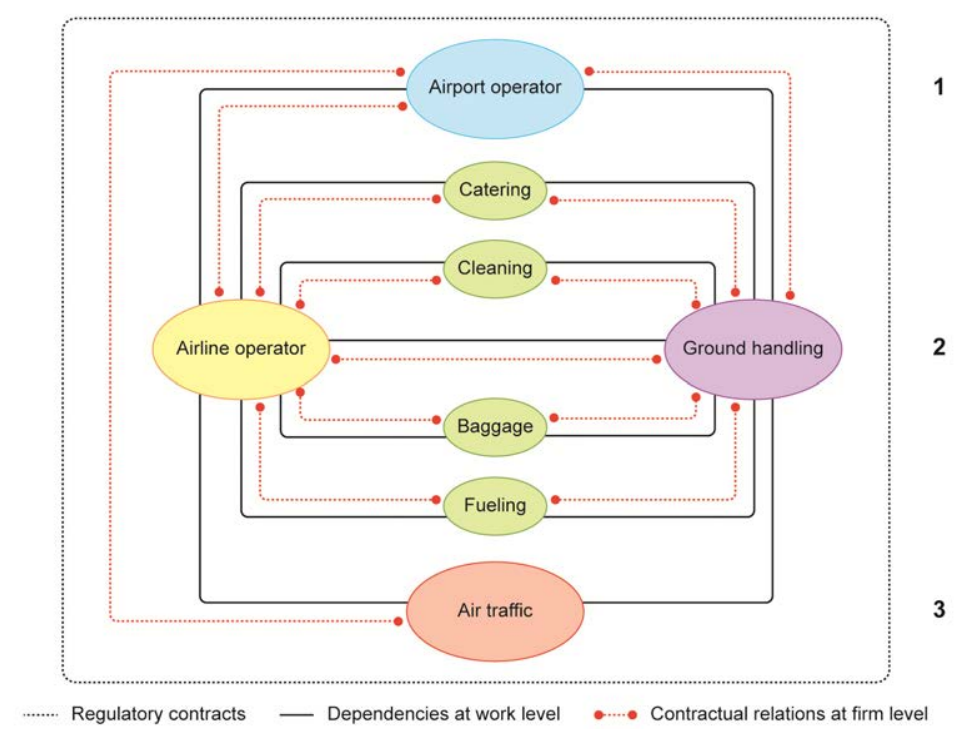

Figure 5.1.1.: A schematic representation showing actors with contractual and workrelated dependencies.

Every actor connected with dotted lines holds other contracts and performs unique duties according to individual services offered in the network. Examining the contracts shows that each actor holds several formal commitments in the turnaround.

It was also found that the contractual relationship dominated most of the collaborations. However, it is important to note that not all actors have contracts to the other actors in the system, though they depend on each other during the turn-around as the nature of the service offered. Below we quote our respondents as way how we reached such conclusions.

"Fueling companies are service companies for oil companies and they do not sign contracts with airlines" (Fueling Company)

"There's a contract between the airport management and us, who could care of what time they have to be at the aircraft the latest and where they should pick up the passengers and everything like that is stated in the contract."

(ANSP) 


\section{Results}

Table A.1.2 on page 168 in Appendix A presents the results obtained from the mutual exchange investigations between actors themselves, i.e. how they perceive each other. Each actor (on top row) was asked how their roles fit with the others actors (on the first column). The cross organization examination among actors is presented in a matrix form. Using the key description to examine the existence of formal roles, informal roles and critical incidents.

The results of roles (formal and informal), critical incidents and dependencies are then presented in Table A.1.2 on page 168 in Appendix B. Although formal roles were identified only between some actors, participants also reported additional informal roles, as well as informal roles arising between other actors, and many dependencies at the work level. For example, although no formal role was reported between airline operators and Air Service Navigation Providers, or Ground Handlers and Air Service Navigation Providers, informal roles arose as part of work routines and during critical incidents. For example, the case of a missing passenger, the Air Service Navigation Providers needed to clear the aircraft but had to wait for ground handlers to remove the bags of missing passengers. In similar way, the mutual exchanges as suggested by actors showed how roles and dependencies are not clear the way it is stated in the contracts as responded by the respondents below.

"For collaboration. It is very difficult to get in contact with the right person. Who knows most of the issue off interest? Even after many years of collaborative -project, I am still not sure of who does what"

(Fueling company)

'Normally, the airport should have power in the network. They dictate many roles through contracts and the allocation of airport resources. But ground handlers take a lot of service work, which is very often depends on the operations of other actors. That's why we get all the blame always"

(Ground handler)

\section{Dependencies within the network}

Dependencies at the work level occurred due to the limited airport resources and infrastructure, physical contraints, or the sequencing of various tasks. For example, 


\subsection{STUdy ONE}

depending on the location of the aircraft's baggage access point, fueling and baggage handling may not be able to take place simultaneously due to limited space around the aircraft and the size of the tankers. Also, multiple ground-handling firms share airport resources and infrastructure such as staircases and de-icing equipment, which can be a scarce resource especially at peak hours. This scarcity of resources and dependencies at the work level needs to be carefully managed.

Airline Operators The following quotes illustrate how the participant's work is impacted by the structure of the dependency network in which they operate:

"We depend a lot on airport resources which are sometimes scarce and how ready they are to be utilized to be utilized by our team."

(Airline operator)

"Situations have been happening, and then sometimes the airport resources are not enough to support what traffic they have accepted as slotted aircraft for the airport"

(Airport operator)

"We are very dependent that the apron tower is giving us these stands in good time, before landing aircraft for example. Then we need to know when they land, where they are supposed to taxi. So then we have like a specific time limit, ten minutes before landing, the landing aircraft should be allocated for a stand"

(Airline operator)

From the above, linking this to the number of Critical incidents it is clear that reported, It is then concluded here that much of the dependency faced by the airline operator is with the ground handlers

Ground handlers Based on the quotes below, it is clear that the ground handlers are an integral part of the network with their own dependencies to deal within the network and across multiple flights.

"It's all dependent on the teamwork between the different groups involved..."

(Ground handler) 


\section{Results}

"When fueling is late, it affects baggage loading since we use the same space on the aircraft. This then increases the baggage time delays and then high turnaround times."

(Ground handler)

"we are very dependent that the Apron tower is giving us these stands in good time, before landing aircraft for example. Then we need to know when they land, where they are supposed to taxi. So then we have like a specific time limit, ten minutes before landing, the landing aircraft should be allocated for a stand, so we know we can plan ahead"

(Ground handler)

\section{ANSP (Air Navigational Service Provider)}

We are always in constant communication with Ground personnel, their information guides our work, it's all about trust.

$(\mathrm{ANSP})$

"I would say everyone is as critical, because if they make a traffic delay, it's bad. If ground handlers don't give us the right information... And if the airport doesn't give us information - this gate is broken, you'll have to do remote parking with bus transport for 15 minutes more, that's not good for us we need information all the time"

$(\mathrm{ANSP})$

Dependencies at work level were also seen as the result of service breakdowns and critical incidents.

From a contractual point of view, a number of findings shows the dominating partner was the airport operator as it holds formal contracts with every other partner (Table A.1.2 on page 168 in Appendix A) in the collaboration matrix. The airport operator in return provides the infrastructure services and airport resources such gates; runways, parking services; rental services plus other services actors in the network may require executing their daily needs

It was also determined that the contractual relationship dominated the most of the collaborations. However, it's important to note that, not all actors have contracts to the other actors in the system, though they depend on each other during the turn-around as the nature of the service offered. For example, fueling companies do not have contracts with the airlines 


\subsection{STUDY ONE}

"There's a contract between the airport management and us, who could care of what time they have to be at the aircraft the latest and where they should pick up the passengers and everything like that is stated in the contract."

$(\mathrm{ANSP})$

Factors identified to generate complexity arising from work dependencies

- Existence Informal roles between actor's due nature of the work

- Existence of critical incidents and uncertainties

- Nonlinear interdependencies between work proc

Critical incidents within the network

Figure 5.1.2 shows that ground handlers experienced the most critical incidents during the turn-round process and due to the large number of formal and informal dependencies with this service, any disruption here can have a major effect on the entire network.

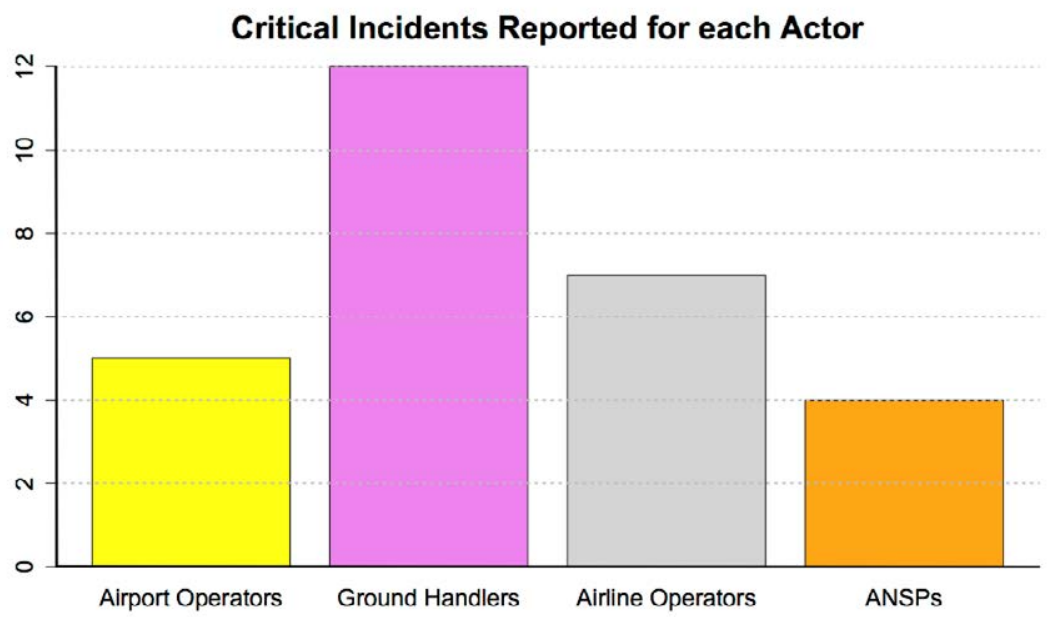

Figure 5.1.2.: Number of critical incidents reported for each actor. (see table A.1.2) 


\section{Results}

Factors identified to contribute to complexity from the work contracts

- Non uniformity of contracts because of different levels of collaborations between actors

- Existence Informal roles between actors

- Existence of critical incidents and uncertainties (external and internal)

- Market completion to win contracts.

\subsubsection{Implications for Performance Measurement and Management}

The goals of this study were to 1) identify the factors that contribute to complexity in the airport turn-around process and 2) understand the implications of this complexity on Performance Measurement and Management. The study was able to extend the descriptions of the turn-around process and explore through new conceptualisations of contractual relationships and work dependencies as main dimensions that affect service deliveries beyond organisational borders. To this end, we have tackled the role of interdependencies as suggested by previous researchers (Hansen and Rasmussen, 2013; Pinho et al., 2014) and contracts (Furlotti, 2007; Möhring and Finch, 2015) which continue to take significant attention in services.

\subsection{Study two-Implementation of COllaborative MEASURES}

\subsubsection{Introduction to study three}

Study two was a longitudinal study which reported on an industrial change case that was about implementation of A-CDM at an airport. The study applied an action-based methodology at a European airport. The main objective was to evaluate what is needed for a collaborative implementation of PMS in an airport. The study provided a test bed for the development of a framework in understanding the notion of organizational capacity to manage change with many actors. A structured inquiry was used with the following dimensions: Operational process, management process, social relations, information and knowledge. These dimensions 
are part of a system logic methodology called the System Change and Operations Evaluation (SCOPE) which provides an analysis of system performance and at different independent levels (McDonald, 2015). The key objective of this study was to report on one of the industrial-based change case studies of the MASCA project (MAnaging System Change in Aviation - EU FP7, 2010-2013). This case study provides a systematic insight into one airport's approach to their preparation for full implementation of Airport Collaborative Decision Making (A-CDM). An action-based methodological approach was applied over a three-year period, and a particular focus of this study is on the application of the MASCA system change and operational evaluation tool (SCOPE / Structured Enquiry). Key recommendations resulted in research-led interventions, such as the development of a Serious Game to facilitate co-ordination and communications. The study also reports on future recommendations for the implementation of A-CDM, such as prioritizing social relations and trust building amongst airport stakeholders as opposed to viewing A-CDM solely as an IT-led project. Recommendations and learning from this case study can also be disseminated to other airports who are about to embark on the preparation for full A-CDM implementation and compliance.

Part 2: Application of the structured enquiry to consolidate the overall evaluation

A question bank was created containing questions on each of the main content Part 2: Application of the structured enquiry to consolidate the overall evaluation process, social relations-team, social relations -trust, information, and knowledge cycles). This question bank was used to structure interviews to ensure that the interview schedules covered each of the key areas. Bespoke interview schedules were created for each stakeholder group using both questions from the bank and novel questions drawn up to address the focus of the final round of interviews (i.e. Preparing for the training session and final evaluation). A total of seven representatives from the following stakeholders took part in the final set of interviews: air traffic control; airport authority; airlines and ground handling companies. Each interview was conducted by at least two researchers, who took independent notes on each interview and then came together to provide an agreed synthesis of the key issues across each of the key elements. This final synthesis not only relied on 


\section{Results}

the final set of interviews but from the insights and findings from the range of methodologies employed throughout the three years.

This section provides a summary of the most pertinent outcomes of the evaluation. As already mentioned this was based on the SCOPE framework that provided a Structured Enquiry which interrogated the operational systems according to the following areas: Operational Process, Management Process, Social Relations-Team, Social Relations -Trust, Information and Knowledge. These findings have been structured under these same areas.

Operational Process Major Ground Handling partners were very much aware of the criticality of their role in the overall success of the A-CDM project. While they are very positive that A-CDM will work in the long run, they did raise some concerns about the short term goals. Their main concerns relate to the uncertainty of how A-CDM will be operationalised, the availability of tools, co-ordinator workload and de-icing. ATC were highly positive about the prospect of A-CDM and felt that it will be a success at this airport. However, they perceived A-CDM to be an IT project that had been brought to the operational space. This perception becomes obvious since automation is key in ATC operations and implementing and integrating A-CDM in ATC environment is more or less dependent on IT solutions. Airline partners are largely positive and can see the obvious benefits and savings that they will make under A-CDM. One concern they did raise was how A-CDM would affect their on-time performance statistics. The airport operator's main concerns rested with getting the stakeholders talking to one another.

The overall attitude towards the A-CDM project and how it has been managed is positive and the critical issue of ongoing communication between key stakeholders will be kept on the agenda. The airport administration has arranged for local airport regulations to be updated in support of Air Traffic Control (ATC) (which will give ATC the mandate they need to request that aircraft stay in their stands until released) and will mitigate any legal implications. The on-time performance focus of airlines will not now be as gravely impacted by A-CDM related delays. EUROCONTROL delay codes will be introduced for A-CDM. These delay codes will be excluded from overall punctuality statistics.

Impact: Considerable progress has been made over the past three years and 
plans are in place to reach compliance in 2014. However in order to achieve this compliance additional work will be required, (e.g., training) to fully prepare all operational staff and consider the introduction of key tools/methods necessary to facilitate all levels of communication.

Management Process A-CDM has been an airport lead project. In support of this a steering group and a dedicated project management team has been established comprising all major stakeholders. The project team's main task has been to get all stakeholders to 'act as family' during the Turn-Around processes. Constructive progress has been achieved within the A-CDM project group in the last six months. They have hosted discussion on numerous matters concerning the impact of A-CDM on current and future working practices. During the interviews, it became apparent that senior members within actor groups were discussing potential problems key information on the A-CDM project not being communicated within all stakeholder organisations. This issue has been brought up to the steering group at several occasions and mitigating measures have been imposed by the stakeholders. Other stakeholders from the project group have expressed difficulty with feedback filtering back to their individual organisations. They would like to engage more management support and involvement to assist in getting the concept of A-CDM and how it will affect working practices back to stakeholders at all levels.

All stakeholder groups highlighted a necessary role for dedicated and collective A-CDM leadership. The issue of leadership is quite a complicated one for this type of change management initiative. There is no actual way to actively enforce the use of A-CDM on any of the stakeholder organisations (Directive 96/97/EC). However, having internal "leaders" within each actor organisation could impose some structure and guidance upon operations and how they should be handled. The leaders within each organisation could then liaise with one another on wider collaborative issues.

Impact: A-CDM leaders for each actor need to be appointed at an early state of the project to avoid delays in implementation. 


\section{Results}

Social Relations Team The A-CDM project group has provided the key coordination mechanism between the airport partners. While all partners participate in the planning for $\mathrm{A}-\mathrm{CDM}$, they did not always send the most relevant people to the meeting which has caused a level of frustration between key stakeholders. Many of those stakeholders involved in the Turn-Around process are also competing entities such as airlines and ground handling companies. The effectiveness of the Turn-Around process is a matter for the ground handlers and the airlines. As mentioned before the role of the airport is to provide necessary infrastructure for the handlers to use. The main challenge for the airport administration in trying to implement A-CDM is getting different competing stakeholders 'to work as family' during the turnaround process.

An imbalance in the extra amount of work they will have to do under A-CDM and an imbalance in rewards for different stakeholders were noted. The airlines are still seen as the big winner under A-CDM and as such they should take a more active role in implementing A-CDM. This puts additional strain on people working together when their advantage in being involved is not perceived as great as others'. The A-CDM project group as well as the steering group, has an indepth knowledge of A-CDM and how this impacts stakeholder roles. Stakeholder's in lower senior grades demonstrated that they do not have a full understanding of one another's roles. The understanding of roles is especially important in raising awareness of the importance of ongoing communication between the key agencies at the ground level.

Impact: Collaboration between stakeholders s must be supported by management and the wider A-CDM project if significant improvement in the turnaround process is to be realised.

Social Relations - Trust The key stakeholders in the turnaround process are in a competitive commercial relationship. However there was a fundamental level of trust between partners and that "trust" was not an issue in the success of A-CDM at the airport. The only concern with trust highlighted was in relation to trust in the "system" and trust in A-CDM rather than a lack of trust between the different stakeholders. An inequity in the perceived benefits of A-CDM was also seen to contribute to this sense of imbalance between stakeholders. 
A theme that has featured in interviews, workshops and in most sections of this case-study so far is a lack of specific objectives and goals. Even though these have been communicated, they may not have been sufficiently shared or understood to foster trust. The objectives should apply globally to A-CDM and locally to each individual stakeholder roles within the organisation. The benefits of being involved in A-CDM should also be outlined at that level too. Agreed ways of working and clearer procedures for A-CDM could foster greater trust in CDM as a "system. There is no history of mistrust; however, there is a reluctance to share some information due to commercial sensitivity. Levels of disagreement about perceived benefits from being involved in A-CDM may also stem from each stakeholder having their own targets and priorities.

Impact: Fundamental trust exists between stakeholders, but greater trust in the A-CDM system would ensure more open engagement from partner groups on all levels.

Information Information sharing is the first and most essential element of A$\mathrm{CDM}$ as it creates a foundation by fostering a common situational awareness and a common operational picture between stakeholders. It also brings predictability and resource efficiency benefits. While there has been good progress in developing supporting IT system the next step is ensuring that each of the stakeholders will share their internal information and knowledge. For the project to be a success the information must flow freely between the right people at the right time. Although the airport as a matter of credibility ensures protection of sensitive business information there is an issue surrounding which data and information will be shared amongst competitive organisations. If too much sensitive information is shared, this could affect contracts with current and future partners. If not enough information is shared, how will stakeholders be able to improve on their performance?

Due to the nature of ground handling companies subcontracting other companies to perform specialised duties, stakeholders also highlighted the lack of information available on other job roles in the turnaround process. They stressed that they may be aware of the consequences of what they do or do not do in their daily job and the impact that this may have on the turnaround process. However they do not know how this fits into other roles in the turnaround process. 


\section{Results}

The Airport administrator understands that communication efficiency must be improved by means of various information/communication channels such as webbased solutions, App, Gate index systems etc. This is a partial solution to the communication difficulties. MASCA held a training workshop on communication and collaboration. It is hoped that this made an impact on those whom attended and that further such training is introduced as a matter of urgency in the interim. Trainees stressed that it was important to carry out process mapping tasks from the workshop with people from all organisations. They also requested further access to the Serious Game from MASCA workshops. The issue of how performance data will be validated and fed back to all stakeholders is a crucial one. It not only serves as a motivator for collaboration and a dissuader for non-collaboration, but also as a measure of equity and transparency. The airport administrator stated that only information pertaining to the A-CDM process will be made available to stakeholders so that more sensitive data will be reserved.

Impact: A lack of timely information could result in blockers to an affective turnaround process.

Knowledge The initial training given by the airport administrator involved 150 staff members across the airport with the objective of ensuring that there was an understanding of the concept of A-CDM. This training is planned to roll out across all key actor functions. One of the outputs of the MASCA intervention, following a workshop dedicated to change management was also a decision to develop and roll out specific training targeted at key roles (e.g. dispatchers). Global understanding of the A-CDM concept is required and shared understanding and values are important for the success of A-CDM. This can be achieved through an appropriate training programme and management planning of how this information will be filtered down from senior management and throughout the organisation. Building a common operational picture and creating shared understanding has been focussed mainly on the IT systems. However, A-CDM will not realise its full potential unless a greater focus is given to the non-technical skills. This has been the focus for the Project team as well as for the steering group as previous experience has shown that non-technical skills are vital for the success of the project. 
It is not clear that there is a common operational understanding amongst those playing a key co-ordination role in A-CDM. Having their shared collective understanding of their role in the wider A-CDM picture is vital. The A-CDM project group agreed that all relevant airport personnel will get basic training in the principles of A-CDM and familiarisation training with the new software system. The MASCA serious games intervention has been successful in the workshop environment in widening knowledge of other roles and operations within the Turn-Around process. A call for this to be extended within stakeholder operations was made on several occasions.

Impact: Less than a full understanding of the A-CMD process will prevent improved Turn-Around times, as those involved in the Turn-Around process will not know or understand what is expected of them.

This airport is aiming for full compliance in 2014 and overall very solid foundations have been laid in order to address some of the challenges raised. There is confidence from the project team that this full compliance will be reached in 2014 . Table 5.2.1 below provides a summary of some of the recommendations that were highlighted following the evaluation.

Table 5.2.1.: Summary Recommendations as per the Structured Enquiry Elements

\begin{tabular}{ll}
$\begin{array}{l}\text { Structured } \\
\text { enquiry } \\
\text { element }\end{array}$ & Recommendations \\
\hline Operational & \\
process & $\begin{array}{l}\text { 1. Focus more attention on key staff and identify the support required } \\
\text { talking. Deploy a Serious Game as part of the overall learning pro- } \\
\end{array}$ \\
& $\begin{array}{l}\text { cess to encourage more active participation and buy-in } \\
\text { running for feedback on operational performance }\end{array}$ \\
&
\end{tabular}


Table 5.2.1.: (continued)

Structured
enquiry Recommendations
element

Management 1 . Foster relations between management of different stakeholder groups process so that they deal with potential problems directly and only escalate if there is serious incompatibility

2. Identify key challenges that need to be overcome in order to involve those stakeholder that are seen as less "invested" and more neutral in the A-CDM process

Social rela- 1. Solve communication support issues - the impact of collaboration tions (team) problems will be minimised if communication support is provided. Additional training focusing specifically on improving communication

2. Prioritise the visiting of other stakeholder's operational space on a regular basis make this a fundamental tool for ensuring a common operational picture between actors

Social rela- 1. Make stakeholders aware of the negative aspects of A-CDM (e.g. tions (trust) substantially increased workload for ground handling and ATC)

2. Focus on fostering trust in the system-designated A-CDM coordinators' roles could involve re-iterating clarity on procedures

Information 1. Provide standard interface for communication tools - all stakeholders need tools to communicate. They must be able to view the information that they need to be able to do their job at a glance

2. Involve third party IT experts in helping to develop new software and to develop guidelines for software development at this airport

3. Increase availability to more test data and information on turnaround statistics from CDM implementation so that stakeholders can improve their performance, e.g. updated taxi times, on-time statistics 
Table 5.2.1.: (continued)

\begin{tabular}{|c|c|}
\hline $\begin{array}{l}\text { Structured } \\
\text { enquiry } \\
\text { element }\end{array}$ & Recommendations \\
\hline Knowledge & $\begin{array}{l}\text { 1. Develop a competency profile of what new skills and competencies } \\
\text { are required for every job role and for every group within organisa- } \\
\text { tions under A-CDM } \\
\text { 2. Use the competency profile to update procedures for A-CDM oper- } \\
\text { ations } \\
\text { 3. Outline a feedback mechanism for actors to suggest ways of improv- } \\
\text { ing A-CDM after implementation-use their operational expertise } \\
\text { to improve A-CDM at this airport } \\
\text { 4. Set up a forum for "like-roles" such as dispatchers within different } \\
\text { ground-handling organisations to meet and gain a common oper- } \\
\text { ational understanding of their key role within the wider A-CDM } \\
\text { context }\end{array}$ \\
\hline
\end{tabular}

\section{Conclusions}

The implementation of A-CDM at the airport has been a case-study of some significance for at least three reasons:

1. It provided a comprehensive and systematic insight into one airport's approach to preparing the ground work for full implementation of A-CDM.

2. An action-based methodological approach was applied over a three year period that resulted in research-led interventions and future recommendations for the implementation of A-CDM.

3. Identification of key dimensions in the management of change and incorporation of these into the overall SCOPE framework. This allowed for a structured and systematic approach to an overall analysis and evaluation of the progress of the change initiative that was validated by the industry. 


\section{Results}

Assessing the Structured Enquiry This case-study adopted an action-based research approach in following and supporting the airport over a three year period. By taking an action-based research approach the research adopted the definition put forward by (Shani \& Pasmore, 1985) '. . . an emergent and ongoing inquiry process in which a scientific approach is integrated with existing organisational knowledge and applied to solve real organisational problems...' it is simultaneously concerned with bringing about change, developing and transferring competencies and capabilities back into the organisations responsible for implementing change and adding to scientific knowledge. The methodology adopted in this research has been an evolving process that has been undertaken in the spirit of collaboration and co-inquiry. It has involved a more qualitative approach to understanding the complexities of A-CDM including interviews with key stakeholders at various stages over the three years, workshops with key stakeholders in relation to developing the Serious Games, a training intervention and mentoring of key management staff all of which have been guided by the evolution of MASCA evaluation methodology, the Structured Enquiry.

This methodological approach provided an invaluable insight into the different stakeholder roles and their views and perceptions on A-CDM and what it would mean for their every-day working practices. The approach also allowed the researchers to establish an effective research-practitioner relationship that enabled mutual support and respect and also enabled the development and implementation of actual interventions to support the implementation of A-CDM (e.g., development of the Serious Game, training and ongoing mentoring).

The overall evaluation tool (Structured Enquiry) was found to have high face validity and strong user acceptance for its concepts and general approach. It generated a cogent analyses of the change initiative and raised a number of questions about the direction of the change initiative and potential and by in large this analysis has been entirely shared between the relevant industry and research partners. It generated a large number of recommendations for the next phase of the case-study, fully endorsed by the airport. Thus as a methodological approach it has achieved the first criterion of descriptive adequacy and relevance (Mc Donald, 2014). 
Recommendations for Airports preparing to implement A-CDM Those airports that have already implemented A-CDM have highlighted the benefits they have achieved. For example they have highlighted that the savings so far are reduced waiting times by 1.5-3 minutes per flight at the runway. They also claim improved situational awareness about aircraft status at outstations, improved predictability, improved operational efficiency and reduced delays. Furthermore reduced ground movements costs, mainly fuel costs are part of the benefits (Metoffice, 2012). However these airports have highlighted similar challenges to those encountered by this case-study and the very real challenge of implementing A-CDM need to be fully understood and disseminated.

In summary some of the key challenges included:

- The overall high level objectives of A-CDM requires more specific goals in order to highlight key operational performance benefits for all actors and ensuring actors are able to understand and to quantify the benefits of ACDM in order to drive them towards a more collaborative approach.

- Shift away from A-CDM being an IT project to one about real co-ordination and collaboration between stakeholders and in many ways is a "cultural change" in every day working practices. Working according to the concept of A-CDM requires a totally new way of thinking and as such takes long time to implement.

- A-CDM awareness not sufficient among all airport partners. This includes not only the four key stakeholders as identified by ECTL but all stakeholders, including for example cleaners, fuel and catering companies etc.

- The overall attitude towards the A-CDM project and how it has been managed is positive but the critical issues of information flow, co-ordination and communication issues will need to be continually prioritised in order to ensure the successful implementation of A-CDM.

- The issue of leadership is quite a complicated one for this type of change management initiative (especially in those airports who do not have a hub monopoly). There is no actual way to actively enforce the use of A-CDM on any of the stakeholder organisations (ref. Directive 96/97/EC). 


\section{Results}

- Stakeholders are reluctant to release more sensitive data/information. There is a lack of timely information and poor quality or insufficient data.

- Insufficient System Integration.

These recommendations are in-keeping with those made in (Salmon et al, 2009), research on multi-agency co-ordination. The MASCA study also put forward a number of specific recommendations for the effective implementation of A-CDM.

The following provides a consolidated overview of the key recommendations that were accepted by the stakeholders at the airport in this case study.

- Appoint a dedicated A-CDM coordinator in all stakeholder organisations (airport, ground handling, airline, ATC, fuel, cleaning, catering etc.) that can attend all project meetings.

- Each coordinator develops a communication strategy for their respective organisations. Create a project team to develop an overall airport-wide communication strategy.

- Create a sense of collective leadership across all actors to ensure a win-win attitude for all actors

- Clearly define and agree objectives and key performance indicators at global and individual stakeholder organisations

- Prioritise the visiting of other stakeholders' operational space on a regular basis. Make this a fundamental tool for ensuring common operational picture between stakeholders. This may be developed into a regular programme of cross-training.

- Encourage the use of the MASCA 'process mapping' exercise to enable key clusters of actors to agree on a common operational picture, current blockers to implementing A-CDM and an agreed strategy and plan to deal with those blockers.

- Develop an agreed strategy for rewarding collaborative behaviour and discouraging non-collaborative behaviour. 
- Develop a dedicated training programme to deal with the softer issues of communication and collaboration.

- Address the issue of what communication support and methods are required to support the turn-around process operations.

The Serious Game (SKYBOARD) was one of the more innovative outputs of the research and provided a very effective medium for highlighting and addressing issues to do with collaboration. Inevitably there was a considerable focus on ensuring adherence to good principles of gamification during the development of the game. However as the game was deployed this created the opportunity to link the game into a wider training and learning program supporting the enhancement of communication and collaboration among multi-agency actors .

\subsubsection{Overall Conclusion}

The origin of this change program predates the MASCA project and will continue beyond the end of the project. However this case-study was a test bed for the development of a framework for understanding the notion of organisation's capacity to manage change and the development of a methodology to evaluate the progress of change. This overall approach is part of a long-term strategy to develop a more powerful model of change evaluation by progressively testing predictions against actual outcomes of change initiatives. Research studies similar to this need to be carried out at the other airports aiming for full compliance and to ensure full compliance in a timely manner. It is imperative that future research adopts methodologies that are capable of understanding the complexities of such change and to direct interventions to ensure the capability to manage the emergent features of the A-CDM change process so as to increase the probability of success.

It will be very interesting to monitor the progress of the remaining airports aiming for full A-CDM implementation and compliance. In a joint press statement released in November 2013 by ACI Europe and EUROCONTROL they referred to A-CDM as "a tool that allows for real time sharing of operational data and information between the actors using an airport, thus creating 'common situational awareness.' This in turn improves interaction between airport operators, air traffic 


\section{Results}

control and airlines on the ground, allowing for a more optimised use of scarce airport capacity."

However the recommendations from this study would highlight that the focus on implementing A-CDM needs to move away from it being seen primarily as an IT/tool-driven project. One of the interviewees who took part in this study summed it up as "A-CDM is 10\% technology and 90\% people, process and culture."

It is fundamental to consider the fact that A-CDM is a concept to facilitate enhanced collaboration between multi-agency stakeholders to ensure more timely decision making. Therefore the focus can not only be on the tools and software integration but more importantly on the issues of social relations and cohesion (particularly for multi-agency actors ), the right level of information and knowledge processes and systems (that will engage people and make future systems work) and the capability of the new process (both operational and management) to deliver the key strategic performance targets of A-CDM at the local airport levels and to the wider European Air-Space.

\subsection{Study three-Exploring the Management of Collaborative Measures}

\subsubsection{Introduction to study four}

The purpose of this study is to explore turnaround performance as a resultant from both Collaborative Decision Making (CDM) processes and collaborative measures from different actors. This study presents how CDM operates in the Turnaround Process(TAP) to propose a new method for managing the collaborative turnaround performance of all actors by predicting the most critical indicators. To achieve this, data from a CDM airport is used. Sample data of 6500 observations, taken from turnaround movements handled in 2014 at Madrid-Barajas Airport, were obtained from three separate databases and analysed separately (in three databases). To predict turnaround performance, this study also introduces a predictor dependent variable called "star values" " as a measure of delay conditions in order to predict

\footnotetext{
${ }^{1}$ This term is introduced in this study to represent delay conditions, which are the dependent variables used in the calculations in Section 3.
} 


\subsection{StUdy THREE}

time performance. The analysis shows that the proposed method unveils a new approach in determining how collaborative performance can be measured in the TAP and the predicted key performance indicators, which shows variations in the predicted CDM indicators. Results challenge managers and policymakers to find which improvements can be enacted for better usage of airport infrastructures and resources for optimum use as well as enhanced TAP. In terms of theory use and extension, the study reveals how CDM is an essential element in the literature on air traffic management.

Using collaborative measures as a feedback mechanism for all airport actors (Van Bakel et al., 2015) enables the alignment of the output from different CDM users as well as their push to change the behaviour for their input. Moreover, by being able to measure turnaround performance within the CDM framework, this will contribute to the future functioning and continued improvement of ACDM (Eurocontrol, 2015b). In addition, turnaround performance is important because when showing how CDM indicators are critical, the system will be comprehensive of all operations. Ultimately, understanding the measures from local turnaround performance contributes to the airport performance benchmarking system-wide (Oum and $\mathrm{Yu}, 2004$; Lupo, 2015). Overall, understanding the implications of these measures would maintain the credibility of CDM at airports and long-term visions of using the CDM framework.

As such, this study argues that despite many studies on CDM functioning, there has not been enough research to explore how turnaround performance measures can be managed and aligned between CDM users and their collaborative output. We propose a new method that determines collaborative turnaround performance, in a way that enables tracked measures to be used as a performance management system. The study does so by answering the following research question: How is TAP performance within CDM managed through collaborative measures? To answer this question, it is important to understand how CDM operates and what operational benefits it brings to the turnaround (see Appendix).

The research adapted insights from Performance Measurement Management (PMM) literature that show how integrated PMM with many actors can be achieved. It also adapted the use of the Classification and Regression Tree (CART) method, using the QUEST algorithm. A classification tree is a non-parametric 


\section{Results}

statistical method that, by using a predictor variable (star values in this case), can classify recursive partitioning to analyze and predict objects. The proposed framework consists of several stages: data mining, data processing, and data analysis and result validation. The results show that this method identifies turnaround performance by predicting the most critical KPIs that affect CDM operations, which then are linked back to the airport actors to manage delay reductions in the turnaround and, hence, both strategically and operationally drive collaborative performance.

\subsubsection{Analysis of Results}

The study explored how TAP performance within CDM is managed through collaborative measures. In examining it, the analysis covered several steps, starting with data mining, data processing, and analysis. This section presents the steps taken to reach the results.

\section{Data reduction}

In analysing the correlation matrix between variables, high correlations were observed, thus indicating redundancy in the data. In this case, a multivariate analysis was performed in all sets to reduce the number of independent variables. By applying principal component analysis as an extraction method and varimax with Kaiser Normalization as a rotation method, four sets of variables in the group of independent variables were produced, as shown in Table 5.3.1, and arranged according to how significant each variable was. This is also considered a suitable technique because it is a synthesis technique for reduction of variables by maintaining as much information possible for each observation. Just a few components account for much of the total variability. Thus, the table 5.3.1 on the next page shows the four components obtained in the data reduction process.

\section{Technical analysis and post data reduction}

After reducing the independent variables, a classification tree technique was then performed with the QUEST algorithm; this resulted in three classification charts 
Table 5.3.1.: Set of components extracted from independent variables

\begin{tabular}{ll}
\hline Component & Set of KPIs \\
\hline \multicolumn{3}{c}{ Selection of components in Database 1} \\
Component 1 & ASRT_TSAT, ASAT_TSAT, ASAT_ASRT), \\
Component 2 & AOBT_TOBT, ASRT_TOBT, TSAT_TOBT), \\
Component 3 & TOBT_SOBT, AOBT_SOBT \\
Component 4 & AOBT-ASAT \\
\hline \multicolumn{2}{c}{ Selection of components in Database 2} \\
Component 1 & ASRT-TSAT, ASAT-TSAT, TSAT-TOBT) \\
Component 2 & TOBT-SOBT, AOBT-SOBT \\
Component 3 & AOBT_TOBT, ASRT-TOBT, ASAT-ASRT \\
Component 4 & AOBT-ASAT, AXOT_EXOT \\
\hline Selection of components in Database 3 \\
Component 1 & AOBT-TOBT, ASRT-TOBT, TOBT-SOBT \\
Component 2 & ASRT-TSAT, ASAT_TSAT, ASAT_ASRT \\
Component 3 & AOBT-ASAT, AXOT-EXOT \\
Component 4 & AOBT-SOBT \\
\hline
\end{tabular}

where all independent variables were examined on how they are affected by the dependent variables. In order to predict which of the CDM KPIs are those that can be considered more important, a closer analysis on nodes of the tree were studied, as any change in them can significantly impact the value of the dependent variable.

From the initial split at Node 0, the dependent variable is branched into two nodes ( 1 and 2 ) belonging to Component 2. This shows that these indicators from CDM turnaround performance are the most important for this sample. Secondly, by observing the values of the dependent variable on Nodes 1 and 2, the category of the dependent variable, shaded gray, is then predicted; in this case Node 1 predicts values in the category value OT $=56.6 \%$, while Node 2 predicts the values corresponding to the category $\mathrm{OT}=87 \%$, after which each of the two nodes branch off, thereby giving rise to new nodes.

From Node 1, we see that the next split branches at Nodes 3 and 4, whose most influential variables belong to Component 3 (TOBT_SOBT, AOBT_SOBT). This means that this set of variables will be the second most important within the group of independent variables studied. It also shows that Node 3 emphasizes 


\section{Results}

the category of the dependent variable $\mathrm{T}$, which is the objective role of the CDM system and assigns a prognostic value of $74.3 \%$ to the category $\mathrm{T}$, as well as assigns $25.7 \%$ to the category OT. On the other hand, with Node 4 the same category emphasizes OT with $94.7 \%$ and only $5.3 \%$ assigned in category $\mathrm{T}$, causing this node not to branch any further.

Node 2 branches at Nodes 5 and 6, having an influencing variable as Component 2, which shows that Component 2 is a very important variable in measuring turnaround performance. It is then observed that Node 5 emphasizes the category of the dependent variable OT, assigned a prognostic value of $63.3 \%$, and category $\mathrm{T}$ that is assigned $36.7 \%$. As for Node 6 , the same category emphasizes OT with $94.8 \%$, and only $5.2 \%$ is assigned to category $\mathrm{T}$.

To further analyze the classification tree, take Node 3 together with Nodes 5 and 6 . We see a final split, which branches into Nodes 7 and 8 with an influence on Component 3 (TOBT_SOBT, AOBT_SOBT). This means that these are a set of variables that influences this new prediction. However, Node 9 is subdivided as having influence over variable Component 3, and is split into Nodes 13 and 14, where it is observed that at Node 13, the largest predicted value of category $\mathrm{T}$ obtained is $85.7 \%$.

In summary, from the analysis of the first database, the set of indicators that best predict the behavior of the CDM system are Component 2 (AOBT_TOBT, ASRT_TOBT, TSAT_TOBT) as most important, and Component 3 (TOBT_SOBT, AOBT_$S O B T$ ) as second most important.

For the second database, starting at Node 0, it is noted that the dependent variable is branched into two nodes ( 1 and 2 ) that belong to Component 2 (TOBT_SOBT, AOBT_SOBT). This shows that these are the most important CDM indicators. In other words, Component 2 is the indicator or set of indicators that best determine, predict or measure whether the collective processes in the turnaround are on time from all actors.

To continue monitoring Node 1, we see that it branches at Nodes 3 and 4, whose most influential variable is Component 3 (AOBT_TOBT, ASRT_TOBT, ASAT_ASR T), which means that this set of indicators will be the second most important within the group of independent variables studied. It also shows that Node 3 emphasizes the category of the dependent variable OT, and is assigned a value of 


\subsection{StUdy THREE}

$67.9 \%$ with $\mathrm{T}$ at $32.1 \%$. In the same category, Node 4 emphasizes OT with $89.7 \%$, but with very low observations compared to the initial 2167 observations that were considered from the beginning. Following the analysis of the resulting tree, it can be seen that Node 3 continues subdividing into Nodes 5 and 6 , with the variable corresponding to Component 3 (AOBT_TOBT, ASRT_TOBT, ASAT_ASRT).

In summary, the set of indicators that best predict the behavior of a CDM system along with the delay conditions of star values, are those matching Component 2 , followed by those in Component 3 .

From the third calculation which corresponds to the third database. Starting at Node 0 , the dependent variable branches into two nodes (1 and 2) belonging to Component 4 (AOBT_SOBT), showing that this is the most important set of CDM indicators, and that Component 4 is the indicator that best determines, predicts or measures whether the processes of the airport's turnaround for this particular sample are on time or delayed. By observing the values of the dependent variable at Nodes 1 and 2, Node 1, in this case, predicts values in the category value OT as Node 2 .

To continue monitoring Node 1, we see that other branches at Nodes 3 and 4 whose most influential variable is Component 4 (AOBT_SOBT). This means that this variable will be the second most important in the group of independent variables studied. It also shows that Node 3 emphasizes the category of the dependent variable OT, and is assigned a prognostic value of $88.3 \%$ to category T. Regarding the calculation at Node 4, the same emphasis in the category $\mathrm{T}$ with $63.1 \%$ resulting classification. Additionally, it can be seen that Node 4 branches off into Nodes 5 and 6, with Component 2 (ASRT_TSAT, ASAT_TSAT, ASAT_ASRT).

In summary, the set of CDM indicators that best predict the behavior of the star value are those matching Component 4; of second importance are those that correspond to Component 4, and reassigned to third place was the set of indicators corresponding to Component 2.

\section{Validity of Calculation and Results}

In analysing the validity of our results, we first determined the estimated risk of calculation, and then the classification table. We found that the results were 


\section{Results}

Table 5.3.2.: Predicted CDM indicators from turnaround

\begin{tabular}{ll}
\hline Data set & Predicted indicators as most critical \\
\hline Database One & AOBT_TOBT, ASRT_TOBT, TSAT_TOBT \\
Database Two & TOBT_SOBT, AOBT_SOBT \\
Database Three & AOBT_SOBT \\
\hline
\end{tabular}

consistent with the estimated risks. The risk estimates show the proportion of the data that is not predicted by the tree. For example, Table 5.3.3 shows less risk from all three databases that were utilized in the calculation. This risk is represented in percentage of the data.

Table 5.3.3.: Risk Tables

\begin{tabular}{|c|c|c|c|c|c|c|}
\hline \multirow[b]{2}{*}{ METHOD } & \multicolumn{2}{|c|}{$\begin{array}{c}\text { Risk table } \\
\text { Database } 1\end{array}$} & \multicolumn{2}{|c|}{ Database 2} & \multicolumn{2}{|c|}{ Database 3} \\
\hline & Estimate & $\begin{array}{l}\text { Std. } \\
\text { Error }\end{array}$ & Estimate & $\begin{array}{l}\text { Std. } \\
\text { Error }\end{array}$ & Estimate & $\begin{array}{l}\text { Std. } \\
\text { Error }\end{array}$ \\
\hline Resubstitution (\%) & 0.098 & 0.008 & 1.080 & 0.007 & 0.124 & 0.007 \\
\hline
\end{tabular}

Table 5.3.4 shows how much the quantity of prediction in the classification the algorithm correctly classified in all the cases. Comparing from Table 4.1.4 on page 78 , the number of observations in all the three databases, QUEST algorithm was able to classify to the highest. From our results, it can be seen in Table 5.3.4 that the overall percentage of declared capacity was $90.2 \%$, and the risk was low at $9.8 \%$ in Database 1, which is considered sufficient for this type of technique. The classification was high, with less risk in the rest of the databases as well.

\subsubsection{Discussion of Results}

The purpose of this study was to explore Turn Around Performance (TAP) as a result of both CDM processes and collaborative measures from different actors. The results are discussed by the need for a cross-organizational strategy and central authority. The study has argued that since CDM operates with many stakeholders and is highly integrated, broad, and complex, there is still lack of 
Table 5.3.4.: Classification Table

\begin{tabular}{|c|c|c|c|c|c|c|c|c|c|}
\hline \multirow[b]{3}{*}{ Observed } & \multicolumn{9}{|c|}{ PREDICTED } \\
\hline & \multicolumn{3}{|c|}{ Database 1} & \multicolumn{3}{|c|}{ Database 2} & \multicolumn{3}{|c|}{ Database 3} \\
\hline & $\mathrm{T}$ & $\mathrm{OT}$ & $\begin{array}{c}\% \\
\text { correct }\end{array}$ & $\mathrm{T}$ & $\mathrm{OT}$ & $\begin{array}{c}\% \\
\text { correct }\end{array}$ & $\mathrm{T}$ & $\mathrm{OT}$ & $\begin{array}{c}\% \\
\text { correct }\end{array}$ \\
\hline $\mathrm{T}$ & 302 & 94 & 76.3 & 229 & 146 & 61.1 & 248 & 167 & 59.8 \\
\hline $\mathrm{OT}$ & 53 & 1049 & 95.2 & 81 & 1641 & 95.3 & 104 & 1662 & 94.1 \\
\hline Overall \% & 23.7 & 76.3 & 90.2 & 14.8 & 85.2 & 89.2 & 16.1 & 83.9 & 87.6 \\
\hline
\end{tabular}

Growing Method: QUEST, Dependent Variable: Star value

feedback mechanisms to inform airport actors by using the performance indicators to push for improvements. As such, this study was able to propose a method on how collaborative measures can be applied for management. In order for airports to use measures for managing operations, there is a need for airports to consolidate collaborative measures not only from an ATM system to a PMS, but also to consolidate collaborative measures to collaborative strategies in the turnaround.

\section{Variation in Predicted Measures}

Initially, we know that with CDM, turnaround indicators have been regularly static. The easiest integrated performance indicator for airports has been on-time performance. Airport actors use delay code systems that only show the end results, but are not able to track the propagated (or reactionary) delay implications. With the advent of CDM, the results show that airport managers can track back through the milestone approach and enhance their operations with regard to the predicted indicators. The variations in the predicted indicators show that collaboration in the turnaround process has moved from static to dynamic because of different strengths in the operations as well as by different actors with different interests, who are also bonded. These results highlight an important feature for the quality of Target Off-Block Time (TOBT) ${ }^{2}$ (see Appendix). As part of the whole network, the stability of TOBT depends on how stable the collaborative measures predicted

\footnotetext{
${ }^{2}$ TOBT is an important value for all airport partners because it is used to predict the subsequent
} phases in the departure process and plan the pre-departure sequence. 


\section{Results}

are, and get used by management for bottleneck reduction. In brief, the selected or predicted indicators will reflect how stable TOBT will finally appear, which has a big impact with on-time performance. Moreover, the dynamic nature of the indicators conforms to the guidelines given in the CDM implementation manual to airports that state that actors involved in airport activities that correspond to such KPIs need continuous monitoring for improved delay reductions.

Given these results, several insights into CDM operations are obtained. With this feedback mechanism, CDM becomes an extendable, profitable, self-learning system, as well as having a prudent feature - ownership rights - as an implication. These CDM features are discussed in more detail below.

Extendable system The results show that turnaround performance can be both extended and enhanced. Based on our sample, the dependent variables used were set to minimal delay conditions. Moreover, the prediction of the measures shows that the CDM system is still an extendable system. The findings show that its extandable because through predicted measures, the airport can predict how much more movements it can handle with such delay or even adjusting the delays. Depending on the supply and demand on the runway and with the delay conditions provided, the current calculations show even more flights can be handled when all airport resources are fully optimized by using a feedback mechanism if the amount of collaboration, information sharing could be enhanced through continuous improvement. As such, the airport can be able to predict the maximum number of movements it can handle while maintaining minimal delay conditions in operations, which could also be adjusted accordingly.

Profitable system Since continuous improvement is the key factor to enhance the system, all actors will then benefit from the envisioned CDM benefits, as they will be able to derive tangible benefits from the feedback mechanism for continuous improvement. For example, airport actors will normalize how many additional slots can be sold and airlines will estimate how many additional rotations can be made with the same fleet. Ground handlers will normalize, using their resources adequately and service however many additional aircrafts they can with few resources, while air navigation services will handle more movements and increase 


\subsection{StUdy THREE}

runway throughput.

Self-learning system From the predicted indicators, the significance of examining the future performance of such a system is that the use of collaborative measures creates a self-learning platform. This is because the dynamic nature of the indicators will motivate actors for continuous improvement and, through continuous improvements, the system will gradually be transformed to meet new target times for future flights, and collaboration and information sharing will continue to be improved. This is an important aspect as more target time will be refined and, hence, the quality of on-time performance can be advanced to remedy bottlenecks and redundancy in the system.

Lack of ownership rights for collaborative measures Fig. 6 shows how collaborative CDM measures can be used as a feedback mechanism, as opposed to the previous system of using delay codes. With CDM airports and the predictions of our results, continuous improvement can be enacted with less ignorance concerning KPIs.

This study argues that CDM indicators are collaborative and include the behaviour of many actors; however, there is no feedback mechanism for how to use collaborative measures. Among all actors, important questions for management may arise: Who owns the rights to shared data, and who should be responsible for adjusting the system? Overall, we find that our results highlight the important managerial aspects in the turnaround process, like actors that use CDM requiring robust collaborative leadership that amplifies their activities beyond their individual organizational borders, as well as policy recommendations. These are also important for the system during continuous improvement tasks. Further, with regard to policy recommendations, this research shows how contracts between actors in collaboration can be adapted to CDM operational requirements.

\subsubsection{Conclusions and Implications for Future Research}

This study started by presenting that it is now an accepted fact that air traffic has increased to a level of capacity that airports cannot handle, and that CDM 


\section{Results}

at airports, if well implemented and managed, is meant to optimize and remedy capacity challenges and put a dent in environmental concerns. Moreover, this study draws on CDM operational principles and real operational data to explore the role of collaborative measures in managing the turnaround process at airports. The data included turnaround times, such as Scheduled Off-Block Time (SOBT), airport slots, touchdown times, taxi-in times, on-block times, off-block times, taxiout times, and Calculated Take-Off Time (CTOT), which is a process that includes all CDM operations before, during, and after turnaround.

Our method was able to capture the dynamic nature of CDM KPIs collectively as collaborative performance from all actors. The predicted measures then showed us how airports could use CDM measures to assess on-time performance as a result of their activities in the turnaround process. However, our method was able to predict measures that actors can use to align their strategies for CDM to benefit all parties involved. As such, the major conclusion that can be drawn from this study is that collaborative CDM measures can be used by management as a feedback mechanism to push for more enhanced decision-making and use of airport resources.

For future work, it would be worthwhile to include network benefits and performance within the framework of CDM, which can be achieved by including departure planning information as inbound and outbound indicators. In addition, this study used a predictor variable with a minimal tolerance of delay condition. Future study should enhance the delay conditions within, say, a window of \pm 5 -minute delays (i.e., -5 star values 5), in order to explore the process of predicting the indicators. Further, more studies are called for to propose other ways that airport actors can have a cross-organizational methodology to measure turnaround performance or how collaborative measures can be used as a feedback mechanism.

With more airports being classified as capacity-critical airports (Gelhausen et al., 2013), the demand for airports to increase their capacity throughput with scarce resources is enormous. CDM is one of the innovative standards through which the future ATM system plans to fully integrate airports into a collaborative network. If well implemented and well managed, the envisioned benefits, such as the enhancement of runway throughput, proper use of resources, less taxi times, and various environmental benefits, including those at the European level as tar- 
geted by Single European Sky ATM Research (SESAR, 2014), will be realized. Accordingly, this study has presented a new method for further understanding of airport TAP in relation to CDM operations. In a similar manner, this new framework provides an understanding that performance as a collaborative system can be analysed and later improved. It is through cross-organizational performance that discrepancies can be detected and linked to individual companies for optimal network benefits, that is, to better determine, predict, or measure the efficiency of the airport processes of all actors. 
5. Results

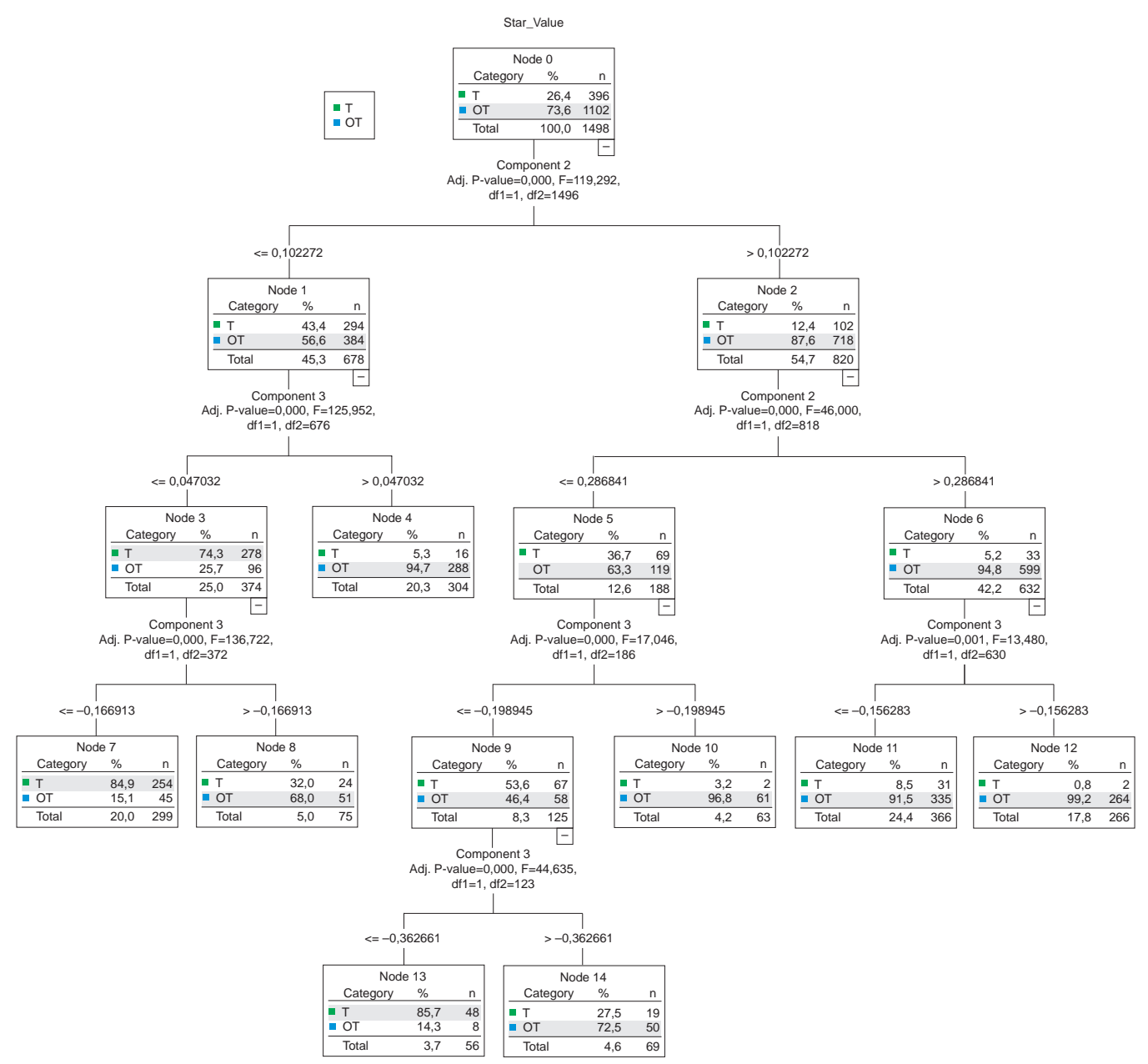

Figure 5.3.1.: Classification tree plot for Database 1 


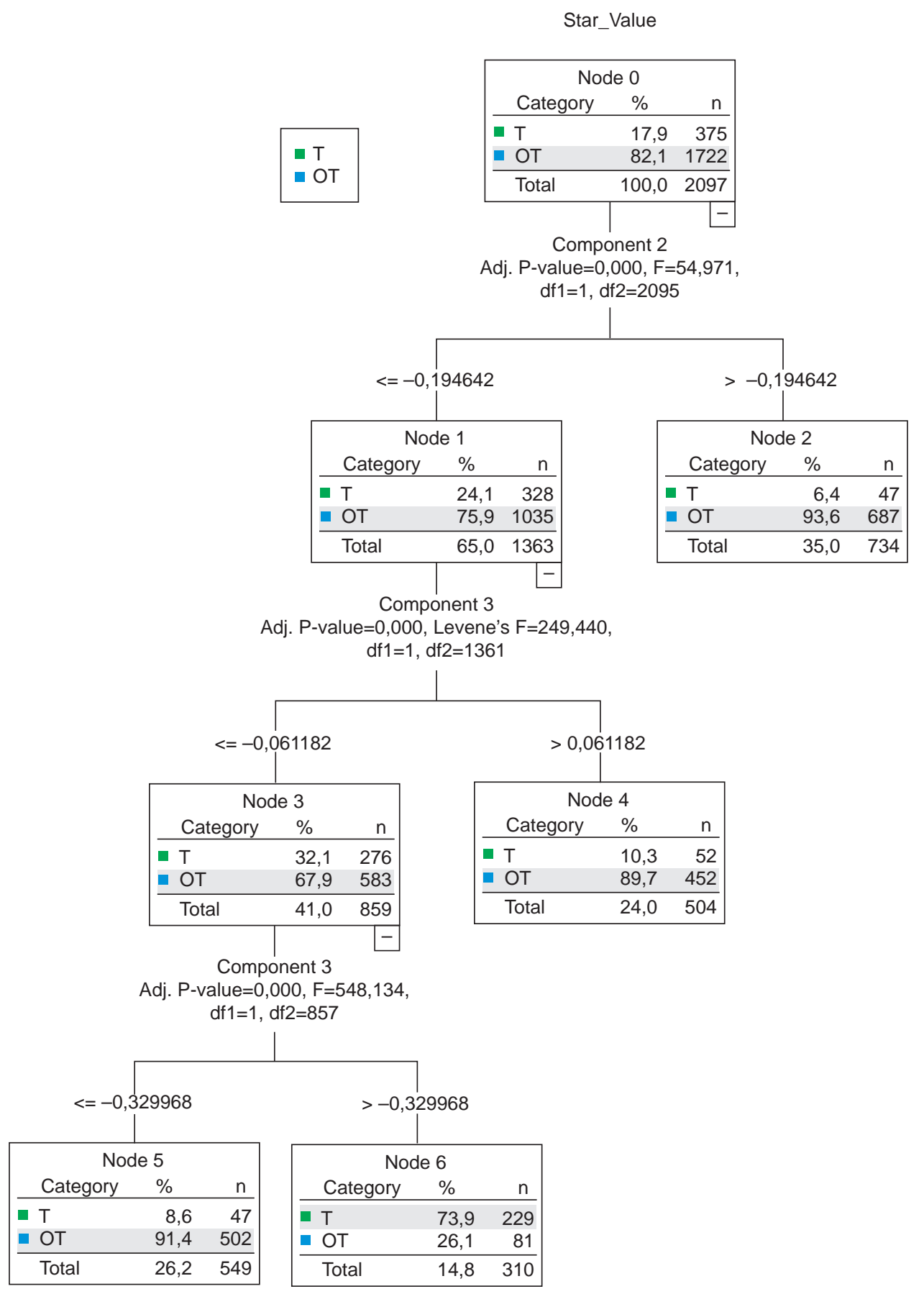

Figure 5.3.2.: Classification tree plot Database 2 


\section{Results}

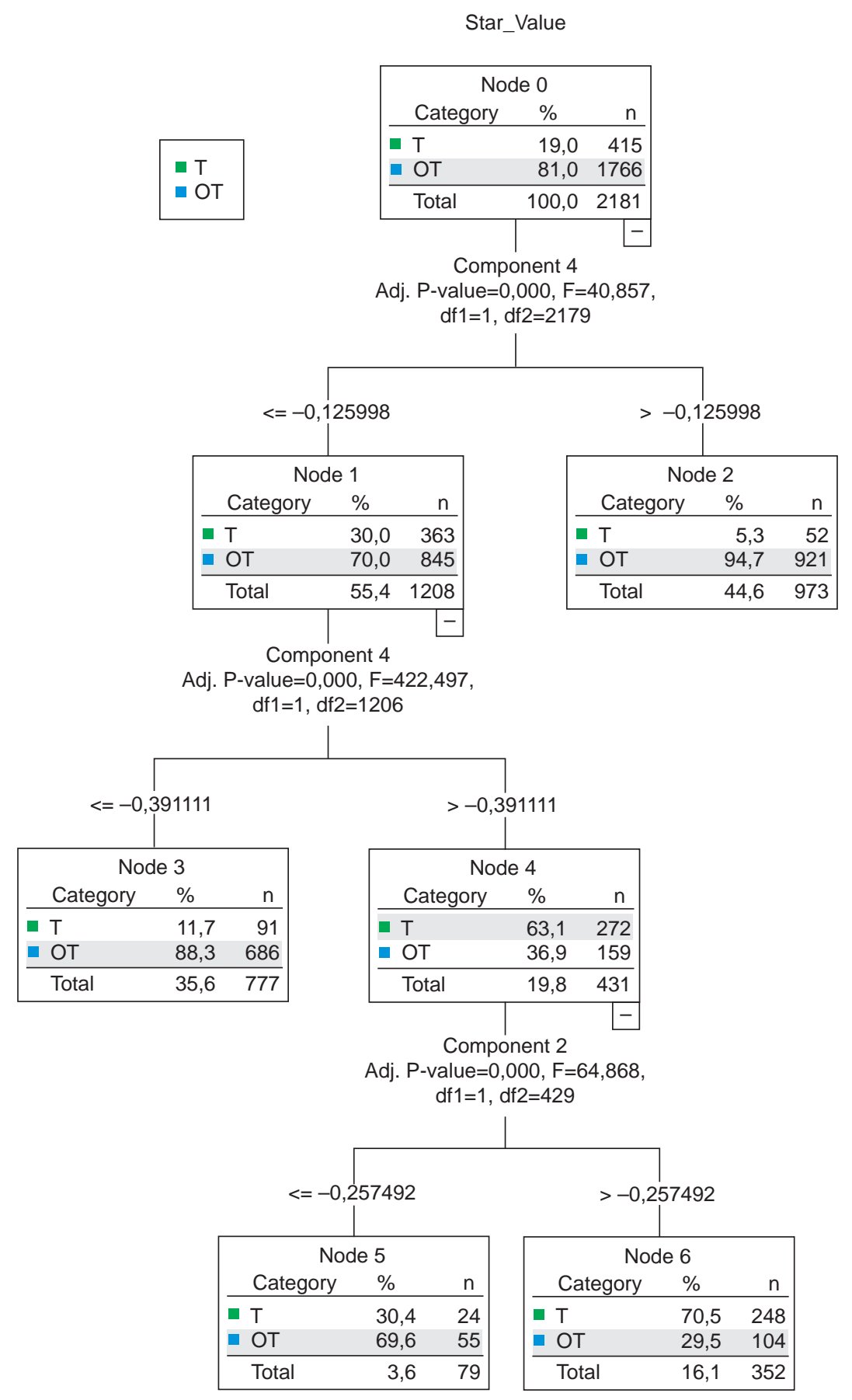

Figure 5.3.3.: Classification tree plot for Database 3 
5.3. Study three

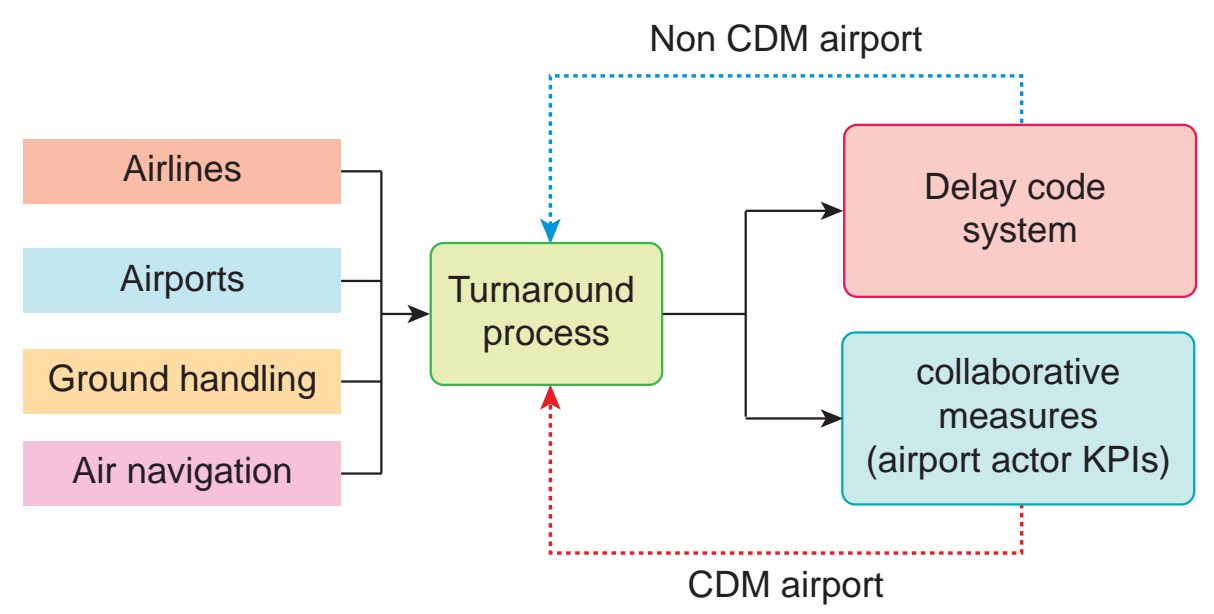

Figure 5.3.4.: CDM airport vs non-CDM Feedback Mechanism 


\section{Results}

\subsection{Study four-A Neural Network Method to Predict Performance of Collaborative Measures}

\subsubsection{Introduction to study four}

Airport capacity has become a limiting factor in accommodating the rise in air traffic. The aim of this study is to identify specific airport infrastructures as exogenous factors from the network that are indicative to cause delays as a result of Airport Collaborative Decision Making (CDM). Consequently, a method is developed through the identified elements to predict future behaviour by a predictive model that is operationalized with the technique called Multilayer Perceptron with neural networks. Using real- turnaround flight data from Madrid Barajas airport, a total of 2100 turnaround movements have been used in this analysis. Results show that aside from Key Performance Indicator (KPI) system defined by CDM, airport infrastructure effect on- time performance in turnaround operations with a high degree of relevance to airside operations. These are the stand/gate, type of aircraft, Company (Type of airline) and selection of selection of runaway.

The purpose of these study is to explore among other factors, what is critical to CDM when it comes to the use of airport resources, such as gates, runaways, type of aircraft and company (type of of airline). Which of these is of high importance when it comes to turnaround on time performance. This is important because airport actors such Airport Operations, Air Traffic Controllers (ATC) Aircraft Operators, and Ground handlers collaborate to link inbound, turnaround and outbound process where these airport resources are collaboratively shared and which one are important especially at peak times.

For this study, we used collaborative measures from CDM database at Madrid airport. We used known indicators as independent variables by introducing a predictor variable called start value. This gave us predictions on the behaviour of exogenous factors that are more important. 


\subsection{STUdy FOUR}

\subsubsection{Results}

The results are based on the comparison of the two neural networks analysis performed and the results showing the sensitivity-specificity analysis thereof (ROC curves). This analysis provides tools to select possibly optimal models and discard sub-optimal models regardless of (and before specifying) the cost of distribution of the two classes which decides (Javier et. al. 2004). In the first analysis the partition used for training samples, test and reserve performed automatically by the SPSS software, the results of this analysis are shown below: Results show that 1230 was allocated corresponding to $61.7 \%$ of cases in the training sample and $585(29.4 \%)$ to the test sample and reserved was assigned 178 cases (8.9\%). In 107 cases the results of the analysis are shown excluded. The network information table displays the number of units in the input layer that constitute the variables used as factors and covariates, it is noteworthy that none of the categories are considered "redundant" units. Similarly, a unit separate results for each category of the dependent variable Star-Value is created, for a total of two units in the output layer. Automatic architecture chooses five units in the hidden layer. The activation function is the hyperbolic tangent, and the output layer uses softmax activation function, which is why the error entropy, which is the error function that the network tries to minimize during training as shown in the table 5.4.1.

Table 5.4.1.: Error computations based on testing sample

\begin{tabular}{lll}
\hline Model Summary & \\
Training & Cross Entropy Error & 611,181 \\
& Percent Incorrect Predictions & $19,8 \%$ \\
& Stopping Rule Used & 1 consecutive step(s) with no de- \\
& crease in errora \\
& Training Time & $0: 00: 03,88$ \\
Testing & Cross Entropy Error & 276,542 \\
& Percent Incorrect Predictions & $18,1 \%$ \\
Holdout & Percent Incorrect Predictions & $20,2 \%$ \\
\hline Dependent Variable: STAR_VALUE & \\
\hline
\end{tabular}

This table above shows that the entropy error was 611.18 with a percentage of incorrect prediction of $19.8 \%$, when performing the calculations for the train- 


\section{Results}

ing sample error entropy of 276.54 with a percentage of incorrect predictions is obtained $19.8 \%$, which is good in this type of models.

The neural network obtained a higher percentage of correct cases in the training sample and worse results in the holdout sample to predict the activities that had actually caused failures optimum times assigned to airport operations. (79.8\% correct in the reserved sample relative to $80.2 \%$ in the training sample). Combined with the stopping rule indicated in the summary table model, which also is a reason to suspect that the network may be overtraining; i.e. it is detecting false patterns that appear in the training data by random variation.

Dependent Variable: STAR_VALUE

Table 5.4.2.: Classification of neural network training

\begin{tabular}{lllll}
\hline SAMPLE & OBSERVED & \multicolumn{3}{l}{ PREDICTED } \\
& & OT & T & PERCENT CORRECT \\
\hline TRAINING & OT & 987 & 0 & $100.0 \%$ \\
& $\mathrm{~T}$ & 243 & 0 & $0.0 \%$ \\
& Overall percent & $100.0 \%$ & $0,0 \%$ & $80.2 \%$ \\
\hline \multirow{2}{*}{ TESTING } & OT & 479 & 0 & $100.0 \%$ \\
& $\mathrm{~T}$ & 106 & 0 & $0.0 \%$ \\
& Overall percent & $100.0 \%$ & $0.0 \%$ & $81.9 \%$ \\
\hline \multirow{2}{*}{ HOLDOUT } & OT & 142 & 0 & $100.0 \%$ \\
& T & 36 & 0 & $0.0 \%$ \\
\hline & Overall percent & $100.0 \%$ & $0.0 \%$ & $79.8 \%$ \\
\hline
\end{tabular}

To correct this situation, we proceed to perform a second analysis where a test sample and a new variable partition to help maintain the specified network properly adjusted. This correction analysis shown below and the results will be compared with the analysis already described. Therefore, the partition variable is created to re-create the reserved and training samples, taken a portion of the training sample and we will assign a test sample. In the new analysis $71.5 \%$ of cases in the training sample and $28.5 \%$ to the Holdout.

In the table of network information can be seen that the change becomes visible 


\subsection{STUdy FOUR}

is that the automatic architecture that takes the network are assigned to process only three hidden layers.

The model summary table shows that the error was 637.248 entropy with a percentage of incorrect prediction of $18.8 \%$, which is down from the first analysis, when performing the calculations for the training sample is obtained a percentage of incorrect predictions of $18.1 \%$, which is good in this type of models.

Table 5.4.3.: Classification of neural network training for second test

\begin{tabular}{lllll}
\hline SAMPLE & OBSERVED & \multicolumn{3}{l}{ PREDICTED } \\
& & OT & T & PERCENT CORRECT \\
\hline TRAINING & OT & 1152 & 22 & $98.1 \%$ \\
& T & 249 & 20 & $7.4 \%$ \\
& Overall percent & $97.1 \%$ & $2.9 \%$ & $81,1 \%$ \\
\hline HOLDOUT & OT & 439 & 19 & $95 \%$ \\
& T & 114 & 4 & $3.4 \%$ \\
\hline & Overall percent & $96.0 \%$ & $4.0 \%$ & $76.9 \%$ \\
\hline
\end{tabular}

The leaderboard in table 4 shows that, cutting pseudo-defined variable partition for classification, the network works considerably better forecasting processes that do not have deviations in estimates in airport operations times as well as those that have accused. So comparing this prediction with the previous performed mind and their respective ROC curves can be seen better. In the case of airport processes individual causing deviations in expected times randomly selected and one that does not cause selected deviations randomly, there is a probability of 0.703 that the predicted pseudo predictive model specified by the neural network is greater for the case caused the deviation in the estimates for which it does not cause times.

While the area under the curve is a summary of a statistical precision of the service network, you can choose a specific criterion by which to classify airport operations.

Finally, the tables of the importance of the variables in the model are shown:

The importance of an independent variable is a measure of how much the predicted by the network model for different values of the independent variable value changes. The importance chart (see Figure 5.4.1 on page 134), is ranked in des- 


\section{Results}

cending value of importance. It seems that the variables related to the stand, the type of aircraft and the company have the greatest effect on how the network classifies the operations or activities that accuse or deviations in the expected timing of airport operations; you could say that the large number of stand and operations carried out there can cause much of the deviations that occur in airport operations, however, can be further analysis to clarify this point.

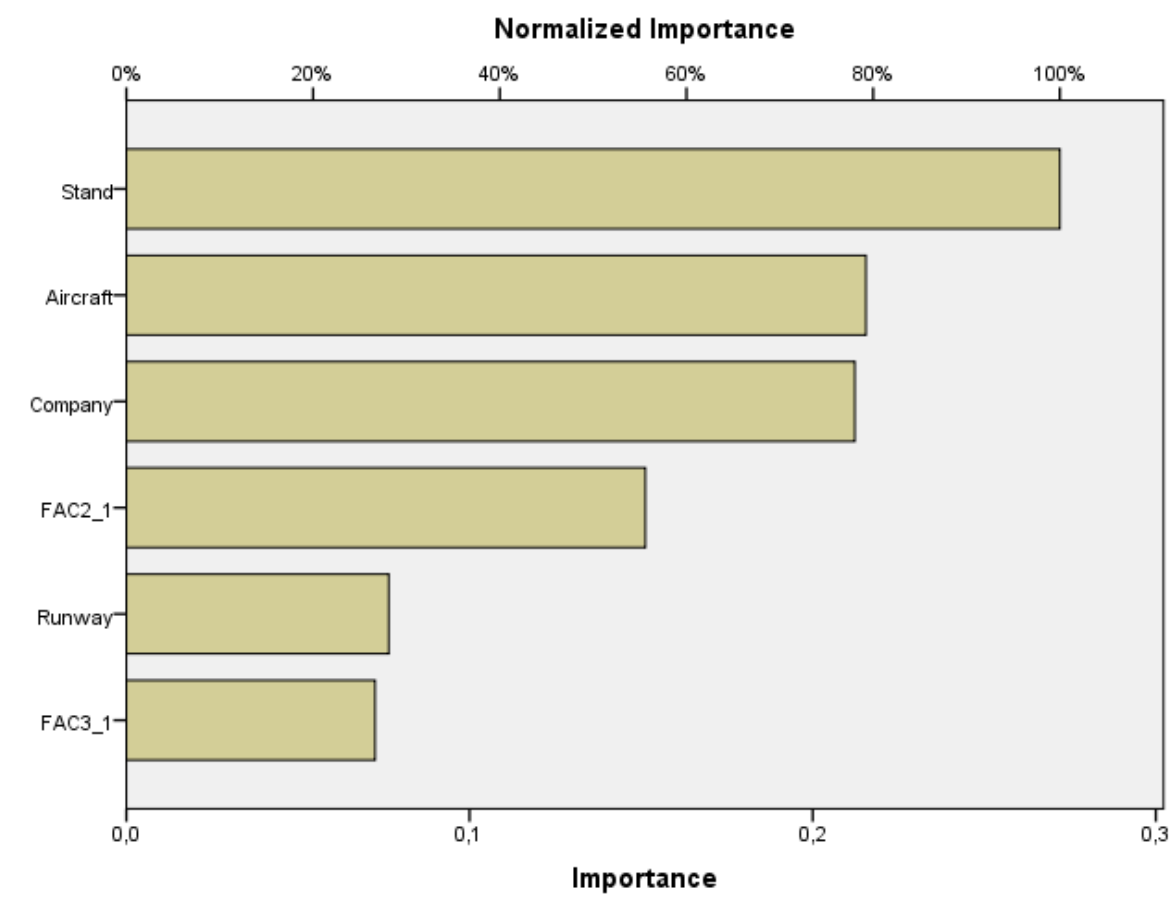

Figure 5.4.1.: The critically of importance of exogenous on time performance

\subsubsection{Conclusions}

The purpose of this analysis was to identify the features or elements that are indicative of cause delays or slows down airport operations in the turnaround and use those elements to identify future risks in such transactions through a predictive model, it is considered that the model explains that in addition to KPI system-defined, other factors that are relevant in the analysis with a high degree of relevance are the stand, aircraft, Company, runaway, In that order. 
These use these elements to identify future risks in such operations avoiding the "standby moments" and reducing time and resources through a predictive model. The implementation of this prediction tools in airport operations will provide information on how they affect the factors and variables to the correct development of activities and airport processes and their consequences 



\section{6 \\ Discussion}

This chapter answers three sub-questions and discusses the results by analytically applying CCT theory under the three dimensions. There are three main findings: interactive complexity as systemic complexity, performance in ignorance, and factors that affect social systems in an inter-organizational setting. The findings from each research question are discussed separately.

\subsection{ReSEARCH QUESTIONS ANSWERED}

RQ1.1: What are the sources of inter-organizational complexity?

The first question explored the first dimension in inter-organizational PM is organizational complexity. Results from Paper 2 show factors that induce complexity, including the existence of informal roles between actors, and critical incidents and non-linear interdependencies between work processes. Other sources of complexity were the number of actors involved, the size of entire network, and the quality of information needed to be shared among actors. These factors were shown to induce complexity in the network. From Paper 3, findings indicate that PMS exists with an intrinsic complexity, which is termed Performance Measurement Com- 


\section{Discussion}

plexity (PMC). Six sources of PMC were identified as analytical, methodological, technological, role, procedural, and task complexities.

This finding revealed that actors operate with several sources of complexity in their internal organizations. It follows that if actors were to collaborate with distinct roles, organizational complexity in the network is amplified at the system level, meaning that actors who manage using collaborative performance measures operate with several sources of internal complexity, which aggregates to the system level. In the context of this thesis, system complexity that results from each actor internally is termed interactive complexity, and thus identification and regulation of iterative complexity is one of the roles between collaborating actors, which in this case is the process actor and sensor actor. According to cybernetics, the process actor is the system itself. The behavior of the system is monitored through control variables such as information, knowledge, and trust. The actor's role in this case is to monitor and identify sources of complexity within the system. For the sensor actor, which is for error detection, its role is to interpret the behavior. For cause and effect to apply, a tentative proposition from cybernetics control theory is that the sensor actor monitors for error detection while the process actor interprets the errors.

\section{RQ1.2: How do actors collaborate while continuously improving?}

The second sub research question explored the second dimension which is continuous improvement. This deals with organizational performance that controls best practices. Studies in this thesis suggest that continuous improvement is hindered, causing collaborative PMS to be static and less responsive. This was demonstrated in Papers 1, in which actors lacked collaborative strategies, and because of their differing interests, they lacked interpretive rights to set measures. Such a network "performs in ignorance." These findings were tested in Papers 4 and 5 to examine the usefulness of collaborative measures. In Paper 4, by introducing the predictor variable star value, it captured the dynamic nature of collaborative PMS. The predicted measures showed how airports can use collaborative measures to assess on-time performance resulting from activities during turnaround. The method in Paper 4 also predicted measures that actors can use to align strategies so a collaborative PMS benefits all parties involved. By considering a predictive model, Paper 5 shows which airport resources are critical to 


\subsection{RESEARCH QUESTIONS ANSWERED}

causing delays. Results from Papers 4 and 5 reveal that collaborative measures can be used by managers as a feedback mechanism to push for enhanced decisionmaking. However, actors still lack a premise with which collaborative measures can be adjusted to continuous improvement.

Strategic control systems, such as those discussed by Ferreira and Otley (2009), offer possibilities for structuring decision-making to continuous improvement. Regarding collaborative decision-making, these models are limited since they do not cater to all demands of the network. Inter-organizational PM lacks interpretive rights to capture full system effectiveness. It follows that managing collaboratively for continuous improvement should be extended to acquire cybernetic roles and therefore be more reflective of a rebalanced network. The tentative proposition, according to the cybernetic framework, would be actuator for its roles as manipulator and interpreter of the system.

RQ1.3:How do social aspects affect inter-organizational performance?

As a social-technical process, turnaround directs attention to sequencing activities that are highly technical, but with people as agents in the system. Their know-how, actions, and interactions collectively produce the social system. When it comes to inter-organizational PM, social systems comprise constant reproduction of social interactions. Results from Papers 1 and 3 indicate that social logic affects management of collaborative measures in two ways. First, Paper 1 explores social logic by using a conceptual architecture for system performance, as developed by McDonald (2015), which explored two dimensions: trust and team structure. Inter-organizational PM under this dimension is largely affected since partners lack trust in the shared PMS, rather than trust between stakeholders.

There is an imbalance in team structures since steering groups from disparate groups have different logic maps from other stakeholders in lower positions. In contrast to Paper 3, results show that users lack clear and concise administration in terms of how to balance objectivity and subjectivity when applying social and technical controls. From Paper 1, the team map (see Figure 2 of Paper 3) shows social logic being affected by trust and team structure, whereas in Paper 3, the model that typifies social and technical shows sources of social complexity. This means social systems interfere with collaborative measures in a broader way, and several views exist. Other social aspects reported in the network, such as poor 


\section{Discussion}

communication, sense of urgency, and lack of collaborative leadership, show the role of social aspects when creating a guiding coalition to institutionalize new approaches for inter-organizational PM. For managers of collaborative measures to go beyond these social tensions, the cybernetic role as the controller actor must be included in the network. In cybernetics thinking, the controller actor executes commands between social and technical network processes, thereby creating a balance for all actors because the task of command not only is determined as a correction function, but also considers actors' interests through the sensor element.

\subsection{Reconnecting to the Main Research Question}

Having discussed results in relation to the sub-questions, this section explores how the sub-questions relate to the main research question.

MRQ: How do actors manage operations through inter-organizational performance measures?

Actors who manage using collaborative PMS operate with a range of interacting elements and processes that create redundancies in operational measurements, resulting in technical complexity that is systemic. This complexity type, termed interactive complexity, influences the process of maintaining a collaborative PMS. Since operations are broad, covering a dependency network, important measures are dynamic, multifaceted, multileveled, and multilateral in such settings. Based on findings from Study 4, a collaborative PMS lacks interpretive rights to set new measures, making it static.

Findings from Papers 1 and 3 reveal several social aspects that affect actors who manage using collaborative measures. First is a lack of clear and concise administration between the balance of objectivity and subjectivity at different PMS stages. Second, Paper 1 suggests a lack of trust, not between actors themselves, but in the shared PMS. In such settings, actors operate with disparate professional knowledge. Stakeholders on operational level do not have similar knowledge to those in senior management positions. Airport actors also face issues around information sharing, leading to various contradictory factors and incongruences, in terms of what to measure and how.

Contributing to the main research question regarding how actors manage through 
a collaborative PMS, the method theory suggests that actors adopt a cybernetic framework which is summarized in Figure 6. The figure shows a proposal for such a framework, emphasizing the misalignment between inputs and outputs, and the need for a feedback loop. Based on the discussion in Section 6.1, the cybernetic framework recognizes that there exist several PM dimensions that can be adapted and explored for inter-organizational PM. The proposed framework uses the three PM dimensions to illustrate how it should function. The proposed framework functions with the recognition of three layers - the functionality, interoperability, and inter-performance management layers - which result in collaborative decisionmaking. Role distribution in these three layers is illustrated by the four cybernetic roles, which then influence each other to produce a cause and effect through a Reflective Performance Measurement System.

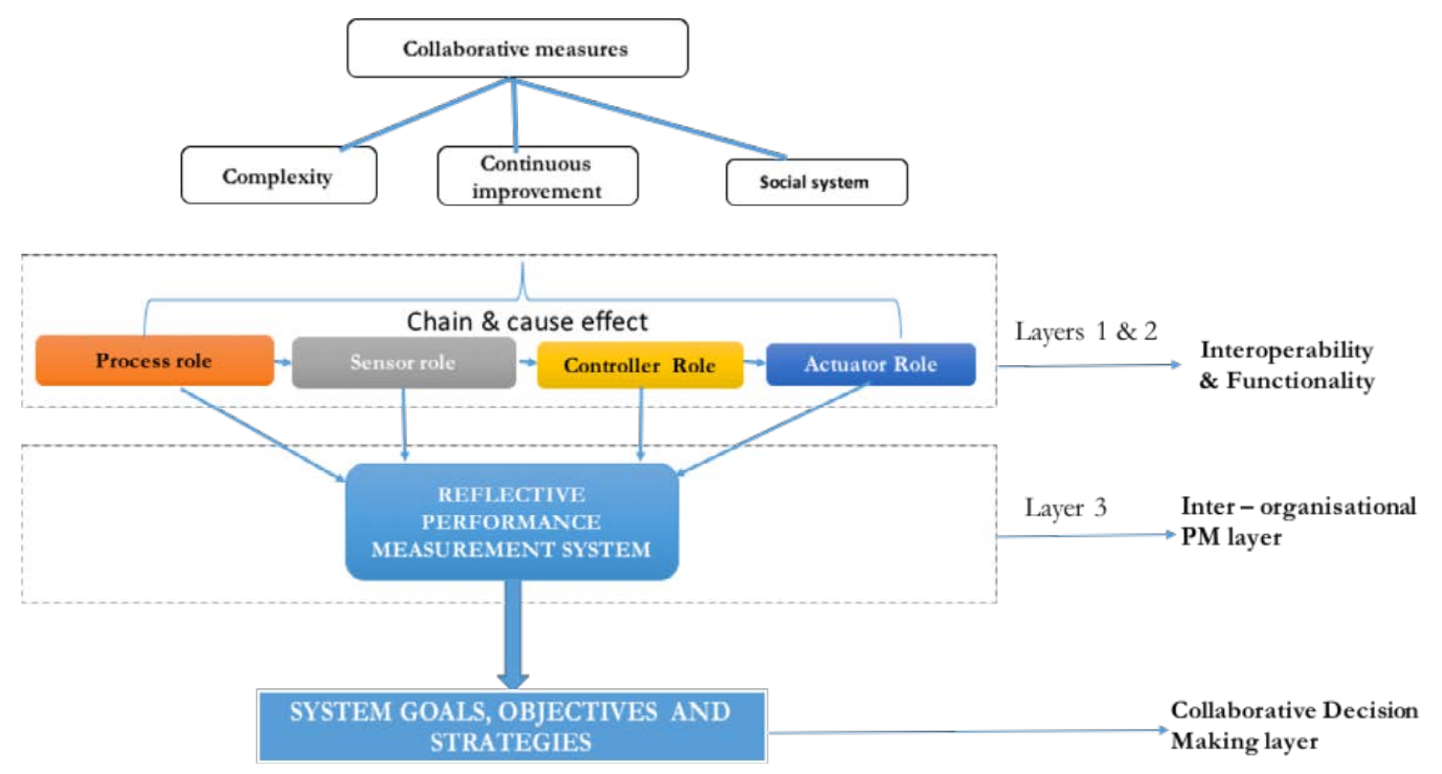

Figure 6.2.1.: A cybernetic framework for collaborative measures

There are three main considerations that the framework puts forward. First it considers the importance of cause and effect as described by CCT theory. Second, the importance of RPMS with general conditions stated in section 7.1.2 on page 144. Third, it puts forward the importance of cybernetic role distribution among actors. 



\section{7 \\ Conclusions}

This chapter concludes by discussing the usefulness of adapting CCT as a method theory and presents implications to both theory and practice with anticipation for future research.

\subsection{THE IMPLICATION FOR THE THEORY}

The findings from this investigation contribute to the theory of collaborative PM in three ways. First, by extending a theoretical model for continuous improvement to a reflective PMS. Second, by advancing our understanding of the evolution of inter-organizational complexity as a result of new types of complexities emerging internally within each organization. Third, by operationalizing PM as a social system in behavioral factors that affect the process of inter-organizational PM.

\subsubsection{Organizational complexity}

The main theoretical contribution made under this dimension is the understanding of how internal complexity propagates and aggregates as systematic complexity 


\section{Conclusions}

plus its evolution, which is termed as interactive complexity in this thesis. To start with, previous research in PMM has mainly documented complexity based on the idea that it is a result of external environments (Grobman, 2005; Harkness and Bourne, 2015; Morel and Ramanujam, 1999). This research agrees with this view that external complexity exists, but also argues that internal complexity is paramount and has been ignored in extant literature. The results detailed in paper three show sources of new types of internal complexity. Ultimately, collaborating organizations will have an impact with their internal complexity, which propagates and aggregates in the system and is what is termed as interactive complexity in this thesis. This research defines interactive complexity as the contest between

the internal complexity of each collaborative organization which aggregates and is systemic in nature.. The theory contribution here is that it extends the discussion developed by Folan and Browne (2005) on the evolution of complexity in inter and intra systems, the agreed evolution is that as PM practices matures and expands, intra-organizational PM achieves lower complexity and reaches its limit as it is easier to managed. However, for inter-organizational PM, complexity will keep increasing as the system is open and dynamic, to this end, this research shows that with the identification of internal complexity as shown in paper three, it follows that the evolution of inter-organizational PM will be amplified due to two reasons; firstly, due to interactive complexity and secondly, due to the incompatibility of frameworks between intra and inter. This is because Extended PM literature assumes more similarity between inter and intra and frameworks are not primarily designed to manage diversity of interactive complexity, hence the reason of incompatibility. Lastly, since PMM is too focused on intra complexity as an external source, it is observed that interactive complexity is underestimated. Figure 7.1.1 on the facing page shows how interactive complexity contributes to the previously known evolution of inter-organizational complexity.

\subsubsection{Continuous improvement}

The theoretical impact under this dimension is seen in two ways: firstly, by extending the theoretical model for continuous improvement, and secondly by coming to the realization that a broader way of assessing measures that is systematic is 


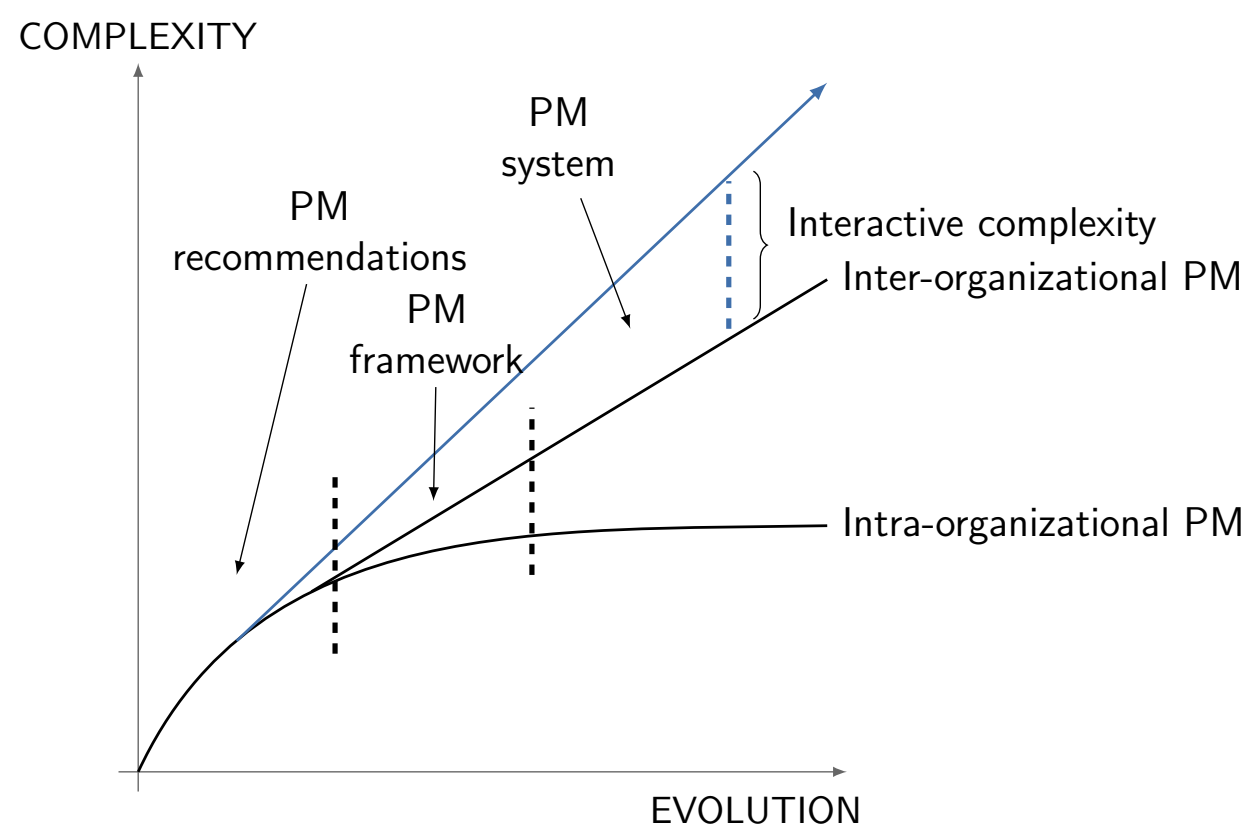

Figure 7.1.1.: The evolution of inter-organizational PM as a result of interactive complexity (expanded from Folan and Browne, 2005)

needed in PMM literature. To begin with, the theory contribution is discussed by the need for an additional performance system which is termed as Reflective Performance Measurement System (RPMS). This was analyzed and interpreted through the theoretical model for continuous improvement by Pinheiro De Lima et al. (2013), which is a influenced by Folan and Browne (2005). When it comes to inter-organizational PM, this model becomes limited since both double and single loops become limited. As shown within the context of this thesis, the process of continuous improvement for collaborative measures is limited for the following reasons. Firstly, the results from paper four show that actors in collaboration were unable to discern the most optimal way for a process of continuous improvements. The paper applied a new component called star values, which was adapted to fill this gap as a decisive measure to examine the operational capabilities of collaborative measures to facilitate continuous improvement. Without star values it appears that such a network is marked as one that is performing in ignorance. Secondly, the single and double loops did not allow all actors' views and interests, and such a system was therefore not balanced to keep the system dynamic and 


\section{Conclusions}

responsive. To this end, if the system is to learn, adapt and produce a predictive element for future risks to be identified then these roles should be distributed within such a system. The theoretical model as shown by Pinheiro De Lima et al. (2013) will then be functional for all actors. Figure 7.1.2 shows the additional system, termed as reflective performance measurement, extending the theoretical model in question.

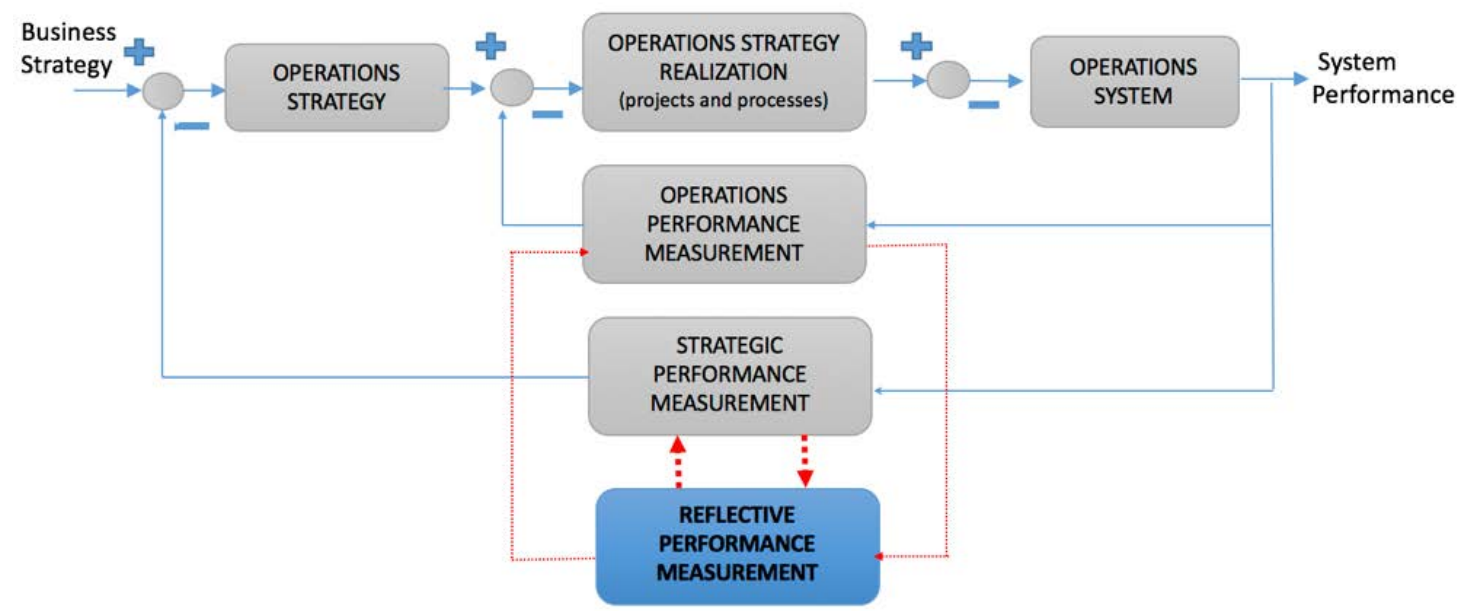

Figure 7.1.2.: Reflective performance measurement system for continuous improvement adapted for the Operational Strategic Management System by Pinheiro De Lima et al. (2013)

As an implication for theory, a new PMS called reflective performance measurement is proposed, thereby extending the model to set the process of continuous improvement between actors. Given the nature of systems of systems, two sets of conditions are proposed for $R P M S$ as an important role in facilitating interorganizational continuous improvement. First, there are general conditions which are universally applicable and unique conditions which are more specific.

For general conditions of a reflective PMS:

- It should be centralized with a balanced reporting history.

- It should possess a balanced information infrastructure dispersed to all actors and be able to reassure partners on the confidentiality of data. 


\subsection{THE IMPLICATION FOR THE THEORY}

- It should consider social and technical aspects to be able strike a balance between the two whenever necessary.

- It should allow stakeholders to trust data and have balanced knowledge about shared PMS.

- It should be able to validate their business cases.

For unique conditions:

- Greater emphasis on balance between social and technical controls is critical.

- It should include an element of meta-reflective, which questions how the single and double loop measures, and if such measures are correctly assessed or appropriate. This means that the first loop in Figure 7.1.2 would consider efficiency, the second loop would consider effectiveness and the final contribution as unique conditions would be to consider the appropriateness of PM.

- It should be able to accommodate standard acronyms and have systematic definitions and also propose standard non-disclosure agreements.

With these conditions, RPMS allows the network to stay dynamic but balanced. The system will then be improved and organizational aspects of the system will be enhanced as continuous improvement will be enacted. The implication for theory is that when considering the theoretical model which discusses feedback loops in Figure 7.1.2, there is an importance in terms of the broader way of assessing measures that is systematic, which PM literature is currently in greater need of.

\subsubsection{Social system}

Under the third dimension, previous research shows that organizations are social systems and people run their operations. However, previous literature has not paid much attention and little documentation exists on how PM exists as a social system. In line with paper one and paper three, the findings under this dimension were able to attempt to operationalize PM as a social system and contribute to theory in the following ways. Firstly, by adopting the system performance 


\section{Conclusions}

conceptual architecture developed by McDonald (2015) (see Figure 5.3.2 on page 127 in Study 3) which shows the social logic being affected by trust and team structure. Secondly, the implication for theory is that, as opposed to previous notions on social-technical approach, these social factors were deemed to be vital for inter-organizational PM, something that PMM literature has asked for but rarely discussed.

\section{Cybernetic control theory as a method theory}

The overall implication for PMM literature is that by adopting Cybernetic Control Theory as method theory, it was possible to explain the substantive challenges in the feedback dilemma. As a result, PMM literature can be expanded with new cybernetic functions and roles. Such an extension to the literature field is seen through the analytical association of inter-organizational PM roles to organizational cybernetics. As such, the reflective PMS for the continuous improvement model, the identification of internal complexity, and the examination of the social logic create significant steps in terms of how paradigm shifts in PMM literature will be further discussed and later developed for inter-organizational PM.

Table 7.1.1.: Contributions made in this thesis from appended papers

\begin{tabular}{|c|c|c|c|c|}
\hline PM dimensions & RQ1.1 & RQ1.2 & RQ1.3 & Conclusion \\
\hline $\begin{array}{l}\text { Organizational } \\
\text { complexity }\end{array}$ & $\begin{array}{l}\text { Study } 2 \\
\text { Study } 3\end{array}$ & \multirow{3}{*}{$\begin{array}{l}\text { Study } 4 \\
\text { Study } 5\end{array}$} & & $\begin{array}{l}\text { Inter-organizational PM is chal- } \\
\text { lenged with the misalignment } \\
\text { between inputs and outputs, }\end{array}$ \\
\hline $\begin{array}{l}\text { Continuous } \\
\text { improvement }\end{array}$ & & & & $\begin{array}{l}\text { which impedes collaborative } \\
\text { decision-making. For such a } \\
\text { system to stay dynamic and }\end{array}$ \\
\hline social system & & & $\begin{array}{l}\text { Study } 1 \\
\text { Study } 3\end{array}$ & $\begin{array}{l}\text { responsive, actors should adapt } \\
\text { to unique and specific cybernetic } \\
\text { roles to correct the misalignment } \\
\text { dilemma through a chain and } \\
\text { cause effect. }\end{array}$ \\
\hline
\end{tabular}

\subsection{IMPLICATION FOR PRACTICE}

Managing PM within a single organization is not an easy task. Managing interorganizational PM, as this thesis has shown, is not only difficult but almost im- 
possible (Folan and Browne, 2005).

First, managers have to realize that the contemporary business context is characterized by the overall tendency of alliance formations among businesses, thus establishing strategic alliances (Semlinger, 2008; van Wijk et al., 2012). The reason for such trends is embedded in the nature of firms - they are involved in various network formations and inter-business relationships to co-create and appropriate value (Johansson, 2012).

Second, there are important frameworks managers could apply in managing through collaborative measures. In paper four, a model to evaluate Performance measurement management at airports using Collaborative Decision Making was proposed at tested with real turnaround flight data. This model takes into account airport operators, aircraft operators, ground handlers, and air navigation service providers as airport partners, and their activities as input to the system. As for outputs, this model considers all areas that impact airport activity, such as efficiency, environment, capacity, and safety. Managers could apply different star values to evaluate system performance. Additionally, a model that typifies social and technical controls was proposed in paper three, Managers would map which processes require technical or social controls. Furthermore, a predictive model in paper five was also also proposed and tested which predicted critical use of airport resources. It is now that actors can apply this model to allow proper usage of airport resources.

Third, the findings made from testing the three PM dimensions reinforce the practical interaction and use of organizational controls such as technical and social controls to cause complexity. This process in measurement was seen as being emergent, unintended, unpredictable, and ambiguous in terms of what to measure and how to manage it. The results posit that users' responses to the external environment cause internal Performance Measurement Complexity (PMC). This means that stakeholders will have two tasks: to manage their unique internal complexity which was seen to propagate through six sources as analytical, methodological, technological, role, procedural and tasks, but also to be able to collaborate on managing the interactive complexity at system level which has a huge impact on the process of managing inter-organizational PM. It is therefore observed that because collaborative measures become a critical factor for developing strategic alliances, 


\section{Conclusions}

team leaders must realize the importance of controlling and managing internal complexity as opposed to the tradition of primarily focusing on the external complexity. This is illustrated better by Deloitte, a multinational professional services provider. While reinventing its PMS system, Deloitte found that approximately 2 million hours a year were spent on formalities of performance management (Buckingham and Goodall 2015). The point here is if Deloitte was to collaborate with other organizations with similar levels of complexity, the focus has to be on shared complexity that emerges which is termed as interactive complexity in this thesis. As a contribution to practice, team leaders will now realize the importance of including a reflective element for the whole system rather than ad hoc adaptations with selected parts of the system.

Four, the thesis has shown that organizations are naturally social systems. The implication for practice here is that managers will have to pay attention to the people component by controlling the use of technical and social controls and striking a balance where it is needed. Then again, managers have to understand that different organizations have different social logical maps for what to measure and how The implication here is that understanding the use of collaborative leadership, communication and dialogue (Yates and Orlikowski, 1992) will delimit the imbalance in knowledge know-how and strategic mismatch that exist with a diversity of actors. The impact for practice is that emphasizing open information platforms would narrow the strategic consensus which presently varies considerably between steering managers and operators (Edh Mirzaei et al., 2016).

Furthermore, another implication for managers operating with PM that transcends organizational borders is to allow cybernetic roles for the chain-cause effect. As an implication, the network would then understand collaborators if they are contender, partner, and integrator and balancing their views and interests. Ultimately, such definitions have an implication for the technological development of the future of PM tools. PM tool developers and providers will advance them to provide unique constructs for actors operating with collaborative measures by providing information sharing flexibility and network feedback alignment that is balanced for all actors while maintaining trust and ethics of partnering and thus contributing to the reflective PMS for interoperability and functionality.

Last but not least is decentralizing by delegation of decision rights. Management 
must realize that the critical role to attain a central decision-making authority is to be able to delegate jointly by concentrating on all actors without excluding others. Finally, as this thesis has explored a highly regulated setting, there are important implications for policy. Regulations on industrial collaboration and its governance are fairly important for PM and also for the economy. With the understanding from this thesis, regulators will now realize that systematic measuring is important, and new regulations will be designed to allow collaborating businesses to involve cybernetic thinking especially in contract formations and memorandums of association. Managers would then face the challenge of feedback with ease and in an equivocal manner, especially when dealing with trust and removing extra intentions such monopolistic tendencies, estranger behaviors, syncretic rent-seeking behavior and profit seeking.

\subsection{Avenues For further ReSearch}

The results of this thesis highlight several avenues of inquiry. Most importantly, this research has taken a perspective in PMM literature based on the philosophy of managing through measures. However, new perspectives in literature have repeatedly emerged that suggest managing through measures is outdated and more freedom motivates collaboration. Therefore, future research could employ this perspective to understand whether inter-organizational PM can be managed with less or no measurement at all.

There are three immediate avenues for further research suggested by this thesis. First, only three dimensions have been explored in this thesis. In order to explore further what sustains a collaborative PMS, future studies can exploit additional dimensions from PMM literature. For example, organizational learning, actors' satisfaction with PMS design, productivity through team tasks - i.e. the amount of a resource used to produce a unit of work. Future research could also extend to different settings where conditions vary such as business size, degree of technical and social controls, variety of KPIs and so forth.

Second, another avenue for further research would be to explore the sustainability of PMS design in collaborative networks For this, this thesis suggests that future research could examine operational reward systems within stakeholders if 


\section{Conclusions}

they sustain the functionality and commitment of stakeholders to the network demands.

Finally, the methods proposed and applied for investigation in this research can be complemented and widened. Future research should seek to enhance the methodology selection and its rigor. For example, new methods to capture what makes PM a social system such as ethnography can be applied. For matters of generalization, future research could be conducted in other industrial sectors to advance or challenge the findings in this thesis. PMM researchers could explore complexity in emergency health care where many actors collaborate on the inflow of severe inpatient cases. Other contexts that would be worth investigating would be the railway network, the complexity that exists between army units and military logistics in terms of frontline battlefields, and the operation management stage of plays and theaters. The operational complexity and tensions that exist in these contexts could have several interesting results in terms of how a shared PMS can be managed.

\subsection{REFLECTIONS AND FINAL REMARKS}

Having conducted this research over a period of four years, and as an insider researcher at Madrid airport. There are four final remarks that are worth mentioning.

First, in addition to cybernetic roles in such a network, the idea of incorporating automated systems such as Cyber-Physical Production Systems (CPPS) in the turnaround would be worth would be worth examining as another alternative (Frazzon et al., 2013). This is because cyber-physical systems focus more on connectivity in the network and are more objective. This cryptal-physical (Angelis and Okwir, 2017) has a physical world and digital world. It would then mean; this would go beyond social - technical process to be at the individual level which makes the system to be highly connected as the virtual reality will be connected to operations management of the turnaround.

Second, there are the diverse interactions and relationships with specific contingencies that were challenging to operationalize. Given the nature of operations and the collaborations involved, focusing on inter-organizational PM was a better 
choice as it uncovered important implications, and as airports are performancebased organizations. However, it was challenging to capture all contingencies that exist from the empirics for this research. Therefore, to remedy such a challenge, it might have been worth conducting an extended pre-study in order to discern several factors that affect collaboration and the complexity of operations in such settings.

The third relates to the observation of the diversity of actors in this context. As a researcher, I have observed that other operations management processes such as assembly lines, automotive and collaborative supply chains all focus on lean thinking, and have similar tac times, similar quality levels, and the same structure of operation. However, in contrast to such similarities, operations management at airports involves a great deal of diversity in terms of what actors focus on, their views and their interests. For example, the airport management will focus on how many additional slots can be sold, airlines will focus on how many rotations can be made with a different quality such as smooth boarding and de-boarding, ground handling companies will focus on how many flights can be served with the same staff to reduce costs and the air traffic department will focus on the throughput of the runway. On another level, regulators focus on the environment and capacity enhancements, and ultimately it is quite difficult to find common indicators for all stakeholder.

Last but not least, after examining PMM literature, I agree with Marr and Schiuma (2003) who acknowledge that the present body of literature is diverse in terms of issues of collaboration and inter-organizational PM and a more cohesive body of frameworks is needed. As a matter of fact, the recent special issue on performance measurement and management conference (Editorial, 2016) confirmed that despite abundant research within several areas, a meta theory on PMM has failed to emerge.

In conclusion, this thesis began by observing that, as PMM literature continues to discuss the design of collaborative PMS, there is still a central phenomenon of feedback resulting from inter-organizational PM that has long been ignored. The thesis argued that it is time to start a discussion on how to extend this discourse by developing and new theoretical insights into managing through collaborative measures. For this, three PMM conceptions were explored with the purpose of 


\section{Conclusions}

investigating how they affect management of collaborative measures. In order to achieve this, the thesis sought to explore how collaborative PMS is managed with different actors in airport operations. The study was based on different methods, including a longitudinal action research in study one that explored the challenges of implementing a shared PMS. Study two employed a case study to explore sources of complexity and understand the context. Study three examined the literature review in PM practices, while the Classification and Regression Tree method (CART) and the Artificial Neural Network method were applied in study four.

As a tentative approach, the study adopted the use of Cybernetic Control Theory as a lens to explain and advance our understanding of the challenge of feedback in PMM literature. Cybernetic Control Theory was able to explain how such loops can be corrected as an alternative way for actors to overcome this challenge. If such an idea is accepted, the content of feedback discussed in this thesis is also characterized by having fast responses, especially in decision-making between parties, such as collective interpretive rights to set measures, collective rights to own measures, and collective rights to inform management for continuous improvement and controlling organizational complexity, including what exactly needs to be measured and how. It is then that collaborative measures are expanded for many functions to move the network both strategically and operationally while using measures such as those for intra-organizational PM.

This thesis has analytically argued that inter-organizational PM can be achieved through the chain and cause effect when actors in collaboration share specific roles to mimic feedback in cybernetics, i.e. when outputs of a system are rerouted back into the system as inputs. This thesis also suggests that actors in collaboration would not collaborate particularly, but would influence each other for re-alignment and for a re-balanced network. Ultimately, the significance for collaboration through collaborative measures is a process of influence from one actor to another. Finally, this thesis pointed out that collaborative PMS is set to shift from being static to being dynamic and therefore not just being a performance management system but also a collaborative system.

In closing, this thesis creates a foundation to further understand inter-organizational PM. Hopefully, it will signpost a number of other research lines and 
7.4. REFLECTIONS AND FINAL REMARKS

enhance our present knowledge within the field of PMM and more specifically on how inter-organizational PM can be administered. 



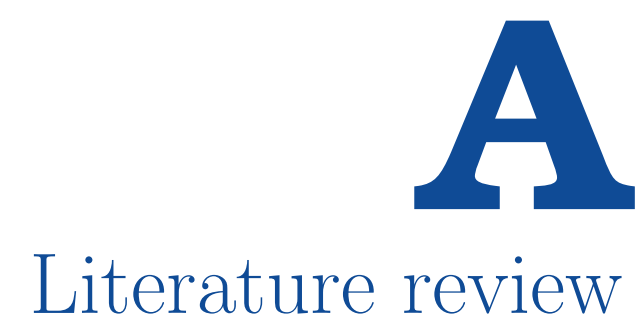


Table A.1.1.: The interaction between control factors at different process stages

\begin{tabular}{|c|c|c|c|c|c|}
\hline $\begin{array}{l}\text { Key } \\
\text { Publication }\end{array}$ & Research Question/Purpose & $\begin{array}{l}\text { Research } \\
\text { Approach }\end{array}$ & Indicators & Control Factors & $\begin{array}{l}\text { Process } \\
\text { Stage }\end{array}$ \\
\hline $\begin{array}{l}\text { Bititci et } \\
\text { al. }(2000)\end{array}$ & $\begin{array}{l}\text { "Develops a model for integrated and dy- } \\
\text { namic PMS, provides a critical review of ex- } \\
\text { isting system" }\end{array}$ & Case study & $\begin{array}{l}\text { Studies } \\
\text { frameworks }\end{array}$ & $\begin{array}{l}\text { Technical } \\
\text { controls }\end{array}$ & Use \\
\hline $\begin{array}{l}\text { Neely et al. } \\
(2000)\end{array}$ & $\begin{array}{l}\text { "Describes the process of designing a per- } \\
\text { formance measurement system and testing" }\end{array}$ & $\begin{array}{l}\text { Action } \\
\text { research }\end{array}$ & $\begin{array}{l}\text { Automotive } \\
\text { and } \\
\text { Aerospace } \\
\text { industry }\end{array}$ & $\begin{array}{l}\text { Technical } \\
\text { control, Dynamic } \\
\text { change, Social } \\
\text { control }\end{array}$ & $\begin{array}{l}\text { Design, Im- } \\
\text { plementation }\end{array}$ \\
\hline $\begin{array}{l}\text { Hudson et } \\
\text { al. }(2001)\end{array}$ & $\begin{array}{l}\text { "To develop measures that drive opera- } \\
\text { tional performance towards the achievement } \\
\text { of strategic objectives" }\end{array}$ & $\begin{array}{l}\text { Action } \\
\text { research }\end{array}$ & SMEs & Dynamic change & Use \\
\hline $\begin{array}{l}\text { Ngai and } \\
\text { Cheng } \\
(2001)\end{array}$ & $\begin{array}{l}\text { "To understand how PMS perform as a res- } \\
\text { ult of applying knowledge based system" }\end{array}$ & Case Study & $\mathrm{N} / \mathrm{A}$ & $\begin{array}{l}\text { Technical } \\
\text { control, Dynamic } \\
\text { change }\end{array}$ & $\begin{array}{l}\text { Design, } \\
\text { Implementa- } \\
\text { tion; } \\
\text { Use }\end{array}$ \\
\hline $\begin{array}{l}\text { Bourne et } \\
\text { al. }(2002)\end{array}$ & $\begin{array}{l}\text { "To investigate the contribution of business } \\
\text { PM and human resource management prac- } \\
\text { tices to business performance" }\end{array}$ & Case study & $\begin{array}{l}10 \\
\text { companies }\end{array}$ & $\begin{array}{l}\text { Technical } \\
\text { control, Dynamic } \\
\text { change, Social } \\
\text { control }\end{array}$ & $\begin{array}{l}\text { Design, } \\
\text { Implementa- } \\
\text { tion, } \\
\text { Use }\end{array}$ \\
\hline $\begin{array}{l}\text { McAdam } \\
\text { and Bailie } \\
(2002)\end{array}$ & $\begin{array}{l}\text { "To explore longitudinal alignment between } \\
\text { performance measures and business } \\
\text { strategy" }\end{array}$ & $\begin{array}{l}\text { Literature } \\
\text { review on } \\
\text { PMM }\end{array}$ & $\mathrm{N} / \mathrm{A}$ & $\begin{array}{l}\text { Technical } \\
\text { control, Dynamic } \\
\text { change, Social } \\
\text { control }\end{array}$ & Use \\
\hline $\begin{array}{l}\text { Santos et } \\
\text { al. }(2002)\end{array}$ & $\begin{array}{l}\text { "To show the role of system dynamics and } \\
\text { multicriteria decision analysis" }\end{array}$ & $\begin{array}{l}\text { Analysis of } \\
\text { frameworks }\end{array}$ & $\mathrm{N} / \mathrm{A}$ & $\begin{array}{l}\text { Technical } \\
\text { control, social } \\
\text { controls }\end{array}$ & Design, Use \\
\hline
\end{tabular}


Table A.1.1.: (continued)

\begin{tabular}{|c|c|c|c|c|c|}
\hline $\begin{array}{l}\text { Key } \\
\text { Publication }\end{array}$ & Research Question/Purpose & $\begin{array}{l}\text { Research } \\
\text { Approach }\end{array}$ & Indicators & Control Factors & $\begin{array}{l}\text { Process } \\
\text { Stage }\end{array}$ \\
\hline $\begin{array}{l}\text { Lohman et } \\
\text { al. (2004) }\end{array}$ & $\begin{array}{l}\text { "To show how KPIs at various levels in the } \\
\text { organization can be incorporated into one } \\
\text { system convince potential user for its use" }\end{array}$ & Case study & Company & $\begin{array}{l}\text { Technical } \\
\text { control, Dynamic } \\
\text { change, Social } \\
\text { control }\end{array}$ & $\begin{array}{l}\text { Design, } \\
\text { Implementa- } \\
\text { tion, } \\
\text { Use }\end{array}$ \\
\hline $\begin{array}{l}\text { Bititci et } \\
\text { al. }(2005)\end{array}$ & $\begin{array}{l}\text { "To demonstrate how existing performance } \\
\text { measurement may be adopted to measure } \\
\text { and manage performance in extended enter- } \\
\text { prises" }\end{array}$ & $\begin{array}{l}\text { Literature in } \\
\text { PMM }\end{array}$ & $\mathrm{N} / \mathrm{A}$ & $\begin{array}{l}\text { Technical } \\
\text { control, Dynamic } \\
\text { change, Social } \\
\text { control }\end{array}$ & Use \\
\hline $\begin{array}{l}\text { Díaz et al. } \\
(2005)\end{array}$ & $\begin{array}{l}\text { "To identify the performance measurement } \\
\text { systems that are used to test their corres- } \\
\text { pondence with the objectives that motivated } \\
\text { the investments" }\end{array}$ & Survey & $\begin{array}{l}20 \\
\text { companies }\end{array}$ & $\begin{array}{l}\text { Technical control } \\
\text { Dynamic change, } \\
\text { Social control }\end{array}$ & Use \\
\hline $\begin{array}{l}\text { Folan and } \\
\text { Browne } \\
(2005)\end{array}$ & $\begin{array}{l}\text { "To develop of a performance measurement } \\
\text { system specifically designed for the require- } \\
\text { ments of the extended enterprise" }\end{array}$ & $\begin{array}{l}\text { Analysis of } \\
\text { Frameworks }\end{array}$ & $\begin{array}{l}\text { Test case in } \\
\text { automotive } \\
\text { industry }\end{array}$ & $\begin{array}{l}\text { Technical } \\
\text { control, Dynamic } \\
\text { change, Social } \\
\text { controls }\end{array}$ & Design, Use \\
\hline $\begin{array}{l}\text { Garengo et } \\
\text { al. }(2005)\end{array}$ & $\begin{array}{l}\text { "To clarify whether changes in PMS are due } \\
\text { to the evolution of the generic models or an } \\
\text { attempt to introduce models suited to the } \\
\text { needs of SMEs" }\end{array}$ & Models/litera & $\notin \mathrm{A}$ & $\begin{array}{l}\text { Dynamic change, } \\
\text { Social control }\end{array}$ & Use \\
\hline $\begin{array}{l}\text { Greiling } \\
(2005)\end{array}$ & $\begin{array}{l}\text { "The use of performance measurement } \\
\text { within the German public sector" }\end{array}$ & $\begin{array}{l}\text { Literature } \\
\text { search }\end{array}$ & $\begin{array}{l}\text { Public } \\
\text { sector }\end{array}$ & Technical control & $\begin{array}{l}\text { Use, Imple- } \\
\text { mentation }\end{array}$ \\
\hline
\end{tabular}


Table A.1.1.: (continued)

\begin{tabular}{|c|c|c|c|c|c|}
\hline $\begin{array}{l}\text { Key } \\
\text { Publication }\end{array}$ & Research Question/Purpose & $\begin{array}{l}\text { Research } \\
\text { Approach }\end{array}$ & Indicators & Control Factors & $\begin{array}{l}\text { Process } \\
\text { Stage }\end{array}$ \\
\hline $\begin{array}{l}\text { Johnston } \\
(2005)\end{array}$ & $\begin{array}{l}\text { "How the conflicts related to economic and } \\
\text { social agency within particular public sec- } \\
\text { tor performance measurement arrangements } \\
\text { can work for and against the application of } \\
\text { balanced scorecard style systems" }\end{array}$ & Case study & $\begin{array}{l}\text { Gondolier } \\
\text { Italian } \\
\text { companies }\end{array}$ & $\begin{array}{l}\text { Technical } \\
\text { control, Social } \\
\text { control }\end{array}$ & Use \\
\hline $\begin{array}{l}\text { Micheli and } \\
\text { Kennerley } \\
(2005)\end{array}$ & $\begin{array}{l}\text { "To review frameworks currently developed } \\
\text { and implemented in public and non- profit } \\
\text { organizations and to identify the require- } \\
\text { ments of a framework for new contexts" }\end{array}$ & Case study & $\begin{array}{l}\text { Review of } \\
\text { three PMS }\end{array}$ & $\begin{array}{l}\text { Technical } \\
\text { control, }\end{array}$ & Design, Use \\
\hline $\begin{array}{l}\text { Mol and } \\
\text { Beeres } \\
(2005)\end{array}$ & $\begin{array}{l}\text { "To stress out the need to adjust perform- } \\
\text { ance management to the deficiencies inher- } \\
\text { ent in the output controls" }\end{array}$ & $\begin{array}{l}\text { Action } \\
\text { research }\end{array}$ & $\begin{array}{l}\text { The } \\
\text { Netherlands } \\
\text { defence } \\
\text { forces }\end{array}$ & $\begin{array}{l}\text { Technical } \\
\text { control, Dynamic } \\
\text { change, Social } \\
\text { control }\end{array}$ & Use \\
\hline $\begin{array}{l}\text { Nudurupati } \\
\text { and Bititci } \\
(2005)\end{array}$ & $\begin{array}{l}\text { "To implement IT-PMS: assess the impact } \\
\text { of IT-PMS on management and business, } \\
\text { identify the factors supporting IT-PMS that } \\
\text { were impacting management and business, } \\
\text { establish the pattern of occurrence of the } \\
\text { factors impacting on management and busi- } \\
\text { ness" }\end{array}$ & Case study & $\begin{array}{l}46 \\
\text { interviewees }\end{array}$ & $\begin{array}{l}\text { Social controls, } \\
\text { Technical controls }\end{array}$ & $\begin{array}{l}\text { Design, } \\
\text { Implementa- } \\
\text { tion, } \\
\text { Use }\end{array}$ \\
\hline $\begin{array}{l}\text { Turner et } \\
\text { al. }(2005)\end{array}$ & $\begin{array}{l}\text { "This paper describes how performance } \\
\text { measures were selected and then implemen- } \\
\text { ted in two small to medium size enterprises } \\
\text { (SMEs) in Central Scotland" }\end{array}$ & $\begin{array}{l}\text { Literature } \\
\text { Review }\end{array}$ & 2 SMEs & Social control & Use \\
\hline
\end{tabular}


Table A.1.1.: (continued)

\begin{tabular}{|c|c|c|c|c|c|}
\hline $\begin{array}{l}\text { Key } \\
\text { Publication }\end{array}$ & Research Question/Purpose & $\begin{array}{l}\text { Research } \\
\text { Approach }\end{array}$ & Indicators & Control Factors & $\begin{array}{l}\text { Process } \\
\text { Stage }\end{array}$ \\
\hline $\begin{array}{l}\text { Wouters } \\
\text { and Sportel } \\
(2005)\end{array}$ & $\begin{array}{l}\text { "To investigate the role of existing, local per- } \\
\text { formance measures in the process of devel- } \\
\text { oping and implementing an integrated per- } \\
\text { formance measurement system" }\end{array}$ & Case study & $\begin{array}{l}28 \\
\text { interviews, } \\
61 \text { meetings } \\
\text { in a Dutch } \\
\text { brewing } \\
\text { company }\end{array}$ & $\begin{array}{l}\text { Technical control } \\
\text { Social control }\end{array}$ & $\begin{array}{l}\text { Use, Imple- } \\
\text { mentation }\end{array}$ \\
\hline $\begin{array}{l}\text { Sharma and } \\
\text { Bhagwat } \\
(2006)\end{array}$ & $\begin{array}{l}\text { "To develop a framework that measures and } \\
\text { evaluates performance" }\end{array}$ & Survey & $\begin{array}{l}147 \text { Indian } \\
\text { firms }\end{array}$ & $\begin{array}{l}\text { Technical } \\
\text { control, Dynamic } \\
\text { change, Social } \\
\text { control }\end{array}$ & Use \\
\hline $\begin{array}{l}\text { Wijngaard } \\
\text { et al. } \\
(2006)\end{array}$ & $\begin{array}{l}\text { "To link concepts from organisational and } \\
\text { social psychology to production planning } \\
\text { and control" }\end{array}$ & $\begin{array}{l}\text { Action } \\
\text { research }\end{array}$ & $\begin{array}{l}11 \text { manufac- } \\
\text { turing } \\
\text { firms }\end{array}$ & Technical control & Use \\
\hline $\begin{array}{l}\text { Yilmaz and } \\
\text { Bititci } \\
(2006)\end{array}$ & $\begin{array}{l}\text { "To compare the performance measurement } \\
\text { of manufacturing and tourism industries } \\
\text { from a value chain perspective" }\end{array}$ & Conceptual & $\begin{array}{l}\text { Literature } \\
\text { output }\end{array}$ & $\begin{array}{l}\text { Technical } \\
\text { control, Social } \\
\text { control }\end{array}$ & Use \\
\hline $\begin{array}{l}\text { Franco- } \\
\text { Santos et } \\
\text { al. }(2007)\end{array}$ & $\begin{array}{l}\text { "To identify the key characteristics of a } \\
\text { Business Performance Measurement sys- } \\
\text { tem" }\end{array}$ & Literature & $\begin{array}{l}\text { Document } \\
\text { analysis }\end{array}$ & Technical control & Use \\
\hline $\begin{array}{l}\text { Ukko et al. } \\
(2007)\end{array}$ & $\begin{array}{l}\text { "To investigate the impacts of performance } \\
\text { measurement (PM) on management and } \\
\text { leadership" }\end{array}$ & Case study & $\begin{array}{l}28 \\
\text { companies }\end{array}$ & $\begin{array}{l}\text { Technical } \\
\text { control, Social } \\
\text { control }\end{array}$ & Use \\
\hline $\begin{array}{l}\text { Carpinetti } \\
\text { et al. } \\
(2008)\end{array}$ & $\begin{array}{l}\text { "To model for performance measurement } \\
\text { and management of a cluster based on the } \\
\text { concepts of the Balanced Scorecard and } \\
\text { other models" }\end{array}$ & $\begin{array}{l}\text { Action } \\
\text { research }\end{array}$ & Clusters & $\begin{array}{l}\text { Technical control } \\
\text { Social control }\end{array}$ & Design, Use \\
\hline
\end{tabular}


Table A.1.1.: (continued)

\begin{tabular}{|c|c|c|c|c|c|}
\hline $\begin{array}{l}\text { Key } \\
\text { Publication }\end{array}$ & Research Question/Purpose & $\begin{array}{l}\text { Research } \\
\text { Approach }\end{array}$ & Indicators & Control Factors & $\begin{array}{l}\text { Process } \\
\text { Stage }\end{array}$ \\
\hline $\begin{array}{l}\text { Pongatichat } \\
\text { and } \\
\text { Johnston } \\
(2008)\end{array}$ & $\begin{array}{l}\text { "To explore the possibility that some degree } \\
\text { of misalignment between performance meas- } \\
\text { ures and strategy, far from being counterpro- } \\
\text { ductive" }\end{array}$ & 30 interviews & $\begin{array}{l}\text { Public } \\
\text { sector }\end{array}$ & Technical control & Use \\
\hline $\begin{array}{l}\text { Broadbent } \\
\text { and } \\
\text { Laughlin } \\
(2009)\end{array}$ & $\begin{array}{l}\text { "Studies the interrelationships among } \\
\text { strategy systems, PMMs and organizational } \\
\text { change programmes within Pettigrew's } \\
\text { model" }\end{array}$ & Conceptual & $\begin{array}{l}\text { Theoretical } \\
\text { frameworks }\end{array}$ & $\begin{array}{l}\text { Technical control } \\
\text { Dynamic change }\end{array}$ & $\begin{array}{l}\text { Design, } \\
\text { Implementa- } \\
\text { tion, } \\
\text { Use }\end{array}$ \\
\hline $\begin{array}{l}\text { Haponava } \\
\text { and } \\
\text { Al-Jibouri } \\
(2009)\end{array}$ & $\begin{array}{l}\text { "To identify process-based KPIs for use in } \\
\text { control of the pre-project stage" }\end{array}$ & $\begin{array}{l}\text { Case study } \\
\text { and } \\
\text { Literature } \\
\text { review }\end{array}$ & Company & $\begin{array}{l}\text { Technical control } \\
\text { Dynamic change, } \\
\text { Social control }\end{array}$ & Design, Use \\
\hline $\begin{array}{l}\text { Elzinga et } \\
\text { al. (2009) }\end{array}$ & $\begin{array}{l}\text { "The role of behavioural factors in the use } \\
\text { of performance management systems" }\end{array}$ & Case study & $\begin{array}{l}4 \text { Dutch or- } \\
\text { ganisations }\end{array}$ & $\begin{array}{l}\text { Technical } \\
\text { control, Social } \\
\text { control }\end{array}$ & Use \\
\hline $\begin{array}{l}\text { Ferreira } \\
\text { and Otley } \\
(2009)\end{array}$ & $\begin{array}{l}\text { "To describe the structure and operation of } \\
\text { performance management systems (PMSs) } \\
\text { in a more holistic manner" }\end{array}$ & Observation & Company & $\begin{array}{l}\text { Technical } \\
\text { control, Dynamic } \\
\text { change, Social } \\
\text { control }\end{array}$ & $\begin{array}{l}\text { Design, } \\
\text { Implementa- } \\
\text { tion, } \\
\text { Use }\end{array}$ \\
\hline $\begin{array}{l}\text { Hansen } \\
(2010)\end{array}$ & $\begin{array}{l}\text { "The paper presents an analysis of the resol- } \\
\text { ution of organisational externalities through } \\
\text { the use of nonfinancial performance meas- } \\
\text { ures for planning" }\end{array}$ & $\begin{array}{l}\text { Comparative } \\
\text { Case study }\end{array}$ & $\begin{array}{l}\text { Financial } \\
\text { sector }\end{array}$ & $\begin{array}{l}\text { Technical } \\
\text { control, Social } \\
\text { control }\end{array}$ & Use \\
\hline
\end{tabular}


Table A.1.1.: (continued)

\begin{tabular}{|c|c|c|c|c|c|}
\hline $\begin{array}{l}\text { Key } \\
\text { Publication }\end{array}$ & Research Question/Purpose & $\begin{array}{l}\text { Research } \\
\text { Approach }\end{array}$ & Indicators & Control Factors & $\begin{array}{l}\text { Process } \\
\text { Stage }\end{array}$ \\
\hline $\begin{array}{l}\text { Toor and } \\
\text { Ogunlana } \\
(2010)\end{array}$ & $\begin{array}{l}\text { "To investigate the perception of the key } \\
\text { performance indicators (KPIs) in the con- } \\
\text { text of a large construction project in Thai- } \\
\text { land" }\end{array}$ & Survey & $\begin{array}{l}\text { Construction } \\
\text { companies }\end{array}$ & Technical control & Use \\
\hline $\begin{array}{l}\text { van } \\
\text { Veen-Dirks } \\
(2010)\end{array}$ & $\begin{array}{l}\text { "To examine the importance that is at- } \\
\text { tributed to a variety of financial and non- } \\
\text { financial performance measures" }\end{array}$ & Survey & $\begin{array}{l}\text { Financial } \\
\text { sector }\end{array}$ & $\begin{array}{l}\text { Technical } \\
\text { control, Social } \\
\text { control }\end{array}$ & Design, Use \\
\hline $\begin{array}{l}\text { Adler } \\
(2011)\end{array}$ & $\begin{array}{l}\text { "To examine how performance management } \\
\text { systems are designed to meet and sup- } \\
\text { port the implementation of a confrontation } \\
\text { strategy" }\end{array}$ & Case Study & 9 companies & Technical control & $\begin{array}{l}\text { Use, Imple- } \\
\text { mentation }\end{array}$ \\
\hline $\begin{array}{l}\text { Braz et al. } \\
\text { (2011) }\end{array}$ & $\begin{array}{l}\text { "To show difficulty and complexity of re- } \\
\text { viewing and updating an energy company's } \\
\text { PMS for its maritime transportation area" }\end{array}$ & $\begin{array}{l}\text { Action } \\
\text { research }\end{array}$ & Company & $\begin{array}{l}\text { Technical } \\
\text { control, Dynamic } \\
\text { change }\end{array}$ & $\begin{array}{l}\text { Design, } \\
\text { Implementa- } \\
\text { tion, } \\
\text { Use }\end{array}$ \\
\hline $\begin{array}{l}\text { Jain et al. } \\
\text { (2011) }\end{array}$ & $\begin{array}{l}\text { "Presents a data envelopment analysis } \\
\text { (DEA) based approach for performance } \\
\text { measurement and target setting of manufac- } \\
\text { turing systems" }\end{array}$ & Case study & Manufacturing & g Technical control & Use \\
\hline $\begin{array}{l}\text { Nudurupati } \\
\text { et al. } \\
(2011 b)\end{array}$ & $\begin{array}{l}\text { "To review literature on the role of MIS and } \\
\text { change management throughout the lifecycle } \\
\text { of performance measurement, i.e. design, } \\
\text { implementation and use stages" }\end{array}$ & Literature & Conceptual & $\begin{array}{l}\text { Technical and } \\
\text { Social controls }\end{array}$ & $\begin{array}{l}\text { Design, } \\
\text { Implementa- } \\
\text { tion, } \\
\text { User }\end{array}$ \\
\hline $\begin{array}{l}\text { Pavlov and } \\
\text { Bourne } \\
(2011)\end{array}$ & $\begin{array}{l}\text { "To propose a theoretical model of measure- } \\
\text { ment on performance" }\end{array}$ & $\begin{array}{l}\text { Review of } \\
\text { PM Systems }\end{array}$ & Conceptual & Technical control & Use \\
\hline
\end{tabular}


Table A.1.1.: (continued)

\begin{tabular}{|c|c|c|c|c|c|}
\hline $\begin{array}{l}\text { Key } \\
\text { Publication }\end{array}$ & Research Question/Purpose & $\begin{array}{l}\text { Research } \\
\text { Approach }\end{array}$ & Indicators & Control Factors & $\begin{array}{l}\text { Process } \\
\text { Stage }\end{array}$ \\
\hline Sillanpää (20 & $\begin{array}{l}\text { "To identify the focal elements of perform- } \\
\text { Jannce in Finnish welfare service organisa- } \\
\text { tions" }\end{array}$ & Case study & $\begin{array}{l}15 \\
\text { interviews in } \\
\text { welfare } \\
\text { services }\end{array}$ & Technical control & Use \\
\hline $\begin{array}{l}\text { Tung et al. } \\
\text { (2011) }\end{array}$ & $\begin{array}{l}\text { "To examine the association between the use } \\
\text { of multidimensional performance measures } \\
\text { and factors that affect the effectiveness of } \\
\text { PMSs" }\end{array}$ & Survey & $\begin{array}{l}\text { Australian } \\
\text { manufactur- } \\
\text { ing } \\
\text { organiza- } \\
\text { tions }\end{array}$ & $\begin{array}{l}\text { Technical } \\
\text { control, Social } \\
\text { control }\end{array}$ & Use \\
\hline $\begin{array}{l}\text { Valmoha- } \\
\text { mmadi and } \\
\text { Servati } \\
(2011)\end{array}$ & $\begin{array}{l}\text { "To design and implement a performance } \\
\text { management system using third-generation } \\
\text { Balanced Scorecard (BSC) to compare and } \\
\text { evaluate some strategic measures of the com- } \\
\text { pany against those of a leading company" }\end{array}$ & Case study & $\begin{array}{l}24 \\
\text { comparative } \\
\text { managers } \\
\text { cases }\end{array}$ & $\begin{array}{l}\text { Technical control } \\
\text { Dynamic change, } \\
\text { Social control }\end{array}$ & $\begin{array}{l}\text { Design, } \\
\text { Implementa- } \\
\text { tion, } \\
\text { Use }\end{array}$ \\
\hline $\begin{array}{l}\text { Chalmeta } \\
\text { et al. } \\
(2012)\end{array}$ & $\begin{array}{l}\text { "To propose a methodology for designing } \\
\text { and implementing PMS adapted to the char- } \\
\text { acteristics of SMEs" }\end{array}$ & Case study & $22 \mathrm{SME}$ & $\begin{array}{l}\text { Technical } \\
\text { controls, social } \\
\text { controls }\end{array}$ & Implementation \\
\hline $\begin{array}{l}\text { Pedersen } \\
\text { and } \\
\text { Sudzina } \\
(2012)\end{array}$ & $\begin{array}{l}\text { "To outline the anatomy of firms which } \\
\text { adopt comprehensive performance measure- } \\
\text { ment systems in order to gain an under- } \\
\text { standing of how internal (organisational cap- } \\
\text { abilities) and external (perceived environ- } \\
\text { mental uncertainties) factors shape perform- } \\
\text { ance measurement practices" }\end{array}$ & Sur & Danish firms & $\begin{array}{l}\text { Technical } \\
\text { control, Social } \\
\text { control }\end{array}$ & Use \\
\hline
\end{tabular}


Table A.1.1.: (continued)

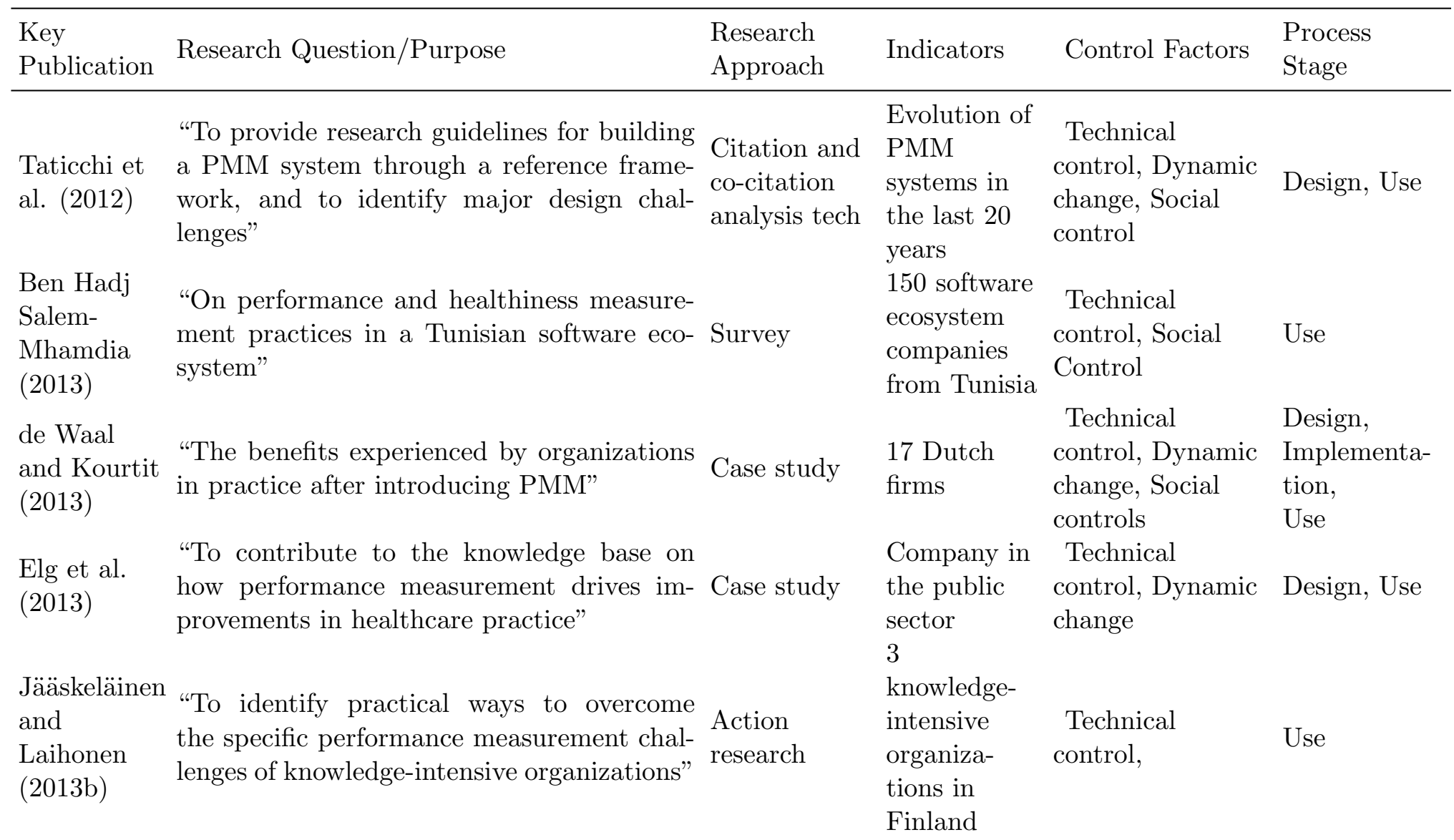


Table A.1.1.: (continued)

\begin{tabular}{|c|c|c|c|c|c|}
\hline $\begin{array}{l}\text { Key } \\
\text { Publication }\end{array}$ & Research Question/Purpose & $\begin{array}{l}\text { Research } \\
\text { Approach }\end{array}$ & Indicators & Control Factors & $\begin{array}{l}\text { Process } \\
\text { Stage }\end{array}$ \\
\hline $\begin{array}{l}\text { Jääskeläinen } \\
\text { and Sil- } \\
\text { lanpää (2013) }\end{array}$ & $\begin{array}{l}\text { "To evaluate factors affecting the success of } \\
\text { the measurement system implementation in } \\
\text { the context of two case services with a spe- } \\
\text { cific measurement object" }\end{array}$ & Case study & $\begin{array}{l}22 \\
\text { interviews in } \\
\text { Social } \\
\text { services in } \\
\text { Finland }\end{array}$ & Technical control & Design, Use \\
\hline $\begin{array}{l}\text { Vernadat et } \\
\text { al. }(2013)\end{array}$ & $\begin{array}{l}\text { "To propose new performance measurement } \\
\text { and management framework based on value } \\
\text { and risk" }\end{array}$ & Case study & Company & Technical control & Design, Use \\
\hline $\begin{array}{l}\text { Caniato et } \\
\text { al. }(2014)\end{array}$ & $\begin{array}{l}\text { "Understanding what are the most adopted } \\
\text { indicators, what are the key elements char- } \\
\text { acterising the implementation process and } \\
\text { what are the differences" }\end{array}$ & Case study & $\begin{array}{l}9 \text { large mul- } \\
\text { tinationals } \\
\text { of different } \\
\text { industries }\end{array}$ & $\begin{array}{l}\text { Technical control } \\
\text { Social control }\end{array}$ & Use \\
\hline $\begin{array}{l}\text { Garengo } \\
\text { and Sharma } \\
(2014)\end{array}$ & $\begin{array}{l}\text { "To investigate the role of corporate gov- } \\
\text { ernance structure as a PMS contingency } \\
\text { factor" }\end{array}$ & Case study & $\begin{array}{l}\text { Italian/Indian } \\
\text { SMEs }\end{array}$ & $\begin{array}{l}\text { Technical } \\
\text { control, Social } \\
\text { control }\end{array}$ & Use \\
\hline $\begin{array}{l}\text { Laihonen et } \\
\text { al. (2014) }\end{array}$ & $\begin{array}{l}\text { "To investigate the implications of the net- } \\
\text { worked and open nature of the service busi- } \\
\text { ness on performance measurement" }\end{array}$ & Case study & $\begin{array}{l}2 \text { companies } \\
\text { of the public } \\
\text { and private } \\
\text { sector }\end{array}$ & $\begin{array}{l}\text { Technical } \\
\text { control, Dynamic } \\
\text { change, Social } \\
\text { control }\end{array}$ & $\begin{array}{l}\text { Design, } \\
\text { Implementa- } \\
\text { tion, } \\
\text { Use }\end{array}$ \\
\hline $\begin{array}{l}\text { Melnyk et } \\
\text { al. }(2014)\end{array}$ & $\begin{array}{l}\text { "To resolve the issue of "Fit" of the revised } \\
\text { measures to the needed strategy" }\end{array}$ & $\begin{array}{l}\text { Delphi } \\
\text { approach }\end{array}$ & $\mathrm{N} / \mathrm{A}$ & $\begin{array}{l}\text { Technical } \\
\text { control, Dynamic } \\
\text { change }\end{array}$ & $\begin{array}{l}\text { Use, Imple- } \\
\text { mentation }\end{array}$ \\
\hline $\begin{array}{l}\text { Spekle and } \\
\text { Verbeeten } \\
(2014)\end{array}$ & $\begin{array}{l}\text { "To study the use of performance measure- } \\
\text { ment systems in the public sector" }\end{array}$ & Survey & $\begin{array}{l}101 \text { organiz- } \\
\text { ations of the } \\
\text { public sector }\end{array}$ & $\begin{array}{l}\text { Technical control } \\
\text { Dynamic change, } \\
\text { Social control }\end{array}$ & Use \\
\hline
\end{tabular}


Table A.1.1.: (continued)

\begin{tabular}{|c|c|c|c|c|c|}
\hline $\begin{array}{l}\text { Key } \\
\text { Publication }\end{array}$ & Research Question/Purpose & $\begin{array}{l}\text { Research } \\
\text { Approach }\end{array}$ & Indicators & Control Factors & $\begin{array}{l}\text { Process } \\
\text { Stage }\end{array}$ \\
\hline $\begin{array}{l}\text { Taylor and } \\
\text { Taylor } \\
(2014)\end{array}$ & $\begin{array}{l}\text { "Investigates the influence of organisation } \\
\text { size on the effective implementation of per- } \\
\text { formance measurement systems (PMSs)" }\end{array}$ & Case study & $\begin{array}{l}349 \text { Survey - } \\
\text { Manufactur- } \\
\text { ing }\end{array}$ & $\begin{array}{l}\text { Technical } \\
\text { controls }\end{array}$ & Implementatior \\
\hline $\begin{array}{l}\text { Angelis and } \\
\text { Jordahl } \\
(2015)\end{array}$ & $\begin{array}{l}\text { "To compare management practices in } \\
\text { private and publicly owned elderly care } \\
\text { homes" }\end{array}$ & Survey & 500 homes & Technical control & Use \\
\hline $\begin{array}{l}\text { Bititci et } \\
\text { al. (2015) }\end{array}$ & $\begin{array}{l}\text { "To explore how visual strategy and per- } \\
\text { formance management techniques impact } \\
\text { performance measurement and management } \\
\text { practices of organisations" }\end{array}$ & $\begin{array}{l}\text { Action } \\
\text { research }\end{array}$ & $\begin{array}{l}7 \text { manufac- } \\
\text { turing } \\
\text { firms }\end{array}$ & Technical control & Use \\
\hline $\begin{array}{l}\text { Canonico et } \\
\text { al. (2015) }\end{array}$ & $\begin{array}{l}\text { "To consider how and to what extent it is } \\
\text { possible to interpret a PMS as a typical con- } \\
\text { trol mechanism" }\end{array}$ & Case study & 3 interviews & Technical control & Use \\
\hline $\begin{array}{l}\text { Carlsson- } \\
\text { Wall et al. } \\
(2015)\end{array}$ & $\begin{array}{l}\text { "Role of performance measurement systems } \\
\text { (PMS) in managing the co-existence of dif- } \\
\text { ferent institutional logics" }\end{array}$ & Case study & $\begin{array}{l}\text { Social Or- } \\
\text { ganisation }\end{array}$ & $\begin{array}{l}\text { Technical } \\
\text { control, Dynamic } \\
\text { change, social } \\
\text { control }\end{array}$ & Use \\
\hline
\end{tabular}


Table A.1.2.: Mutual exchanges between actors (interview participants working for each actor in the top row they responded about each actors in the left column)

\begin{tabular}{|c|c|c|c|c|}
\hline ACTORS & Airport Operators & Ground Handlers & Airline Operators & ANSPs \\
\hline $\begin{array}{c}\text { Airport } \\
\text { Operators }\end{array}$ & $\mathrm{N} / \mathrm{A}$ & $\begin{array}{r}\text { Formal Roles: } 1 \\
\text { Informal Roles: } 0 \\
\text { Critical Incidents: } 3 \\
\text { Dependencies: } 1\end{array}$ & $\begin{array}{r}\text { Formal Roles: } 1 \\
\text { Informal Roles: } 0 \\
\text { Critical Incidents: } 3 \\
\text { Dependencies: } 0\end{array}$ & $\begin{array}{r}\text { Formal Roles: } 1 \\
\text { Informal Roles: } 0 \\
\text { Critical Incidents: } 2 \\
\text { Dependencies: } 1\end{array}$ \\
\hline $\begin{array}{l}\text { Ground } \\
\text { Handlers }\end{array}$ & $\begin{array}{r}\text { Formal Roles: } 1 \\
\text { Informal Roles: } 1 \\
\text { Critical Incidents: } 3 \\
\text { Dependencies: } 1\end{array}$ & $\mathrm{~N} / \mathrm{A}$ & $\begin{array}{r}\text { Formal Roles: } 1 \\
\text { Informal Roles: } 1 \\
\text { Critical Incidents: } 3 \\
\text { Dependencies: } 1\end{array}$ & $\begin{array}{r}\text { Formal Roles: } 0 \\
\text { Informal Roles: } 1 \\
\text { Critical Incidents: } 3 \\
\text { Dependencies: } 1\end{array}$ \\
\hline $\begin{array}{c}\text { Airline } \\
\text { Operators }\end{array}$ & $\begin{array}{r}\text { Formal Roles: } 1 \\
\text { Informal Roles: } 0 \\
\text { Critical Incidents: } 3 \\
\text { Dependencies: } 0\end{array}$ & $\begin{array}{r}\text { Formal Roles: } 1 \\
\text { Informal Roles: } 1 \\
\text { Critical Incidents: } 2 \\
\text { Dependencies: } 1\end{array}$ & $\mathrm{~N} / \mathrm{A}$ & $\begin{array}{r}\text { Formal Roles: } 0 \\
\text { Informal Roles: } 1 \\
\text { Critical Incidents: } 2 \\
\text { Dependencies: } 1\end{array}$ \\
\hline ASNPs & $\begin{array}{r}\text { Formal Roles: } 1 \\
\text { Informal Roles: } 0 \\
\text { Critical Incidents: } 2 \\
\text { Dependencies: } 0\end{array}$ & $\begin{array}{r}\text { Formal Roles: } 0 \\
\text { Informal Roles: } 1 \\
\text { Critical Incidents: } 3 \\
\text { Dependencies: } 1\end{array}$ & $\begin{array}{r}\text { Formal Roles: } 0 \\
\text { Informal Roles: } 1 \\
\text { Critical Incidents: } 2 \\
\text { Dependencies: } 1\end{array}$ & $\mathrm{~N} / \mathrm{A}$ \\
\hline $\begin{array}{l}\text { KEY } \\
\text { Formal Roles: } \\
\text { Informal Roles: }\end{array}$ & $\begin{array}{l}0 \ldots \text { None reported } \\
0 \ldots \text { None reported }\end{array}$ & $\begin{array}{l}1 \ldots \text { Roles reported } \\
1 \ldots \text { Roles reported }\end{array}$ & & \\
\hline $\begin{array}{l}\text { Critical } \\
\text { Incidents: }\end{array}$ & \multicolumn{4}{|c|}{$\begin{array}{l}1 \text {... Critical: e.g. Lack of fuel figures, Change of gates, late arrivals } \\
2 \text {... Very Critical: e.g. Late fueling, Late boarding fo crew, De-icing delays, Runaway traffic } \\
3 \text {... Extremely Critical: e.g. Miscommunication between pilots and ASNPs, Poor weather } \\
\text { conditions }\end{array}$} \\
\hline
\end{tabular}




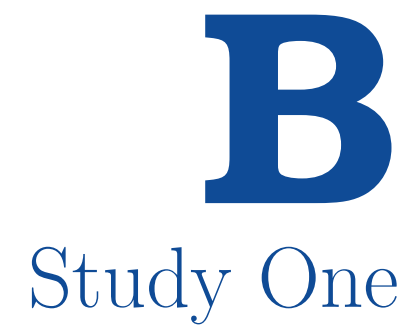




\section{B. Study One}

Table B.1.1.: Profiles of companies participating as turn-round actors.

\begin{tabular}{|c|c|c|c|c|}
\hline Actors & Revenue & Services provided & Ownership & $\begin{array}{l}\text { No. of } \\
\text { employ- } \\
\text { ees }\end{array}$ \\
\hline $\begin{array}{l}\text { Swedavia } \\
\text { (Mannnages } \\
10 \text { airports in } \\
\text { Sweden) }\end{array}$ & $\begin{array}{l}5.2 \\
\text { Billion } \\
\text { SEK }\end{array}$ & $\begin{array}{l}\text { Managing airport estate } \\
\text { and provides resources used } \\
\text { in the turnaround, such as } \\
\text { gates, stands, runways. } \\
\text { Provides Environmental in- } \\
\text { formation, airport slots. } \\
\text { Some flight times, special } \\
\text { events. }\end{array}$ & $\begin{array}{l}\text { State- } \\
\text { owned } \\
\text { enterprise }\end{array}$ & $\begin{array}{l}(2013) \\
2,369\end{array}$ \\
\hline $\begin{array}{l}\text { SAS Airlines } \\
\text { (Number of } \\
\text { passengers: } \\
29.4 \mathrm{M})\end{array}$ & $\begin{array}{l}39 \text { Billion } \\
\text { SEK }\end{array}$ & $\begin{array}{l}\text { Dominannt clients in the } \\
\text { turnaround, providing in- } \\
\text { formation to toher actors, } \\
\text { shares movement data and } \\
\text { flight plan, target turn- } \\
\text { around times and aircraft } \\
\text { type }\end{array}$ & $\begin{array}{l}\text { Private } \\
\text { enterprise } \\
\text { (SAS } \\
\text { Group) }\end{array}$ & $\begin{array}{l}(2014) \\
12,329\end{array}$ \\
\hline $\begin{array}{l}\text { Norwegian } \\
\text { Airlines } \\
\text { (Number of } \\
\text { passengers in } \\
\text { 2014: } 24 \mathrm{M} \text { ) }\end{array}$ & $\begin{array}{l}19,540 \\
\text { Million } \\
\text { NOK }\end{array}$ & $\begin{array}{l}\text { Dominant clients in the } \\
\text { turnaround, providing in- } \\
\text { formation to other actors }\end{array}$ & Private & 4,500 \\
\hline $\begin{array}{l}\mathrm{LFV} \\
\text { (Operates in } \\
26 \text { locations } \\
\text { throughout } \\
\text { Sweden) }\end{array}$ & $\begin{array}{l}2.6 \\
\text { Billion } \\
\text { SEK }\end{array}$ & $\begin{array}{l}\text { Services: Air Traffic Con- } \\
\text { trol Service, remote tower } \\
\text { services }\end{array}$ & $\begin{array}{l}\text { Public en- } \\
\text { terprise }\end{array}$ & 1200 \\
\hline $\begin{array}{l}\text { Menzies } \\
\text { Aviation AB } \\
\text { (Manages } 149 \\
\text { stations in } 31 \\
\text { countries) }\end{array}$ & & $\begin{array}{l}\text { Ground handling services } \\
\text { mainly to arilines and shar- } \\
\text { ing operational data }\end{array}$ & Private & 21,500 \\
\hline $\begin{array}{l}\text { SAS Ground } \\
\text { Handling (30 } \\
\text { stations at } \\
\text { over } 30 \\
\text { ariports) }\end{array}$ & & $\begin{array}{l}\text { Ground handling to air- } \\
\text { lines and sharing opera- } \\
\text { tional data }\end{array}$ & $\begin{array}{l}\text { Private } \\
\text { (SAS } \\
\text { Group) }\end{array}$ & 8,400 \\
\hline $\begin{array}{l}\text { AFCO } \\
\text { AB-Fueling }\end{array}$ & & $\begin{array}{l}\text { Services: Fueling and shar- } \\
\text { ing real time information to } \\
\text { other actors }\end{array}$ & Private & 42 \\
\hline
\end{tabular}


Interview schedule for Airline 

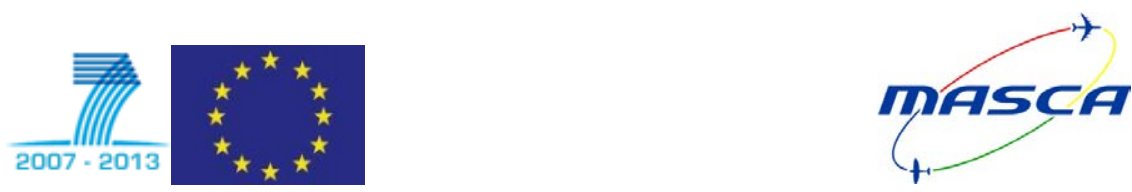

Interview Objectives:

1. Obtain a clear understanding of the challenges involved in the implementation of A-CDM

2. Obtain sufficient understanding of these challenges to feed into training design

General

1. How long have you been in your role?

2. There were a number of recent delays in implementation of A-CDMWhat do you think was the cause of these delays?

3. Will these delays have a knock-on effect on targets for next year?

4. Is there sufficient capability to deliver A-CDM?

5. How does A-CDM benefit Arlanda?

6. How does A-CDM improve your day-to-day working life?

7. What problems does A-CDM solve?

8. Did you attend any of the bi-weekly meetings?

9. If "yes": Were the meetings effective?

If "no": Do you know someone from your organisation that attended the meetings?

Milestones/Process

10. From this diagram (show global 16 milestone diagram), could you tell me which are the most critical points for airline operations?

11. From the following diagram (show global 16 milestone diagram), which are the most critical points for the turnaround process from an overall A-CDM point of view?

12. What are the key gaps between the previous working practices and ACDM?

Information Systems

13. Are there any barriers to you giving or receiving information for A-CDM? a. How well do the information systems support A-CDM?

b. Do you have all the information you need to be able to do your job under the new A-CDM working practices?

c. Is there a clear way of working understood by all stakeholders?

Team

1. Are the relationships between stakeholders strong enough to make ACDM work?

2. What needs to be done to strengthen those relationships from a training point of view?

3. We are running a training workshop on 26th November which you would be very welcome at. Will you be able to attend?

a. What are the challenges to developing collaborative teamworking?

b. What are the challenges to developing collaborative leadership?

Professor Lena Mårtensson, KTH (+ 4670660 7723) Dr Siobhan Corrigan,

TCD (+353 1896 2605)

email: lena.martensson@indek.kth.se

siobhan.corrigan@tcd.ie

email: 
c. Are there any issues that couldn't be spoken about openly with other stakeholders?

d. Are there times when you feel that other stakeholders are competitors rather than collaborators?

e. What do your collaborators/competitors do to make you feel this way?

f. Is there sufficient trust to support A-CDM?

g. Do all stakeholders understand one-another well enough to support A-CDM?

Professor Lena Mårtensson, KTH (+ 4670660 7723)

TCD (+353 1896 2605)

email: lena.martensson@indek.kth.se

siobhan.corrigan@tcd.ie
Dr Siobhan Corrigan,

email: 



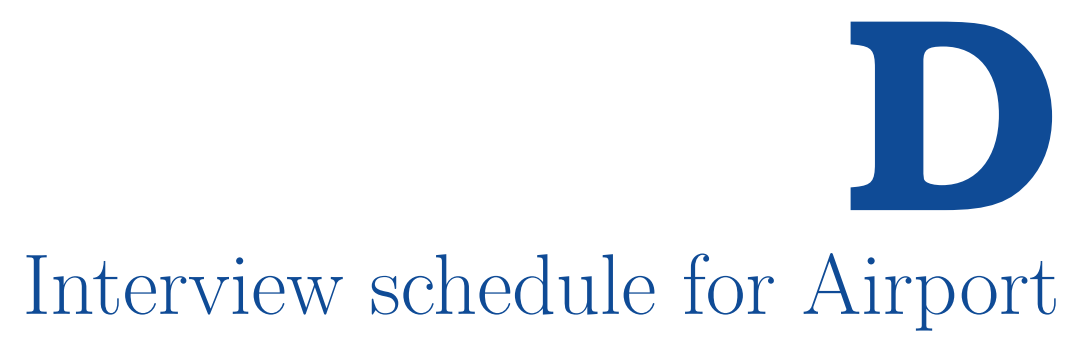



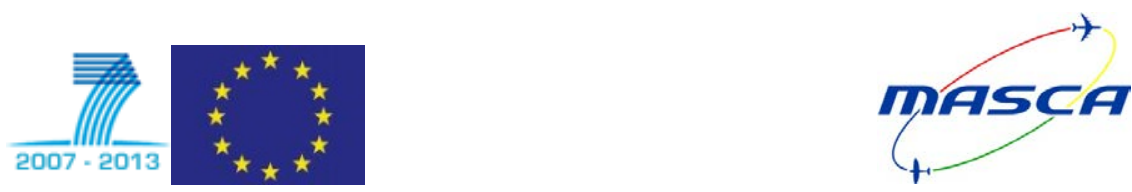

Interview Objectives:

1. Obtain a clear understanding of the challenges involved in the implementation of A-CDM

2. Obtain sufficient understanding of these challenges to feed into training design

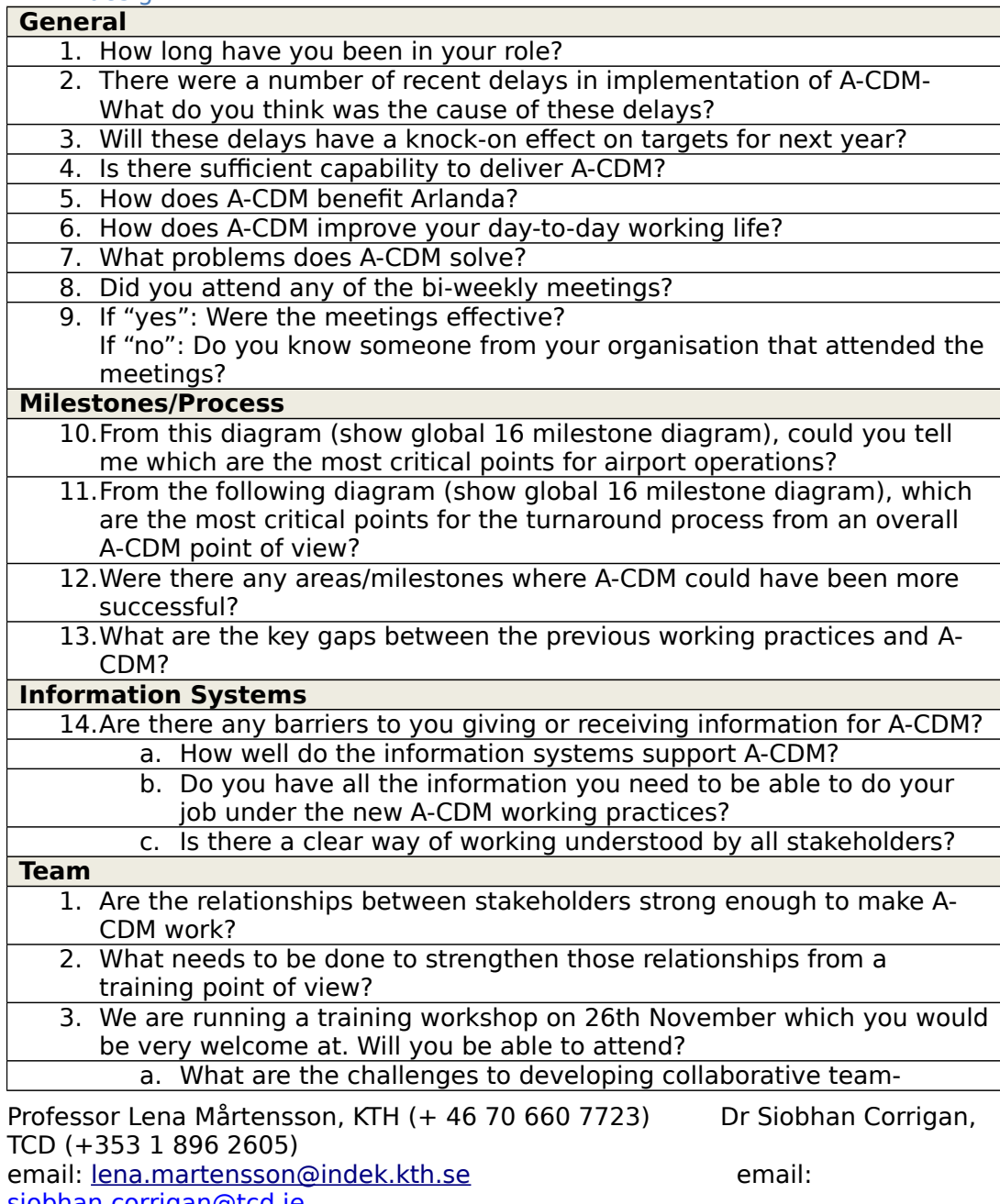

siobhan.corrigan@tcd.ie 
D.1. INTERVIEW SCHEDUlE FOR AIRPORT

IMPLEMENTING A-CDM AT ARLANDA AIRPORT

\begin{tabular}{|l|}
\hline working? \\
\hline b. What are the challenges to developing collaborative leadership? \\
\hline c. Are there any issues that couldn't be spoken about openly with \\
other stakeholders?
\end{tabular}

Professor Lena Mårtensson, KTH (+ 4670660 7723)

TCD (+353 1896 2605)

email: lena.martensson@indek.kth.se

siobhan.corrigan@tcd.ie
Dr Siobhan Corrigan,

email: 



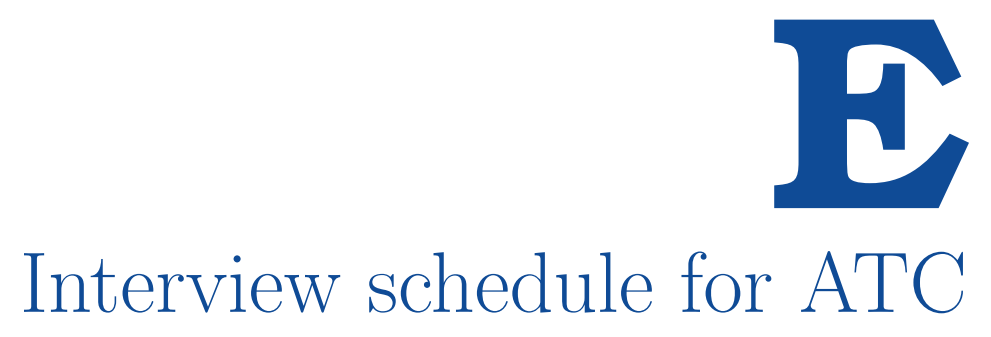




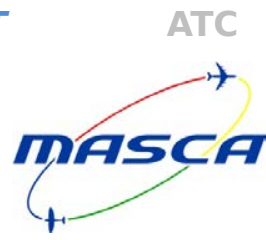

Interview Objectives:

1. Obtain a clear understanding of the challenges involved in the implementation of A-CDM

2. Obtain sufficient understanding of these challenges to feed into training design

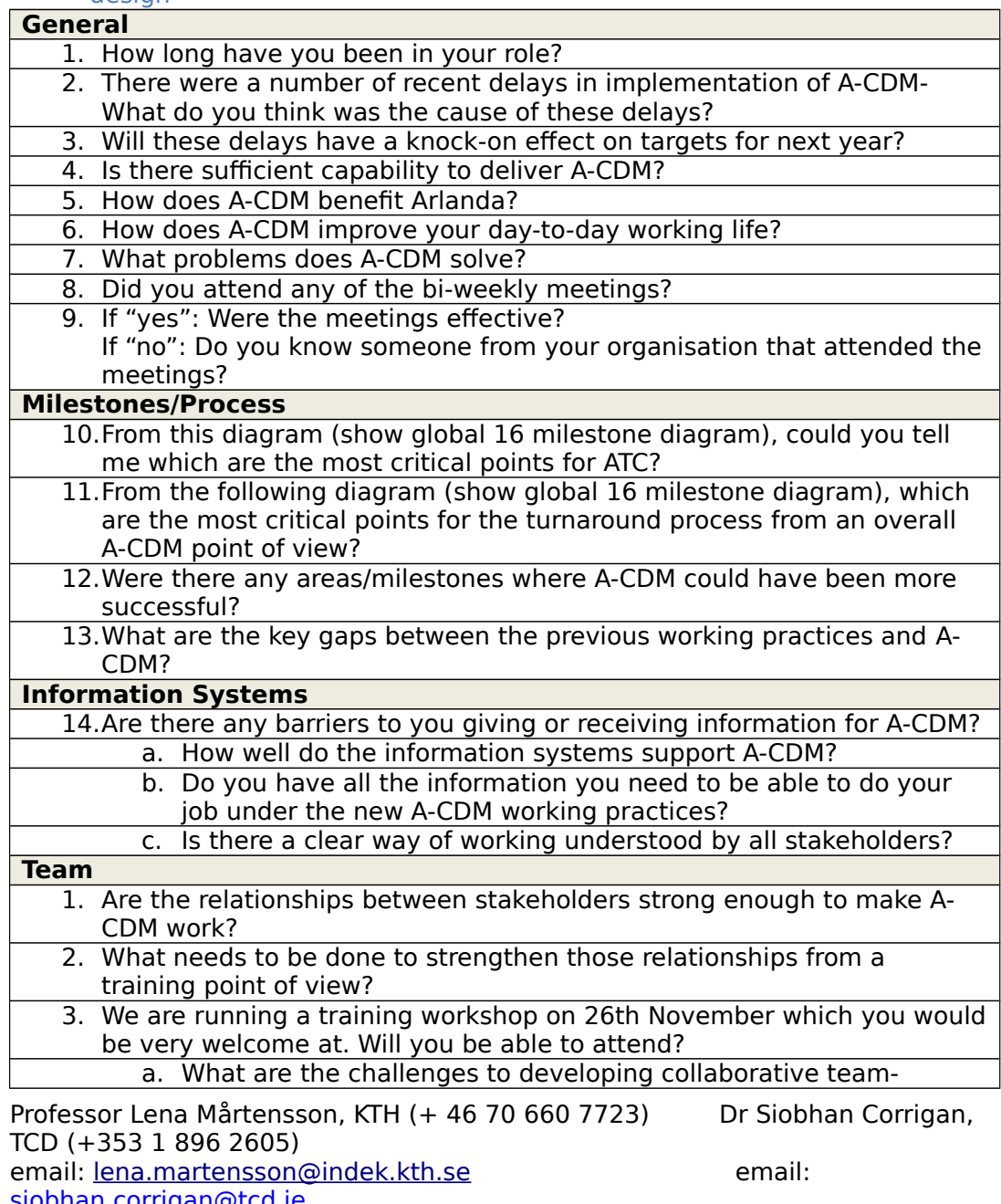

siobhan.corrigan@tcd.ie 
E.1. Interview SCHEDULE FOR ATC

IMPLEMENTING A-CDM AT ARLANDA AIRPORT

working?

b. What are the challenges to developing collaborative leadership?

c. Are there any issues that couldn't be spoken about openly with other stakeholders?

d. Are there times when you feel that other stakeholders are competitors rather than collaborators?

e. What do your collaborators/competitors do to make you feel this way?

f. Is there sufficient trust to support A-CDM?

g. Do all stakeholders understand one-another well enough to support A-CDM?

Professor Lena Mårtensson, KTH (+ 46706607723 )

TCD (+353 1896 2605)

email: lena.martensson@indek.kth.se

siobhan.corrigan@tcd.ie
Dr Siobhan Corrigan,

email: 



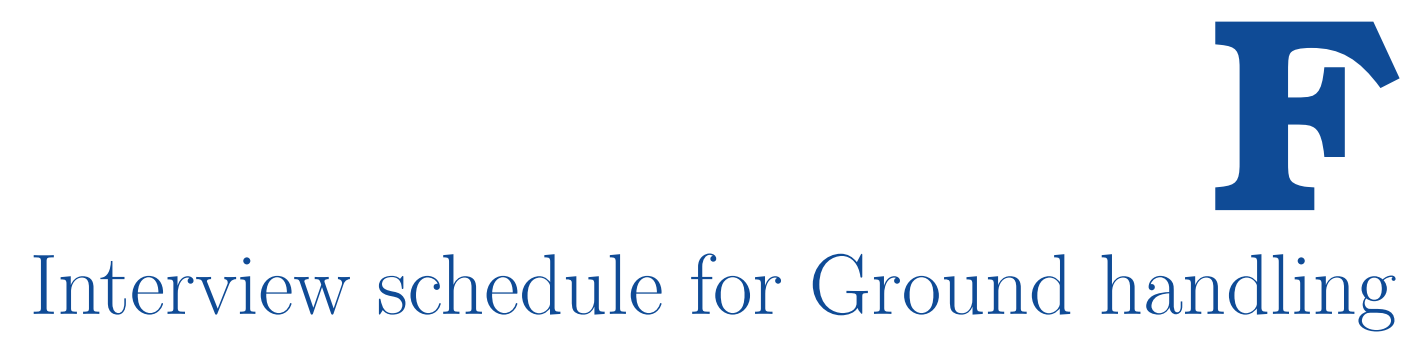




\section{F. InTERVIEW SCHEDULE FOR GROUND HANDLING}

IMPLEMENTING A-CDM AT ARLANDA AIRPORT

Handling
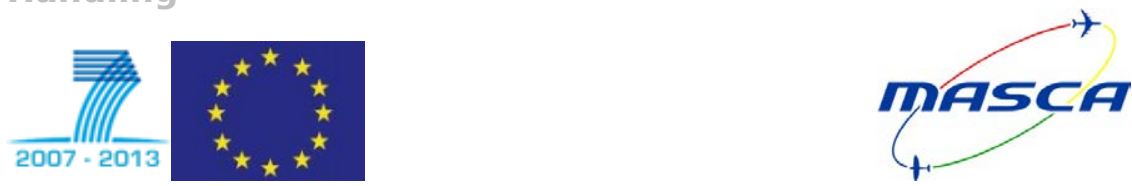

Interview Objectives:

1. Obtain a clear understanding of the challenges involved in the implementation of A-CDM

2. Obtain sufficient understanding of these challenges to feed into training design

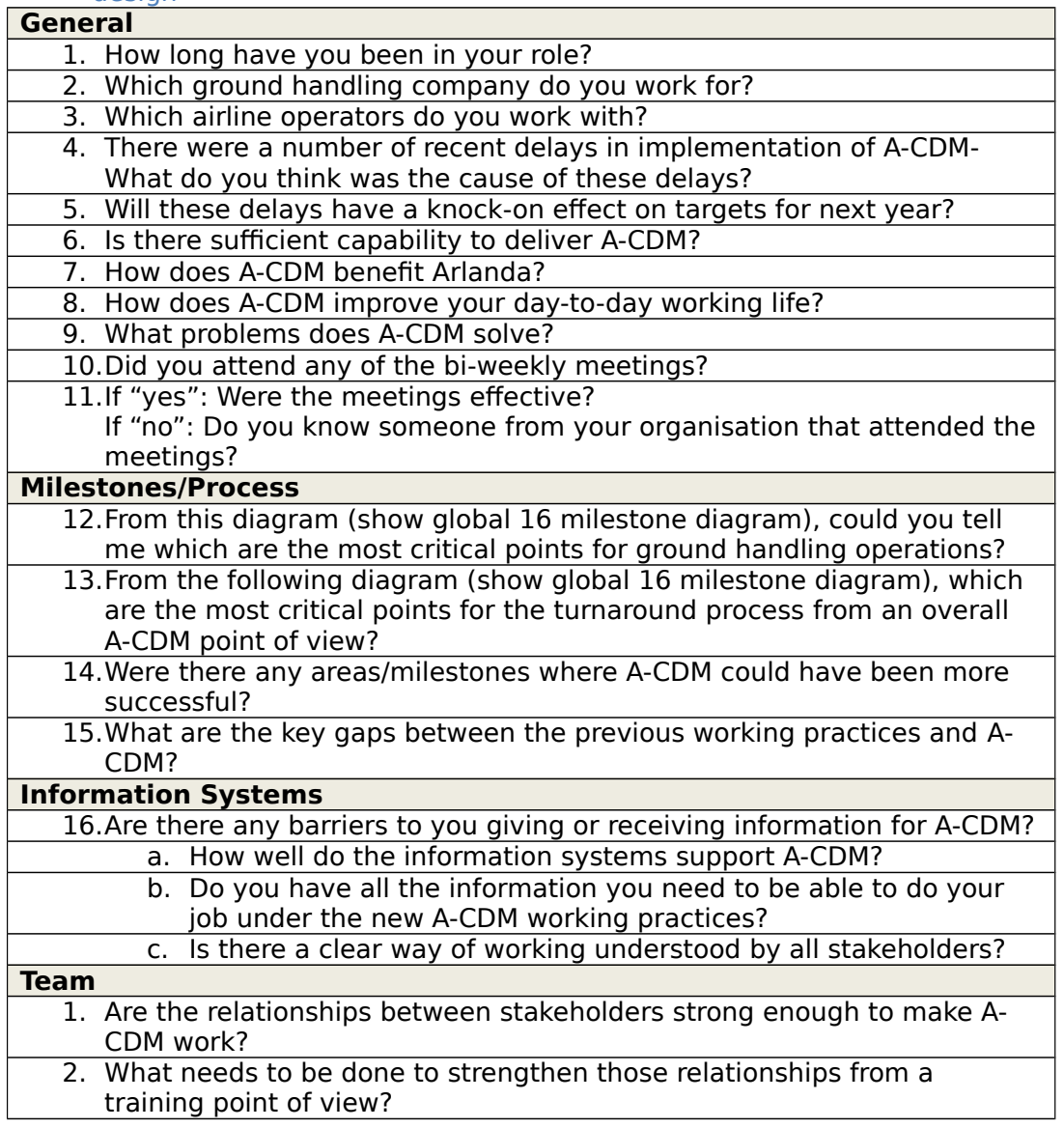

Professor Lena Mårtensson, KTH (+ 4670660 7723)

TCD (+353 1896 2605)

email: lena.martensson@indek.kth.se

Dr Siobhan Corrigan,

siobhan.corrigan@tcd.ie

email: 
3. We are running a training workshop on 26th November which you would be very welcome at. Will you be able to attend?

a. What are the challenges to developing collaborative teamworking?

b. What are the challenges to developing collaborative leadership?

c. Are there any issues that couldn't be spoken about openly with other stakeholders?

d. Are there times when you feel that other stakeholders are competitors rather than collaborators?

e. What do your collaborators/competitors do to make you feel this way?

f. Is there sufficient trust to support A-CDM?

g. Do all stakeholders understand one-another well enough to support A-CDM?

Professor Lena Mårtensson, KTH (+ 46706607723 )

TCD (+353 1896 2605)

email: lena.martensson@indek.kth.se

siobhan.corrigan@tcd.ie
Dr Siobhan Corrigan,

email: 



\section{References}

Ashmos, D., Duchon, D., McDaniel, R. and Huonker, J. (2002), "What a mess! Participation as a simple managerial rule to 'complexify' organizations", Journal of Management Studies, Vol. 39, No. 2, pp.189-206.

Alter, S. (2008), "Service system fundamentals: Work system, value chain, and life cycle", IBM Systems Journal, Vol. 47 No. 1, pp. 71-85.

Anderson, P.W. (1999), "Complexity Theory and Organization Science", Organization Science, Vol. 10 No. 3, pp. 216-232.

Angelis, J. and Jordahl, H. (2015), "Merciful yet effective elderly care performance management practices", Measuring Business Excellence, Vol. 19 No. 1, p. 61.

Auerbach, S. and Koch, B. (2007), "Cooperative approaches to managing air traffic efficiently-the airline perspective", Journal of Air Transport Management, Vol. 13 No. 1, pp. 37-44.

van Bakel, M., van Oudenhoven, P., Marinel, G., King, K.A., Authors, F., King, K.A., Goel, A., et al. (2015), "Performance measurement and management in practice Advantages, disadvantages and reasons for use", pp. $1-6$.

Beer, S. (2002), "What is cybernetics?", Kybernetes, Vol. 31 No. 2, pp. 209-219.

Bertallanffy, L. (1969), "General System Theory: Foundations, Development, Applications".

Bititci, U., Cocca, P. and Ates, A. (2015), "Impact of visual performance management systems on the performance management practices of organisations", International Journal of Production Research, Vol. 7543 No. October, pp. 1-23.

Bititci, U., Garengo, P., Dörfler, V. and Nudurupati, S. (2012), "Performance Measurement: Challenges for Tomorrow", International Journal of Management Reviews, Vol. 14 No. 3, pp. 305-327.

Bititci, U., Mendibil, K., Nudurupati, S.S. and Garengo, P. (2006), Dynamics of Performance Measurement and Organizational Culture, International Journal of Operations \&5 Production Management, Vol. 26, available at:http://doi.org/10.1108/01443570610710579.

Bititci, U.S. (2015a), Managing Business Performance, edited by Bititci, U.S., 


\section{F. InTERVIEW SCHEDULE FOR GROUND HANDLING}

John Wiley \& Sons, Inc., Hoboken, NJ, USA, available at: http:// doi.org/10.1002/9781119166542.

Bititci, U.S. (2015b), "Balancing Organisational Controls".

Bititci, U.S., Carrie, A.S. and McDevitt, L. (1997), "Integrated performance measurement systems: a development guide", International Journal of ..., Vol. 17 No. 5, pp. 522-534.

Bititci, U.S., Mendibil, K., Martinez, V. and Albores, P. (2005), "Measuring and managing performance in extended enterprisesnull", International Journal of Operations 85 Production Management, Vol. 25 No. 4, pp. 333-353.

Bititci, U.S., Turner, Ut. and Begemann, C. (2000), "Dynamics of performance measurement systems", International Journal of Operations $\&$ Production Management, Vol. 20 No. 6, pp. 692-704.

Bond, T.C. (1990), "The role of performance measurement in continuous improvement", International Journal of Operations $\&$ Production Management, Vol. 1318, pp. 1318-1334.

Boulding, K.E. (1956), "General Systems Theory-The Skeleton of Science Author ( $\mathrm{s}$ ): Kenneth E . Boulding Published by: INFORMS Stable URL: http://www.jstor.org/stable/2627132

Accessed: 01-03-2016 08: 02 UTC Your use of the JSTOR archive indicates your acceptance of the Term", Vol. 2 No. 3, pp. 197-208.

Bourne, M., Mills, J., Wilcox, M., Neely, a and Platts, K. (2000), "Designing, implementing and updating performance measurement systems", International Journal of Operations \& Production Management, Vol. 20 No. 7, pp. $754-771$.

Bourne, M., Neely, A., Mills, J., Platts, K., Bourne, M., Neely, A., Mills, J., et al. (2003), "Implementing performance measurement systems: a literature review", Int. J. Business Performance Management, Vol. 5 No. 1, pp. $1-24$.

Bourne, M., Neely, A., Platts, K. and Mills, J. (2002), "The success and failure of performance measurement initiatives", International Journal of Operations $\&$ Production Management, Vol. 22 No. 11, pp. 1288-1310.

Braz, R.G.F., Scavarda, L.F. and Martins, R.A. (2011), "Reviewing and improving performance measurement systems: An action research", International Journal of Production Economics, Elsevier, Vol. 133 No. 2, pp. 751760.

Brignall, S. and Modell, S. (2000), "An institutional perspective on performance measurement and management in the "new public sector" ", Management Accounting Research, Vol. 11 No. June 1999, pp. 281-306.

Brinton, C., Provan, C., Lent, S., Prevost, T. and Passmore, S. (2011), "An Ex- 
ample of Airport Collaborative Decision Making in the United States", Ninth USA/Europe Air Traffic Management Research and Development Seminar (ATM2011) Collaborative.

Briscoe, G., Keränen, K. and Parry, G. (2012), "Understanding complex service systems through different lenses: An overview", European Management Journal.

Brown, S.L. and Eisenhardt, K.M. (1997), "The art of continuous change", Administrative Science Quarterly, Vol. 42 No. 1, pp. 1-34.

Brudan, A. (2010), "Rediscovering performance management: systems, learning and integration", Measuring Business Excellence, Vol. 14 No. 1, pp. 109-123.

Busi, M. and Bititci, U.S. (2006), "Collaborative performance management: present gaps and future research", International Journal of Productivity and Performance Management, Vol. 55 No. 1, pp. 7-25.

Canonico, P., De Nito, E., Esposito, V., Martinez, M., Mercurio, L. and Pezzillo iacono, M. (2015), "The boundaries of a performance management system between learning and control", Measuring Business Excellence, Vol. 19 No. 3, pp. 7-21.

Cesar Ribeiro Carpinetti, L., Cardoza Galdámez, E. and Cecilio Gerolamo, M. (2008), "A measurement system for managing performance of industrial clusters", International Journal of Productivity and Performance Management, Vol. 57 No. 5, pp. 405-419.

Chang, L.Y. (2012), "International air passenger flows between pairs of APEC countries: A non-parametric regression tree approach", Journal of Air Transport Management, Elsevier Ltd, Vol. 20, pp. 4-6.

Checkland, P. (1994), "Systems Theory and Management Thinking", American Behavioral Scientist, Vol. 38 No. 2, pp. 75-91.

Chenhall, R.H. and Langfield-Smith, K. (2007), "Multiple Perspectives of Performance Measures", European Management Journal, Vol. 25 No. 4, pp. 266-282.

Christopher, W.F. (2011), "A new management for enduring company success", Kybernetes, Vol. 40 No. 3/4, pp. 369-393.

Cook, D.J., Sackett, D.I. and Spitzer, W.O. (1995), "Methodological Guidelines for systematic reviews of randomized control trials in health care from the postdam consultation on meta-analyisis", Journal of Clinical Epidemology, Vol. 48, pp. 167-171.

Corrigan, S., Mårtensson, L., Kay, A., Okwir, S., Ulfvengren, P. and Mcdonald, N. (2015), "Preparing for Airport Collaborative Decision Making (ACDM) Implementation: An Evaluation and Recommendations", Cogn. Technol. Work. 


\section{F. InTERVIEW SCHEDULE FOR GROUND HANDLING}

Deng, F., Smyth, H. and Anvuur, A. (2012), "A critical review of PMS in construction: Towards a research agenda", In: ANNUAL ARCOM CONFERENCE, 28., 2012. Edinburgh, No. September, pp. 807-816.

Dormer, R. and Gill, D. (2010), "Managing for performance in New Zealand's public service - a loosely coupled framework?", Measuring Business Excellence, Vol. 14 No. 1, pp. 43-59.

Elg, M., Palmberg, K., Beata, B., Elg, M., Palmberg, K., Beata, B., Management, P., et al. (2014), Performance Measurement to Drive Improvements in Healthcare Practice.

Elzinga, T., Albronda, B. and Kluijtmans, F. (2009), "Behavioral factors influencing performance management systems' use", International Journal of Productivity and Performance Management, Vol. 58 No. 6, pp. 508-522.

ETSI. (2010), Collaborative, Airport Making, Decision Specification, Community European, Single Interoperability, Sky Ec, Regulation, Vol. 1.

Eurocontrol. (2006), Airport CDM Implementation, Eurocontrol, Brussels, Belgium, available at: http://goo.gl/eavh6.

EUROCONTROL. (2012), The Manual: Implementation, Airport C D M, Brussels.

EUROCONTROL. (2015), Performance Review Report: An Assessment of Air Traffic Management in Europe.

Fawcett, T. (2006), "An introduction to ROC analysis", Pattern Recognition Letters, Vol. 27 No. 8, pp. 861-874.

Folan, P. and Browne, J. (2005), "A review of performance measurement: Towards performance management", Computers in Industry, Vol. 56 No. 7, pp. 663-680.

Forsyth, P. (2007), "The impacts of emerging aviation trends on airport infrastructure", Journal of Air Transport Management, Vol. 13 No. 1, pp. $45-52$.

Franco-Santos, M. and Bourne, M. (2005), "An examination of the literature relating to issues affecting how companies manage through measures", Production Planning \&S Control, Vol. 16 No. 2, pp. 114-124.

Franco-santos, M. and Bourne, M. (2012), "Contemporary performance measurement systems: A review of their consequences and a framework for research Contemporary performance measurement systems: A review of their consequences and a framework for research", Management Accounting Research, Elsevier Ltd, Vol. 23 No. 2, pp. 1-85.

Franco-Santos, M., Kennerley, M., Micheli, P., Martinez, V., Mason, S., Marr, B., Gray, D., et al. (2007), "Towards a definition of a business performance measurement system", International Journal of Operations 
E Production Management, Vol. 27 No. 8, pp. 784-801.

Franco-Santos, M., Lucianetti, L. and Bourne, M. (2012), "Contemporary performance measurement systems: A review of their consequences and a framework for research", Management Accounting Research, Elsevier Ltd, Vol. 23 No. 2, pp. 79-119.

Furlotti, M. (2007), "There is more to contracts than incompleteness: A review and assessment of empirical research on inter-firm contract design", Journal of Management and Governance, Vol. 11 No. 1, pp. 61-99.

Garengo, P., Biazzo, S. and Bititci, U. (2005), "Performance measurement systems in SMEs: A review for a research agenda", International Journal of Management Reviews, Vol. 7 No. 1, pp. 25-47.

Garengo, P. and Sharma, M.K. (2014), "Performance measurement system contingency factors: a cross analysis of Italian and Indian SMEs", Production Planning 83 Control, Vol. 25 No. 3, pp. 220-240.

Gelhausen, M.C., Berster, P. and Wilken, D. (2013), "Do airport capacity constraints have a serious impact on the future development of air traffic?", Journal of Air Transport Management, Elsevier Ltd, Vol. 28, pp. 3-13.

Geraldi, J., Maylor, H. and Williams, T. (2011), "Now, let's make it really complex (complicated)", International Journal of Operations \& Production Management, Vol. 31 No. 9, pp. 966-990.

Ginieis, M., Sánchez-Rebull, M. V and Campa-Planas, F. (2012), "The academic journal literature on air transport: Analysis using systematic literature review methodology", Journal of Air Transport Management, article, , Vol. 19 No. 0, pp. 31-35.

Graham, A. (2013), "Understanding the low cost carrier and airport relationship: A critical analysis of the salient issues", Tourism Management, Elsevier, Vol. 36, pp. 66-76.

Groppe, M. and Bui, M. (2007), "Applying pretopological concepts \& negotiation analysis to study cockpit's perspective to collaborate decision making - Research on complex systems modelling", Proceedings of the ISSAT International Conference on Modeling of Complex Systems and Environments, Proceedings, No. May, p. 111-115 \r221.

Halachmi, A. (2005), "Performance measurement is only one way of managing performance", edited by Halachmi, A.International Journal of Productivity and Performance Management, Vol. 54 No. 7, pp. 502-516.

Hansen, Z.N.L. and Rasmussen, L.B. (2013), "Outsourcing relationships: Changes in power and dependency", European Management Journal, Elsevier Ltd, Vol. 31 No. 6, pp. 655-667.

Harkness, M. and Bourne, M. (2015), "Is complexity a barrier to the practice of performance measurement?", Proceedings of the Performance Man- 


\section{F. InTERVIEW SCHEDULE FOR GROUND HANDLING}

agemnet Association Conference, Auckland.

Harper, P.R. and Winslett, D.J. (2006), "Classification trees: A possible method for maternity risk grouping", Vol. 169, pp. 146-156.

Hayes, R.H. and Abernathy, W.J. (2007), "Managing our way to economic decline", Harvard Business Review, available at:http://doi.org/Article.

Humphreys, I. and Francis, G. (2002), "Performance measurement: A review of airports", International Journal of Transport Management, Vol. 1 No. 2, pp. $79-85$.

Jääskeläinen, A. and Roitto, J. (2015), "Designing a model for profiling organizational performance management", International Journal of Productivity and Performance Management, Vol. 64 No. 1, pp. 5-27.

Jääskeläinen, A. and Sillanpää, V. (2013), "Overcoming challenges in the implementation of performance measurement", International Journal of Public Sector Management, Vol. 26 No. 6, pp. 440-454.

Jääskeläinen and Laihonen. (2014), "Applying performance measurement in service operations: Analysis of contextual differences", International Journal of Business Performance Management, Vol. 15 No. 3, pp. 243-261.

Jain, S., Triantis, K.P. and Liu, S. (2011), "Manufacturing performance measurement and target setting: A data envelopment analysis approach", European Journal of Operational Research, Elsevier B.V., Vol. 214 No. 3, pp. 616-626.

Johnston, J. (2005), "Performance measurement uncertainty on the Grand Canal", edited by Halachmi, A.International Journal of Productivity and Performance Management, Vol. 54 No. 7, pp. 595-612.

Kandjani, H. and Bernus, P. (2012), "Towards a Cybernetic Theory and Reference Model of Self-designing Complex Collaborative Networks", Collaborative Networks in the Internet of Services, Vol. 380, pp. 485-493.

Kennerley, M. and Neely, A. (2002), "A framework of the factors affecting the evolution of performance measurement systems", International Journal of Operations $\&$ Production Management, Vol. 22 No. 11, pp. 12221245 .

Keong Choong, K. (2013), "Understanding the features of performance measurement system: a literature review", Measuring Business Excellence, Vol. 17 No. 4, pp. 102-121.

Kim, S.H. (Georgia I. of T., Feron, E. (Georgia I. of T., Clarke, J.-P. (Georgia I. of T., Marzuoli, A. (École N. de l'Aviation C. and Delahaye, D. (École N. de l'Aviation C. (2013), "Airport Gate Scheduling for Passengers, Aircraft, and Operations", Tenth USA/Europe Air Traffic Management Research and Development Seminar (ATM2013) Airport. 


\section{F.1. REFERENCES}

Koeners, G.J.M. and Rademaker, R.M. (2012), "Ground control support functions to optimize surface traffic flow in a CDM environment", AIAA/IEEE Digital Avionics Systems Conference - Proceedings, pp. 1-11.

Krstić Simić, T. and Babić, O. (2015), "Airport traffic complexity and environment efficiency metrics for evaluation of ATM measures", Journal of Air Transport Management, Vol. 42, pp. 260-271.

Ladyman, J., Lambert, J. and Wiesner, K. (2013), "What is a complex system?", European Journal for Philosophy of Science, Vol. 3 No. 1, pp. 33-67.

Lehtinen, J. and Ahola, T. (2010), "Is performance measurement suitable for an extended enterprise?", International Journal of Operations and Production Management, Vol. 30 No. 2, pp. 181-204.

Liu, Y., Hansen, M., Gupta, G., Malik, W. and Jung, Y. (2014), "Predictability impacts of airport surface automation", Transportation Research Part C: Emerging Technologies, Elsevier Ltd, Vol. 44, pp. 128-145.

Lohman, C., Fortuin, L. and Wouters, M. (2004), "Designing a performance measurement system: A case study", European Journal of Operational Research, Vol. 156 No. 2, pp. 267-286.

Loi, R., Lam, L.W., Ngo, H.Y. and Cheong, S. (2015), "Performance measurement systems, competitive priorities, and advanced manufacturing technology Some evidence from the aeronautical sector", Journal of Managerial Psychology, Vol. Vol. 30 No, pp. 645-658.

Lopreato, J. and von Bertalanffy, L. (1970), "General System Theory: Foundations, Development, Applications.", American Sociological Review.

Lukka, K. and Vinnari, E. (2014), "Domain theory and method theory in management accounting research", Accounting, Auditing \&3 Accountability Journal, Vol. 27 No. 8, pp. 1308-1338.

Lukka, K. and Vinnari, E. (2016), "Domain theory and method theory revisited: a reply to Lowe, De Loo and Nama", Accounting, Auditing 83 Accountability Journal, Vol. 29 No. 2, pp. 317-322.

Lupo, T. (2015), "Fuzzy ServPerf model combined with ELECTRE III to comparatively evaluate service quality of international airports in Sicily", Journal of Air Transport Management, Elsevier Ltd, Vol. 42, pp. 249259.

Madas, M.A. and Zografos, K.G. (2008), "Airport capacity vs. demand: Mismatch or mismanagement?", Transportation Research Part A: Policy and Practice, Vol. 42 No. 1, pp. 203-226.

Malmi, T. and Brown, D.A. (2008), "Management control systems as a packageOpportunities, challenges and research directions", Management Accounting Research, Vol. 19 No. 4, pp. 287-300.

Martini, G., Manello, A. and Scotti, D. (2013), "The influence of fleet mix, owner- 


\section{F. InTERVIEW SCHEDULE FOR GROUND HANDLING}

ship and LCCs on airports' technical/environmental efficiency", Transportation Research Part E: Logistics and Transportation Review, Elsevier Ltd, Vol. 50 No. 1, pp. 37-52.

Mason-Jones, R. and Towill, D.R. (2000), "Designing,implementing and updating performance measurement system.", International Journal of Operations and Production Management, Vol. 20 No. 7, pp. 754-771.

McAdam, R. and Bailie, B. (2002), "Business performance measures and alignment impact on strategy", International Journal of Operations \& Production Management, Vol. 22 No. 9, pp. 972-996.

McClish, D.K. (2015), "Analyzing a portion of the ROC curve.", Medical Decision Making: An International Journal of the Society for Medical Decision Making, Vol. 9, pp. 190-195.

McDonald, N. (2015), "The evaluation of change", Cognition, Technology and Work, Springer London, Vol. 17 No. 2, pp. 193-206.

Mea, P. (n.d.). "Performance Measurement Systems for designing and managing Interoperability Performance Measures: A literature analysis", pp. 1-8.

Melnyk, S.A., Bititci, U., Platts, K., Tobias, J. and Andersen, B. (2014a), "Is performance measurement and management fit for the future?", Management Accounting Research, Elsevier Ltd, Vol. 25 No. 2, pp. 173-186.

Melnyk, S.A., Bititci, U., Platts, K., Tobias, J. and Andersen, B. (2014b), "Is performance measurement and management fit for the future?", Management Accounting Research, Elsevier Ltd, Vol. 25 No. 2, pp. 173-186.

Merkert, R. and Morrell, P.S. (2012), "Mergers and acquisitions in aviation - Management and economic perspectives on the size of airlines", Transportation Research Part E: Logistics and Transportation Review, Elsevier Ltd, Vol. 48 No. 4, pp. 853-862.

Metz, C.E. (1978), "Basic principles of ROC analysis.", Seminars in Nuclear Medicine, Vol. 8 No. 4, pp. 283-298.

Michel J, L. (1995), "Performance measurement and performance management", International Journal of Production Economics, Vol. 41 No. 1-3, pp. 23-35.

Micheli, P. and Mari, L. (2014a), "The theory and practice of performance measurement", Management Accounting Research, Elsevier Ltd, Vol. 25 No. 2, pp. $147-156$.

Micheli, P. and Mari, L. (2014b), "The theory and practice of performance measurement", Elsevier Ltd, Vol. 25, pp. 147-156.

Michie, S. and West, M. (2004), "Managing people and performance: an evidence based framework applied to health service organizations", Vol. 5 No. 2, pp. 91-111.

Mingers, J. and Taylor, S. (1992), "The use of soft systems methodology in Prac- 
tice", Operational Research Society, Vol. 43 No. 4, pp. 321-332.

Möhring, M.M. and Finch, J. (2015), "Contracts, relationships and innovation in business-to-business exchanges", Journal of Business \& Industrial Marketing.

Mol, N.P. and Beeres, R.J.M. (2005), "Performance management in a setting of deficient output controls", edited by Halachmi, A.International Journal of Productivity and Performance Management, Vol. 54 No. 7, pp. 533550.

Morel, B. and Ramanujam, R. (1999), "Through the Looking Glass of Complexity: The Dynamics of Organizations as Adaptive and Evolving Systems", Organization Science, Vol. 10 No. 3, pp. 278-293.

Neely, A. (1999), "The performance measurement revolution: why now and what next?", International Journal of Operations $\&$ Production Management, Vol. 19 No. 2, pp. 205-228.

Neely, A. (2005), "The evolution of performance measurement research", International Journal of Operations \& Production Management, Vol. 25 No. 12, pp. $1264-1277$.

Neely, A., Mills, J., Platts, K., Gregory, M. and Richards, H. (1996), "Performance measurement system design: Should process based approaches be adopted?", International Journal of Production Economics, Vol. 46, pp. 423-431.

Neely, A., Mills, J., Platts, K., Richards, H., Gregory, M., Bourne, M. and Kennerley, M. (2000), "Performance measurement system design: developing and testing a process-based approach", International Journal of Operations \& Production Management, Vol. 20 No. 10, pp. 1119-1145.

Neely, A., Richards, H., Mills, J., Platts, K. and Bourne, M. (1997), "Designing performance measures: a structured approach", International Journal of Operations $\& 5$ Production Management, Vol. 17 No. 11, pp. 11311152.

Ng, I.C.L., Maull, R. and Yip, N. (2009), "Outcome-based contracts as a driver for systems thinking and service-dominant logic in service science: Evidence from the defence industry", European Management Journal, Elsevier Ltd, Vol. 27 No. 6, pp. 377-387.

Nudurupati, S.S., Bhattacharya, A., Lascelles, D. and Caton, N. (2015), "Strategic sourcing with multi-stakeholders through value co-creation: An evidence from global health care company", International Journal of Production Economics, Elsevier, Vol. 166, pp. 248-257.

Nudurupati, S.S. and Bititci, U.S. (2005), "Implementation and impact of ITsupported performance measurement systems", Production Planning E6 Control, Vol. 16 No. 2, pp. 152-162. 


\section{F. InTERVIEW SCHEDULE FOR GROUND HANDLING}

Nudurupati, S.S., Tebboune, S. and Hardman, J. (2015), "Contemporary performance measurement and management (PMM) in digital economies", Production Planning \& Control, Vol. 7287 No. October, pp. 1-10.

Okwir, S. and Correas, A. (2014), "Collaborative Decision Making (CDM) in Airport Surface: Europe vs usa implementations, challenges and best practices", Integrated Communications, Navigation ..., No. Cdm, pp. $1-15$.

Otley, D.T. (1999), "Performance management: a framework for management control systems research", Management Accounting Research, Vol. 10 No. 4, pp. 363-382.

Oum, T.H. and Yu, C. (2004), "Measuring airports' operating efficiency: A summary of the 2003 ATRS global airport benchmarking report", Transportation Research Part E: Logistics and Transportation Review, Vol. 40 No. 6, pp. 515-532.

Paranjape, B., Rossiter, M. and Pantano, V. (2006), "Performance measurement systems: successes, failures and future - a review", Measuring Business Excellence, Vol. 10 No. 3, pp. 4-14.

Pekkola, S. and Ukko, J. (2016), "Designing a performance measurement system for collaborative network", International Journal of Operations \& Production Management, Vol. 36 No. 11, p. null.

Perkins, M., Grey, A. and Remmers, H. (2014), "What do we really mean by 'Balanced Scorecard'?", International Journal of Productivity and Performance Management, Vol. 63 No. 2, pp. 148-169.

Petruf, M., Korba, P. and Kolesar, J. (2015), "Roles of Logistics in Air Transportation: Uloge logistike u zračnom prometu", Nase More, Vol. 62 No. 1, pp. 215-218.

Petticrew, M. and Robert, H. (2006), "Chapter 1 Why do we need systematic", Systematic Reviews in the Social Sciences: A Practical Guide, pp. 127.

Pettigrew, A.M. (2012), "Context and Action in the Transformation of the Firm: A Reprise", Journal of Management Studies, Vol. 49 No. 7, pp. 13041328.

Pick, a. and Rawlik, T. (2011), "Optimization of airport processes: Support system for human decision making in total airport management", 2011 8th Asian Control Conference (ASCC), pp. 1054-1059.

Da Piedade Francisco, R., Azevedo, A. and Almeida, A. (2012), "Alignment prediction in collaborative networks", Journal of Manufacturing Technology Management, Vol. 23 No. 8, pp. 1038-1056.

Pinho, N., Beirão, G., Patrício, L. and P. Fisk, R. (2014), "Understanding value co-creation in complex services with many actors", Journal of Service 
Management, Vol. 25 No. 4, pp. 470-493.

Platt, A. and Warwick, S. (1995), "Review of soft systems methodology", Industrial Management \& Data Systems, Vol. 95 No. 4, pp. 19-21.

Prakash, B.V.A., Ashoka, D. V and Aradhya, V.N.M. (2012), "Application of Data Mining Techniques for Software Reuse Process", Procedia Technology, Elsevier B.V., Vol. 4, pp. 384-389.

Profillidis, V. and Botzoris, G. (2015), "Air passenger transport and economic activity", Journal of Air Transport Management, Vol. 49, pp. 23-27.

Pun, K.F. and White, A.S. (2005), "A performance measurement paradigm for integrating strategy formulation: A review of systems and frameworks", International Journal of Management Reviews, Vol. 7 No. 1, pp. 49 71.

Rahbek Gjerdrum Pedersen, E. and Sudzina, F. (2012), "Which firms use measures?", International Journal of Operations $\& 5$ Production Management, Vol. 32 No. 1, pp. 4-27.

Roehrich, J. and Lewis, M. (2014), "Procuring complex performance: implications for exchange governance complexity", edited by Mickey Howard and Dr Nigel Caldwell, D.International Journal of Operations \& Production Management, Vol. 34 No. 2, pp. 221-241.

Rosenblueth, A., Wiener, N. and Bigelow, J. (1943), "Behavior, Purpose and Teleology", Philosophy of Science, Vol. 10 No. 1, p. 18.

Sahin, E., Vidal, L.-A. and Benzarti, E. (2013), "A framework to evaluate the complexity of home care services", Kybernetes, Vol. 42 No. 4, pp. 569-592.

Santos, S.P., Belton, V. and Howick, S. (2002), "Adding value to performance measurement by using system dynamics and multicriteria analysis", International Journal of Operations 86 Production Management, Vol. 22 No. 11, pp. 1246-1272.

Schaper, M., Tsoukala, G., Stavrati, R. and Papadopoulos, N. (2011), "Departure flow control through takeoff sequence optimisation: Setup and results of trials at Athens airport", AIAA/IEEE Digital Avionics Systems Conference - Proceedings, pp. 1-13.

Schriber, S. and Löwstedt, J. (2015), "Tangible resources and the development of organizational capabilities", Scandinavian Journal of Management, Vol. 31 No. 1, pp. 54-68.

Schwaninger, M. (2015), "Model-based Management: A Cybernetic Concept", Systems Research and Behavioral Science, Vol. 32 No. 6, pp. 564-578.

SESAR. (2014), European Single Sky ImPlementation Plan.

SESAR. (2015), Proposed European ATM Master Plan Edition 2015.

Sharma, M.K. and Bhagwat, R. (2006), "Performance measurements in the im- 


\section{F. InTERVIEW SCHEDULE FOR GROUND HANDLING}

plementation of information systems in small and medium-sized enterprises: a framework and empirical analysis", Measuring Business Excellence, Vol. 10 No. 4, pp. 8-21.

Spekle, R.F. and Verbeeten, F. (2014), "The Use of Performance Measurement Systems in the Public Sector: Effects on Performance", Management Accounting Research, Elsevier Ltd, Vol. 25 No. 2, pp. 131-146.

Spohrer, J. and Maglio, P.P. (2008), "The Emergence of Service Science: Toward Systematic Service Innovations to Accelerate Co-Creation of Value", Production and Operations Management, Vol. 17 No. 3, pp. 238-246.

Sullivan, T. (2011), "Embracing Complexity", Harvard Business Review, No. September, pp. 89-93.

Suprapto, B., Wahab, H.A. and Wibowo, A.J. (2009), "The Implementation of Balance Score Card for Performance Measurement in Small and Medium Enterprises: Evidence from Malaysian Health Care Services", The Asian Journal of Technology Management, Vol. 2 No. 2, pp. 76-87.

Tobaruela, G., Fransen, P., Schuster, W., Ochieng, W.Y. and Majumdar, A. (2014), "Air traffic predictability framework - Development, performance evaluation and application", Journal of Air Transport Management, Elsevier Ltd, Vol. 39, pp. 48-58.

Trujillano, J., March, J. and Sorribas, A. (2004), "[Methodological approach to the use of artificial neural networks for predicting results in medicine].", Medicina Clínica, Vol. 122 Suppl, pp. 59-67.

Turner, T.J., Bititci, U.S. and Nudurupati, S.S. (2005), "Implementation and impact of performance measures in two SMEs in Central Scotland", Production Planning \& Control, Vol. 16 No. 2, pp. 135-151.

Valmohammadi, C. and Servati, A. (2011), "Performance measurement system implementation using Balanced Scorecard and statistical methods", International Journal of Productivity and Performance Management, Vol. 60 No. 5, pp. 493-511.

Vargo, S.L. and Lusch, R.F. (2004), "Evolving to a New Dominant Logic for Marketing", Journal of Marketing, Vol. 68 No. 1, pp. 1-17.

van Veen-Dirks, P. (2010), "Different uses of performance measures: The evaluation versus reward of production managers", Accounting, Organizations and Society, Elsevier Ltd, Vol. 35 No. 2, pp. 141-164.

Vélez-González, H., Pradhan, R. and Weech-Maldonado, R. (2011), "The Role of Non-Financial Performance Measures in Predicting Hospital Financial Performance: The Case of For-Profit System Hospitals", Journal of Health Care Finance, Vol. 38 No. 2, pp. 12-23.

Vidal, L.-A. and Marle, F. (2008), "Understanding project complexity: implications on project management", Kybernetes, Vol. 37 No. 8, pp. 1094- 
1110.

Voss, C., Tsikriktsis, N. and Frohlich, M. (2002), "Case research in operations management", International Journal of Operations $\&$ Production Management \# MCB UP Limited, Vol. 22 No. 2, pp. 195-219.

Waal, A. De and Kourtit, K. (2013), "Performance measurement and management in practice: Advantages, disadvantages and reasons for use", International Journal of Productivity and Performance Management, Vol. 62 No. 5, pp. 446-473.

Wacker, J.G. (2008), "A conceptual understanding of requirements for theorybuilding research: Guidelines for scientific theory building", Journal of Supply Chain Management, Vol. 44 No. 3, pp. 5-15.

Warner, B. and Misra, M. (1996), "Understanding Neural Networks as Statistical Tools", The American Statistician, Vol. 50 No. 4, p. 284-??

Wiener, N. (1948), "Cybernetics", Scientific American, Vol. 179, pp. 14-18.

Wilcox, M. and Bourne, M. (2003), "Predicting performance", Management Decision, Vol. 41, pp. 806-816.

Williams, G. and Doughty, K. (2007), "Towards an evaluation framework for telecare services", Journal of Assistive Technologies, Vol. 1 No. 1, pp. $42-47$.

Wilson, B.C. and A. (2009), "Customer feedback mechanisms and organisational learning in service operations", International Journal of Logistics Management, Vol. 20 No. 1, pp. 97-123.

Wu, C.-L. and Caves, R.E. (2002), "Research review of air traffic management", Transport Reviews, article, , Vol. 22 No. 1, pp. 115-132.

Wu, C. and Caves, R.E. (2010), "Transport Reviews: A Transnational Research review of air traffic management", No. September 2012, pp. 37-41.

Yadav, N. and Sagar, M. (2013), "Performance measurement and management frameworks", Business Process Management Journal, Vol. 19 No. 6, pp. $947-971$.

Yin, R.K. (2003), "Case study research. 3", Aufl., Thousand Oaks, article, .

Zhang, H. and Bonney, G. (2000), "Use of classification trees for association studies.", Genetic Epidemiology, Vol. 19 No. 4, pp. 323-332. 



\section{Colophon}

7 HIS THESIS WAS TYPESET using LTEX, originally

1 developed by Leslie Lamport and based on Donald

Knuth's TEX. The body text is set in 12 point Computer

Modern (version 0.6.3a, 2008), designed by Donald Knuth specifically for $\mathrm{T}_{\mathrm{E}} \mathrm{X}$, and issued under the terms of $\mathrm{x} 11$ license. A template upon which this thesis is built, that can be used to format a PhD thesis with a similar look and feel, has been released under the permissive MIT (x11) license, and can be found online at github.com/suchow/ or from the author at suchow@post.harvard.edu. 